\title{
The wholeheartedness of becoming: Evidence-based inquiry into practice for inservice teacher educators
}

\author{
Margaret Lamont
}

\author{
A thesis \\ submitted to Victoria University of Wellington \\ in fulfilment of the requirements for the degree of \\ Doctor of Philosophy in Education
}

Victoria University of Wellington

April 2012 


\begin{abstract}
Recent trends in the professional learning and development of teachers are moving more towards the activation of learning rather than content delivery. Teachers are expected to take more responsibility for their learning within collaborative environments. This has implications for the practice and learning of inservice teacher educators. Evidence-based inquiry into practice (EBIP) is one approach that is being adopted, which involves evaluation of practice against values, beliefs and assumptions.
\end{abstract}

This study investigated the professional learning and development experiences and perceptions of a group of 10 inservice teacher educators, who participated in the Inservice Teacher Education Practice (INSTEP) project from 2005 to 2009. INSTEP was a New Zealand Ministry of Education project designed to investigate and develop professional learning approaches for inservice teacher educators. In particular, its focus was on the implementation of collaborative EBIP to improve practice.

Collective case study and grounded theory methodologies were adopted. Semistructured interviews were conducted with participants in 2008 and 2010. The interviews were analysed using inductive content analysis. Theoretical sampling was applied to identify further participants and document sources such as artefacts, reports and publications, which were also used to inform the research.

The findings indicate that, while all participants improved practice and gained knowledge through EBIP, some experienced transformations in their perceptions of themselves, their practice, and their role as inservice teacher educators. Rigorous and systematic EBIP was most effective, and only sustained, when it was supported within formal, informal and social organisational contexts. Such contexts incorporated collective responsibility for learning. This included negotiation and development of shared meanings, tools, mechanisms, and frameworks, which systematised and reified the process of EBIP. This also enabled individual professional learning goals to be located within an overall infrastructure incorporating a shared vision, and alignment with strategic priorities and resourcing.

The study suggests that sustainability of change and improvement of practice within system-wide educational reform is more likely to be achieved by individuals working coherently within an educational system and organisations that value and adopt an 
inquiry approach and nurture collaborative environments. Such environments provide safety to expose vulnerabilities, and enable opportunities for learning that minimise the impact of power relations and contestable environments, while offering challenge, support and diversity of perspectives.

The theoretical framework for EBIP derived from the research, and an integrative analysis of the literature, identifies three interconnected and interdependent components linked by a common vision of purpose, and a collective commitment to learning. The components are: individual learning and transformation; communities and connectedness; and systematisation and reification.

The study includes recommendations for more research into the contexts and processes of collaborative models of professional learning, and into the changing role and professional learning requirements of inservice teacher educators. It also identifies a need to investigate valid means of judging effectiveness of practice for inservice teacher educators, since evidence of enhanced student learning is linked only by a chain of influence to inservice teacher educator practice. 


\section{Acknowledgements}

This study would not have been possible without the participants and their wholeheartedness, openness and willingness to share their thoughts and experiences with me. Thank you so much for your trust.

Susan Kaiser, your comforting reassurance, compassion, and incredible skills in proofing and formatting my work have been an invaluable support. Thank you.

I have been fortunate to have three supervisors who have encouraged, supported and challenged me throughout. Thanks to Professor Cedric Hall, Dr Liz Jones and Dr Cath Savage for your wisdom, perspectives and rigour.

Thank you to my friends, family, and colleagues for their care and encouragement. My Mum (Christina Arnot), for her love and faith in me; my sons (Paul, Marc, Mike and Marty) and their partners, whose love and support is always with me whatever path I travel; and most especially, my love and gratitude to my wonderful husband (lan) for walking every step of this journey with me. I couldn't have done it without your love, support and encouragement.

I dedicate this work to my father, William Methven Arnot, who passed away when I was nine years old. Your love, and encouragement for me to be the best I can be, is with me every day. You are always by my side, and I can sense your pride. I miss having you in my life. 


\section{Table of Contents}

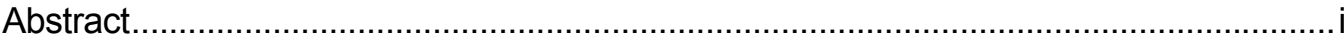

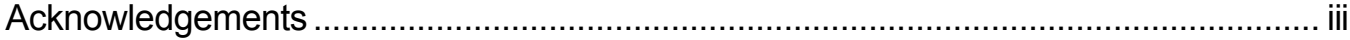

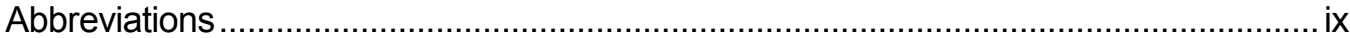

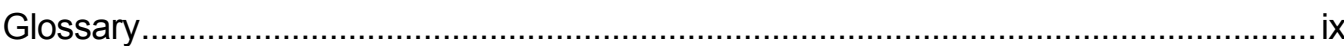

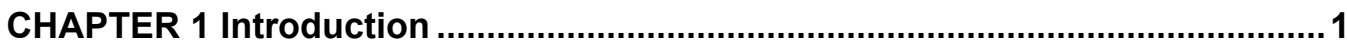

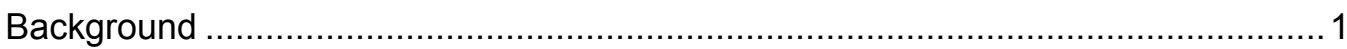

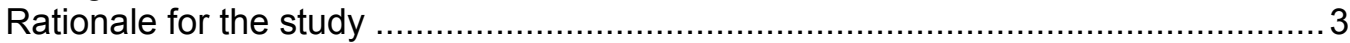

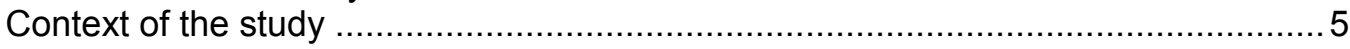

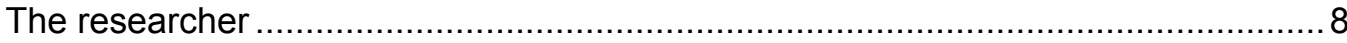

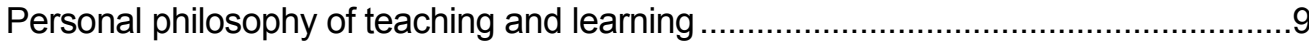

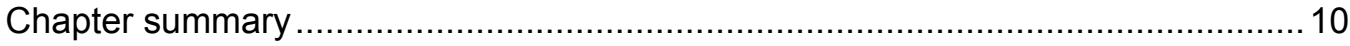

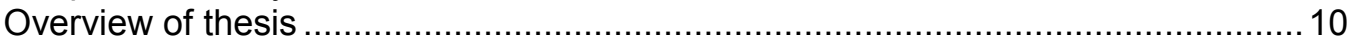

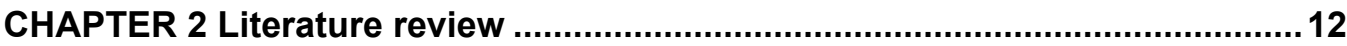

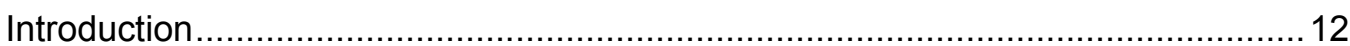

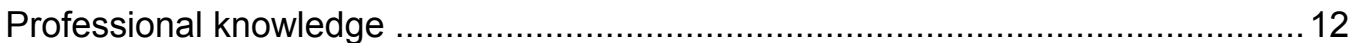

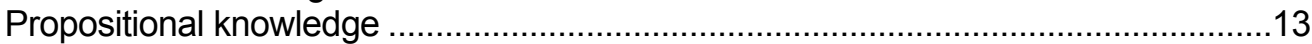

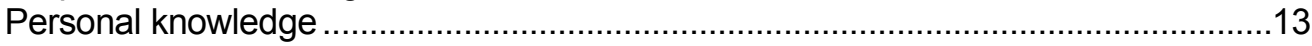

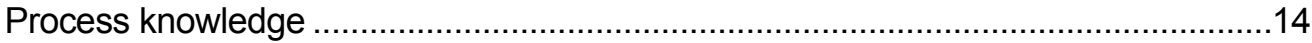

Professional knowledge for inservice teacher educators ................................... 16

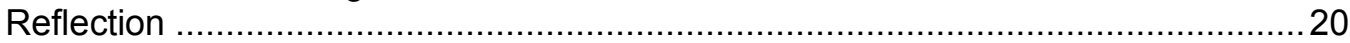

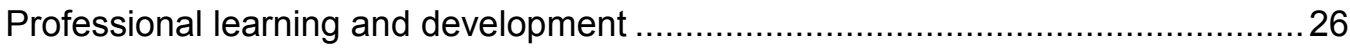

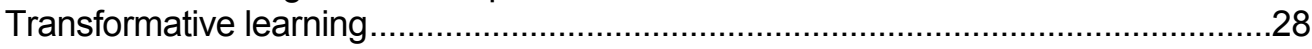

Effectiveness of professional learning and development .......................................32

Trends in professional learning and development................................................37

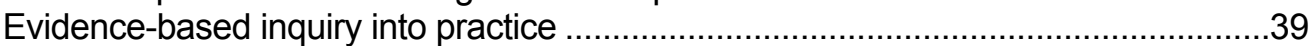

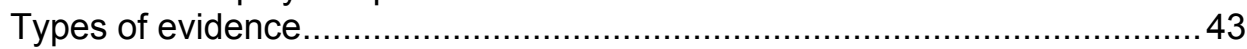

Contexts for professional learning and development ...........................................46

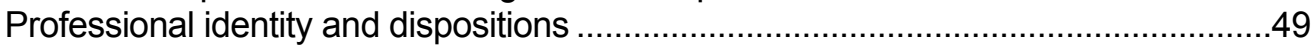

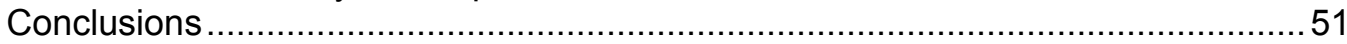

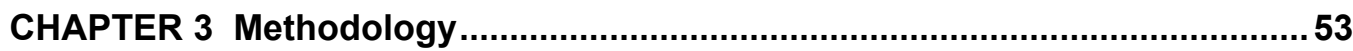

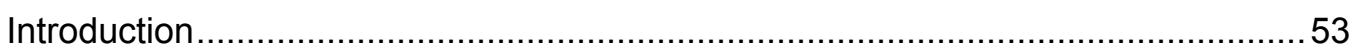

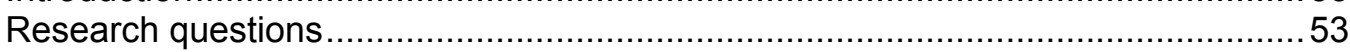

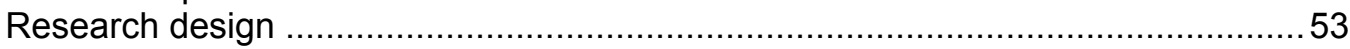

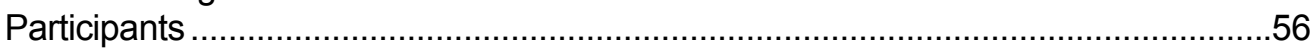

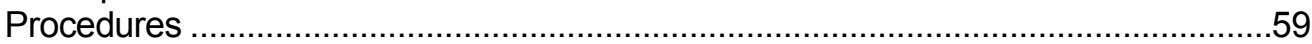

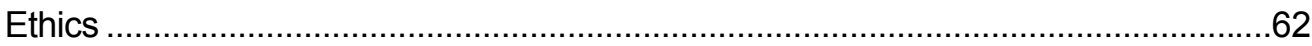

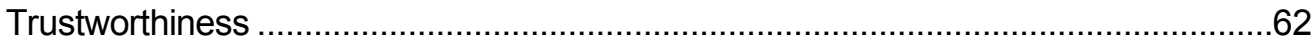

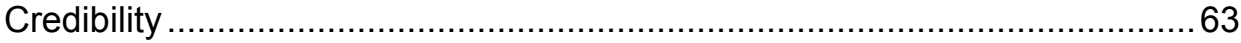

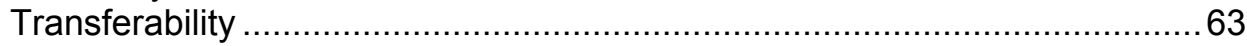

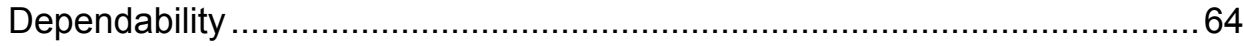

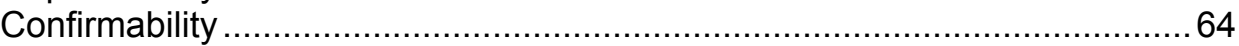

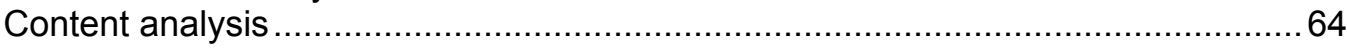

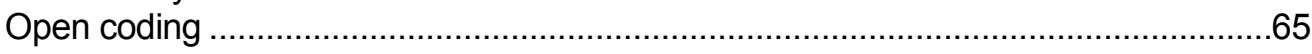

Axial and selective coding ........................................................................ 72

Overarching theme

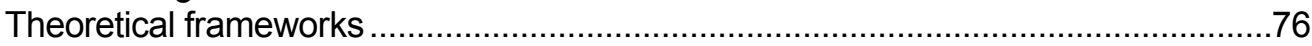

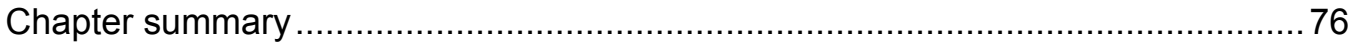


CHAPTER 4 Evidence-based inquiry into practice ...........................................78

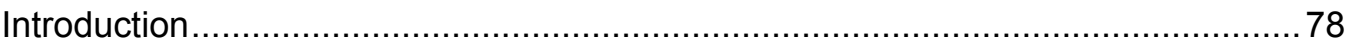

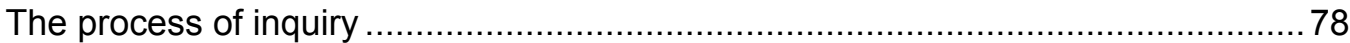

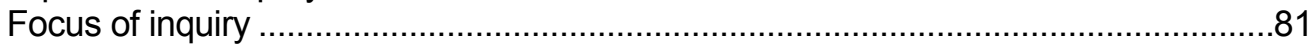

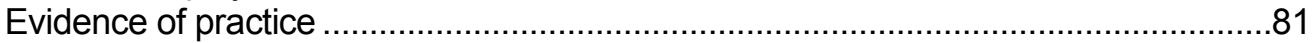

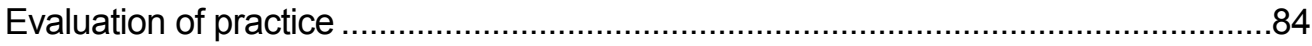

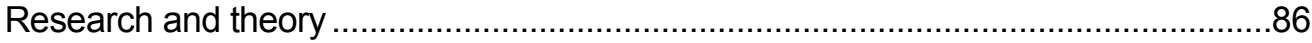

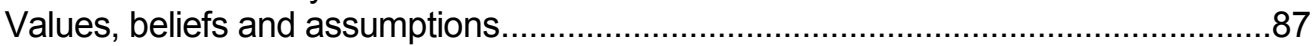

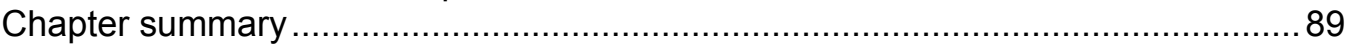

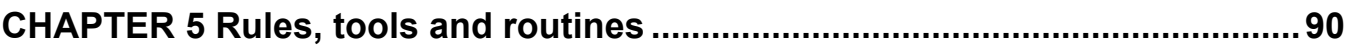

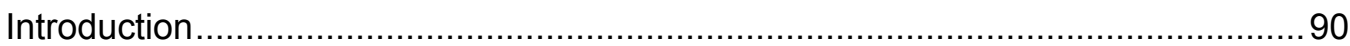

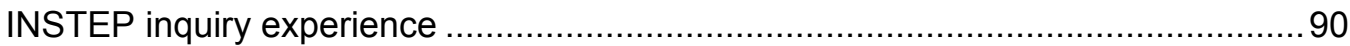

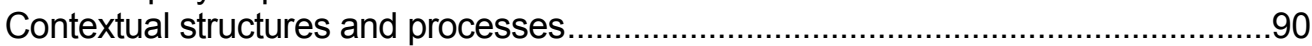

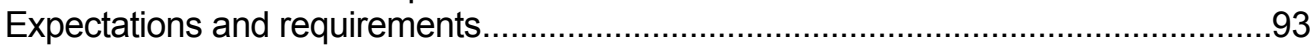

Resources, tools and mechanisms for inquiry ....................................................95

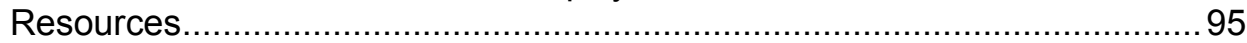

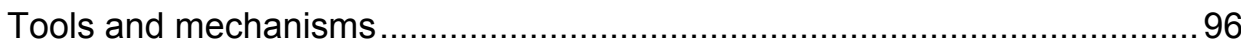

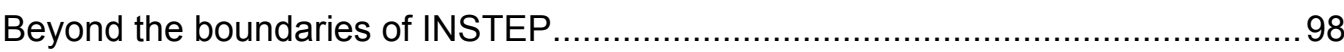

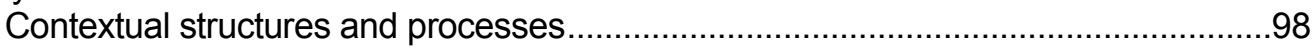

Expectations and requirements...................................................................... 106

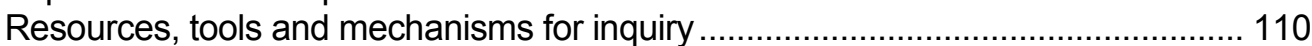

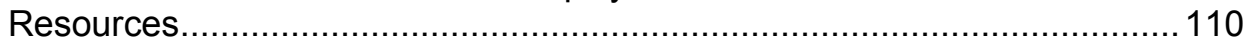

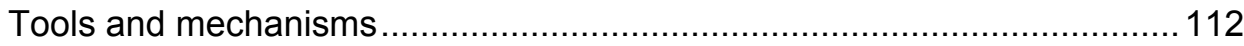

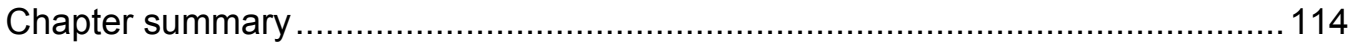

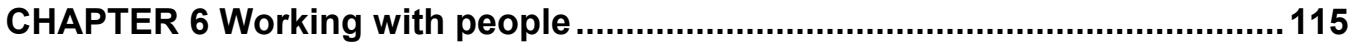

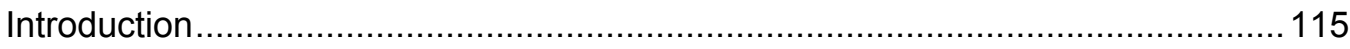

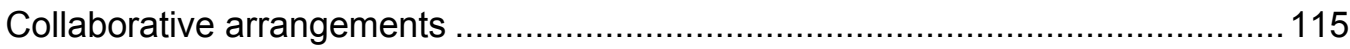

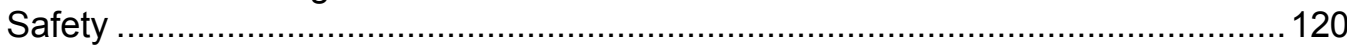

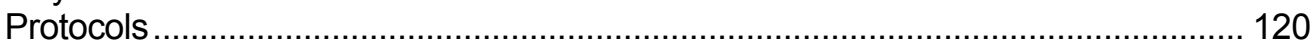

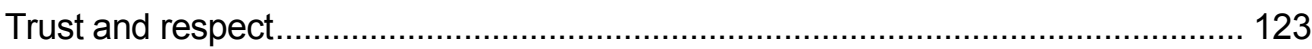

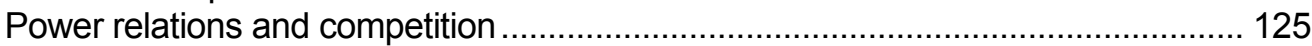

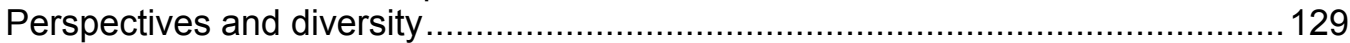

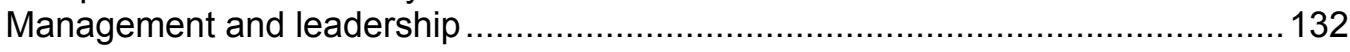

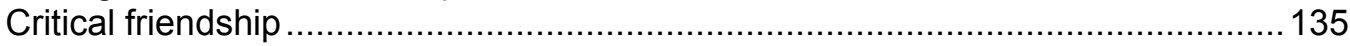

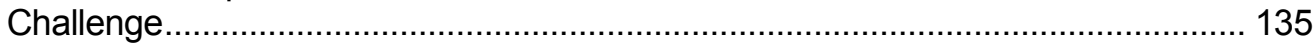

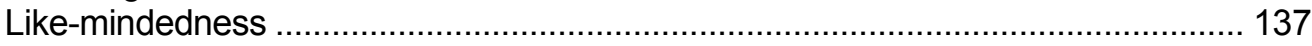

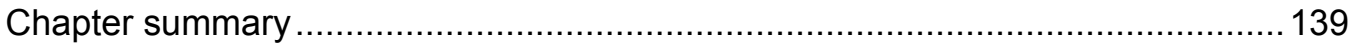

CHAPTER 7 Impact upon individuals ........................................................141

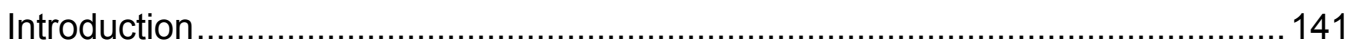

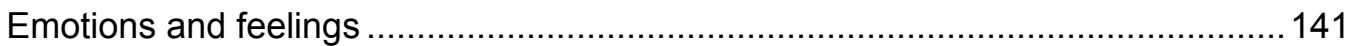

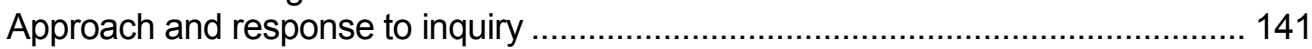

Dissonance and personal challenge ................................................................. 144

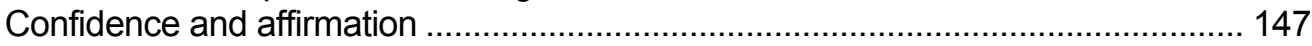

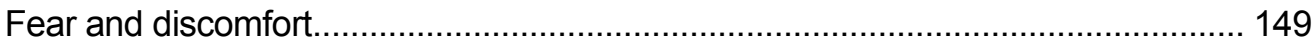

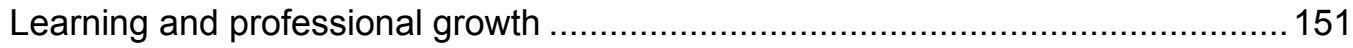

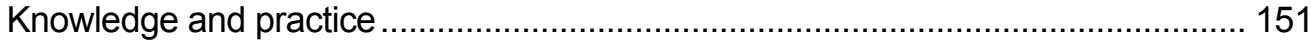

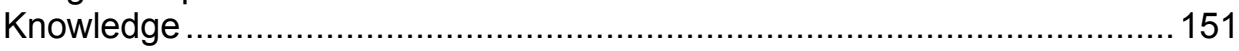

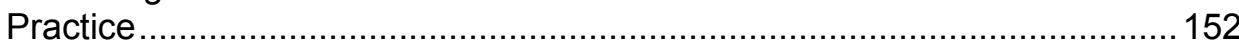

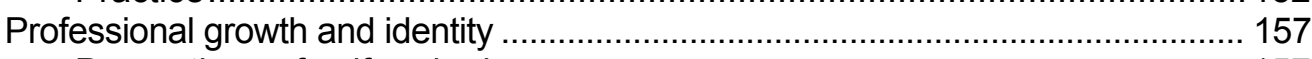

Perceptions of self and role .................................................................. 157

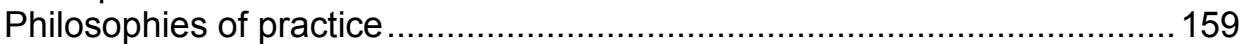

Self efficacy and agency ........................................................... 160

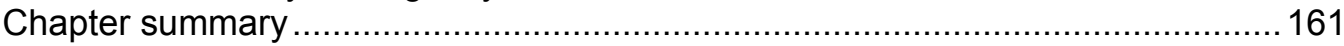




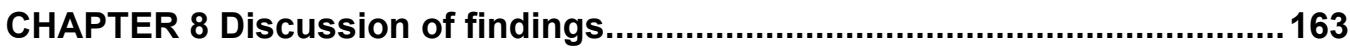

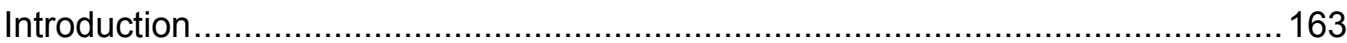

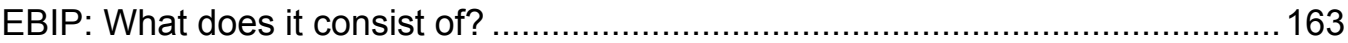

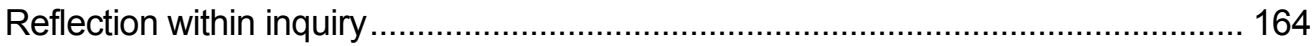

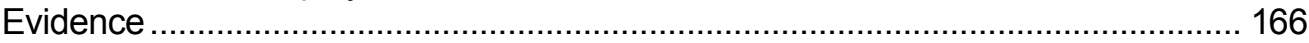

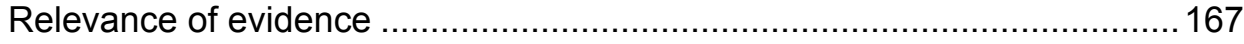

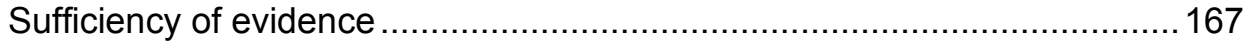

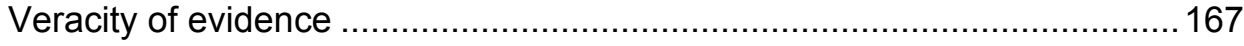

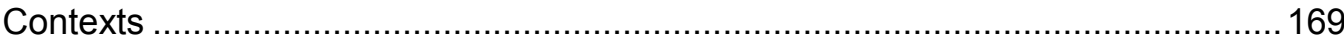

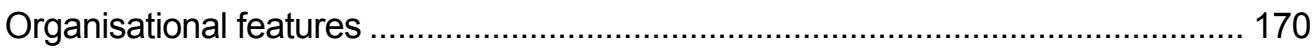

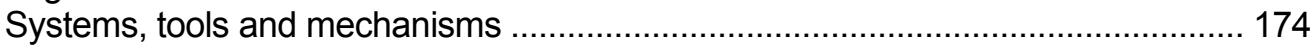

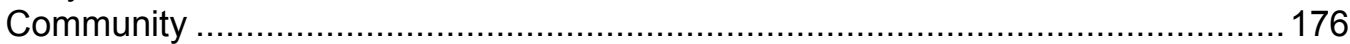

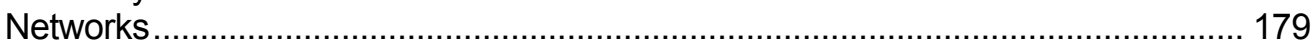

Genesis: the reasons and motivations behind the creation of networks...... 181

Composition: individual and/or collective actors ..................................... 182

Structure: whole system or individual members' structural properties and locations - density, centralisation and connectedness...................... 182

Substance: what interactions are about - missions, purposes, values, social norms, conceptions and perspectives ......................................... 184

Effectiveness: evidence of impact upon members and those with whom

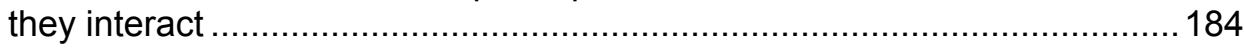

Dynamics: how they develop over time ............................................. 186

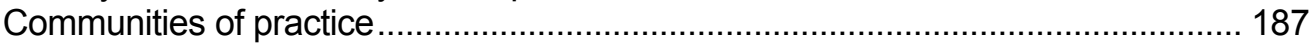

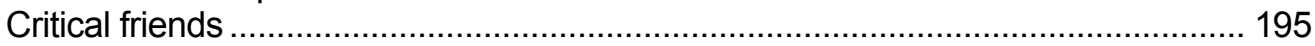

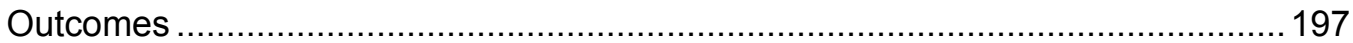

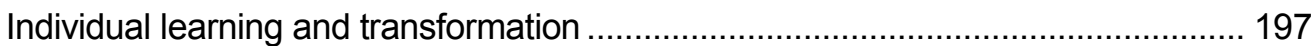

The sense of self (what we bring of ourselves) ....................................... 199

Being in the world (and how we are who we have become)......................200

Liminal space of possibilities (to become what we are 'not yet') .................201

Threshold of becoming (what we are 'not yet') ...........................................203

Reconstruction of self and being (in the world)......................................204

New frontier for the sense of self ............................................................205

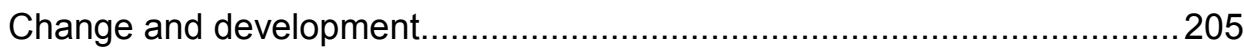

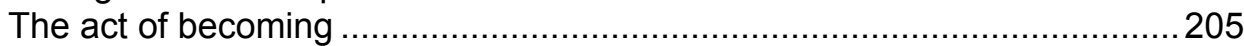

Organisational and system-wide transformation................................................ 206

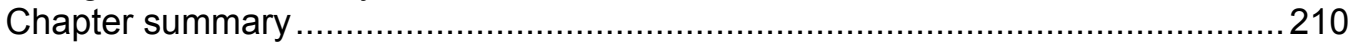

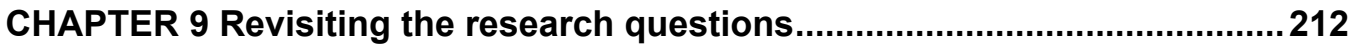

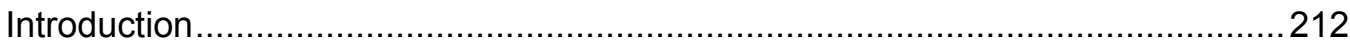

Personal, sociocultural, and organisational factors ..........................................212

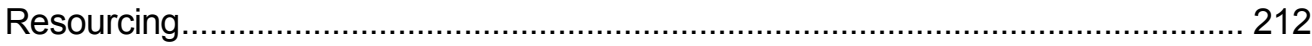

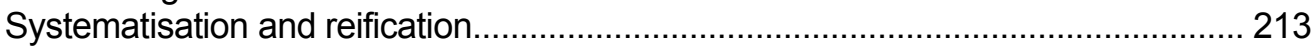

Dispositions to learning ............................................................................. 214

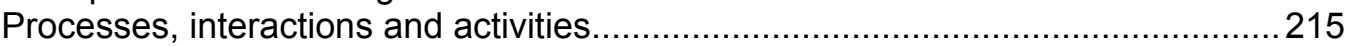

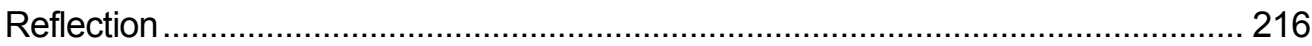

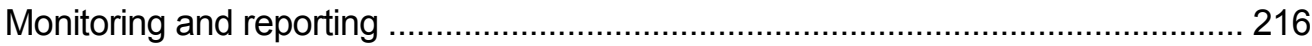

Communities of practice ................................................................................ 217

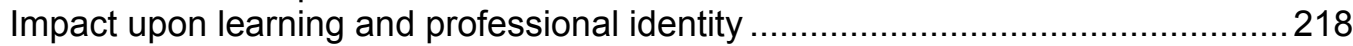

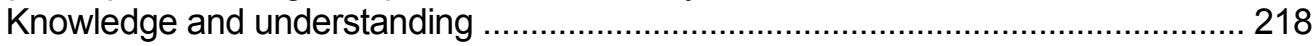

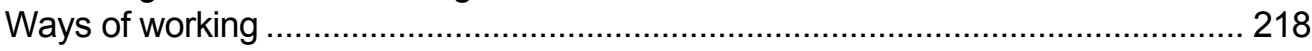

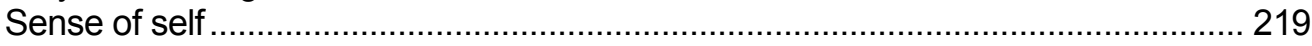

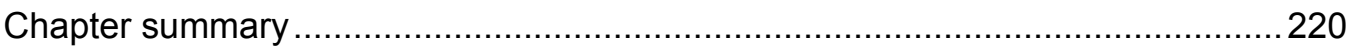


CHAPTER 10 Conclusions, limitations and implications ...............................221

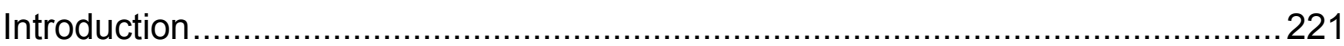

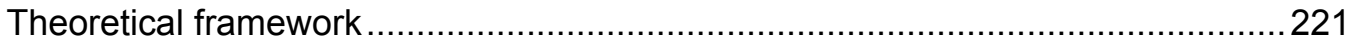

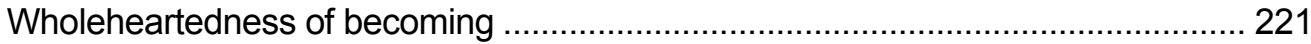

Shared vision of purpose ................................................................222

Collective responsibility for, and commitment to, learning ........................ 222

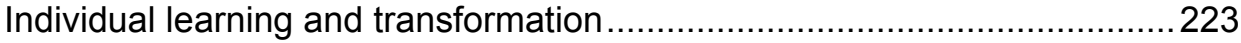

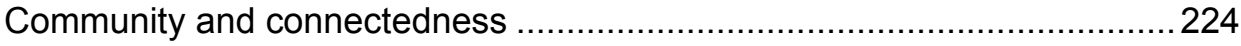

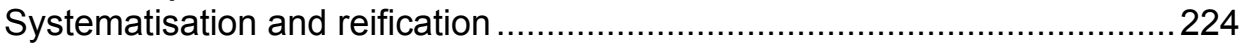

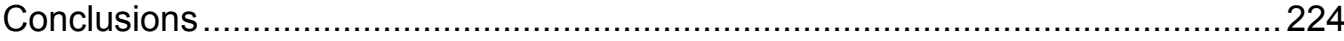

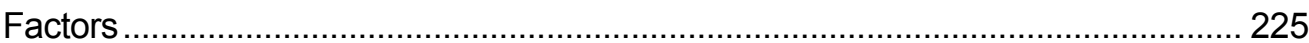

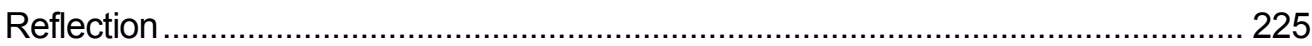

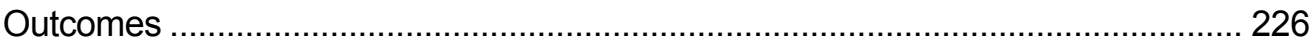

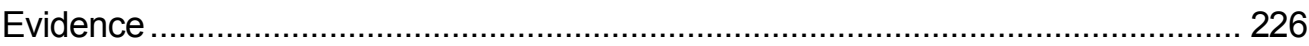

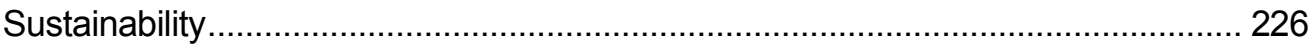

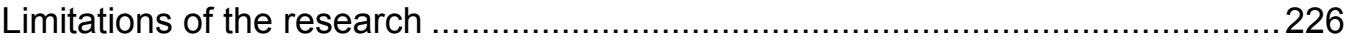

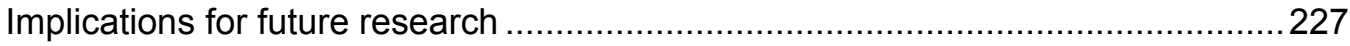

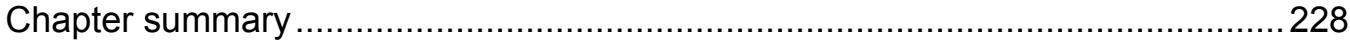

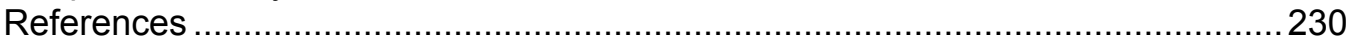

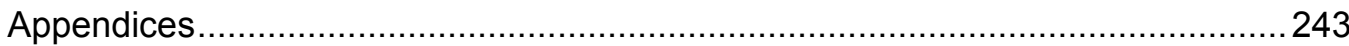

Appendix A: Invitation to Participate In Doctoral Research.................................. 244

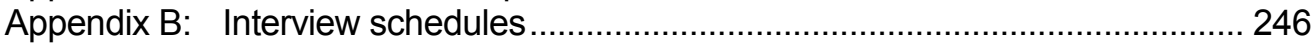

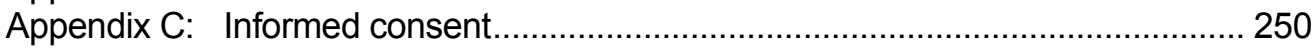

Appendix D: Participant profiles ....................................................................... 253

Appendix E: Open coding with categories and dimensionalised properties of

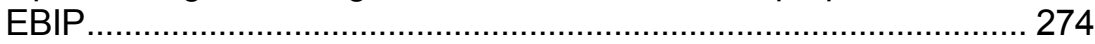

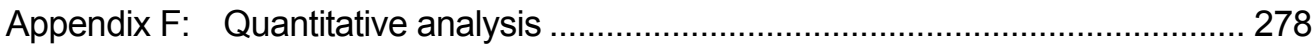

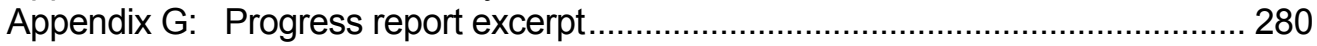

Appendix H: Teacher feedback analysis ........................................................ 283

Appendix I: Visual conversation analysis ...................................................... 284

Appendix J: Subjective/objective conversation analysis................................... 285

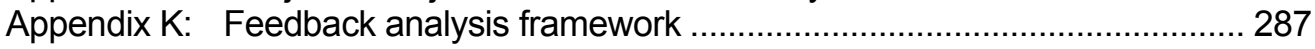

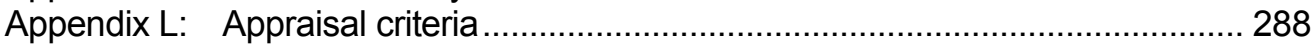

Appendix M: Summarised list of participants and document sources ................... 292

\section{List of Tables}

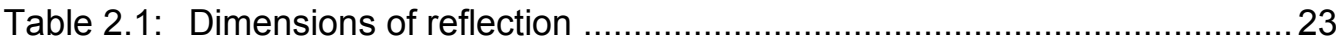

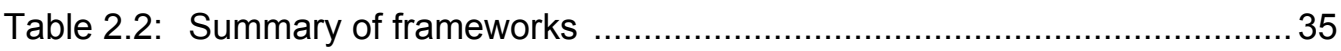

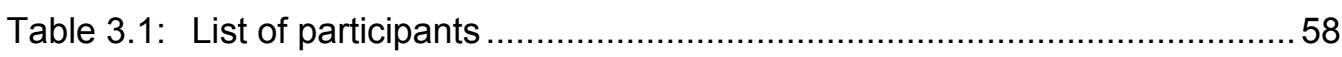

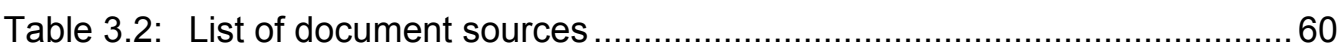

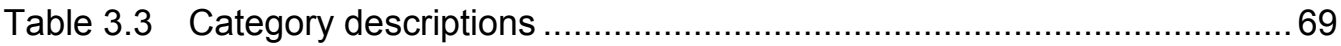

Table 3.4: Open coding excerpt of categories and dimensionalised properties

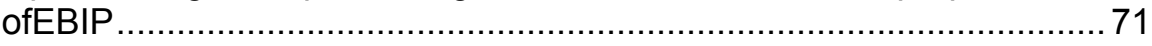

Table 3.5: Quantitative significance of categories .......................................... 72

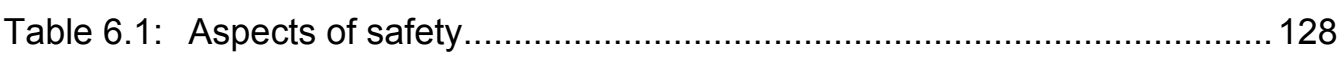

Table 8.1: Key dimensions for the analysis of networks in education ..................... 179

Table 8.2: Dimensions, activities and mediating factors of INSTEP communities of practice 


\section{List of Figures}

Figure 1.1: Focus of this study within the Inquiry and Knowledge-building Cycle for Inservice Teacher Educators.

Figure 1.2: Focus of this study within the chain of influence: ISTE learning to student achievement

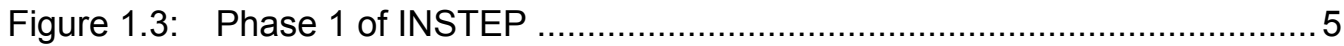

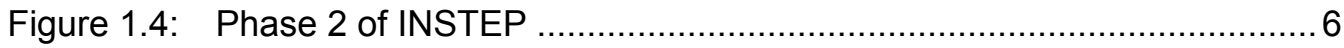

Figure 1.5: Phase 3 of INSTEP: Multiple layers of research participation in the Expansion and Refinement Phase ................................................... 7

Figure 2.1: A conceptual framework for the professional practice of ISTEs ......... 18

Figure 2.2: A chain of influence: ISTE learning to student achievement ..............33

Figure 2.3: Evidence-practice cycles ........................................................ 44

Figure 3.1: Sequence of data collection and analysis ...................................... 61

Figure 3.2: Stages of coding and content analysis ........................................ 65

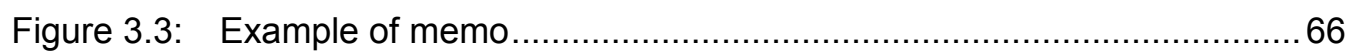

Figure 3.4: Level 1 analysis - open coding categories....................................... 67

Figure 3.5: NVivo Screenshot: Section of coded transcript ...............................68

Figure 3.6: A coding paradigm for evidence-based inquiry into practice for inservice teacher educators....................................................... 73

Figure 3.7: Stages in development of theoretical framework.............................. 75

Figure 4.1: An Inquiry and Knowledge-building Cycle for Inservice Teacher

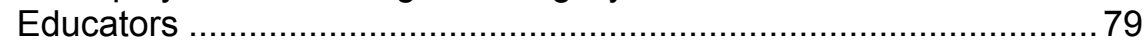

Figure 4.2: Inquiry plan model [Document Source A] .................................... 80

Figure 4.3: Overview of inquiry framework [Document Source A] ...................... 80

Figure 4.4: Audio recording prompts [Document Source A] ............................. 85

Figure 4.5: Values and beliefs questionnaire [Document Source A] ................... 88

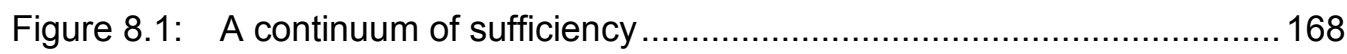

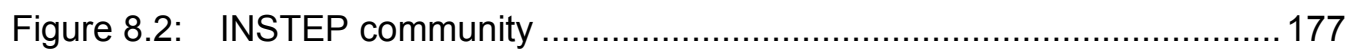

Figure 8.3: Generalised activity system for INSTEP networks ......................... 181

Figure 8.4: Dimensions of practice as the property of a community ................... 190

Figure 8.5: A conceptual framework for the process of becoming ..................... 199

Figure 10.1: Proposed theoretical framework: The wholeheartedness of becoming. 222 


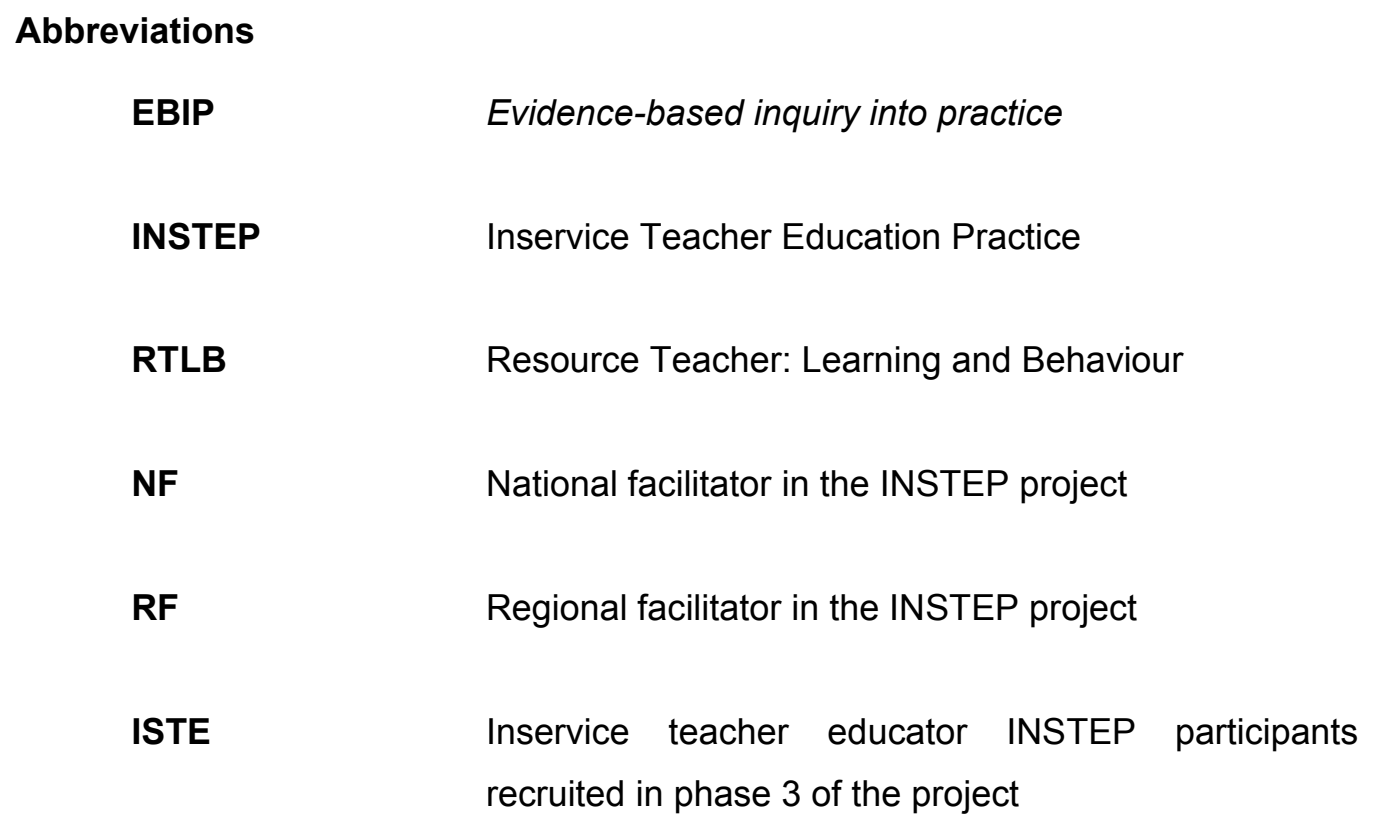

\section{Glossary}

Inservice teacher educator - This is a general reference to the sector of inservice teacher educators within a global context. They consist of advisers, facilitators, resource teachers, lead teachers, and other educators who work with teachers and leaders in schools to improve student learning outcomes.

Facilitator - Inservice teacher educators employed within a particular service or provider organisation. 


\section{CHAPTER 1 \\ Introduction}

\section{Background}

This is a study of the experiences and perceptions of 10 New Zealand inservice teacher educators who were engaged in evidence-based inquiry into practice (EBIP) within a professional learning and development initiative. They engaged wholeheartedly, with a willingness to critically examine values and beliefs (Dewey, 1933) in a process of becoming (Dall'Alba, 2009; Loughran, 2006):

Developing an identity and practices in teacher education is best understood as a process of becoming. (Loughran, 2006, p. 14)

Inservice teacher educators are those advisers, facilitators, resource teachers, and other providers who work with teachers and leaders in schools to improve student learning outcomes. Like teachers, inservice teacher educators work in an environment that is subject to constant change. They must constantly strive to monitor and improve their practice and to be responsive to the needs of students, teachers and leaders in schools within the contexts of national, regional and schoolbased initiatives and priorities.

Recent studies of professional learning and development for teachers (Fraser, Kennedy, Reid, \& McKinney, 2007; Robinson, Hohepa, \& Lloyd, 2009; Timperley, Wilson, Barrar, \& Fung, 2007; Wilson \& Berne, 1999) report a growing emphasis on the trend towards activation rather than delivery of learning, and approaches which are collaborative and inquiry oriented, promote teacher ownership and responsibility for the process, and acknowledge the collective responsibility of the profession to enhance learning and performance. This shift in trend has implications for the kinds of knowledge that teachers require, and in turn, the changing role, knowledge and practice of inservice teacher educators (Day, 1995; Evans, 2008). However, inservice teacher educators receive little specific training or attention to ongoing professional learning (Korthagen, 2001).

Within New Zealand, Sankar (2009) reported an evaluation of inservice teacher education provision, prior to 2005 , found some significant challenges for inservice teacher educators which contributed to the "variable and anecdotal" (Sankar, 2009, p. 1) delivery of services. The evaluation reported that inservice teacher educators were not supported in the transition from school teachers or principals to the role of 
inservice teacher educator. Factors that were identified as impacting on effectiveness of delivery of inservice teacher education services were: lack of experience in working in adult education; the output-driven nature of inservice teacher education services; and the perceived pressure to take on the role of expert (Sankar, 2009). Particular areas of practice that were affected were identified as: quality of data analysis; insufficient preparation and planning; induction processes; and insufficient attention to personal professional growth.

There is a paucity of research in the professional learning and development of teacher educators (Korthagen, 2001; Martinez, 2008; Timperley et al., 2007; Villegas-Reimers, 2003; Zeichner, 2005). Addressing this gap, and the need for research and development to inform continuous system-wide improvements in education in New Zealand (OECD, 2003), the New Zealand Ministry of Education funded a research and development project about the learning and practice of inservice teacher educators. The Inservice Teacher Education Practice Project (INSTEP) was designed to investigate and develop professional learning approaches for inservice teacher educators (Ministry of Education, 2006). INSTEP involved an evidence-based approach to improving professional practice across the education system, drawing on current research, and aimed to generate, use and disseminate new knowledge about what constitutes effective inservice teacher educator practice and learning.

The objectives of INSTEP were to:

1. explore and develop effective approaches for the professional learning of inservice teacher educators;

2. strengthen and promote evidence-based inservice teacher education practice; and

3. support professional leadership and ongoing improvement within the inservice teacher education sector (Ministry of Education, 2006, p. 4).

The participants of INSTEP included school leaders, teachers and students, as well as approximately 440 inservice teacher educators within twelve regional research and development projects throughout New Zealand.

It is against this backdrop that my study takes place. More detail on the context and rationale are provided in the following sections of this chapter. 


\section{Rationale for the study}

In recent years there has been an increasing focus on the professional learning and development needs of teachers and the ways in which quality and effectiveness of professional learning and development experiences are assured (Day \& Sachs, 2004a; Fraser et al., 2007; Kennedy, 2005; Townsend \& Bates, 2007). Internationally there is a great deal of research on the professional learning and development of teachers, and there is a move towards contextually based professional learning and development, which is evidence based and informed by current research findings (Campbell, McNamara, \& Gilroy, 2004; Cochran-Smith, 2005; Darling-Hammond, 2000; Day, 1999a; Forde, McMahon, McPhee, \& Patrick, 2006; Loughran, 2006; Thomas \& Pring, 2004; Timperley \& Parr, 2004; Timperley et al., 2007). There is currently a dearth of research literature in the area of professional learning and development for teacher educators (Korthagen, 2001; Martinez, 2008; Timperley et al., 2007; Villegas-Reimers, 2003; Zeichner, 2005).

New Zealand inservice teacher educators engage in a variety of formal and informal professional learning activities. In the current climate of change in the nature of professional development for teachers, there is a need to understand more clearly what kinds of professional learning environments are required in order to address the diverse needs of inservice teacher educators who are very well qualified and experienced experts in their fields. This study will add to the knowledge base of professional learning and development for this group of practitioners, and contribute to the improvement of inservice teacher education provision in general.

The study includes an exploration of the particular learning contexts, processes and activities of some inservice teacher educators who participated in the INSTEP project between May 2005 and July 2009, and who were collaboratively and critically reflecting on their practice in light of research and evidence. In particular, the study examines the process of EBIP for those inservice teacher educators who are based in a range of environments from universities to private organisations and schools. Their roles range from delivering Ministry of Education contracts for initiatives such as the literacy and numeracy, and assessment projects (Ministry of Education, 2008b, 2008c), to providing in-school support, and responding to specific school and cluster requests for teacher professional development.

It is not the aim of this study to examine evidence of effectiveness of participants' practice, or the impact of practice, but to examine their reflections on their learning experiences and their perceptions of the impact of those experiences. 
Figures 1.1 and 1.2 illustrate the focus of this study and where it is located within the cycle of inquiry (Ministry of Education, 2008) and chain of influence (Ministry of Educ

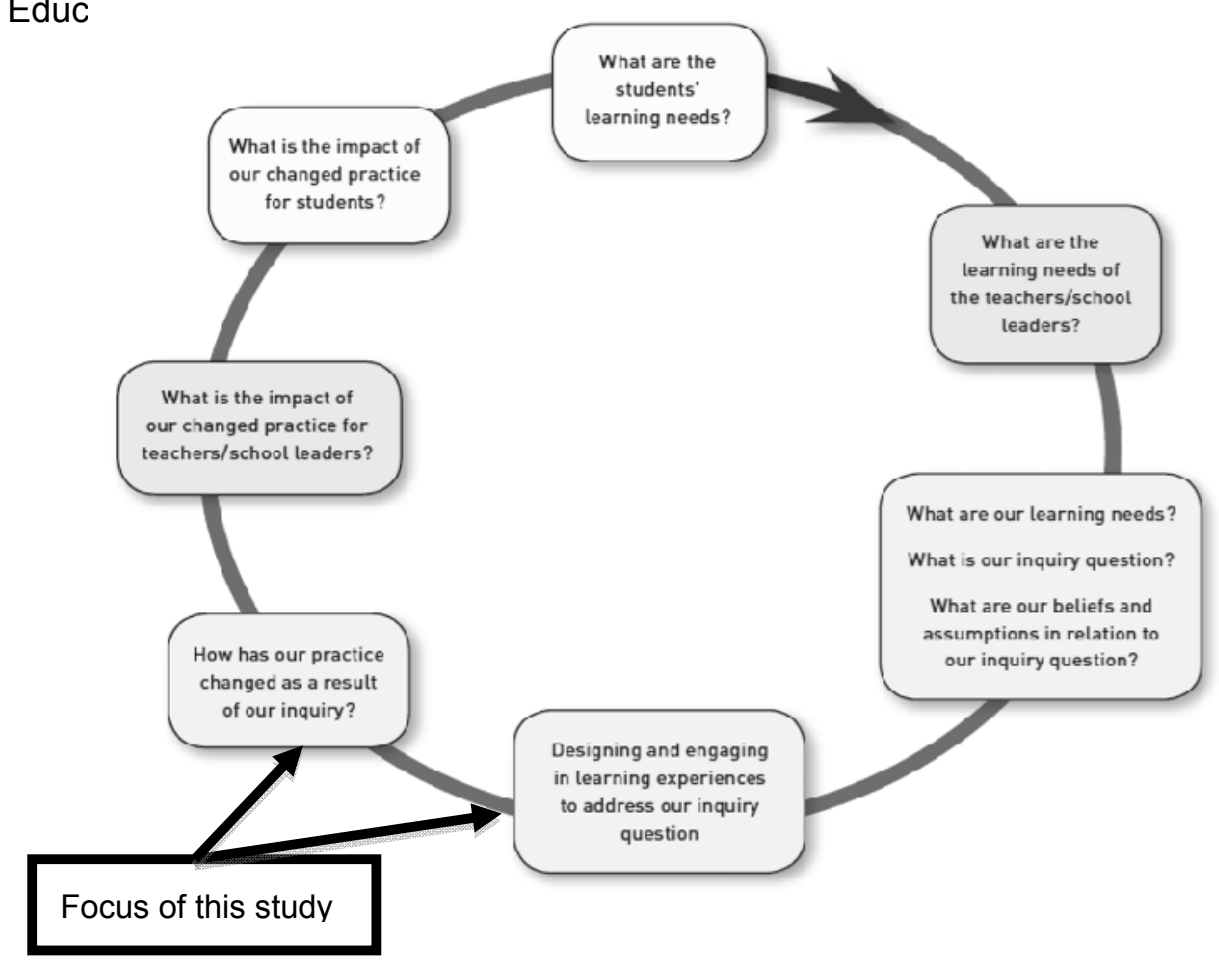

Figure 1.1: Focus of this study within the Inquiry and Knowledge-building Cycle for Inservice Teacher Educators (Ministry of Education, 2008, p. 44)

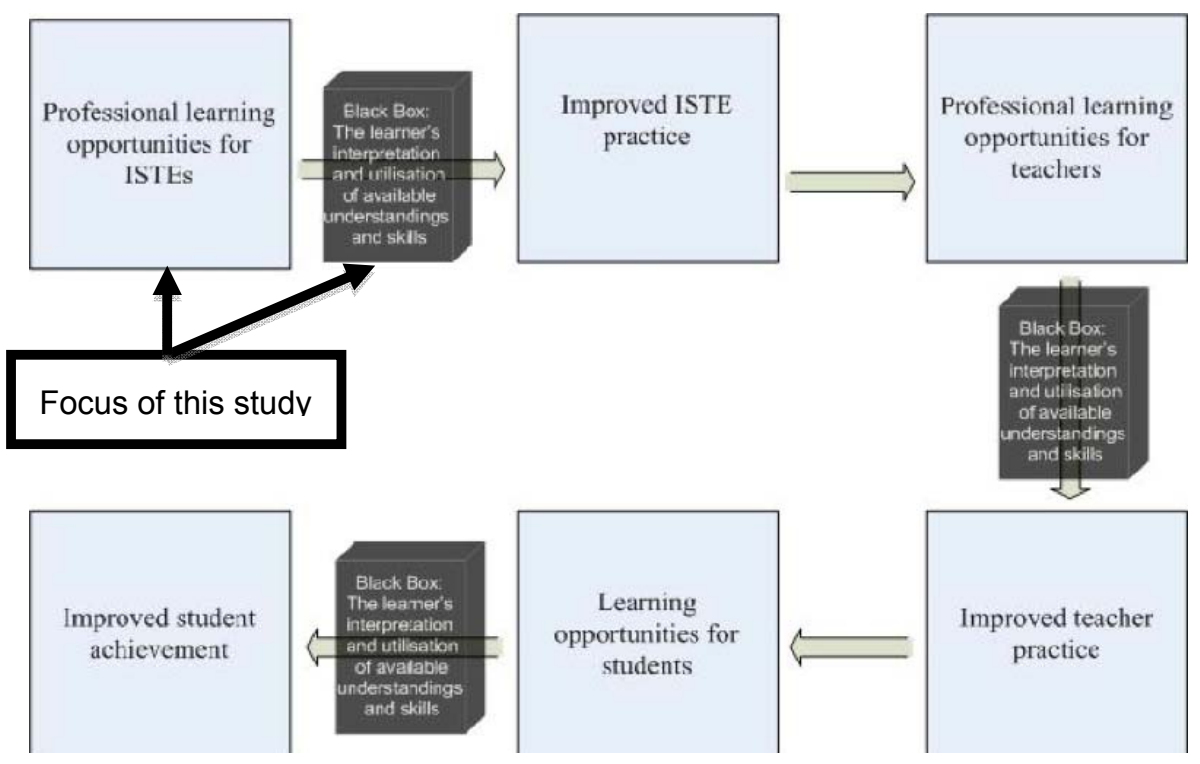

Figure 1.2: Focus of this study within the chain of influence: ISTE learning to student achievement (Ministry of Education, 2006, p. 12) 
The purpose of this qualitative grounded theory study is to generate a theoretical framework for the process of EBIP for inservice teacher educators by investigating the experiences and perceptions of INSTEP participants who engaged in EBIP. Such a framework will help us to understand more clearly how to promote and support this aspect of learning to positively impact on inservice teacher educator practice.

EBIP is only one approach to professional learning and development. It is not the purpose of this study to consider the appropriateness of such a model for the professional learning and development of inservice teacher educators, but to provide a rich qualitative analysis of the contexts, processes and activities experienced by the study participants while engaging in EBIP.

\section{Context of the study}

INSTEP was implemented in four phases between May 2005 and July 2009. Research and development informed the project throughout its duration. The Phase 1 (Figure 1.3) work on project design and planning (May 2005 - December 2005) was conducted in consultation with stakeholders.

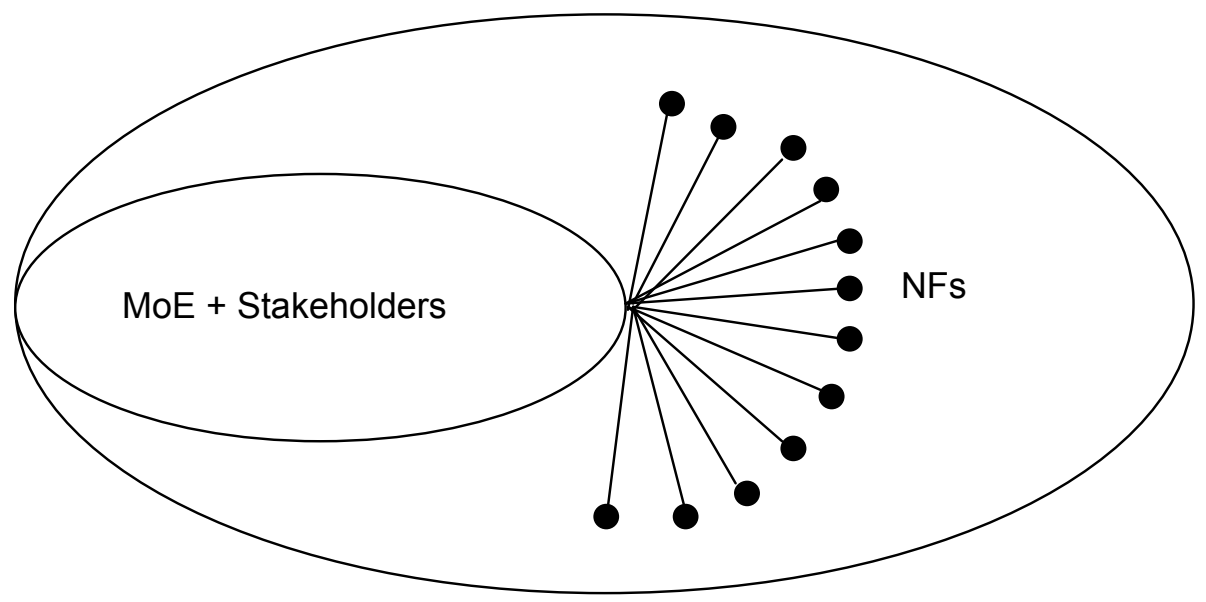

\section{Phase 1: Design and planning}

To develop a draft framework and identify a range of approaches to professional learning

Figure 1.3: Phase 1 of INSTEP

Twelve national facilitators (NFs) were appointed, and they worked with the Ministry of Education project management team, and stakeholder representatives, to develop a draft framework and to identify a range of approaches to professional learning and development. 
During Phase 2 (Figure 1.4), which was termed the exploration phase (January 2006 - July 2006) each NF worked with five regional facilitators (RFs).

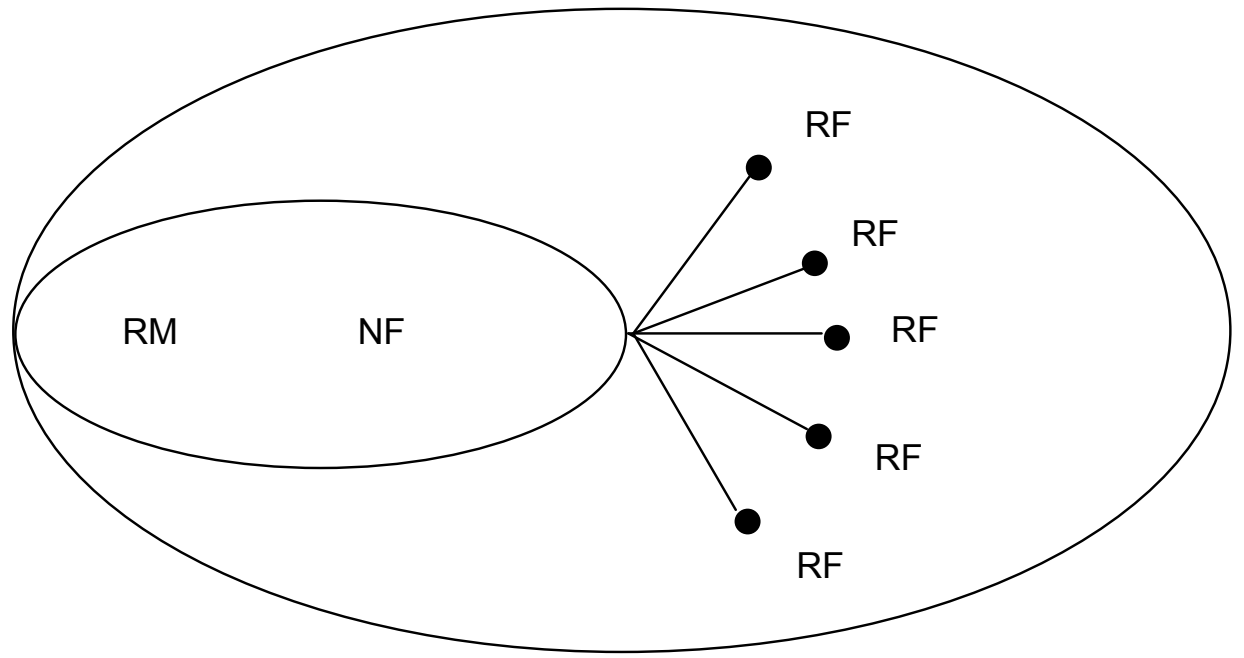

Phase 2: Exploration

Each NF worked with five RFs to trial the draft framework and implement approaches to professional learning and development

Figure 1.4: Phase 2 of INSTEP

Each RF worked to improve their practice in the course of their work with teachers by exploring and trialling the initial framework and approaches to professional learning and development. Research mentors (RMs) in each location supported the work of NFs and RFs. The knowledge and experience gained during this phase was used to reshape the initial draft framework and approaches to the professional learning and development of inservice teacher educators, and to inform the design of the next phase of the project.

Phase 3 (July 2006 - June 2007) allowed for expansion and refinement (Figure 1.5). 


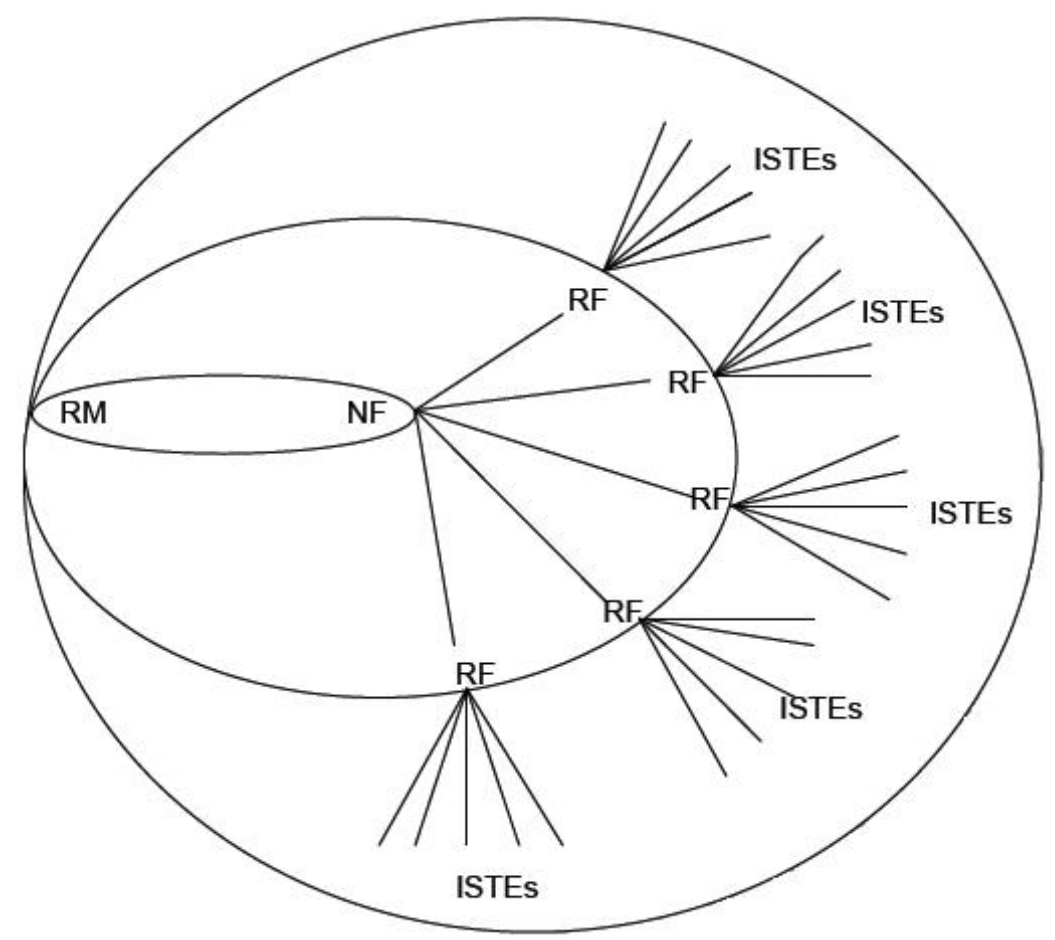

Phase 3: Expansion and refinement

NFs and RFs worked with ISTEs to implement inquiry based research projects. The framework and resource materials were revised.

Figure 1.5: Phase 3 of INSTEP: Multiple layers of research participation in the Expansion and Refinement Phase (Higgins, 2008, p. 7)

Phase 3 provided time for each RF to work with a group of inservice teacher educators (ISTEs) to improve their practice in the normal course of their work with teachers and schools. The NFs worked with the RFs and research mentors to implement inquiry-based research projects focused on the professional learning of ISTEs, and the revised drafts of the framework and accompanying materials were developed (Ministry of Education, 2006).

Phase 4 was the final consolidation phase of this research and development project (July 2007 - July 2009). The final framework and accompanying resource materials Ki te Aotūroa (Ministry of Education, 2008a) were published and distributed to inservice teacher educator organisations throughout New Zealand; a project report was completed, providing a synthesis of the research projects and evaluation activities (Higgins, 2008); and selected professional learning initiatives operating within some participating groups were supported. 


\section{The researcher}

I qualified as a primary and secondary teacher in 1980 at Dundee University, Dundee, Scotland. I have been employed both in Scotland and New Zealand as a teacher of Mathematics and Information and Communications Technology in secondary schools. For most of my career I have been a teacher educator, having been employed at Northern College of Education (Dundee), MultiServe Education Trust (Wellington), and in the Faculty of Education, Victoria University, Wellington. During my time at Northern College, I was involved in teacher professional development and also coordinated a project funded by the Scottish Executive which was concerned with effective professional development for teacher educators.

I have a substantial history in working within the field of professional development for teachers and teacher educators, and I am passionate about engaging all teachers and teacher educators in professional learning to improve practice. I am therefore very familiar with the working environments, challenges, dilemmas, and learning cultures of the research participants as well as the domains of schooling, teacher education, and professional learning. My background of promoting and supporting information and communications technologies within the primary, secondary and higher education sectors means I have experience of working with practitioners across a range of curriculum areas, levels and disciplines.

I was contracted by the New Zealand Ministry of Education as one of the 12 NFs in the INSTEP project from May 2005 - July 2009. During this time I worked with NFs and other stakeholders to contribute to the development and dissemination of the project framework and first draft of resource materials (Ministry of Education, 2006). I also recruited and worked with a group of five RFs and their pods of ISTEs in a variety of projects focusing on collaborative EBIP. My role within this context included being a critical friend to RFs and ISTEs, leadership and co-ordination of professional learning and development experiences, and collation and final production of related research reports for the Ministry of Education. During the final phase of the INSTEP project, I was a member of the writing advisory group for the resource materials: Ki te Aotūroa (Ministry of Education, 2008a).

My role as NF in the INSTEP project has provided me with additional experience in the field of inservice teacher education provision. As a researcher with some experience and expertise in the domain of inservice teacher educator professional learning and development, I have some understanding of the context and nature of their practice and professional learning and development environments. 


\section{Personal philosophy of teaching and learning}

I believe all learners are empowered by taking ownership of, and responsibility for their learning, and having a commitment to lifelong learning, self-regulation, critical reflection and collaborative, collegial professional development. These skills and attributes are reflected in the Graduating Teaching Standards (NZTC, 2007), and the Registered Teacher Criteria (NZTC, 2010), which should underpin all preservice and inservice teacher education programmes.

I relate to Boud's (2000) articulation that learners should be equipped to be lifelong assessors, and his concept of sustainable assessment underpins lifelong learning. This requires assessment to be put in the hands of the learners rather than assessors, and learners to be able to undertake assessment and self-regulate their learning throughout their lives.

Reflection involves the learner in scrutinising his/her beliefs, values and assumptions and making tacit knowledge explicit (Schön, 1983). In this way, student teachers, teachers and teacher educators are able to reflect on their learning and practice and develop and refine their own personal philosophies of teaching and learning (Darling-Hammond \& Bransford, 2005). I understand that not all tacit knowledge can be made explicit, but believe in the value of critically examining practice and evaluating it within the context of personal philosophies of teaching and learning.

I agree with L. Shulman (2004), who acknowledges the importance of collaboration, and with Moseley and Ramsay (2005), who suggest that teachers and student teachers "need to experience the joy of collaborative discussion, dialogue, critique, and research" (p. 36), and that peer collaboration and mentoring can add value as a means of authentic assessment.

I believe new technologies can be used as mindtools: intellectual partners in the learning process facilitating constructive, critical, higher order thinking and reflective processes (Jonassen, 2000). Jonassen asserts that multimedia authoring tools can be used for knowledge construction and reflection on learning. I believe that teacher educators need to be creative with new technologies to meet the demands of the digital age. This can be achieved by exploiting the communicative and adaptive capabilities of the new technologies (Laurillard, 2002). I particularly value the potential of new technologies such as digital audio and video to gather and critique evaluation of practice for teachers and teacher educators. 


\section{Chapter summary}

This study investigates the professional learning and development experience of a group of inservice teacher educators who participated in the INSTEP project, and examines what constitutes EBIP within this context. The experiences of the participants are analysed and discussed with reference to relevant literature in the field. The study presents a theoretical framework for this process and its impact on the participants. The limitations of the study are presented in the concluding chapter. The next chapter presents a preliminary literature review for the topic of the study.

\section{Overview of thesis}

The first section (Chapters 1-3) of the thesis sets the scene for the research, presents a literature review, and describes and justifies the research design and content analysis. Chapters 4-7 present the findings of the study which consist of the main categories that were developed from inductive analysis of interview data, and were informed by theoretical sampling of document sources. Chapters 8-10 present a discussion of the findings relating them to the research questions. It also presents the theoretical framework derived from the research, and the conclusions and implications arising from the study.

Chapter 1 introduces the research and outlines its significance for inservice teacher educators in an environment of educational change. The context is a New Zealand research and development project, focussing on professional development approaches, that was funded by the Ministry of Education. I outline my own teaching and learning philosophy, and my position in relation to the context and participants.

Chapter 2 presents the preliminary literature review which informed the research questions and methodology. A selective overview of the research on professional knowledge, learning, and development is given, including current trends and future implications.

Chapter 3 describes the case study and grounded theory methodology, and the design and implementation of the research. It also describes the process of content analysis and the development of emergent themes and categories.

Chapter 4 is designed not to report specific findings in relation to the participants, but to draw on a wide range of evidence from the participants, and from across the INSTEP project, to convey the kinds of contexts that the participants were working 
within, and to illustrate the kinds of evidence, criteria and validatitation processes that they used in EBIP.

Chapters 5 to 7 present the findings from the three main categories derived from the data: rules, tools and routines; working with people; and impact upon individuals. Rules, tools and routines consists of: formal and informal expectations and requirements; resources, tools and mechanisms; and contextual structures and processes. Working with people consists of: collaborative arrangements; aspects of safety in collaborative environments; perspectives and diversity; critical friendship; and aspects of management and leadership. Impact upon individuals consists of: dispositions; emotions and feelings; and learning and professional growth.

Chapter 8 presents a discussion and further deductive analysis of the key themes with reference to literature and relevant theoretical frameworks.

Chapter 9 presents the findings in relation to the research questions.

The final chapter (Chapter 10) presents the theoretical framework which was derived through an integrative analysis of: primary and secondary data; the preliminary literature review; and further literature identified in an ongoing way throughout data analysis. Finally, it presents the conclusions of the study and implications for professional practice and learning, and further research. 


\section{CHAPTER 2 \\ Literature review}

\section{Introduction}

Internationally there is a great deal of research on the professional learning and development of teachers. Much of the literature identifies EBIP as an integral part of teachers' professional learning (Crockett, 2002; Darling-Hammond, 2000; Day, 1999b; Reid, 2004; Timperley \& Parr, 2004). There is currently a dearth of research literature in the area of professional learning for teacher educators (Martinez, 2008; Timperley et al. 2007; Villegas-Reimers, 2003; Zeichner, 2005).

Professional learning and development for professional practitioners such as teachers and teacher educators must take account of the distinctive and complex nature of their role and practice, and the implications for effective professional learning processes and contexts (Cheetham \& Chivers, 2001; Darling-Hammond, 2000; Day, 2007; Loughran, 2006; Timperley et al., 2007). This chapter presents an overview of some of the prominent literature on the topic of learning and development for professional practitioners. It will explore the types of knowledge and skills required by professionals and the types of learning experiences that have been identified as effective in contributing to their professional growth. In particular, it will elaborate on the place of EBIP as an approach to professional learning and development. The review of literature will identify the key issues around learning and development for professional practitioners generally, and then relate the issues to the practice, knowledge and learning of inservice teacher educators in particular.

This literature review is preliminary to the grounded theory study, which develops a theoretical framework for EBIP for inservice teacher educators. The purpose of the review is to investigate the current contexts and roles of inservice teacher educators, and their professional learning and development, and derive some operational definitions of terms for the study.

\section{Professional knowledge}

In considering what constitutes a professional learning environment for inservice teacher educators, one of the key issues is the complexity of their professional role and the nature of the knowledge required to execute it effectively. There has been 
much written regarding the particular kinds of knowledge that professionals require in order to undertake their professional activities competently and effectively (Cheetham, 2005; Cheetham \& Chivers, 1998; Eraut, 1994; Schön, 1987). One of the key challenges is the definition of knowledge and how it is acquired and applied. The following paragraphs explore the concept of professional knowledge, and consider the implications for inservice teacher educators engaging in EBIP.

Eraut (1994) identifies three kinds of knowledge: propositional knowledge (the what); personal knowledge (personal experience); and process knowledge (the how). Eraut believes that the way in which knowledge is acquired and used is significant when considering professional knowledge.

\section{Propositional knowledge}

Propositional knowledge consists of the specialised knowledge required in any profession. Schön (1983) refers to propositional knowledge as theoretical and codified knowledge. Shulman and Shulman (2004) observe that in teaching, this specialised knowledge incorporates understanding and being "capable of performing" (p. 262). They cite some examples of this knowledge for teaching including:

- disciplinary content knowledge;

- curriculum knowledge;

- pedagogical content knowledge;

- knowledge of classroom management and organisation;

- knowledge of assessment;

- knowledge of accomplishing community (within the classroom, school, community and profession); and

- knowledge and understanding of learners.

These aspects of knowledge are featured prominently in teacher professional education programmes. However, the propositional knowledge for inservice teacher educators is less clear and not featured in the literature (Day, 1999b; Korthagen, 2001).

\section{Personal knowledge}

Personal knowledge "includes ideas, feelings and understandings from all realms of a professional's life that become inextricably bound to propositional knowledge gained during professional training and practice" (Jones, 2007, p. 29). This includes 
an affective domain and is determined by individuals' unique prior experiences, knowledge, values, beliefs and assumptions. Zeichner and Liston (1996) use the term "appreciative system" (p. 23) for this type of knowledge that individuals bring to their professional practice. Since inservice teacher educators are usually recruited because of their experience (Korthagen, 2001), their personal knowledge can be considered well established, having developed over years of professional education and practice.

\section{Process knowledge}

Process knowledge is the kind of knowledge that is required in the application to practise, of other types of knowledge. This type of knowledge requires first-hand experience within professional practice. Eraut (1994) identifies some of the processes required for the application of knowledge in practice: acquiring information, skilled behaviour, deliberative processes, giving information, and metaprocesses, which are summarised as follows:

- Acquiring information requires skills of inquiry. It also requires an existing knowledge base, and the disposition to inquire into, and add to, that knowledge base.

- Skilled behaviour incorporates behaviour that has evolved through experience, as being routine, and that requires little or no conscious cognitive activity. Jones (2007) observes that skilled behaviour is very similar to Schön's (1987) "knowing-in-action" (p. 28) and tacit knowledge. Schön's term "artistry" (1987, p. 13) conveys the type of knowledge practitioners exercise within the context of their professional practice when they draw upon their "unique, uncertain, and conflicted situations of practice" (p. 22). Tacit knowledge is a term introduced by Polanyi (1967) as implicit and subconscious knowledge that is brought to bear in some situations, and which often cannot be made explicit. It is knowing "more than we can tell' (p. 4).

- Deliberative processes are those actions that require deliberation, professional judgement, and decision-making based on existing knowledge. They are dependent on the understanding of existing knowledge.

- Giving information consists of skills in communicating and conveying knowledge. This also involves the identification of relevant knowledge to convey to others.

- Metaprocesses are the skills of metacognition incorporating a conscious awareness and control of one's learning. 
It is process knowledge, therefore, that enables the enactment in practice of propositional knowledge and personal knowledge. When considering this generic definition of process knowledge, one might assume that this, in practice, is very similar for teachers and inservice teacher educators. However, it is so dependent on the propositional and personal knowledge for each, that it is crucial to clarify the propositional knowledge for inservice teacher educators.

All three types of knowledge are interdependent and interconnected. The process of acquiring the different types of knowledge, however, differs. While propositional knowledge can be attained largely by reading, listening and discussion, process knowledge requires professional experience and action (Jones, 2007), personal knowledge is acquired throughout a lifetime, and is impacted upon by personal, professional and sociocultural influences.

Korthagen (2001) and Loughran (2006) consider the types of knowledge required for teachers and inservice teacher educators. Korthagen (2001), like Eraut (1994), places emphasis on the process of learning. He draws on Plato and Aristotle's work to make the distinction between episteme (Theory with a capital T), which he defines as conceptual knowledge, and phronesis (theory with a small t), which he classifies as perceptual knowledge. Korthagen believes that an episteme approach to professional learning is technical-rational, with insufficient acknowledgement of context and process. He proposes a "realistic approach" (p. 254), which has an emphasis on phronesis. He asserts that within an episteme approach, theory and practice are disconnected, while a phronesis approach incorporates practical wisdom and conceptual knowledge, thus theory is approached through practice: "The person of practical wisdom inhabits the human world and does not attempt to rise above it" (p. 27). Korthagen acknowledges that critical reflection on practical situations is a key feature of the realistic approach, where "the emphasis shifts toward inquiry-oriented activities, interaction among learners, and the development of reflective skills" (p. 15). The concept of reflection is considered an important one in the development of professional knowledge, and will be addressed in a later section in this chapter.

Loughran (2006) defines episteme as: "propositional knowledge, consisting of assertions of a general nature that apply to many different situations and problems ... [which] is traditional, scientifically derived knowledge" (p. 8); and phronesis as: "a form of practical wisdom that is derived through understanding specific situations and cases" (p. 8). He also suggests that in constructing new knowledge, 
generalisations can arise from phronesis and be verified to align with episteme. It is in this way that the gap can be bridged between theory and practice by extending learning and building on existing knowledge through experience.

The concept of different types of knowledge and the ways in which they are attained is an important one when considering professional learning and development. Although there is no definitive classification of types of knowledge, I believe that Eraut's (1994) conception of knowledge is particularly relevant for this study. Eraut's distinction between propositional, process and personal knowledge lends more clarity to the identification and attainment of professional knowledge. Although process knowledge might appear to be the type of knowledge most relevant in EBIP, its dependence on propositional and personal places equal emphasis on all three.

It is interesting that a key component of process knowledge is the ability to use skills of inquiry to question and validate existing knowledge, acquire new knowledge and understanding, and interpret, convey or enact new knowledge. This core component is the catalyst for, and means of, further developing propositional and personal knowledge. Personal knowledge is also significant for inservice teacher educators, and requires some attention in this study, as it is the affective domain of personal knowledge that determines attitudes and dispositions to learning, which, in turn, impact upon the capacity to inquire into practice and gain new knowledge.

In terms of aligning theory with practice, Korthagen's (2001) and Loughran's (2006) perspectives are of value in identifying particular approaches to professional learning. By adopting a phronesis approach, the focus remains on the application of propositional knowledge and personal knowledge within the context of professional practice. Propositional knowledge or theory, therefore, is aligned with professional practice in a meaningful way.

The following section discusses the types of knowledge that are particularly relevant for inservice teacher educators.

\section{Professional knowledge for inservice teacher educators}

Inservice teacher educators practise in a rapidly changing society, and in an educational environment which is constantly subject to changes in policy, and where "reculturing is the name of the game" (Fullan, 2007, p. 177). In addition to the element of change, educators must deal with uncertainty on a daily basis: 
Professions (like teaching) deal with that part of the universe where design and chance collide. One cannot resolve that uncertainty by writing new rules. The way forward is to make that collision, that unpredictability in our fields, itself an object of individual and collective investigation. We can never fully remove the uncertainty from teaching ... But as a profession, we can grow much wiser about how to anticipate and deal with uncertainty. (L. Shulman, 1999, p. 15)

Schön's (1983) analogy of a "swampy lowland" (p. 42) conveys the complex, ambiguous and uncertain nature of inservice teacher educator contexts of practice. Much of the practice in which inservice teacher educators engage is unique, with diverse individual and organisational problems which rely on Schön's dual processes of reflection-in-action and knowledge-in-action, which are the processes that professionals rely upon in order to make spontaneous decisions within the contexts of their practice. Inservice teacher educator practice and the roles they adopt are very diverse and generally not clearly defined. The inservice teacher educator role involves interacting professionally within a range of different contexts with a diverse population of teachers/educators, who may themselves be experts in their field. Although most inservice teacher educators are, or have been, primary, secondary or tertiary teachers in their professional lives, there is no evidence to suggest that the knowledge, skills and dispositions required for effective teaching in primary/secondary/tertiary sectors are those that apply to inservice teacher educator professional practice (Korthagen, 2001). In fact, teacher educators are usually recruited on the "basis of extensive and successful teaching experience, and/or an academic education" (Korthagen, 2001, p. 240). Korthagen found a dearth of studies on the professional learning and development of teacher educators. On the whole, they receive no specific training and there is little attention to ongoing professional growth. The exploration of effective practice and effective professional learning for inservice teacher educators is, therefore, largely uncharted territory. This study is therefore well positioned to add to this knowledge base. One of the key challenges is to define the components of this very complex professional practice.

In exploring approaches to the professional learning and development of inservice teacher educators, one of the outcomes of the first phase of the INSTEP project was a proposed conceptual framework for inservice teacher educator practice (see Figure 2.1). 


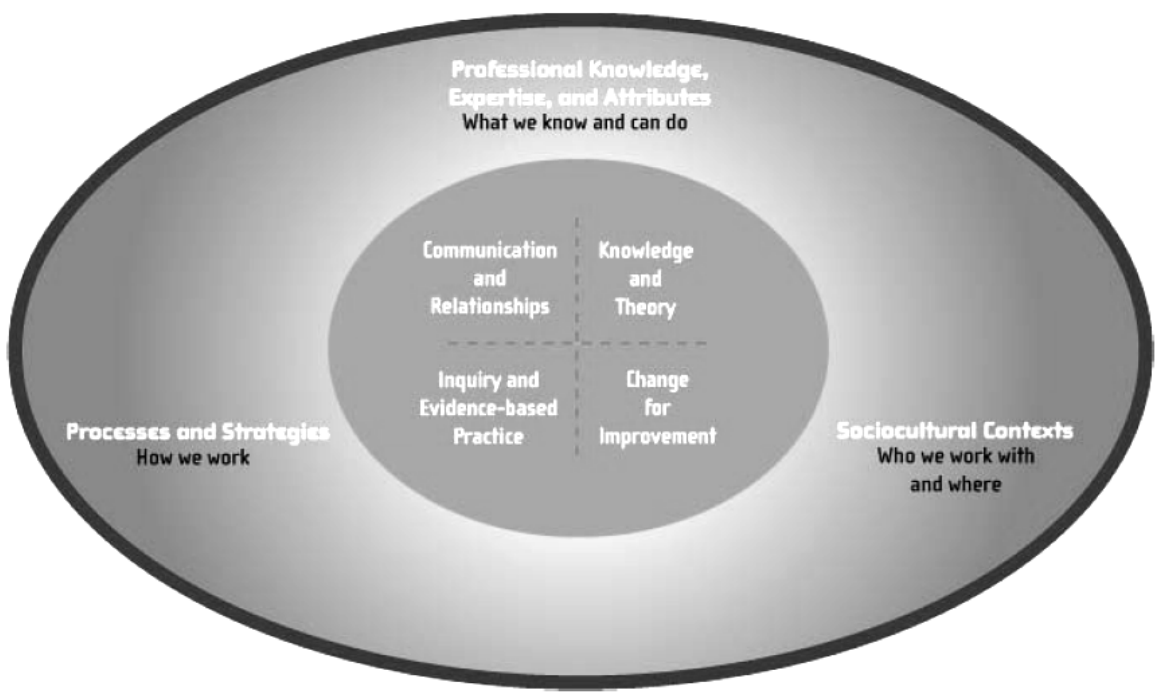

Figure 2.1: A conceptual framework for the professional practice of ISTEs (Ministry of Education, 2006, p. 14)

The framework identifies four central dimensions of effective inservice teacher educator practice: communication and relationships; knowledge and theory; change for improvement; and inquiry and evidence-based practice. It is proposed that these four dimensions encapsulate the kinds of knowledge essential for effective inservice teacher educator practice (Ministry of Education, 2006). In Figure 2.1 the four dimensions of practice are situated within surrounding and influencing factors which impact upon pedagogical decisions made, and actions taken by inservice teacher educators: professional knowledge, expertise and attributes; sociocultural contexts; and processes and strategies.

The dimensions of effective practice above incorporate particular aspects of inservice teacher educators' personal propositional and process knowledge, which include the following components:

- content knowledge;

- pedagogical knowledge;

- pedagogical content knowledge;

- knowledge of learners;

- knowledge of self; and

- knowledge of context. (Ministry of Education, 2006, p. 18)

Within the field of teacher education, pedagogical content knowledge is knowledge of teaching about teaching (Loughran, 2006). Although pedagogical content knowledge for teachers is well represented and debated in the literature of teacher education (Darling-Hammond \& Bransford, 2005; Darling-Hammond \& Snyder, 
2000; Townsend \& Bates, 2007), it is less well informed for inservice teacher educators (Day, 1999a; Korthagen, 2001).

The factors surrounding the dimensions of inservice teacher educator practice in Figure 2.1 (sociocultural contexts; processes and strategies; professional knowledge, expertise and attributes) reflect the following aspects of knowing:

- knowing why this is important;

- knowing what to do;

- knowing how to do it;

- knowing when to do it. (Waters, Marzano, \& McNulty, 2003, cited in Ministry of Education, p. 18)

Much of this might fall within the realm of Schön's (1987) artistry, which is "knowledge which enables a competent professional to make a judgement or take automatic highly skilled action but for which the professional is unable to analyse precisely what sequence took place or explain clearly what factors led to the judgement or action" (Churchman \& Hall, 1997, p. 6).

Loughran (2006) acknowledges the complexity and ambiguity of teacher educators' practice when he considers their teacher of teachers role. He urges teacher educators to deconstruct their teaching to expose the "dilemmas of practice" (p. 6) and pedagogical decision-making, in order to convey the problematic nature of teaching. Korthagen (2001) and Loughran (2006) articulate the difference between phronesis and episteme, in terms of the teacher educator's dual role of teaching about teaching and teaching: a phronesis approach involves teaching about teaching through teaching. In this way, Loughran emphasises the need for preservice teacher educators to articulate pedagogical content knowledge (teaching about teaching), and to attempt to make their practice explicit in order to convey its complexity to those who are learning about the process of teaching. He asserts that by unpacking the complexities of their practice, teacher educators will be "challenged about the why of practice not just the how of practice" (2006, p. 9), and by doing so will "push beyond the technical-rational, or tips-and-tricks approach" (Loughran, 2006, preface), and therefore will be more likely to be valued and have an impact.

This process of deconstructing practice to reveal the complexities is complex in itself, and involves unpacking propositional, process and personal knowledge. This is a process of reflection on practice, which has come to be expected of the teaching profession (Forde et al., 2006). The topic of reflection relates closely to inquiry, and will be addressed in more detail in the next section of this chapter. 
Although Korthagen (2001) and Loughran (2006) place an emphasis on phronesis, Cheetham and Chivers $(2000,2001)$ caution against this, and report that "although much professional activity operates at a semi automatic level, it is mediated and informed by specialist knowledge and interspersed with elements of rational and systematic thought" (2000, p. 381). They introduce an epistemology of practice which recognises the need for a combination of "applied specialist knowledge, rationality and more intuitive forms of thought" (2000, p. 381).

It is very timely to consider the knowledge that inservice teacher educators will require in the future, as the approaches to professional learning and development are moving increasingly towards activation rather than delivery of learning (Wilson \& Berne, 1999), and with the responsibility for learning being jointly owned in a collaborative partnership of inservice teacher educators and teachers (Day, 1995). Day proposes a partnership model, and believes the role of the teacher educator is to:

\begin{abstract}
Promote and sustain an environment which provides challenge and support through research which is embedded in development. Teacher educators are, in a sense, interventionists who aim to seek questions which are perceived by the teachers as relevant to their needs, to investigate answers to these questions collaboratively and to place the onus for action on the teachers themselves. (p. 367)
\end{abstract}

Day (1995) asserts that such a role requires new knowledge and skills, and a change to the status quo. Wilson and Berne (1999) observe that this "positions the 'what' of teacher knowledge in a much different place than it has been" (p. 194). It also, as Day suggests, has implications for the what of inservice teacher educator knowledge. It seems, therefore, that the knowledge required for inservice teacher educators is on shifting ground. There are also implications for the approaches that are adopted by inservice teacher educators for the professional learning and development of teachers, which may involve changes in the ways in which they conduct professional practice.

\title{
Reflection
}

Reid (2004) advocates that rigorous inquiry into practice, incorporating reflection, collaboration, trust and mutual respect, is central to professional learning that will improve practice and increase knowledge and depth of understanding. Although reflection is considered by many to be central to inquiry and transformational learning (Korthagen, 2001; Mezirow \& Taylor, 2009; Reid, 2004), there are a number of interpretations of the meaning of the term reflection. This section will explore some perspectives of reflection, and conclude with an operational definition of the term. 
van Manen (1977) identifies three levels of reflection, which are considered to be hierarchical. The first is the technical-practical, with a focus on the effectiveness of teaching and learning, and applying knowledge to practice. The second level is interpretative. This involves consideration of personal espoused theory, established theories, and theories-in-use, in order to identify congruence of practice with theory (Argyris \& Schön, 1974; Griffiths \& Tann, 1992). van Manen (1977) considers that the third, critical level, is most crucial. This involves consideration of the broader sociocultural and political issues that mediate teaching and learning.

Schön $(1983,1987)$ emphasises the role of reflection in improving professional practice and creating new knowledge, and introduces the notion of the reflective practitioner. In acknowledging the dilemma of "rigor [sic] or relevance" (1983, p. 44) as being the gap between scientific professional knowledge and the demands of the real world in the practice of professionals, Schön (1983) explores the aspect of reflection in a number of professional contexts. He introduces knowing-in-action and reflection-in-action as the process "which is central to the art by which practitioners sometimes deal well with situations of uncertainty, instability, uniqueness and value conflict" (Schön, 1983, p. 50). These two aspects of practice draw on the "tacit knowing" which he refers to as "knowing more than we can say" (p. 52). He argues that by acknowledging this process and making it more explicit, these aspects of reflection will be legitimised and the problem of rigour or relevance addressed. Schön believes that in this way, reflective practitioners incorporate the element of research into their practice.

Whereas Schön's (1983) reflection-on-action is the process whereby practitioners reflect on actions that have been taken, or when contemplating what action to take, Killon and Todnew (1991) add reflection-for-action which involves making decisions for the future, based on reflections on a past event. All of these "moments" (Reid, 2004 , p. 4) of reflection are integral to becoming a reflective practitioner, as defined by Schön (1983), or adopting inquiry and evidence-based practice as defined by Reid (2004).

Loughran (1996) adopts Dewey's (1933) view of reflection in defining reflective practice in preservice teacher education:

I consider reflection as the purposeful, deliberate act of inquiry into one's thoughts and actions through which a perceived problem is examined in order that a thoughtful, reasoned response might be tested out. This process involves the five phases outlined by Dewey (1933) of suggestions, problem, hypothesis, reasoning and testing, and, although they do not necessarily follow a particular order or sequence, the five combined comprise a 
reflective cycle. The results of the test from the reflective cycle may not satisfy the inquiring mind and may therefore lead to further reflection. Experience from one context may influence thoughts and actions in another, but the complex nature of teaching and learning means that each situation may effectively be a new situation. (Loughran, 1996, p. 21)

In order to encourage and promote reflection in student teachers, Loughran uses the strategies of thinking aloud and journal writing to model reflection in his practice. In this way, the students are not only being taught, but being taught how to think about and reflect on their teaching.

Schön (1983) acknowledges that the richness of prior knowledge and experience that practitioners have to draw upon impacts upon their knowing-in-action and reflection-in-action, and that practitioners' professional decisions in unfamiliar practice situations are framed by the quality and breadth of that knowledge and experience. Zeichner and Liston (1996) agree that individuals' practice and practical theories are informed and affected by their "appreciative system" (p. 23). They cite as an example, that although the situational context of a school may be the same for all teachers within it, each will respond in their own individual way according to their own appreciative systems and personal practical theories. Personal practical theories are "the intermingling of personal experiences, transmitted knowledge and core values ... that help structure teachers' work and their interpretation of externally generated theories and ideas" (Zeichner \& Liston, 1996, p. 24).

Schön (1983) asserts that due to the ongoing creation of new knowledge arising from new learning and experience, the nature of the practical theories that reflective practitioners bring to their practice are always fluid, and professional practitioners are required to review and reframe them within the context of their practice. Argyris and Schön (1974) believe that individuals form theories of action that determine and explain their behaviour. They propose that there are two types of theories of action: espoused theories (what they think they do) and theories-in-use (what they actually do). Robinson and Lai (2006) explain this very clearly:

Theories of action that are derived from people's descriptions of how they act, or have acted in the past, and from the explanations they give for such actions are called espoused theories. Theories of action that are derived from firsthand observations are called theories-in-use. Because people are not always aware of what causes their actions, the theories that people claim to be using and the theories that are actually determining their behaviour may not be the same. (Robinson \& Lai, 2006, p. 26)

Mezirow (1990) considers that a primary function of reflection is one of meaning making, and "validating what is known" (p. 18). He considers that "meaning 
schemes and perspectives that are not viable are transformed through reflection" (p. 18). He believes that transformative learning involves reflecting on values, beliefs and assumptions and a reassessment of meaning perspectives. However, as Brookfield (2000) asserts, critical reflection is a necessary but not sufficient condition for transformative learning. Transformative learning takes place when "the idea or practice concerned undergoes substantial revision to the extent that its new form is qualitatively different from the old" (p. 143). Brookfield points out, therefore, that critical reflection and transformative learning are not synonymous and interchangeable terms. Although critical reflection can take place without transformative learning, critical reflection is an essential component of transformation. The concept of transformative learning is an important one in the context of this study, and is addressed fully in the next section of this chapter.

Zeichner and Liston (1996) consider reflection within the context of teaching and learning. They cite the work of Griffiths and Tann (1992) who build on Schön's (1983, 1987) work and articulate a framework of the temporal dimensions of reflection in Table 2.1.

Table 2.1: Dimensions of reflection (Zeichner \& Liston, 1996, p. 47)

\begin{tabular}{|c|l|l|}
\hline 1. & RAPID REFLECTION & Immediate and automatic Reflection-in-Action \\
\hline 2. & REPAIR & Thoughtful Reflection-in-Action \\
\hline 3. & REVIEW & $\begin{array}{l}\text { Less formal Reflection-on-Action at a particular } \\
\text { point in time }\end{array}$ \\
\hline 4. & RESEARCH & $\begin{array}{l}\text { More systematic Reflection-on-action over a } \\
\text { period of time }\end{array}$ \\
\hline 5. & $\begin{array}{l}\text { RETHEORIZING and } \\
\text { RESEARCH }\end{array}$ & $\begin{array}{l}\text { Long-term Reflection-on-Action informed by } \\
\text { public academic theories }\end{array}$ \\
\hline
\end{tabular}

In Table 2.1, Zeichner and Liston introduce a systematised approach over time. They assert that all dimensions are crucial, with no hierarchy or focus on a particular one, otherwise reflection is superficial and teachers' practical theories are not questioned. Although the critical aspect, as identified by van Manen (1977), Mezirow (2000a) and E. W. Taylor (2009), is not immediately apparent in Zeichner and Liston's dimensions of reflection, it can be incorporated within formal, systematic and long-term reflection. Zeichner and Liston emphasise the importance of consideration beyond technical skills and strategies, incorporating the social conditions and contexts of practice. They articulate the need for teachers to reflect not only internally on their own practice, but also "externally on the social conditions of their practice, and that their action plans for change should involve efforts to improve both individual practice and their situations" (p. 19). They relate this to 
teacher agency and encourage active responsibility not just for teachers' individual practice but for the broader social context.

They caution that reflection can be disempowering and does not always necessarily result in good teaching, since it sometimes serves to "legitimate and strengthen practices that are harmful to some students" (p. 48). They subscribe to a concept of critical reflection that entails collaborative inquiry into the immediate and the broader socio-political contexts of practice, including surfacing of values and beliefs, and incorporating the reframing of personal theories of practice. Their articulation of reflective teaching is one which enables "an understanding of the consequences of one's teaching, the ability to provide heartfelt justifications for one's beliefs and actions and a commitment to equality and respect for differences" (p. 48).

Mezirow (2000a) and E. W. Taylor (2009) suggest three types of reflection: reflection on the content (what we perceive), process (how we perceive) and premises (why we perceive) of teaching and learning. They suggest that by reflecting on the content and process of a teaching/learning situation, assumptions can be examined, and performance can be improved. E. W. Taylor asserts that reflection on the premise of teaching and learning is least common, and most crucial for critical reflection, as it involves "examining the presuppositions underlying our knowledge of the world" (p. 8). van Manen (1977), Mezirow (2000a), and E. W. Taylor (2009) reserve the term critical for what is considered to be a higher level of cognitive development and critical consciousness, and one that is perceived to be more meaningful (E. W. Taylor, 2009).

Brookfield $(1995,2000)$ adopts a critical theory perspective to critical reflection, and believes there is only one form of critical reflection that cannot be separated into different types or levels. Brookfield (2000) regards critical reflection as "making explicit and analyzing that which was previously implicit and uncritically accepted" (p. 131). Brookfield and van Manen (1977) regard the prime focus of critical reflection is to expose hidden power dynamics and hegemonic assumptions.

Whereas critical reflection is concerned with individuals reflecting on particular situations, participants, and moments in time, critical reflexivity acknowledges the subjective aspect of reflection on professional practice, and the "living connections" (Kemmis, 2009, p. 26) that surround it. Critical reflexivity involves introspection to examine thoughts, feelings and behaviour (Ryan, 2005), and looking outwards to the "different kinds and complexes of relationships between practitioners and those 
involved in and affected by theiir practices" (Kemmis, 2009, p. 26). Critically reflexive practitioners engage in exploration of the ways in which "we construct our ways of being in the world" (Cunliffe, 2004, p. 414). They engage in the identification and questioning of assumptions and actions in order to surface "uncertainty and contradictions" (p. 419). Cunliffe (p. 415) differentiates between reflection and reflexivity:

\begin{abstract}
Whereas reflective analysis is concerned with a systematic searching for patterns, logic, and order, critically reflexive questioning opens up our own practices and assumptions as a basis for working toward more critical, responsive, and ethical action.
\end{abstract}

This section has presented a number of different perceptions of reflection, and critical reflection. Although there may not be consensus on the dimensions or levels of reflection, and whether or not they are linear or hierarchical, there is consensus that critical reflection incorporates the surfacing of values, beliefs and assumptions, and consideration of the immediate and broader sociocultural and political contexts of practice. It also incorporates a systematic and rigorous approach over time. In conclusion, the different levels and forms of reflection in teaching and learning are interwoven and complex, and are not distinct or hierarchical, with some being more meaningful than others.

Within the context of this thesis, reflection involves a rigorous and systematic approach over time, is informed by evidence, and can incorporate any or all of the three levels identified by van Manen (1977): technical-practical, interpretative, and critical. Critical reflection involves examining values, beliefs and assumptions, and consideration of the broader sociocultural and political factors mediating teaching and learning. Reflection considers any or all of the following:

- the content and process of teaching and learning (the immediate contexts, actions, and purposes within the teaching and learning situation);

- established research and theory;

- personal practical theories and theories-in-use;

- the broader sociocultural and political contexts and consequences that influence practice.

The following sections discuss the different approaches to professional learning and development, and the trends in recent years. This has relevance to the knowledge that teachers and inservice teacher educators require in the current environment. 


\section{Professional learning and development}

Day (1999a) defines professional development as:

The process by which, alone and with others, teachers review, renew and extend their commitment as change agents to the moral purposes of teaching; and by which they acquire and develop critically the knowledge, skills, planning and practice with children, young people and colleagues through each phase of their teaching lives. (p. 4)

Evans (2008) perceives that professional development is much broader and "extends from an individual - to a profession-wide level" (p. 20). In fact, the nature, purpose and contexts of professional learning and development for teachers and inservice teacher educators are so diverse that arriving at a useful definition is a challenging prospect. This section presents an operational definition of professional learning and development for the purposes of this study, and explores a range of approaches to, and evaluation of, professional learning and development.

The professional learning and development needs of teachers, and the quality and effectiveness of their professional learning experiences has been the subject of much debate and investigation in recent years. In the United Kingdom, United States, Australia and New Zealand there have been some major shifts towards approaches that:

- are driven by more coherent, collective strategic plans;

- focus more on students' needs and learning outcomes;

- are embedded within practice and implemented on site;

- emphasise activation of learning rather than transmission of knowledge;

- acknowledge all who influence student learning;

- promote collaboration and collegiality through the creation of learning communities;

- promote ownership of the process by teachers;

- allow longer timeframes for action and reflection; and

- acknowledge the need for school reform and restructuring as well as professional development for teachers. (Bolam \& McMahon, 2004; Day \& Sachs, 2004b; Grundy \& Robison, 2004; Timperley et al., 2007)

These changes have taken place largely to address the fact that investment in educational reform initiatives over the last few decades has not led to substantial improvements in education as intended and anticipated (Day, 2007; Evans, 2008; Fullan, 2001a, 2006; Timperley et al., 2007). However, in spite of reforms to 
professional learning and development approaches, Evans (2008) found a distinct lack of attention to definitions of professional learning and development by key contributors to the field. She defines it simply as "the process whereby people's professionality and/or professionalism may be considered to be enhanced" (p. 30). Evans uses Hoyle's (1975) terms professionalism and professionality to convey the distinction between the status-related aspects of professionalism, and the knowledge, skills and procedures that constitute the work of teachers. In doing so, her definition encompasses individuals, groups and institutions. Evans also makes the distinction between professionalism that is demanded or requested, prescribed, or enacted, observing that the latter is "the only meaningful conception of professionalism; any others represent insubstantiality ranging from articulated ideology to wishful thinking" (p. 29). She believes enacted professionalism is not possible without professionality. Her use of the term may be enhanced acknowledges the subjectivity of judgements regarding effectiveness and enhancement.

Evans (2008) identifies two constituent elements of professional learning and development: attitudinal, incorporating modified attitudes, and mediated by motivational and intellectual factors; and functional, which relates to changed performance incorporating procedural and productive elements. Evans views that functional development can be attained by imposition of professional development initiatives, while attitudinal development requires the individual's subjective view of enhancement or change, and cannot be imposed. It follows, therefore, that in order to influence attitudes, some degree of ownership and responsibility must be assumed by the teacher. This distinction has implications for the design of professional learning and development approaches in relation to their purpose.

The aforementioned shifts in approaches have been judged, in some way, to be effective in a range of contexts and for different purposes. In fact, professional learning and development may be designed by providers for groups or institutions, and/or undertaken by individuals to fulfil a multitude of purposes and goals. In some cases the focus will be on increasing teacher knowledge, for example, of innovations in particular curriculum areas. In others, teachers will enhance their pedagogical content knowledge, aligning their skills of teaching with knowledge of the curriculum. Others may engage in activities and interactions to improve their practice by increasing knowledge of theory and research and incorporating new knowledge into their practice. The degree to which teachers engage in learning activities, and the consequences of the learning, is mediated by a multitude of complex personal, sociocultural and political factors. The consequences of 
engagement in professional learning and development, therefore, can range from enhanced knowledge and/or changed practice to a more holistic change in the ways in which teachers perceive themselves, their professional identity, and their role as educators within society. While these represent valid outcomes of professional learning and development, they also present challenges to judging the effectiveness of professional learning and development initiatives and activities.

Within the context of this study, the term professional learning and development is taken to encompass holistic professional learning and growth. This consists of all experiences contributing to formal and informal professional learning, ranging from the processes by which professional knowledge is created, such as analysis of learning and practice, and the internal processes of creating knowledge, to the transmission of information in order to influence practice (Timperley et al., 2007), such as the content of formalised professional development programmes and courses developed and delivered by external agencies. As such, professional learning and development may be applied to individuals, groups or institutions (Evans, 2008). For the purposes of this study, professional learning and development is taken to encompass all aspects of learning for teachers and inservice teacher educators including Evans' functional and attitudinal elements.

This section has introduced the topic of professional learning and development for teachers and inservice teacher educators, and the potential challenges in judging effectiveness. It has also highlighted the issues of the broad range of purposes and consequences of professional learning and development, and concluded with a definition of professional learning and development for this study.

\section{Transformative learning}

Transformation is often cited as a desired consequence of learning. Since Mezirow (1991) proposed his theory of transformative learning, there have been calls for a more holistic approach to learning and transformation (Dall'Alba, 2009; Dall'Alba \& Barnacle, 2007; E. W. Taylor, 1997). This section explores some theoretical perspectives on transformative learning.

Mezirow's $(1990,1991,1994,2000 b)$ theory of transformative learning was conceptualised in 1978, and it gave birth to continued discussion and debate about the nature and process of transformative learning in adults. Mezirow (1994) defines transformative learning as "the social process of construing and appropriating a new 
or revised interpretation of the meaning of one's experience as a guide to action" (pp. 222-223). The six core elements of Mezirow's theory of transformative learning are:

- individual experience, which is what each individual brings to the situation in terms of knowledge, experience and their existing values and beliefs;

- critical reflection, which questions assumptions, values and beliefs;

- dialogue with self and others, which allows the exploration of boundaries and meanings;

- holistic orientation, which incorporates the affective dimensions of feelings and emotions;

- awareness of context, including personal, sociocultural, temporal and situational factors; and

- $\quad$ authentic relationships, which are trusting and genuine. (Mezirow \& Taylor, 2009)

Mezirow's theory reflects what Habermas (1991) terms communicative learning, which is characterised by engagement in informed, rational and objective discourse to uncover rationale and justification for particular values, beliefs and assumptions. Mezirow identifies key factors mediating such an environmental of transformational learning. They are: safety, freedom, equality, empathy, objectivity, trust, inclusivity, democracy, openness and willingness (Mezirow, 2000b).

Kegan (2000) distinguishes between informational learning, which involves changes in "what we know" and transformative learning which involves changes in "how we know". In the former, resources are being added to an already existing frame of reference, while in the latter, the frame of reference itself is being reconstructed. Kegan asserts that although informational learning can bring about changes in knowledge base, confidence, self-esteem and self-perception, they are not transformative changes because they can occur within the same frame of reference. They are "meaning forming" (Kegan, 2000, p. 52). Transformative learning, however, involves changing the frame of reference, or way of knowing, and is "reforming our meaning forming" (p. 52). This process does not happen in any explicit manner, but at a subconscious level, and it is often dependent on a trusting, collaborative environment with a focus on connectedness and community (E. W. Taylor, 1997).

Both Mezirow (1990, 1991, 1994, 2000b) and Kegan (2000) perceive transformative learning to encompass a change in the way in which the world is perceived, and imply the need for a collaborative trusting environment to enable transformation. 
Dall'Alba (2005, 2009) and Dall'Alba and Barnacle (2007) take a holistic, ontological approach, and Dall'Alba (2009) draws on Heidegger (1962/1927) when she describes the process of transformative learning as one of "becoming what we are 'not yet"' (p. 36). She asserts that ontology and epistemology are inseparable, and that professional learning enables practitioners to "integrate their ways of knowing, acting and being professionals" (p. 44). Knowledge and being, therefore, are interdependent, where "being-in-the-world" (p. 42) is one of engagement with, rather than containment within. This is articulated by Dall'Alba and Barnacle (2007):

Knowing is understood as created, embodied and enacted. In other words, the question for students would be not only what they know, but also who they are becoming. Rather than treating knowledge as information that can be accumulated within a (disembodied) mind, learning becomes understood as the development of embodied ways of knowing or, in other words, waysof-being. (p. 683)

Dall'Alba (2009) asserts that what the individual brings, and the embodiment of their knowing and being, determine the openness, willingness and readiness for learning, which in turn impacts upon the opportunities seized and the possibilities for "becoming what we are "not yet"' (p. 36). She regards learning as a continual process where "the past opens a range of possibilities that can be taken up in the present. ... At the same time the past becomes a resource in the present and for the future" (p. 39). Dall'Alba believes that the element of continuity, in the form of familiar everyday routines and ready-made solutions, is what enables individuals to function within their normal frame of reference. Resistance to change would be to maintain the "path of least resistance" (p. 40) by not taking up opportunities. Like Mezirow and Taylor (2009), Dall'Alba and Barnacle (2007) emphasise the significance of interaction and engagement with others, and the need to acknowledge the complexity of relationships, practice and contexts for learning.

Barnett (2005), Meyer and Land (2006), Meyer, Land and Baillie (2010), and Berger (2004) highlight the notion of "liminal" spaces, where limitations of knowing become explicit and are challenged and stretched. These spaces lead to portals which give glimpses of untravelled worlds "not yet entered" (Land, 2010). They acknowledge that the state of liminality can lead to new and previously inaccessible ways of thinking and being.

Barnett (2005) highlights that transformation involves developing the capacity to "tolerate strangeness" (p. 685) within the liminal spaces, and "to go on producing strangeness by and for oneself" (p. 685). Dall'Alba (2009) identifies features of learning within periods of transition or liminality. The features include: 
- continuity over time;

- change in ways of being;

- possibilities and constraints in the way we can be;

- openness in, and resistance to taking up possibilities; and

- individuals and others involved in the process of becoming.

Meyer et al. (2010) develop the notion of threshold concepts, which, once crossed, lead the way to another dimension from which there is no return to the previous state of knowing. Characteristics of a threshold concept are that it is likely to be: transformative, involving a significant shift in perspective; irreversible, in that it is unlikely to be forgotten or unlearned; integrative, in that it exposes previously unseen relationships to other things; (often) bounded by other thresholds into new areas of understanding; and potentially troublesome involving significant shifts in understanding (Meyer et al., 2010).

While Meyer and Land's (2006) threshold concepts are presented within the context of particular disciplines, where specific threshold concepts can be defined, Schwartzman (2010) argues for a transdisciplinary theoretical foundation where the boundaries are more fluid and correspond to transformations in meaning making rather than disciplinary concepts. She identifies defensiveness and reflectiveness within the liminal space, which are akin to Dall'Alba's (2009) constraints within, and openness and resistance to, the challenges inherent in the liminal space. These challenges are referred to by Meyer and Land (2006) and Perkins (2006) as troublesome knowledge including conceptually difficult knowledge; foreign or alien knowledge, which conflicts with our own; and tacit knowledge encompassing beliefs, values and assumptions.

In conclusion, bringing some of the key aspects of transformative learning together, it seems that transformative learning:

- represents a shift in an individual's frame of reference, and in the ways that meaning is constructed;

- involves individuals in a holistic process of questioning and challenging existing knowledge, assumptions, values and beliefs, and the ways in which these are embedded and enacted in practice;

- incorporates liminal spaces which are the contexts within which possibilities and opportunities for learning exist;

- incorporates possibilities and opportunities for learning which are mediated by dispositions to learning; 
- is mediated by contextual factors such as the nature of relationships, and other personal and sociocultural and political factors, and is more likely to take place within collaborative, trusting and challenging environments.

- is usually irreversible since, once an individual's frame of reference has changed, there is no going back to the previous state of being.

In conclusion, it is important to differentiate between the experience of transformative learning (crossing a threshold or boundary into a transformed state of being) and the contexts, processes and dispositions that support learning and transformation. Perhaps it is not so much the actual transformation that is the crucial element, as the possibilities and opportunities that might optimise the potential for rigorous critical reflection on practice and the contexts within which it takes place. Learning and transformation are optimised within such contexts, and transformation is not necessarily the ultimate goal of professional learning and development. It is also important to acknowledge that transformation and changes in meaning making may not always impact positively on professionality and professionalism as defined by Evans (2008).

This section has reviewed some theoretical perspectives on transformative learning, and presented some of the key ideas relevant to this study. The following section explores some of the issues related to evaluation of the effectiveness of professional learning and development.

\section{Effectiveness of professional learning and development}

One of the fundamental considerations in professional learning and development for teachers and inservice teacher educators is evaluation of effectiveness of that learning which, in turn, should lead to improved inservice teacher educator and teacher practice, and improved outcomes for students. The INSTEP project derived 5 Principles of effective inservice teacher educator practice within a theory of improvement:

1. Effective ISTE learning and practice lead to improvements in teacher practice and student outcomes.

2. Effective ISTE learning and practice are underpinned by inquiry and research evidence.

3. Effective ISTE learning and practice are developed through collaborative relationships.

4. Effective ISTE learning and practice are influenced by and responsive to context and culture.

5. Effective ISTE learning and practice provide and build leadership in a range of contexts. (Ministry of Education, 2008, p. 22) 
Within INSTEP, there was an assumption that, in striving to improve their practice, inservice teacher educators were enacting the principles to guide practice; engaging in a collaborative inquiry cycle; and examining evidence of practice and impact on teachers/students.

Although it is recognised that there is no direct relationship between improved inservice teacher educator professional learning and improved student outcomes, the assumption is founded on a chain of influence linking the two:

Little is known about how teachers interpret the understandings and utilise the particular skills made available through professional learning opportunities, and about the consequent impact on teaching practice, except that the relationship is far from simple. How teachers change their practice, of course, impacts on student outcomes. (Timperley et al., 2007, p. 7)

The cause and effect relationship and the chain of influence are illustrated in Figure 2.2 (note that ISTE - inservice teacher educator).
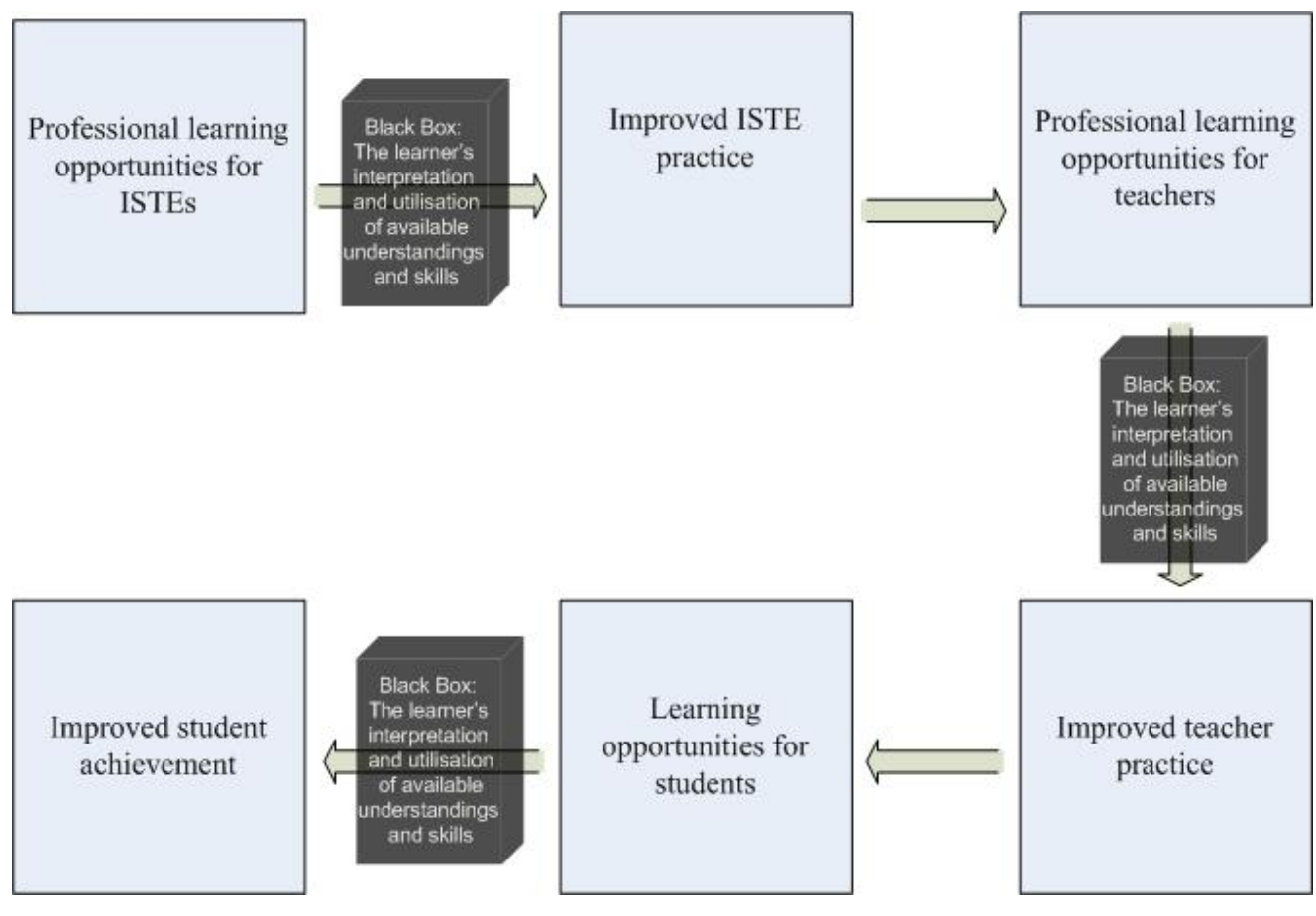

Figure 2.2: A chain of influence: ISTE learning to student achievement (Ministry of Education, 2006, p. 12)

Due to the diverse and broad nature of the range of factors impacting on the practice of inservice teacher educators and teachers, and then in turn student achievement, the challenge is to identify valid and reliable indicators of effective professional learning experiences. This involves consideration of what constitutes relevant and appropriate evidence and criteria for evaluation of professional learning and development. 
There is a substantial body of research and knowledge around effectiveness of teaching, which informs the black box between learning opportunities for students and improved student achievement. Although there is an increasing body of research around effective professional development for teachers, establishing links between the professional development initiatives and student outcomes is problematic (Timperley et al., 2007). This is due to the variety of factors impacting upon student outcomes, and the definition and means of evaluating the outcomes.

Timperley et al.'s (2007) study is one of the most recent and comprehensive syntheses of international research informing the black box between learning opportunities for teachers and improved teacher practice. They applied a framework of 97 characteristics of professional learning and development to analyse 217 studies that demonstrated links between teachers' professional learning and development and valued student outcomes (academic, social, personal, performance). Based on this synthesis, Timperley (2008) proposes ten principles of professional learning and development that are likely to impact positively on student outcomes. They are that professional learning and development:

- promotes teacher responsibility and self efficacy by focusing on student learning needs and valued student outcomes;

- adopts context-specific approaches that are established as being effective in developing the required knowledge and skills that will lead to improved student outcomes;

- integrates knowledge and understanding of theory with teachers' contexts of practice, and current knowledge and understanding;

- promotes teacher inquiry and self regulation, incorporating shared understandings of goals and valid evidence to identify needs and monitor the effects of changed practice;

- constitutes a variety of meaningful activities and multiple opportunities to enact new knowledge, skills and understandings, which incorporate the challenging of existing assumptions and negotiation of existing and new theories within contexts of trust and challenge;

- adopts approaches and activities that take cognisance of the degree of congruence with, or dissonance from, the new knowledge and skills to be learned;

- provides opportunities for collegial communities, with goals that are focused on responsiveness to students and consideration of valued student outcomes; 
- engages external expertise to challenge assumptions and social norms, and provide new perspectives to support teachers' development and enactment of theoretical perspectives within their own contexts;

- incorporates leaders who establish a vision of new possibilities, lead and participate in learning, and manage and organise learning opportunities coherent with other strategic priorities;

- incorporates relevant knowledge and skills and supportive organisational conditions and infrastructure. (Timperley, 2008)

Timperley asserts that the above principles are integrated and interdependent and incorporated within iterative inquiry cycles. It would seem then that the key components of effective professional learning and development for teachers are:

- the support for teacher inquiry incorporating shared goals directly related to student outcomes; and

- that opportunities are provided for professional communities with colleagues and leaders in an environment of trust, where challenging existing assumptions and opportunities for contextualised enactment of new knowledge are prioritised.

Fraser et al. (2007) take a different approach, and propose a triple-lens framework as an alternative to measuring effectiveness of teachers' professional learning and development using only student achievement. Their framework is derived from three conceptual frameworks used to analyse continuous professional development: Bell and Gilbert's (1996) three aspects of professional learning; Kennedy's (2005) framework for analysing models of continuing professional development; and Reid's quadrants of teacher learning (cited in McKinney et al., 2005). The triple lens framework is represented in Table 2.2.

Table 2.2: Summary of frameworks (Fraser et al., 2007, p. 162)

\begin{tabular}{lll}
\hline Framework & \multicolumn{1}{c}{ Terms of categorisation } & \multicolumn{1}{c}{ What is being characterised? } \\
\hline $\begin{array}{l}\text { Bell and Gilbert's three } \\
\text { aspects of professional } \\
\text { learning (amended) }\end{array}$ & Personal/social/occupational & $\begin{array}{l}\text { Domain of influence of professional } \\
\text { learning }\end{array}$ \\
$\begin{array}{l}\text { Kennedy's framework for } \\
\text { analysing CPD }\end{array}$ & $\begin{array}{l}\text { Transmission/transitional/ } \\
\text { transformation }\end{array}$ & $\begin{array}{l}\text { Capacity for professional autonomy } \\
\text { and transformative practice } \\
\text { supported by the professional }\end{array}$ \\
$\begin{array}{l}\text { Reid's quadrants of } \\
\text { teacher learning }\end{array}$ & Formal/informal & $\begin{array}{l}\text { Sphere of action in which the } \\
\text { professional learning takes place }\end{array}$ \\
& Planned/incidental & \\
\hline
\end{tabular}

Fraser et al. (2007) claim that the application of such a framework will reveal issues such as the tension between the "collective good" (p. 167) of the school, and 
addressing the needs of individual teachers, and in doing so, will "allow the wider purposes of the education system to be satisfied" (p. 167). An analysis of three case studies using the triple-lens framework concludes that:

- Formal planned opportunities, which are essentially transmissive, are unlikely to result in transformative professional learning for teachers, because they attend primarily to occupational aspects of professional learning.

- Inclusion of formal and informal planned opportunities is more likely to result in transformational learning because they attend to some facets of personal and social, as well as occupational aspects of professional learning. However, mismatches between design and intention and practical implementation may limit attention to personal and social aspects, and hence the degree of transformational learning.

- Opportunities that allow greater ownership and control of the process are likely to attend to more facets of the personal and social aspects of learning and are therefore more likely to result in transformational professional learning for teachers.

- The nature, extent and role of informal incidental opportunities in teachers' professional learning are currently under-researched and therefore remain unclear. (Fraser et al., 2007, pp. 165-166)

Fraser et al.'s (2007) framework seems limited in some respects. It is derived from three perspectives of professional learning and development (personal / social / occupational; transmission / transitional / transformation; and formal / informal / planned / incidental), but with no reference to student learning. It is not clear therefore how effectiveness can be measured, when the purpose of professional learning and development is to enhance learning for students. They also seem to make the assumption that transformation is the goal of professional learning and development, yet they offer no clear definition of transformative learning.

One of the many factors acknowledged to impact on the effectiveness of professional learning and development is leadership (Fullan \& Hargreaves, 1992; Robinson et al., 2009; Timperley et al., 2007). The following qualities and dimensions of leadership are identified as being evident within effective contexts for promoting professional development for teachers:

- active organisation of a supportive environment to promote professional learning opportunities and the implementation of new practices;

- a focus on developing a learning culture within the school, where leaders are learners along with their teachers;

- provision of alternative visions and targets for student outcomes;

- $\quad$ strategic resourcing and creating conditions for distributing leadership;

- $\quad$ establishing goals and expectations; 
- $\quad$ ensuring an orderly and supportive environment; and

- $\quad$ engaging in critical dialogue (Fullan \& Hargreaves, 1992; Robinson et al., 2009; Timperley et al., 2007).

Particular aspects of leadership, therefore, have the potential to influence the contexts and culture of professional learning environments.

In considering what constitutes effective professional learning for inservice teacher educators, it is pertinent to consider the knowledge, skills, and expertise required for effective inservice teacher educator practice and the types of professional learning experiences and contexts that might enhance knowledge, competence and performance. Considering the myriad of factors mediating the impact of professional development on teachers and teacher educators, judgements of effectiveness should not be over simplified by focusing exclusively on student achievement or aspects of professional learning and development. There are many factors that should be considered and evaluated in order to move towards sustained change and improvement for teachers, teacher educators, and educational environments that result in enhanced learning outcomes for students.

The following section reviews current trends in teacher professional learning and development.

\section{Trends in professional learning and development}

The current debate around the features of effective professional learning and development for teachers has seen the examination of existing models, and consideration of how they might impact on teachers' learning and professional growth. In response to a call for more research on teacher learning, Wilson and Berne (1999) conducted a review of what they considered to be high quality research into professional development for teachers. They identify some common themes. The first is the development of learning communities, with a focus on inquiry and incorporation of research and theory. Secondly, all studies were focussed on activating learning rather than disseminating knowledge. This involved teachers taking responsibility for their learning and reconceptualising teaching and their own professional development. Thirdly, the element of collegiality was prominent, where teachers' interactions were privileged, although there were challenges, dependent on context, in fostering trust to support collegiality. These themes are also reflected in Timperley et al.'s (2007) work reported in the previous section. 
Kennedy (2005) proposes a framework of nine models of professional development, and classifies them according to the extent to which they support autonomy and transformative learning. They are: the training model; the award-bearing model; the deficit model; the cascade model; the standards-based model; the coaching/ mentoring model; the community of practice model; the action research model; and the transformative model. The action research and transformative models are the ones she identifies as being most likely to bring about transformative learning and autonomy, while the community of practice model has the potential to bring about transformation, but the extent to which learning is proactive or passive is dependent on the part played by individuals, and uneven relationships of power. The action research model is characterised by teachers becoming researchers, where they are expected to critically examine their practice. Kennedy (2005) acknowledges that the transformative model is not well defined, and is said to be a combination of aspects of the other models, but with a "range of different conditions required for transformative practice" and with "a real sense of awareness of issues of power" (2005, p. 246). She asserts that the transformative model is dependent on critical debate, and contends that "only through the realisation and consideration of conflicting agendas and philosophies, can real debate be engaged in among the various stakeholders in education, which might lead to transformative practice" (p. 247). Kennedy also acknowledges that although the transformative model is becoming prominent in academic literature, there is limited research evidence to support it.

Drawing from an analysis of three examples of professional development initiatives using the triple-lens-framework, Fraser et al. (2007) present a sociocultural model of teacher learning that would seem to fit the latter three of Kennedy's (2005) models, and therefore render it potentially supportive of transformative learning and autonomy. They question the notion of "delivered professional development activities" (p. 166), and their model relies on teacher autonomy and collective decision-making. They emphasise the combination of formal and informal opportunities that promote teacher autonomy and ownership of the learning process, and "attend to some facets of personal and social, as well as occupational aspects of professional learning" (Fraser et al., 2007, p. 165). They conclude by observing, however, that the informal aspects and the role they play is currently underresearched and therefore ambiguous.

Cheetham (2005) believes that due to the diversity and complexity of professional practice, it is not possible or even desirable, to prescribe the nature and content of professional learning and development for individual practitioners. When considering 
the professional learning and development of practising professionals, Cheetham reports that no single approach should be relied upon, and recommended a focus on developing: professional knowledge and theory; workplace competence; rational, reflective and creative thinking; flexible, innovative practice, commitment to lifelong and continuous learning, and the development of learning skills. Concurring with Fraser et al. (2007), Cheetham asserts that professional learning and development for experienced professional practitioners is very personalised, often informal, and should allow for the diversity of practice, knowledge, experience, skills, attitudes and values of the participants. This reflects the emphasis on personal growth, autonomy and agency which can be fostered through the collaborative inquiry approach to professional learning proposed by Fraser et al. (2007), and which features in Kennedy's (2005) transformative models.

There is, therefore, a growing emphasis in teacher professional learning and development on approaches that are collaborative, inquiry oriented, promote teacher ownership and responsibility for the process, and acknowledge the collective responsibility of the profession to enhance learning and performance. The following section explores the concept of evidence-based inquiry and its place within the context of professional learning and development for inservice teacher educators.

\section{Evidence-based inquiry into practice}

An evidence-based approach to professional practice is in line with one of the strategic priorities in the New Zealand Ministry of Education's Schooling Strategy (Ministry of Education, 2005) which states that all those involved in schooling should apply evidence-based practices and "base their thinking and actions on credible information, monitor the impact of their actions on student achievement, and adjust them accordingly" (p. 35). The strategy suggests that "teacher educators and those involved in the professional support and learning of teachers use evidence to improve the quality of their provision in order to improve student outcomes" (p. 36).

Evidence-based practice is defined in the New Zealand Schooling Strategy 2005 2010 as:

the practice of teacher educators that is informed by evidence. Evidence means a combination of: research which links teacher educator actions and behaviours to teacher improved practice and improved student academic and social outcomes; data and information about teacher practice and student learning progress. (Ministry of Education, 2005, p. 35) 
The term evidence-based practice was adopted from the medical profession to address the need to incorporate research evidence into the practice of teaching (D. Hargreaves, 2000; OECD, 2000; Thomas, 2004) in order to obtain "a balance between craft knowledge and declarative research knowledge" (Thomas, 2004, p. 9). However, Cochran-Smith (2005) expresses the concern that unless there is a broad definition of the term to incorporate "a wealth of critical and theoretical inquiry" (p. 15), teacher education will once more be reduced to a training model and teachers will fall prey to deprofessionalisation at the expense of professionalism (Cochran-Smith, 2005; Goodson \& Hargreaves, 2003; A. Hargreaves, 2000).

Cochran-Smith's (2005) concern regarding professionalism and her call for critical inquiry impact on the empowerment and agency of teachers and inservice teacher educators, not only in their immediate environments of practice, but within the broader sociocultural and political contexts (Goodson \& Hargreaves, 2003; A. Hargreaves, 2000). This underlines the importance of a clear operational definition of EBIP, which is derived in the conclusion section of this chapter.

Reid (2004) presents a range of approaches to inquiry to inform decision-making including action research, critical dialogue, classroom/work-place observations, journals, critical data analysis, appreciative inquiry, portfolios, writing, text analysis and program evaluation. His pragmatic approach suggests that inquiry involves the following types of questions:

- What am I/we doing in relation to this practice/issue/question/puzzle (e.g., in the classroom/school/district/central office)

- Why am I/we doing this? (e.g., what theories are expressed in my/our practices, and whose interests do these represent?)

- What are the effects of these practices? Who is most advantaged/least advantaged?

- What alternatives are there to my/our current practice? Are these likely to result in more just outcomes? What will $\mathrm{I} / \mathrm{we}$ do? How will $\mathrm{l} / \mathrm{we}$ monitor these changes in order to assess their outcomes? (pp. 3-4)

These questions are focussed on the why of practice, as well as the what, and incorporate consideration of the broader sociocultural and political contexts. Reid's concept of inquiry, therefore, would seem to incorporate the "critical and theoretical" elements called for by Cochran-Smith (2005, p. 15) that would mitigate the risk of deprofessionalisation by challenging and engaging with established theory and widely accepted practices. 
Darling-Hammond and Bransford (2005) promote the use of evidence from inquiry to inform educational effectiveness, but emphasise that, when analysing evidence of practice, effectiveness must be evaluated with respect to a number of variables that can vary across teaching situations. They also stress the importance of external evidence including research findings and literature. There is some consensus that inquiry evidence, incorporating practice as well as external evidence, is recognised as a method of deepening knowledge and skills (Cochran-Smith \& Lytle, 1999; Darling-Hammond \& Bransford, 2005; Shulman \& Shulman, 2004).

The integration of educational research into the practice of teachers has been problematic in the past due to the inaccessibility of findings to teachers and a lack of relevance and direct applicability to classroom practice (Cordingley, 1999, 2004, 2008; Hammersley, 2002; D. Hargreaves, 1991, 1996; OECD, 2000; Whitty, 2007). Cordingley (2008) asserts that, in order to promote research and evidence-informed practice in classrooms, professional knowledge, in the form of research findings, requires to be translated into particular personal contexts by teachers themselves, or in partnership with school leaders, researchers and teacher educators. This process is one which is acknowledged by Timperley et al. (2007) to be a crucial component of effective professional learning and development. Robinson (2003) also agrees that inquiry should be "both scaffolded on the research findings of others and productive of new knowledge about their particular context" (p. 29).

The nature of inquiry into practice is such that it may necessitate the implementation of particular research strategies and methodologies. There is some debate regarding the extent to which teachers should become researchers. The New Zealand Ministry of Education (2008a) state that although inquiry "draws on research methodologies and on published research" (p. 81), practitioners are not required to "conform to strict research conventions" (p. 81). However, they express an expectation that all educators (researchers and practitioners alike) should engage in inquiry into professional practice. Reid (2004) and Cordingley (2003) accept that sometimes inquiry may involve rigorous research methodologies, but often it may not. Robinson (2003) takes a more rigorous stance and argues that teachers have a professional responsibility to adopt the role of researcher, and that the "enhancement of the research role of teachers is central to sustainable school improvement, to effective teacher development, and, most important of all, to the professionalism of teachers" (p. 29). Similarly, Groundwater-Smith and Dadds (2004) assert that teacher researchers are more empowered to bring about sustained change and improvement in education: 
When teachers are well informed, through evidence-based practice, grounded in their own research, then they are well positioned to make the important practical and moral judgements required for schools to be both effective and socially just institutions. They become what Sachs (2000, 2002) calls 'activist professionals'. In addition, there is evidence that practitioner researchers in schools are capturing a new sense of responsible professional autonomy when they engage in self-directed practitioner research. (p. 259)

It is generally accepted that the use of evidence is important in shaping and enhancing professional practice (Cordingley, 2004; Eraut, 2004; Ministry of Education, 2006; Robinson \& Lai, 2006; Thomas, 2004; Timperley \& Parr, 2004). Within the teaching profession, however, the nature of such evidence and its impact upon practice is much debated. The evidence ranges from that which is "collected almost incidentally" (Thomas, 2004, p. 3), and arises from interactions involving "tacit knowledge/craft knowledge" (p. 9) and decision-making, to published empirical research evidence. Within the realm of EBIP, educators are urged to draw from the full range of qualitative and quantitative evidence which is available to them and relevant to their inquiry (Rebore \& Walmsley, 2007). Factors impacting upon the use of the full range of evidence to shape and enhance practice include accessibility and trustworthiness of evidence and the pragmatics of shaping it into practice (Thomas \& Pring, 2004).

EBIP therefore can be manifested in many different ways, and is a broad term encompassing a variety of types of evidence and degrees of rigour in adopting inquiry strategies. This section concludes with Reid's (2004) definition of inquiry as it is a clear articulation of the nature and contexts of professional inquiry to inform practice:

I understand inquiry to be a process of systematic, rigorous and critical reflection about professional practice, and the contexts in which it occurs, in ways that question taken-for-granted assumptions. Its purpose is to inform decision-making for action. Inquiry can be undertaken individually, but it is most powerful when it is collaborative. It involves educators pursuing their wonderings (Hubbard \& Power, 1993) seeking answers to questions or puzzles that come from real-world observations and dilemmas. (p. 4)

Reid's definition conveys the nature, purpose and context of inquiry. He deems critical reflection integral to inquiry, and seems to rely on this term to qualify the rigour of the approach. An operational definition of EBIP will be presented in the conclusion of this chapter.

The following section explores the types and validity of evidence used in EBIP, and the implications for inservice teacher educators' learning and practice. 


\section{Types of evidence}

Not all teacher inquiry aims to produce evidence and understanding in a public form that can be tested and reviewed by others. Some teacher inquiry simply seeks to enhance the practice of the inquirer through the use of evidence. (Cordingley, 2003, p. 108)

In this quote, Cordingley (2003) acknowledges the distinction between the role of evidence used in teacher inquiry and in other contexts. However, this is an interesting perspective, and begs the question of validity of any form of evidence if it is not capable of withstanding critique by others. This section will review the types and validity of evidence used in inquiry.

For clarity of purpose I will refer to two types of evidence: research-based evidence and practice-based evidence. Both forms of evidence require some means of establishing validity:

\footnotetext{
Relevance - establishing that the information constitutes information for (or against) some proposition;

Sufficiency - corroboration with other instances of the same kind of evidence or other kinds of evidence;

Veracity - establishing that the process of gathering evidence has been free from distortion and as far as possible uncontaminated by vested interests. (Thomas, 2004, p. 5)
}

Validity is established in research-based evidence which is "from published research that satisfies the critical reviews of that area of research" (Eraut, 2004, p. 92), and in practice-based evidence which is "from professional practices recognized [sic] by the relevant profession, and performed in accordance with the criteria expected by the relevant experts within that profession" (p. 92).

For the teaching profession practice-based evidence can include observation data, lesson plans, interview data, journals, reflections, student achievement data and student/teacher voice (Ministry of Education, 2006; Reid, 2004; Robinson \& Lai, 2006; Timperley \& Parr, 2004). This type of evidence embodies the intuitive nature of teaching/inservice teacher educator practice and has "a meaning residing in personal tacit knowledge built out of information - data, evidence - accumulated both deliberately and fortuitously" (Thomas, 2004, p. 2). It is generated from within "the contexts, practices and thinking patterns of its creators" (Eraut, 2004, p. 91) and validated as part of a social process by an expert community of peers. Timperley and Parr (2004, p. 12) refer to this "moment-to-moment" evidence as the "teacher's detailed log-in-the-head". As such it has "respect and worth" (Thomas, 2004, p. 1) within particular situated contexts and the intellectual community of teachers and 
inservice teacher educators. The criteria of relevance, sufficiency and veracity, therefore, are applied in a relatively subjective manner from within that community and according to their understandings of the particular context.

Research-based evidence in the field of education is evidence which is defined and disseminated by educational researchers. The "respect and worth" afforded this type of research is by means of systematic incorporation of rigour in research design, data collection and analysis. This type of evidence includes national surveys, statistical analyses, monitoring and reporting data, externally commissioned projects and research evaluations and reviews (Thomas \& Pring, 2004). The criteria of relevance, sufficiency and veracity, therefore, seem to be applied in a more objective manner than is the case in practice-based evidence. This is not to say, however, that all such educational studies are as robust and free from ambiguity as they claim. Robustness and validity is dependent on the measures taken to ensure aspects of trustworthiness, dependability, credibility, and confirmability (Lincoln \& Guba, 1985).

The above types of evidence are the extremes. In between are degrees of practitioner research, such as action research (Kemmis \& McTaggart, 1988; McNiff, 2002), problem-based methodology (Loughran, 2006; Robinson \& Lai, 2006), and case method (J. H. Shulman, 1992), yielding practice-based evidence which has been subjected to some rigour to assure validity, respect and worth within the education professional community.

Acknowledging the value of all evidence in informing and enhancing practice, in Figure 2.3 Thomas (2004) articulates what Hargreaves (1996) seems to be suggesting in calling for a "more systematic incorporation of research evidence to the tacit knowledge/craft knowledge $\rightarrow$ practice cycle" (Thomas, 2004, p. 9).
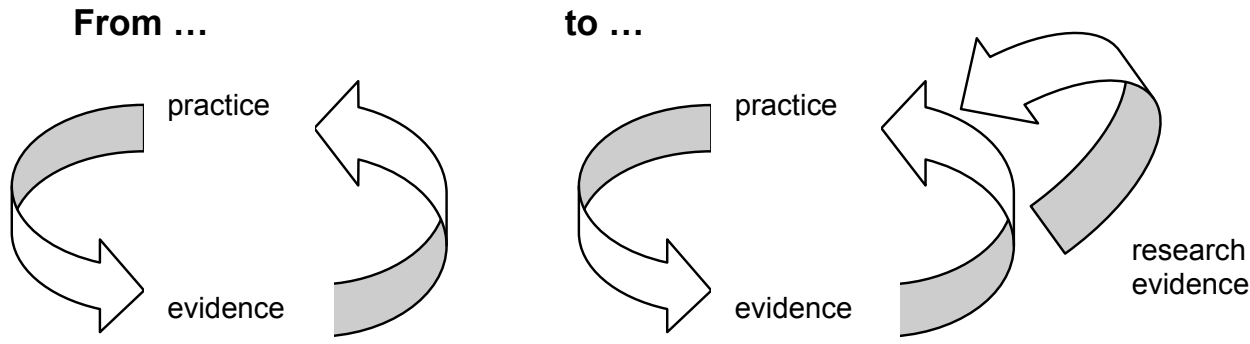

Figure 2.3: Evidence-practice cycles (Thomas, 2004, p. 9) 
Figure 2.3 conveys, on the left, a narrow focus on evidence which Cochran-Smith (2005), Goodson and Hargreaves (2003) and Hargreaves (2000) caution against. The right of the diagram illustrates the incorporation of research evidence.

Cordingley (2004) supports the incorporation of research and theory, and addresses the issue of promoting it in practice. She acknowledges the challenges in truly embedding this in professional practice, and stresses that the process must be understood within the particular professional contexts of practitioners' practice and learning processes. Further to this Thomas (2004) highlights the importance of establishing a common understanding of the terms evidence and practice within these contexts.

Cordingley (2004) presents a historical perspective of initiatives in the United Kingdom to encourage and support teachers in promoting evidence-based practice. She reports that, although these initiatives are numerous and well supported, the key challenge lies within the learning process of teachers and the practicalities of teaching. New knowledge gained from research-based evidence must fit within existing frameworks of knowledge, values and beliefs "rather as a car must insinuate itself into the flow of fast-moving traffic on a motorway" (Cordingley, 2004, p. 79). Teachers must be assured that these new strategies, based on evidence from elsewhere, will work in their contexts with their students before they will be willing to take the risk of implementing them. Timperley et al. (2007) also acknowledge the challenge inherent in assimilating new knowledge and aligning it with current practice, values and beliefs. They identify iterative processes of learning: cueing and retrieving prior knowledge; becoming aware of new information/skills; and integrating them into their values and beliefs system, which can create dissonance with their current position.

Cordingley (2004) highlights the need to make research-based evidence more accessible to practitioners and provide sustained, quality support for practitioner inquiry. She adopts the term research and evidence-informed practice, which is the one used by the National Teacher Research Panel in the United Kingdom.

Although most of the literature on evidence-based practice centres on teacher practice, there are many parallels with inservice teacher educator practice. The Ministry of Education (2005) are explicit in their expectations of inservice teacher educators with regard to evidence-based inquiry: 
Teacher educators involved in both initial and ongoing teacher education play a critical role in the creation, transfer, and use of educational evidence. (p. 37)

Teacher educators and those involved in the professional support and learning of teachers [should] use evidence to improve the quality of their provision in order to improve student outcomes. (p. 37)

In summary, EBIP involves rigorous and systematic critical reflection on practice, incorporating a range of evidence. Evidence for EBIP incorporates evidence from practice, contexts of practice, and research and theory. Establishing the validity of all evidence is important in order to obtain an objective perspective on the factors mediating effective practice. Validity can be established in a number of ways, ranging from rigorous research methodologies to critique with professional peers.

The following section considers the contexts for professional learning and development, and the ways in which these might impact on teachers and inservice teacher educators.

\section{Contexts for professional learning and development}

A collaborative process of inquiry and critical reflection is advocated by many theorists (Cordingley et al., 2005; Crockett, 2002; Darling-Hammond \& Bransford, 2005; Fraser et al., 2007; Fullan \& Hargreaves, 1992; Reid, 2004; Zeichner \& Liston, 1996). Hoban (2002) argues that in order to support the ongoing complex process of educational change, we must focus on the "relationships between and among personal, social and contextual conditions for teacher learning" (p. 65). Although Schön (1983) acknowledges that reflective inquiry can be "self-limiting" without other perspectives on the framing and reframing of practice (p. 283), Zeichner and Liston (1996) criticise Schön's focus on individual activity, which does not take into account the dimensions that the social process adds to reflection. Zeichner and Liston explore reflective practice from a teacher perspective, and articulate that professional learning is limited when teachers do not have the opportunity to articulate and clarify ideas through social forums of discussion where they engage the challenge and support gained through social interaction. Zeichner and Liston also emphasise the need for trust within collaborative and cooperative environments.

Constructive, positive collegial learning communities or communities of practice as defined by Wenger (1999) can provide the setting for collaborative critical reflection on practice which is conscious, planned, intentional, and designed to examine and deconstruct professional practice, assumptions, beliefs and values (Brockbank \& McGill, 2007). Such learning communities can enable collaborative inquiry within an 
inclusive group of like-minded professional practitioners who are motivated to enhance their learning by challenging and supporting each other towards a shared vision of improved practice (Stoll et al., 2005). The extent to which learning communities impact positively on individuals' professional learning and development, however, can depend on the dynamics of the community, perspectives of the participants, and the degree to which a sense of collegiality is evident, where there is mutual and equitable contribution which "is spontaneous, is voluntary, development oriented, unscheduled and unpredictable" (Stoll, 2000, p. 10), and where there is a sense of collective responsibility, shared goals and beliefs, and an enthusiastic commitment to innovation and problem solving to improve practice (Little \& McLaughlin, 1993). In this way, individuals' espoused theories and theories-in-use can be surfaced and considered critically with a view to improving practice and further aligning personal values and beliefs with practice (Argyris \& Schön, 1974). P. Taylor (1996) acknowledges the value of alternative perspectives in reflection, and applies the metaphor of crystallisation to reflective practice, since, like a prism, different perspectives "provide a deepened, complex, thoroughly partial understanding of the topic" (p. 44). Timperley et al. (2007) recommend context-specific approaches to professional learning where there are multiple opportunities to transform new knowledge into practice.

Within such a challenging and vulnerable collaborative environment of critical inquiry into practice, where individuals are deprivatising their practice and surfacing their values and beliefs, trust and mutual respect are central to professional learning that will improve practice and increase knowledge and depth of understanding (Forde et al., 2006; Reid, 2004). Timperley et al. (2007) also emphasise the need for trust within such an environment since "challenge inevitably creates issues of identity, personal dissonance, and motivation" (p. 13). Reid (2004) also argues that a culture of inquiry requires an environment of trust, and one that:

celebrates discussion and debate ... [which is] civil and respectful, where people are not put down or demeaned for holding different viewpoints, where there is a genuine attempt to listen to all not just the most powerful, and where there is a plentiful supply of good humour. (p. 7).

In order to minimise risk and discomfort in such an environment of inquiry and promote a safe environment for professional learning, protocols and norms of working can be negotiated and agreed in order to promote parity of investment in the learning process (Atkin, 1996; Brookfield, 2006; Forde et al., 2006).

Reflective dialogue is what takes place to facilitate the process of reflection which engages realities, is grounded in experience, enables new ideas to emerge, and 
challenges assumptions and world views (Brockbank \& McGill, 2007). By engaging in such dialogue, critical friends help colleagues to make sense of their world by being non-judgmental and trying to understand their perspective. Costa and Kallick (1993) define a critical friend as:

\begin{abstract}
A trusted person who asks provocative questions, provides data to be examined through another lens, and offers critique of a person's work as a friend. A critical friend takes the time to fully understand the context of the work presented and the outcomes that the person or group is working toward. The friend is an advocate for the success of that work. (p. 50)
\end{abstract}

As Costa and Kallick suggest, critical friends share a particular kind of relationship which incorporates both challenge and support.

Brockbank and McGill (2007) acknowledge that learning is not an individual pursuit, and that effective engagement in reflective dialogue requires cognisance of the impact of relationships between and among participants. The nature of these relationships is influenced by each individual's view of the world and their appreciative system which impacts on values and beliefs and perceptions of experience (Brockbank \& McGill, 2007; Schön, 1987; Zeichner \& Liston, 1996). Brockbank and McGill also note that power relations within any group can be an issue whether they are explicit or implicit in interactions and relationships. Little and McLaughlin (1993) observe that local contextual influences such as school or departmental attitudes and approaches impact on individuals' and communities' sense of self efficacy and overall effectiveness in bringing about change.

In summary, it appears that the benefits of inquiry and critical reflection are only fully realised when they are collaborative, invite different perspectives, and involve challenge (Cordingley, Thomas, \& Firth, 2005; Crockett, 2002; Darling-Hammond \& Bransford, 2005; Fraser et al., 2007; Fullan \& Hargreaves, 1992; Reid, 2004; Zeichner \& Liston, 1996). There are, however, a range of external and internal forces which can impact on an individual who is engaging in reflective dialogue within any learning community including dispositions of learners and dynamics of communities.

The following section discusses notions of professional identity and dispositions which may impact upon, and be impacted by, professional learning and development within the range of contexts described in this section. 


\section{Professional identity and dispositions}

The concept of professional identity is a complex one which incorporates notions of self-efficacy, self-esteem and agency which affect performance, job satisfaction, motivation and confidence (Darling-Hammond \& Bransford, 2005; Forde et al., 2006; Sachs, 2001). Forde et al. (2006) discuss teacher agency within the context of professional identity, which is constantly developing in response to: initial teacher education and continuing professional development; expectations of society; perceptions of self as an expert and as a learner; communities of practice; perceptions of autonomy or lack of it; managerial and other discourses; and public perceptions and value of schooling. They state that teachers form their professional identity within "stressful working environments" which are "in flux" (p. 11) and that educational institutions too often ignore the affective domains of self-esteem, selfbelief and self-confidence which in turn, impact upon job satisfaction and motivation. They underline the importance of reflection for the development of professional identity and integration into the profession. Forde et al. explore the extent to which the ideals of professionalism (autonomy, commitment, ownership, self-direction) are developed and enabled within initial teacher education and continuing professional development, and state that "work on reflective practice and teacher development should take account of the complex nature of professional identity and the psychological and emotional nature of the construct" ( $p$ 31). They cite Beijaard, Verloop and Vermunt (2000) who argue that teachers' perceptions of their professional identity "affect their efficacy and professional development as well as their ability and willingness to cope with educational change and to implement innovations in their own teaching practice" (Beijaard et al., 2000, cited by Forde et al., p. 70). Teacher agency and efficacy therefore, are complex notions, which are inextricably linked with professional identity, and are impacted upon by a range of internal and external influences.

There are particular expectations of the role, attributes and dispositions of educators that may impact on professional identity. Reid (2004) believes that in the 21 st century, educators should be "inquirers into professional practice who question their routine practices and assumptions and who are capable of investigating the effects of their teaching on student learning" (p. 1). He believes strongly that professional educators face particular challenges which are bound in particular contexts and not subject to simple solutions. He draws on Darling Hammond (2000) in defining an educator's role:

Educators are professionals who are able to theorise systematically and rigorously in different learning contexts about their professional practices including the issues, problems, concerns, dilemmas, contradictions and interesting situations that confront them in their daily professional lives; and 
can develop, implement and evaluate strategies to address these. That is, educators are understood as people who learn from teaching rather than as people who have finished learning how to teach. (Reid, 2004, p. 2)

Reid argues that this impacts on the way that educators are understood and urges educators to adopt inquiry as "way of professional being" (Reid, 2004, p. 2).

Dewey (1933) recognises that particular personal qualities are required of individuals undertaking critical reflection, and identifies three dispositions which he considers are preconditions: openmindedness (to be open to alternative possibilities); responsibility (to consider the consequences); and wholeheartedness (the willingness to critically examine values and beliefs). Loughran (2006) also acknowledges that these qualities are "essential constituents of a readiness for reflection" (1996, p. 5). He advocates Argyris and Schön's (1974) qualities of professionals who should be:

competent in surfacing conflicts and incongruities in their fields; whose sense of self-esteem and intellectual integrity are high enough so they can admit the differences between what they teach and effective practice; who are strong enough to invite confrontation of their teaching and practice; and who, finally, will confront themselves with the conflict of values implicit in these incongruities. (Argyris \& Schön, pp. 195-196)

Loughran advocates these dispositions for teacher educators who are teaching about teaching. Some personal attributes and skills of critical friends such as knowledge, questioning, caring, listening and perseverance are explored by Baskerville and Goldblatt (2009) in their description of their developing critical friendship.

Cheetham's (2005) pointers for individual learning reflect the characteristics suggested by Reid (2004) and Loughran (2006): readiness for learning; seeking feedback; learning from others; using cognitive strategies; seeking challenges; being positive; taking time to reflect; sharing experiences with others and being self aware (p. 225).

Engaging in critical dialogue can be an uncomfortable process and bring about feelings of dissonance in professional practitioners (Timperley et al., 2007). Boud et al. (cited in Cheetham, 2005, p. 58) argue that "the reflective process is a complex one in which both feelings and cognition are closely related and interactive". They caution that the process of reflection can precipitate loss of confidence and impact negatively on self-efficacy. Candy et al. (cited in Cheetham, 2005, p. 58) suggest that "reflection can sometimes cause a reduction in performance because the individual's attention is divided between executing the activity and consciously observing himself, or herself, doing it". Fullan (2001b) refers to this as an implementation dip - a phase which can occur quite naturally in progression towards improvement of practice. 
The process of developing professional identity, reflecting on and deprivatising practice and critiquing values and beliefs can be a threatening experience. The process of change may necessitate reconstruction of themselves as teachers bringing "tension as well as opportunity" (Forde et al., 2006, p. 13). Brookfield (1995) cautions that reflective practitioners should be aware of the risks involved and encourages the minimisation of the threats in order to optimise the effects of actions. In particular, he identifies four risks: feeling like an impostor because of the awareness of lack of competence; being marginalised and excluded from support networks and communities; grieving for lost certainties in recognising the ambiguity of teaching; and being left in a state of limbo due to "incremental fluctuation" (p. 242).

Rigorous inquiry into practice of the kind that Reid (2004) advocates can challenge professional identity and involve elements of risk and discomfort for individuals (Forde et al., 2006; Ministry of Education, 2006). In order to minimise such risk, professional learning requires a safe learning environment where protocols and norms of working are negotiated and agreed (Atkin, 1996; Brookfield, 2006; Forde et al., 2006).

Engaging in critical inquiry, therefore, requires particular dispositions toward learning that will embrace opportunities to examine values, beliefs and assumptions in order to learn and grow professionally. It is also clear that in an environment that involves such critical examination of practice, values and beliefs, individuals' sense of professional identity is liable to be subject to threat and uncertainty. Explicit efforts to ensure a safe and risk-free environment for such interactions to take place can minimise feelings of threat and insecurity.

\section{Conclusions}

Over the last few decades there has been a move towards sociocultural inquiry models of professional development for teachers. These models aim to promote and facilitate the deconstruction and critical evaluation of existing knowledge, practice, values, assumptions and beliefs; and provide a framework for progressing and creating new knowledge from within contexts of practice. This involves a deprivatisation of practice, and a surfacing of tacit knowledge, values and beliefs in order to align espoused theories with theories-in-use. This is a complex process involving reflection on personal, process, and propositional knowledge, in an environment where the knowledge required for inservice teacher educators is on shifting ground. 
The collaborative environments, within which such professional learning and development takes place, are varied and complex, and present a multitude of mediating factors on the effectiveness of the professional learning and development models. Although such sociocultural models have been advocated, with some exceptions such as Earl \& Katz (2010); Ingvarson, Meiers, and Beavis (2005); and Wyatt-Smith, Bridges, and Hedemann (2008), there has been little research into the processes and systems inherent within such models (de Lima, 2010; Fraser et al., 2007; Kennedy, 2005; Wilson \& Berne, 1999). There has also been little research in the area of professional knowledge and professional learning and development for inservice teacher educators (Day, 1999a; Korthagen, 2001).

This study addresses this gap in the research, and will inform the black box between learning opportunities for inservice teacher educators and improved inservice teacher educator practice in Figure 2.2. The INSTEP project was designed to explore approaches to the professional learning of inservice teacher educators, and to promote EBIP. This study investigates the phenomenon of EBIP and identifies what the process involved, and the impact upon individuals who participated in a variety of contexts. It investigates the process of EBIP as a model of professional learning and development, and in doing so, sheds more light on the types of knowledge it promotes, and the ways in which it impacts upon inservice teacher educators' learning and practice.

According to a review of the literature, EBIP involves a rigorous approach to reflection on practice, incorporating practice and research evidence. Evidence can be validated by professional peers or more traditional research strategies. EBIP requires teachers and teacher educators to deprivatise their practice in trusting and challenging environments. This process can be a threatening one, and impact on professional identities including self-efficacy, agency, job satisfaction, confidence and motivation. Learning communities that promote and support collaborative inquiry into practice are trusting and respectful, with collective responsibility for learning and improvement. 


\section{CHAPTER 3}

\section{Methodology}

\section{Introduction}

The purpose of this qualitative grounded theory study is to understand the perceptions and experiences of inservice teacher educators who are engaging in EBIP, and to generate a theoretical framework for the process of EBIP for inservice teacher educators. Such a framework will help us to understand more clearly how to promote and support this aspect of learning to positively impact on inservice teacher educator practice, teacher practice, and student outcomes. This chapter will present the specific research questions and justify grounded theory and collective case study as appropriate methodologies. It will detail the design of the study, including participants, data sources, procedures, and considerations of ethics and validity. A detailed account of content analysis is presented, and the chapter concludes with an overview of the process of deriving the resulting theoretical framework.

\section{Research questions}

In order to fulfil the purpose of the study, it will be necessary to identify what constitutes EBIP for inservice teacher educators, and how it impacts on their learning and professional identity. The theoretical framework, therefore, will be informed by the following research questions:

1. What are the personal, sociocultural, and organisational factors that impact on EBIP for inservice teacher educators?

2. What are the processes, interactions and activities that constitute effective EBIP for inservice teacher educators?

3. What is the impact of EBIP upon inservice teacher educators' learning and sense of professional identity?

\section{Research design}

This study will draw upon an interpretive approach to research. Key aspects of the rationale are as follows:

- New and emerging areas are particularly suited to an interpretive design (Creswell, 2003). Research in professional learning, and particularly EBIP for 
teacher educators, is a new and emerging area and existing theories in professional learning do not apply necessarily to teacher educators.

- As a researcher, I am interpreting participants' understandings and creating knowledge about a phenomenon (Bernard, 2000).

- The data are open ended, descriptive, and qualitative, enabling the development of themes for analysis (Creswell, 2008).

- The study investigates the socially constructed nature of particular environments and the situational constraints of these environments (Holstein \& Gubrium, 2005).

- The focus of the research is on the experiences and perceptions of individuals, and the ways in which they learn and improve their practice. The data, therefore, are not quantifiable, but more qualitative in nature (Charmaz, 2000; Creswell, 2008).

- The research focuses on inquiry about the processes, activities and interactions that occur, as well as the product or outcome (Stake, 2008).

- The research design is an emergent process where meanings and interpretations will be clarified and confirmed with participants in order to "understand multiple realities" (Creswell, 2003, p. 181).

The phenomenological nature of the research topic and the context render case study and grounded theory the most appropriate methodologies to adopt. The phenomenon I am seeking to understand is evidence-based inquiry into practice for inservice teacher educators. The combination of case study and grounded theory will:

\begin{abstract}
draw us toward observing, even teasing out, the problems of the case, the confidential outpourings, the complex backgrounds of human concern ... help us expand upon the moment, help us see the instance in a more historical light, help us to recognise the pervasive problems in human interactions [and] provide a powerful conceptual structure for organizing [sic] the study of [the] case. (Stake, 1995, p. 17)
\end{abstract}

The case study is defined by its "particularistic, descriptive, and heuristic" (Merriam, 1998 , p. 29) characteristics. It is particularistic in that it focuses on a single phenomenon within the context of everyday experience, with the intention of applying what is learned to other similar situations. The qualitative data provide thick description of the phenomenon, and enable reflection on the many perspectives and factors contributing to the situation. The heuristic nature of the case study provides new understandings of the phenomenon. 
The collective case study (Creswell, 2008; Stake, 2005, 2008) is made up of 10 single cases (the participants), and is embedded within a grounded theory framework. Within the case study, I investigate the "particularity and complexity" of the phenomenon, and come to "understand its activity within important circumstances" (Stake, 1995, p. xi). This case study has been selected for its "very uniqueness, for what it can reveal about a phenomenon, knowledge we would not otherwise have access to" (Merriam, 1998, p. 33).

The multiple cases are bounded (Creswell, 2008; Merriam, 1998; Stake, 2005; Yin, 2003) by participants' common experience of prior participation in the INSTEP project, an awareness of the significance of EBIP, and engagement in such inquiry. Each single case is characterised by organisational context and the participant's role, area of specialisation and unique experience. The collective case study offers a variety of perspectives, enhancing the potential transferability of the findings to other contexts. This balance and variety maximises the learning potential, which is the prime consideration (Stake, 1995, 2008).

Grounded theory, as defined by Charmaz $(2005,2006)$ is the strategy adopted in this study:

Grounded theory methods are a set of flexible analytic guidelines that enable researchers to focus their data collection and to build inductive middle-range theories through successive levels of data analysis and conceptual development. (Charmaz, 2005, p. 507)

As a beginning researcher, I adopted a systematic approach to grounded theory (Strauss \& Corbin, 1990, 1998) as this offered me a clear procedure to interpret and explain the environments, processes, interactions and activities that occurred over time (Creswell, 2008) within the phenomenon of evidence-based inquiry into practice. Grounded theory methodology enabled me to develop a theory that afforded learning "about the experience within embedded, hidden networks, situations and relationships ... making visible hierarchies of power, communication and opportunity" (Creswell, 2007, p. 238).

The characteristics of my study that render grounded theory an appropriate approach are as follows:

- I was deriving an abstract theory of a process grounded in the views of the participants in the study (Glaser, 1992; Strauss \& Corbin, 1990, 1998);

- I was using an inductive approach which entails extrapolation from individual cases to an abstract, conceptual level (Charmaz \& Bryant, 2007); 
- The process involved using multiple stages of data collection and analysis (Charmaz, 2000; Creswell, 2008);

- The process involved the refinement and interrelationship of categories of information (Creswell, 2008; Strauss \& Corbin, 1990, 1998).

Two primary characteristics of the design are the constant comparison of data with emerging categories (Corbin \& Strauss, 2008; Glaser, 1978; Glaser \& Strauss, 1967; Strauss \& Corbin, 1990, 1998), and theoretical sampling of participants and data sources to maximise the similarities and the differences of information (Charmaz, 2000; Creswell, 2008). Constant comparison is the ongoing process of data collection and analysis, in conjunction with comparison of emerging categories and theoretical concepts. Theoretical sampling is the process of collecting more data as categories emerge in order to elaborate and refine the category properties.

\section{Participants}

All participants were inservice teacher educators who had prior experience in the INSTEP project, and who have engaged in EBIP. This ensured that participants had experienced, and had expert knowledge of, the phenomena under investigation (Morse, 2007). The participants provided different perspectives from a range of experience, expertise and learning/practice contexts and sites. They were from a variety of geographical locations throughout New Zealand. They were practitioners who were representative of different geographical sites, areas of the curriculum, roles and responsibilities, lengths of service, roles in INSTEP, and types of organisations (private provider/university/school-based). University-based organisations have evolved from departments within universities and colleges of education that were centrally funded to provide a range of professional development services to schools (School Support Services). Private providers are autonomous organisations that operate independently of central funding. School-based providers in this study are Resource Teachers: Learning and Behaviour (RTLB), who were appointed by the Ministry of Education to support teachers and schools in the education of students with particular learning and behaviour needs.

The initial group of seven participants was purposively selected (Berg, 2004; Charmaz, 2000; Creswell, 2008; Walliman, 2001). As the data were analysed and relationships and themes identified through constant comparison of data, three additional participants and a series of document sources were identified by theoretical sampling (Charmaz \& Bryant, 2007; Creswell, 2008; Merriam, 1998). The 
additional participants and document sources were purposively selected in order to enable fuller understanding of individual learning from INSTEP, and the impact and role of the organisation or community on the process and outcomes of EBIP. The full list of participants is included in Table 3.1. 
Table 3.1: List of participants

EBIP: Research participant roles and responsibilities

\begin{tabular}{|c|c|c|c|c|c|}
\hline Pseudonym & Interviews & INSTEP role & Type of provider & Role in organisation & Status of EBIP in 2010 \\
\hline Alison & 2010 & ISTE & University setting & $\begin{array}{l}\text { Inservice teacher educator } \\
\rightarrow \text { pre-service lecturer }\end{array}$ & Individual pursuit \\
\hline Anne & $2008 / 2010$ & ISTE & RTLB service & $\begin{array}{l}\text { RTLB inservice teacher } \\
\text { educator }\end{array}$ & Some collaborative EBIP \\
\hline Aroha & 2010 & NF & University setting & $\begin{array}{l}\text { Manager within SSS with } \\
\text { key role in developing and } \\
\text { implementing PD } \\
\text { programme }\end{array}$ & $\begin{array}{l}\text { Implemented within organisational learning } \\
\text { and appraisal programme }\end{array}$ \\
\hline Elaine & $2008 / 2010$ & NF & Private provider & $\begin{array}{l}\text { Inservice teacher educator } \\
\rightarrow \text { role in leading learning }\end{array}$ & $\begin{array}{l}\text { Implemented within organisational learning } \\
\text { and appraisal programme }\end{array}$ \\
\hline Eva & $2008 / 2010$ & RF & University setting & $\begin{array}{l}\text { Inservice teacher educator } \\
\rightarrow \text { pre-service lecturer and } \\
\text { researcher }\end{array}$ & Individual pursuit \\
\hline Evelyn & 2010 & RF & University setting & $\begin{array}{l}\text { Inservice teacher educator } \\
\text { within SSS }\end{array}$ & $\begin{array}{l}\text { Individual pursuit; contributing to self review } \\
\text { framework for inservice teacher educators } \\
\text { within a team of } 5 \text { in curriculum area }\end{array}$ \\
\hline Hannah & $2008 / 2010$ & NF & University setting & $\begin{array}{l}\text { Inservice teacher educator } \\
\rightarrow \text { role in leading learning }\end{array}$ & $\begin{array}{l}\text { Implemented within organisational learning } \\
\text { and appraisal programme }\end{array}$ \\
\hline Laura & $2008 / 2010$ & RF & RTLB service & $\begin{array}{l}\text { RTLB inservice teacher } \\
\text { educator }\end{array}$ & Some collaborative EBIP \\
\hline Olivia & $2008 / 2010$ & ISTE & RTLB service & $\begin{array}{l}\text { RTLB inservice teacher } \\
\text { educator }\end{array}$ & Some collaborative EBIP \\
\hline Theresa & $2008 / 2010$ & NF & Private provider & $\begin{array}{l}\text { Inservice teacher educator } \\
\rightarrow \text { teacher }\end{array}$ & Individual pursuit \\
\hline
\end{tabular}

$\rightarrow \quad$ change in role since INSTEP

SSS School Support Services 


\section{Procedures}

All INSTEP ISTEs, RFs and NFs were invited by e-mail to participate in the study (Appendix A). Seven participants volunteered and participated in the first round of interviews which took place in 2008.

The primary sources of data were the document sources, participants' artefacts, open-ended and semi-structured interviews, and researcher memos documenting my ongoing reflections, thoughts and perceptions of the data as they occurred throughout the study.

The semi-structured and semi-standardised interviews were designed to guide conversation in the direction of the questions, while allowing participants the freedom to talk about what they considered to be important to them (Berg, 2009; Hesse-Biber \& Leavy, 2006). This type of interviewing allowed some structure with the opportunity to reorder questions, make clarifications and probe some questions further (Berg, 2009). Careful consideration was given to the development of the interview schedules (Appendix B), with a sequencing of categories of questions, beginning with easy demographic questions, then moving to the more probing and potentially sensitive questions, concluding with reflective questions. In order to put interviewees at ease, I introduced myself, and outlined my involvement in INSTEP to those who had not met me before. For all participants, I explained the research project and the purpose of the interview, and gave the opportunity for questions to be asked or concerns to be voiced at the beginning and end of the interviews. Open-ended interviews allowed me to explore more fully participants' reality, allowing for the generation of theory (Reinharz, 1992). The first interview was trialled by a colleague who was also an INSTEP participant, and no significant amendments were necessary.

Document sources consisted of various publications by INSTEP participants and researchers (for example, the INSTEP evaluation, journal articles and book chapters) and provided detail on the background, design and outcomes of INSTEP, as well as some of the contexts and activities that took place. The list of document sources is provided in Table 3.2. The authors of the document sources are not necessarily the participants of this study, and have not been notified with regard to this study as the publications are already in the public domain. Participant artefacts (for example evaluation criteria, progress reports, journal entries and evidence of practice) were provided by some participants. The document sources and participant artefacts provided a rich source of information to inform both the broader contexts, and specific details of the participants' experiences and environments. 
Table 3.2: List of document sources

\begin{tabular}{|c|c|c|}
\hline $\begin{array}{l}\text { Document } \\
\text { Source }\end{array}$ & Title & Synopsis \\
\hline Source A & $\begin{array}{l}\text { Higgins, J., Parsons, R., \& Bonne, } \\
\text { L. (2011 in press). Processes of } \\
\text { inquiry. Rotterdam: Sense. }\end{array}$ & $\begin{array}{l}\text { An edited book of accounts from the } \\
\text { participants and those involved in the } \\
\text { INSTEP project }\end{array}$ \\
\hline Source B & $\begin{array}{l}\text { Ministry of Education. (2008). Ki te } \\
\text { Aotūroa: Improving inservice } \\
\text { teacher educator learning and } \\
\text { practice. Wellington Learning } \\
\text { Media. }\end{array}$ & $\begin{array}{l}\text { A book and DVD of resources as the } \\
\text { outcome of the INSTEP project }\end{array}$ \\
\hline Source C & $\begin{array}{l}\text { Mcllraith, G., Hope, C., Leslie, S., } \\
\text { \& Pym, C. (2009). INSTEP - } \\
\text { Learning about practice: A } \\
\text { dynamic inquiry. Paper presented } \\
\text { at the New Zealand Association for } \\
\text { Research in Education. }\end{array}$ & $\begin{array}{l}\text { A paper presented at NZARE by } \\
\text { INSTEP participants }\end{array}$ \\
\hline Source D & $\begin{array}{l}\text { Sankar, M.. (2009). Evaluation of } \\
\text { inservice teacher education } \\
\text { practice project (INSTEP) (Report } \\
\text { to the Ministry of Education). } \\
\text { Wellington, NZ: Ministry of } \\
\text { Education. }\end{array}$ & An evaluation of the INSTEP project \\
\hline Source E & $\begin{array}{l}\text { Baskerville, D., \& Goldblatt, H. } \\
\text { (2009). Learning to be a critical } \\
\text { friend: from professional } \\
\text { difference through challenge to } \\
\text { unguarded conversations. } \\
\text { Cambridge Journal of Education, } \\
39(2), 205-221 \text {. }\end{array}$ & $\begin{array}{l}\text { A journal article by } 2 \text { INSTEP } \\
\text { participants about their experience as } \\
\text { critical friends }\end{array}$ \\
\hline Source F & $\begin{array}{l}\text { Lamont, M. (2009). Enhancing } \\
\text { professional learning for the } \\
\text { improvement of practice of } \\
\text { inservice teacher educators: } \\
\text { Professional learning for inservice } \\
\text { teacher educators. The } \\
\text { International Journal of Learning, } \\
\text { 16(16), 431-444. }\end{array}$ & $\begin{array}{l}\text { A journal article by myself (as INSTEP } \\
\text { national facilitator) about findings from } \\
\text { phase } 1 \text { of INSTEP }\end{array}$ \\
\hline
\end{tabular}

Data were collected in three phases during the study as constant comparison of data and theoretical sampling was applied. The sequence of data collection and analysis are portrayed in Figure 3.1. More detail of data content analysis is provided in a later section of this chapter. 


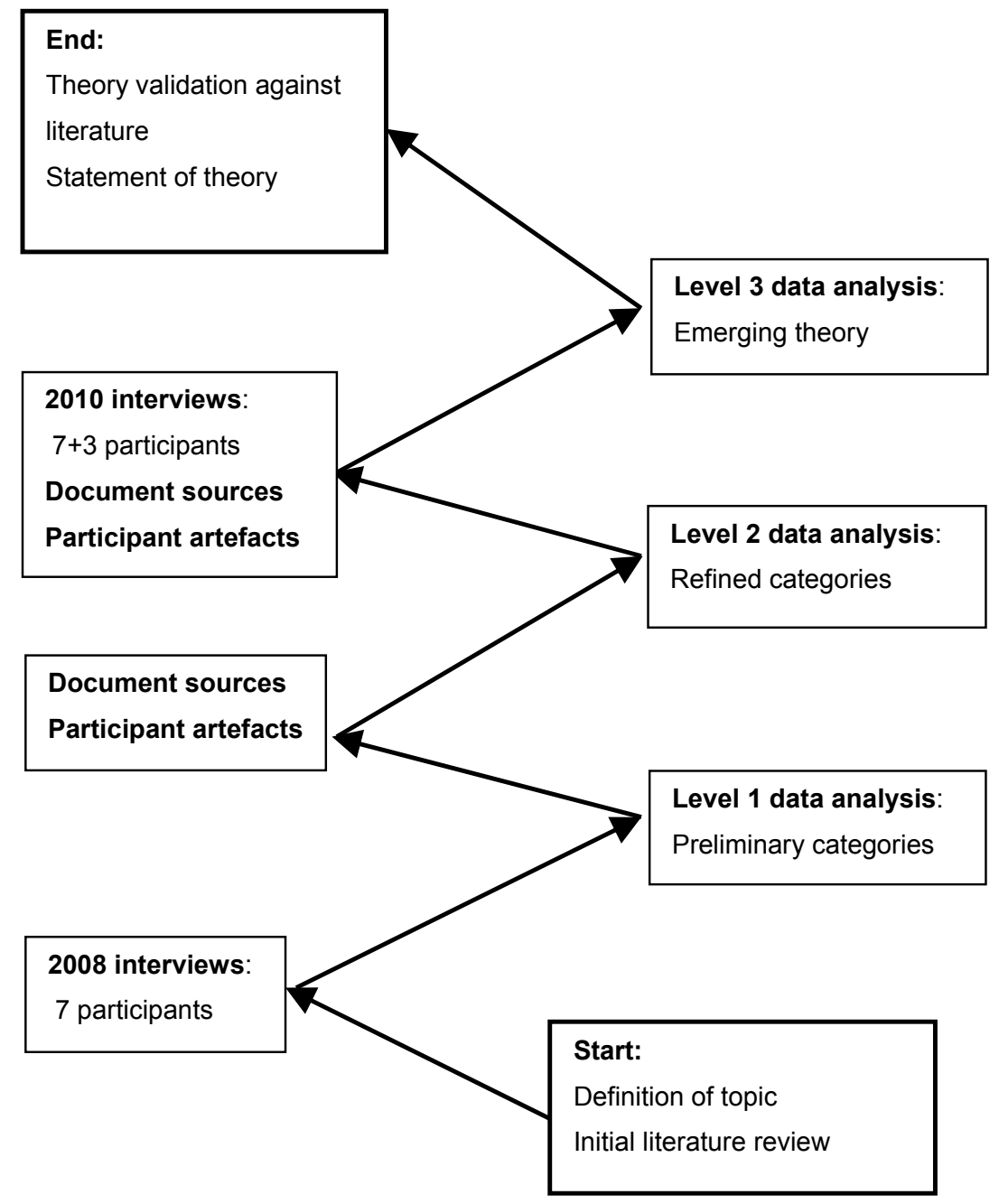

Figure 3.1: Sequence of data collection and analysis

Level 1 of data analysis rendered a broad range of categories inductively derived from the interview transcripts. In level 2 of data analysis, refined categories were derived from the integrative analysis of the document sources, participant artefacts, and the preliminary categories. This process enabled theoretical sampling of further document sources and participants to include in the second round of interviews in 2010. These participants added depth to the categories within the study and filled gaps in the emerging theory in the level 3 analysis. In particular, I sought to increase the representation of private providers, as well as obtain a greater variety of roles and responsibilities within a university context. Although I e-mailed invitations to six potential new participants, the only three who volunteered at this stage were all from a university context: Aroha provided an organisational perspective; Evelyn provided an RF perspective; and Alison an ISTE perspective.

Each of the seven initial participants was interviewed in 2008 and again in 2010. Seven out of 10 participants were known to me personally prior to the study through 
my work within INSTEP and the university. The 2008 interviews took place face-toface, while most 2010 interviews were carried out using Skype video calls. The exceptions to that were: one of the initial participants responded to questions by email in 2010 , and two of the additional participants were interviewed face-to-face in 2010.

The second interviews established whether or not participants were continuing with EBIP, and why; and what they considered they had learned and gained from the INSTEP experience. The interview schedules are provided in Appendix B. The three additional participants offered different perspectives, and provided details on the varied organisational contexts and the impact upon individual experiences. These interviews were also open-ended, but with more specific foci for each individual dependent on their role and context. The schedule for the second interview was therefore used in a more flexible way than the first, and as a guide for the interviews (Hesse-Biber \& Leavy, 2006).

\section{Ethics}

Ethics approval for the study was obtained from the Victoria University of Wellington Faculty of Education Ethics Committee at the commencement of the study. All participants were recruited by invitation, and participation was voluntary. The research is not anonymous but is confidential, and informed consent was obtained from all ISTEs participating in the study (Appendix C). All participants were allocated a pseudonym to preserve confidentiality. The organisations have not been identified by name, but have been identified as private providers, universities or RTLB services. All opinions and data have been reported in aggregated form in such a way that individual persons or specific organisations are not identifiable. The data were stored on my computer in a password-protected file. The digital recordings were deleted after coding, and transcribers signed a confidentiality agreement.

\section{Trustworthiness}

There is much debate in the research field about valid criteria for judging the quality and rigour of qualitative research (Glaser \& Strauss, 1967; Hammersely, 1992; Lincoln \& Guba, 1985; Strauss \& Corbin, 1990, 1998). Lincoln and Guba (1985) say that trustworthiness of the research supports the argument that the findings are "worth paying attention to" (p. 290). They identify four aspects of trustworthiness that require particular attention: credibility, transferability, dependability and confirmability. 


\section{Credibility}

Credibility is an evaluation of the "truth value" (Lincoln \& Guba, 1985, p. 296) of the research, and whether or not the findings are credibly interpreted from the data. In this study, the case for credibility is supported by the constant comparison of data over a prolonged period of three years. Credibility was further enhanced by triangulation of data types and sources (Denzin, 1970; Silverman, 1993). I interviewed most participants twice over a period of two years, and also used documents and artefacts as sources of data. In this way I attempted to eliminate my own subjectivity and its effect on the data (Bogdan \& Biklen, 1992). Theoretical sampling ensured that ongoing data collection was guided by the participants and the emerging findings. A key validation strategy in developing the categories was the production of a summary of each transcript, and verification with the original seven participants that their stories could be told in terms of the main categories (Silverman, 1993; Strauss \& Corbin, 1998). Summaries were subsequently developed for all interviews, and were used to develop participant profiles which are included in Appendix D. While the summaries were being developed, data were being interpreted, and further questions and "plausible answers" (Berg, 2009, p. 358) emerged. I checked the emerging themes with relevant literature on an ongoing basis and exercised theoretical sensitivity throughout, which involved "seeing possibilities, establishing connections, and asking questions" (Charmaz, 2006 , p. 135 italics in original). This process allowed familiarity with the data, and "interrogative hypothesis testing" (Berg, 2009, p. 360), incorporating confirmation, or otherwise, of a developing theory by looking for patterns and inconsistencies in the data. At regular intervals, I debriefed with peers who were familiar with the context of the INSTEP project and the phenomena under investigation. I believe my own rich experience as a teacher educator and engagement with the INSTEP project enhanced credibility as I was familiar with the context under study.

\section{Transferability}

Transferability is the degree to which the findings can be transferred to other contexts outwith the realms of the research. Although this study was focussing on one particular professional development initiative (INSTEP), the phenomenon of EBIP is one which can be identified in a number of different contexts. The rich description of the INSTEP project, the participants and their contexts help the reader make connections and relate the findings to other settings. 


\section{Dependability}

Dependability is an evaluation of the quality and rigour of the processes of data collection, analysis and theory generation. As a new researcher, I adopted a rigorous process of grounded theory methodology incorporating concurrent data collection and constant comparative analysis, theoretical sampling, and memoing. To guide me in the generation of theory, I developed a coding paradigm based on Strauss and Corbin's (1998) model and attended to Strauss' (1987) criteria for identification of a core category (both of which are explained more fully in the content analysis section of this chapter). I also enlisted the support of one of my supervisors to check the rigour and logic of my coding at several stages throughout the project.

\section{Confirmability}

Confirmability is the ability of the researcher to convey the research methods and procedures so that the study could be replicated. The methodology and procedures documented in this chapter provide sufficient detail to enable the reader to identify the processes throughout. I maintained detailed memos of my own thoughts and interpretations as the data were collected and analysed. This helped me to identify instances of my own potential subjectivity, and guard against personal bias.

\section{Content analysis}

I elected to use qualitative research software for coding, as I am particularly comfortable with new technologies, and much more at ease manipulating files on a computer than hard copy papers. I found the reflective questions suggested by Hesse-Biber and Leavy (2006) particularly helpful as I considered my preferred ways of working, the computer facilities available to me, and the type of data analysis I wanted to do.

I chose QSR NVivo version 8 as it provides purpose-built tools for classifying and sorting a variety of types of information. It allowed me to import all interview transcripts as data sources, and then identify categories from the data. It allowed the management and interrogation of themes, categories and sub-categories. As all stages of coding of data were always available in one location, the process of constant comparison and organisation and reorganisation of categories was facilitated throughout. The use of such software therefore supported my grounded theory methodology. 
The stages of coding and content analysis described in the following section are illustrated in Figure 3.2 .

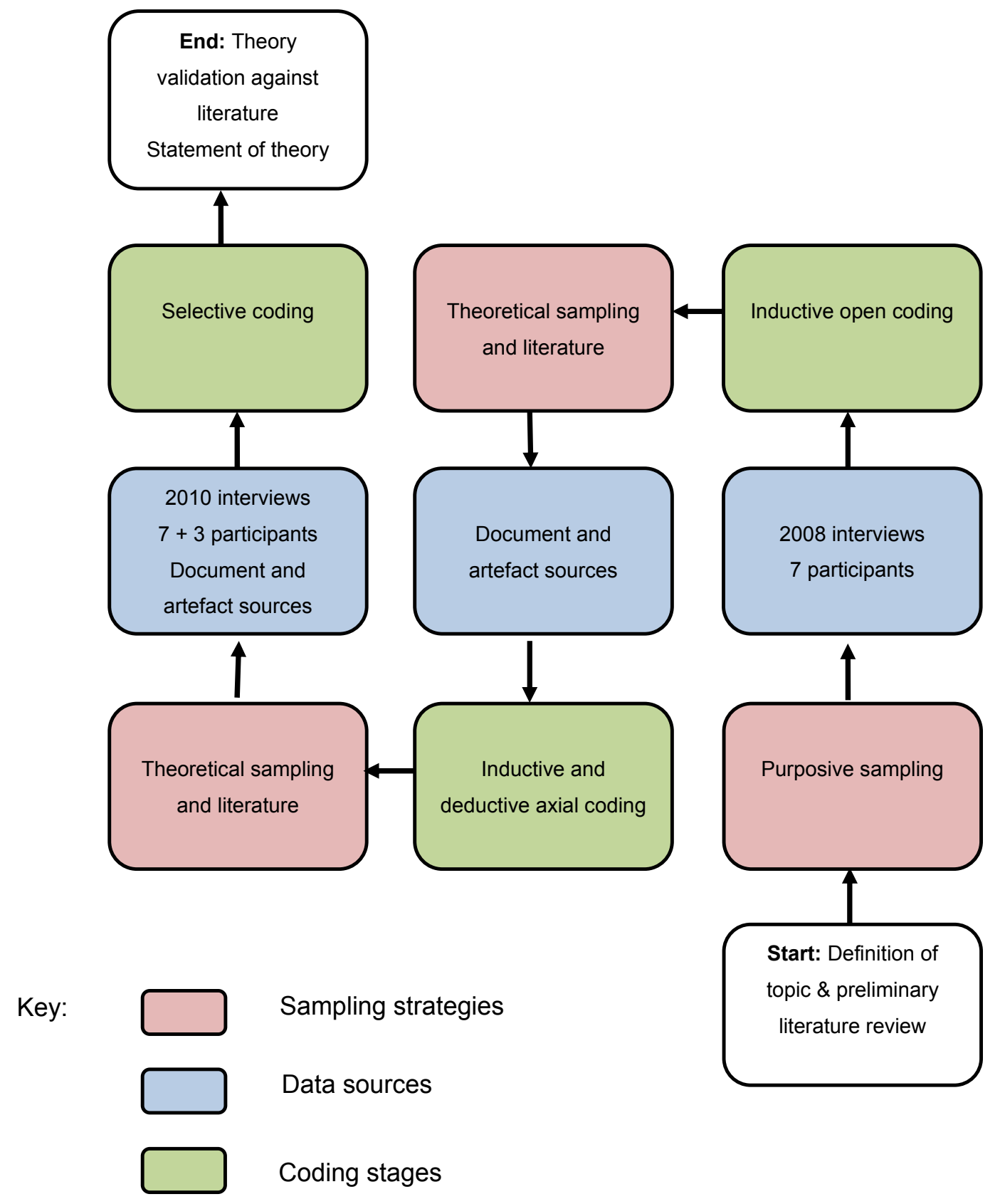

Figure 3.2: Stages of coding and content analysis

\section{Open coding}

The seven participant transcripts from the first stage of data collection were analysed and codes were inductively identified in the open coding phase. An inductive approach was taken in order to "present the perceptions of [the participants] in the most forthright manner" (Berg, 2009, p. 347). This helped to ensure that the codes were grounded in the data. However, I must acknowledge that 
my own experience from participation in INSTEP, and knowledge of the field, meant that I did have some insight of the topic and perceptions of the data. I therefore attempted to immerse myself in the data (Braun \& Clarke, 2006) and attend, in this phase, to the manifest content of the discourse - "those elements that are physically present and accountable" (Berg, 2009, p. 343) - rather than latent content, where I might be tempted to interpret "deep structural meaning" (Berg, 2009, p. 344). This was particularly important in order to maintain an objective stance as a researcher, while interpreting the meaning conveyed by the interviewee. I familiarised myself with the data by repeatedly listening to all interview recordings (Braun \& Clarke, 2006). In instances where I was inclined to interpret meaning more deeply, I made notes in the form of memos (see Figure 3.3), while attempting to "believe everything and believe nothing" as advised by Strauss (1987, p. 30).

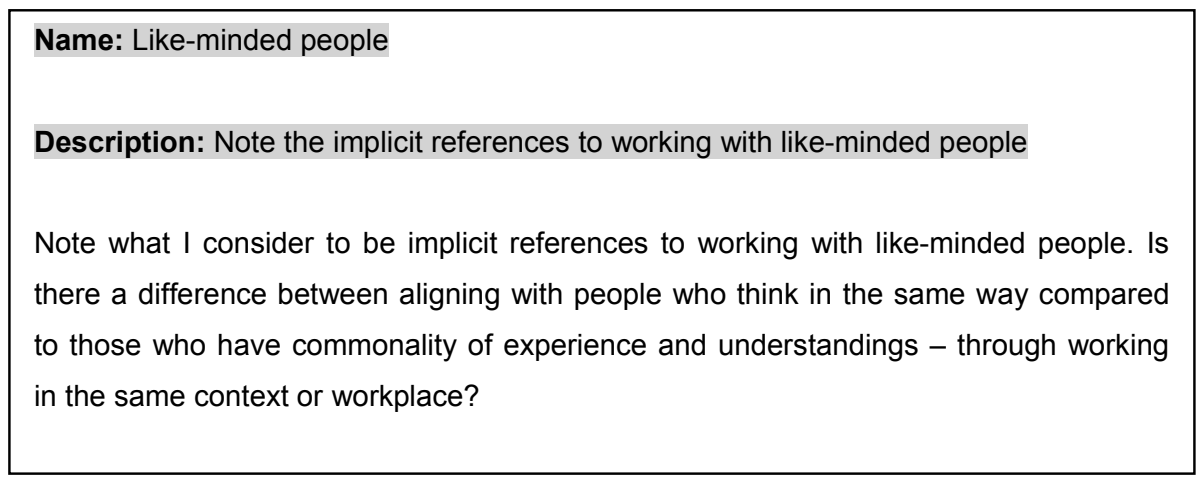

Figure 3.3: Example of memo

In my analysis I adopted the guidelines as suggested by Strauss (1987), and discussed by Berg (2009). I made a conscious effort to: ask the data a specific and consistent set of questions in relation to my research questions; analyse the data minutely; frequently interrupt coding to write a theoretical note; and never assume the analytical relevance of any traditional variable until the data had shown it to be relevant.

All of the data were coded. The elements of analysis were a combination of theme and concept, consisting of phrases, sentences or whole paragraphs as units of analysis. Some extracts were coded in multiple categories as judged appropriate (Braun \& Clarke, 2006). I made sure to maintain context by including surrounding data (Bryman, 2001), and I awarded each category a detailed description to remind me of my criteria for allocation to a category. The criteria were applied rigorously and consistently in order to retain objectivity and ensure that the analysis was not "restricted to material which relates only to the researcher's hypotheses" (Berg, 2009, p. 343). Data that were considered to be irrelevant or questionable were allocated to these categories respectively to enable me to return to them if necessary. 
As categories emerged and developed, concise descriptions were attached to each category. As analysis progressed, some descriptions became more detailed; some categories emerged as subcategories of others; some were merged as they were very similar; and others were retained, although considered to be probably insignificant for the research questions. Figure 3.4 is a snapshot of the level 1 analysis showing some of the initial categories and subcategories.

Model_v3_1-_05_24
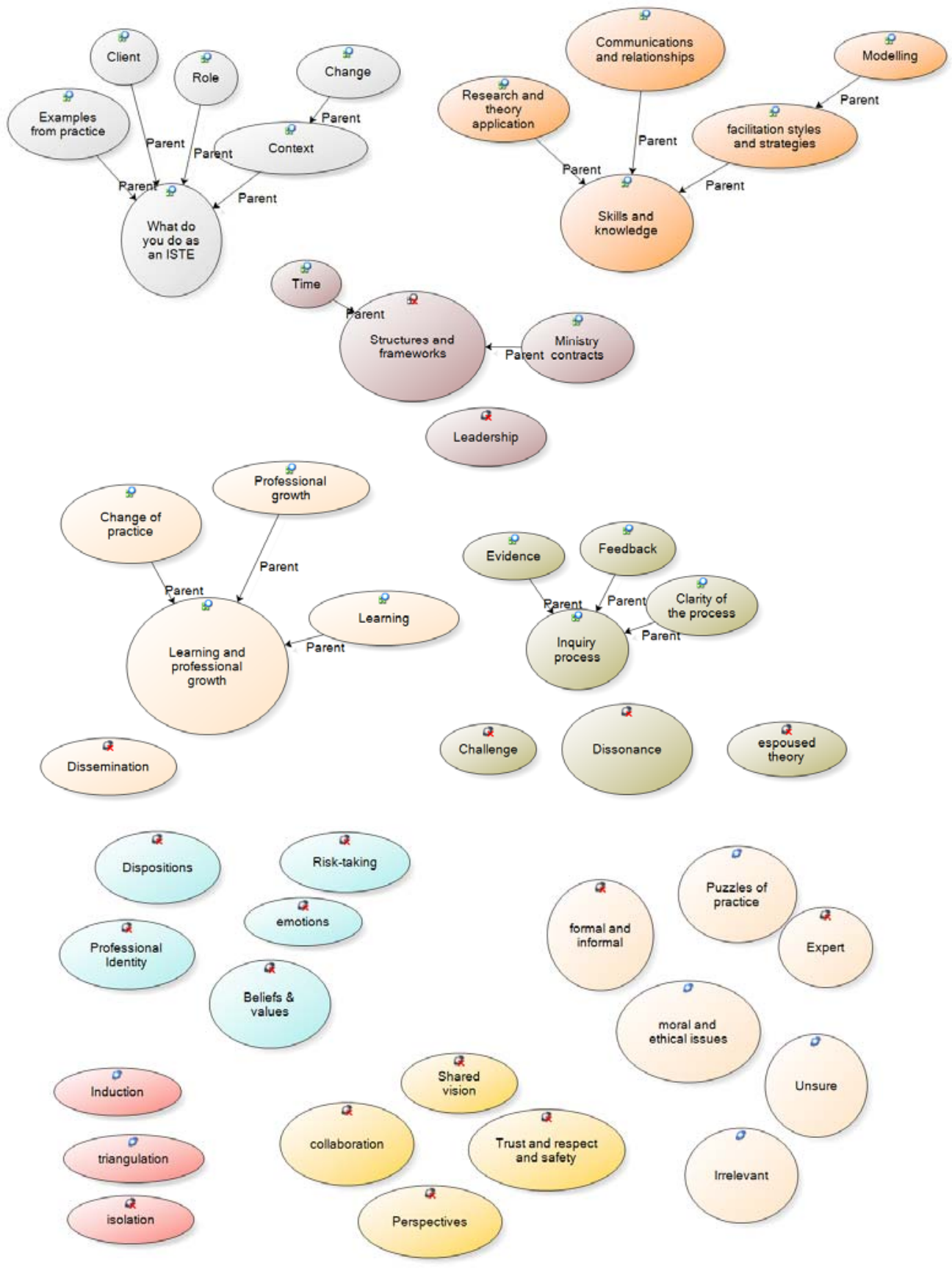

Figure 3.4: Level 1 analysis - open coding categories

67 
In Figure 3.4, I identified five categories which had obvious sub-categories: what you do as an inservice teacher educator; skills and knowledge; learning and professional growth; structures and frameworks; and the inquiry process. Other possible links and groupings were identified by different colours in the diagram. An example of an excerpt from a coded transcript is illustrated in Figure 3.5.

Hannah
Yeah, I think so. I think I'm a much more confident facilitator now. I certainly don't get cold
clammy hands when I'm standing up in front of testy groups of technology teachers who are
wanting the answers to why things don't happen, far more confident in my sort of subject
knowledge and ability.
Margaret
How about you personally? You've said it's clarified your beliefs and values. How has that
impacted on you personally? Can...
Hannah
$\ldots$ I guess it's tied up with that confidence thing that now that I know more about how I operate I
can judge whether that works in a particular situation, where as before I wasn't sure how I
operated and so I will put my beliefs on the table. I believe that we need to refocus on effective
pedagogy rather than assessment and I'll explain why. And so I'll be very upfront about those
sorts of beliefs and values and doing that I guess challenges the teachers to think about well
actually ok NCEA does drive my programme. So let's have a look at your programme, what
could it look like, what would you have a passion for it to look like and then let's look at what the
assessment could look like and those sorts of things.

Figure 3.5: NVivo Screenshot: Section of coded transcript

This process continued until a saturation of categories was reached, and no new categories were emerging from the data. This occurred after five transcripts were coded. At this point I had "squeezed as much conceptual juice" (Robson, 2002, p. 494) from the data as I could.

The next stage within open coding and constant comparison (Glaser \& Strauss, 1967) was where the categories were revisited and compared for similarities and differences and to "make analytic sense of the material, which may challenge takenfor-granted assumptions" (Charmaz \& Bryant, 2007, p. 54). During this stage categories were revised, and sub-categories, properties and property dimensions were refined. Table 3.3 illustrates some of the category descriptions at this stage of analysis. 


\section{Table 3.3 Category descriptions}

\begin{tabular}{|c|c|c|}
\hline Dispositions & & $\begin{array}{l}\text { References to individual personal characteristics, attitudes and approaches to practice and learning (e.g. } \\
\text { openness, courage, motivation) - not including improvement or change in dispositions }\end{array}$ \\
\hline \multirow[t]{8}{*}{ Emotions and feelings } & & Emotions and feelings experienced within inquiry \\
\hline & Affirmation & Feelings of affirmation within aspects of practice and/or within the process of inquiry \\
\hline & Approach and response to inquiry & General references to the way in which the process of inquiry is regarded - both positively and negatively \\
\hline & Clarity of purpose or role & Clarity or ambiguity with the role of the inquirer and/or the process of inquiry \\
\hline & Confidence & Degrees of confidence (or lack of) in the process of inquiry \\
\hline & Dissonance and personal challenge & Feelings of dissonance with aspects of practice, or personal challenge within the process of inquiry \\
\hline & Safety & Degrees of security/insecurity; comfort or fear \\
\hline & Satisfaction & Degrees of satisfaction with the process of inquiry (e.g. frustration, disappointment, encouragement) \\
\hline \multirow[t]{4}{*}{$\begin{array}{l}\text { Learning and } \\
\text { professional growth }\end{array}$} & & $\begin{array}{l}\text { References to individual learning; improvement/transformation; professional growth (within the context of } \\
\text { practice) }\end{array}$ \\
\hline & Change of practice & $\begin{array}{l}\text { Perceptions of how practice has changed; how do we judge improvement/transformation of practice (as a } \\
\text { result of inquiry?) }\end{array}$ \\
\hline & Learning & References to individual learning - including activities, strategies, tools and processes \\
\hline & Professional growth & $\begin{array}{l}\text { Growth within professional/organisational context - in relation to role, including self perception of growth in } \\
\text { characteristics and dispositions }\end{array}$ \\
\hline Philosophy of practice & & Personal philosophy or values and beliefs about own role and practice \\
\hline Personal background & & Details of current or previous positions and roles \\
\hline Professional identity & & References to aspects of professional identity (e.g. agency, efficacy, confidence) \\
\hline
\end{tabular}


In order to assist with this process I developed an open coding matrix (Creswell, 2008) for each of the broad categories. The drilling down of categories was facilitated by the use of questions such as When? Where? How? and Why? (Rose, 2006). The broad categories were revised into four themes: Working with people; Rules, tools and routines; Individual: knowledge, action, being; and Inquiry process. Each broad category was sorted into sub-categories with properties and dimensions. Table 3.4 is an excerpt from the open coding matrix for Individual, knowledge, acting, being. 
Table 3.4: Open coding excerpt of categories and dimensionalised properties of EBIP

\begin{tabular}{|c|c|c|c|}
\hline \multicolumn{4}{|c|}{ Broad category: Individual, knowledge, acting, being } \\
\hline \multirow{2}{*}{$\begin{array}{l}\text { Subcategory } \\
\text { Dispositions }\end{array}$} & \multirow{2}{*}{$\begin{array}{l}\text { Properties/dimensions } \\
\text { Committed, risk-taking, } \\
\text { responsibility, openness }\end{array}$} & \multicolumn{2}{|c|}{ Dimensionalised examples } \\
\hline & & $\begin{array}{l}\text { Self assured } \\
\text { Courageous } \\
\text { Confident 'stroppy moo' }\end{array}$ & $\begin{array}{l}\text { Tentative, unsure 'In a quagmire' } \\
\text { Fearful } \\
\text { No confidence }\end{array}$ \\
\hline Professional identity & $\begin{array}{l}\text { Efficacy, Confidence, Agency, } \\
\text { philosophy }\end{array}$ & $\begin{array}{l}\text { Satisfied with practice } \\
\text { Sense of efficacy } \\
\text { Strong philosophical approach }\end{array}$ & $\begin{array}{l}\text { Sense of dissonance /dissatisfaction } \\
\text { Lack of efficacy } \\
\text { Philosophy not clearly communicated }\end{array}$ \\
\hline \multirow[t]{6}{*}{ Emotions and feelings } & Clarity of role/purpose & ‘I was very clear’ & 'We didn't know what we were doing' \\
\hline & Affirmation & $\begin{array}{l}\text { Affirmed by others facing similar } \\
\text { challenges (It's not an easy job) }\end{array}$ & $\begin{array}{l}\text { Self affirmed by 'finding ways that reflected who I } \\
\text { was and what I bring' }\end{array}$ \\
\hline & Confidence & $\begin{array}{l}\text { Lack of confidence to keep going at } \\
\text { times }\end{array}$ & $\begin{array}{l}\text { 'Being more courageous about what it is I think we } \\
\text { need to do and why we do it' }\end{array}$ \\
\hline & Approach and response to inquiry & Excited and nervous anticipation & Daunting \\
\hline & Safety & $\begin{array}{l}\text { 'I felt quite threatened' 'a constant } \\
\text { feeling of being insecure' }\end{array}$ & 'Quite happy to expose [practice]' \\
\hline & Dissonance / personal challenge & $\begin{array}{l}\text { 'We all have the same kind of } \\
\text { failure' 'It's quite a lesson really, to } \\
\text { listen to yourself' }\end{array}$ & $\begin{array}{l}\text { 'I crashed and burned' 'If I perceive that they're not } \\
\text { contributing ... I find that a real moral and } \\
\text { professional dilemma' }\end{array}$ \\
\hline \multirow[t]{3}{*}{ Learning and growth } & Change of practice & One or two isolated mentions & Embedded change of practice (as a habit) \\
\hline & Learning & $\begin{array}{l}\text { 'Became far more proactive in } \\
\text { seeking feedback from friends' }\end{array}$ & 'hard to teach an old dog new tricks' \\
\hline & Professional growth & 'Almost feeling disillusioned' & 'I am a professional' \\
\hline
\end{tabular}


The complete open coding matrix is included in Appendix E. The remainder of the interview transcripts were coded according to the revised broad categories, subcategories and property dimensions. In order to select the most noteworthy categories to take forward for further analysis, I also applied a quantitative perspective, and took cognisance of the quantitative significance of categories. Table 3.5 portrays the weighting of the coded references for each category.

Table 3.5: Quantitative significance of categories

\begin{tabular}{|l|c|c|}
\hline \multicolumn{1}{|c|}{ Broad category/ theme } & $\begin{array}{c}\text { Total } \\
\text { references } \\
\text { coded }\end{array}$ & $\begin{array}{c}\% \text { of } \\
\text { references } \\
\text { coded }\end{array}$ \\
\hline Working with people & 386 & 21.7 \\
\hline Rules, tools, routines & 313 & 17.6 \\
\hline Individual: knowledge action, being & 756 & 42.6 \\
\hline Inquiry process & 320 & 18 \\
\hline
\end{tabular}

The complete quantitative analysis of all coded references is included in Appendix F.

Berg (2009) asserts that both inductive and deductive approaches are relevant in analysis of grounded theory, although there should be an emphasis on induction. This stage also incorporated theoretical sensitivity (Strauss \& Corbin, 1998), where I consciously attempted to "read beyond local meaning" and develop categories that might reflect broader "sociological constructs" (Berg, 2009, p. 345) that come from the domain of knowledge of professional learning, as well as my knowledge of the field. In an attempt to reconcile theoretical sensitivity and avoid imposing preconceived concepts (Kelle, 2007), I refrained from engaging in broader reading until the final stages of open coding. I then referred to literature to obtain a theoretical perspective, thus incorporating a deductive aspect to analysis at that stage.

\section{Axial and selective coding}

Axial coding and selective coding are closely related. Axial coding is the process of systematically establishing the relationship between categories. It is the process of "putting together again in some way the data which have been effectively split apart into categories by open coding" (Robson, 2002, p. 494). Selective coding is the process of identifying a core category, placing it at the centre as the phenomenon, and relating all other categories to it (Strauss \& Corbin, 1998). Based on the models presented by Strauss (1987) and Strauss and Corbin (1990), a coding paradigm was adapted for this study (Figure 3.6) showing the interrelationships of the core 
phenomenon, wholeheartedness of becoming, with causal conditions (categories of conditions that influence the core category), strategies (the specific actions or interactions that result from the core phenomenon), contextual conditions (the specific conditions that influence the strategies), intervening conditions (general contextual conditions that influence strategies), and consequences (the outcomes of employing the strategies) (Creswell, 2008).

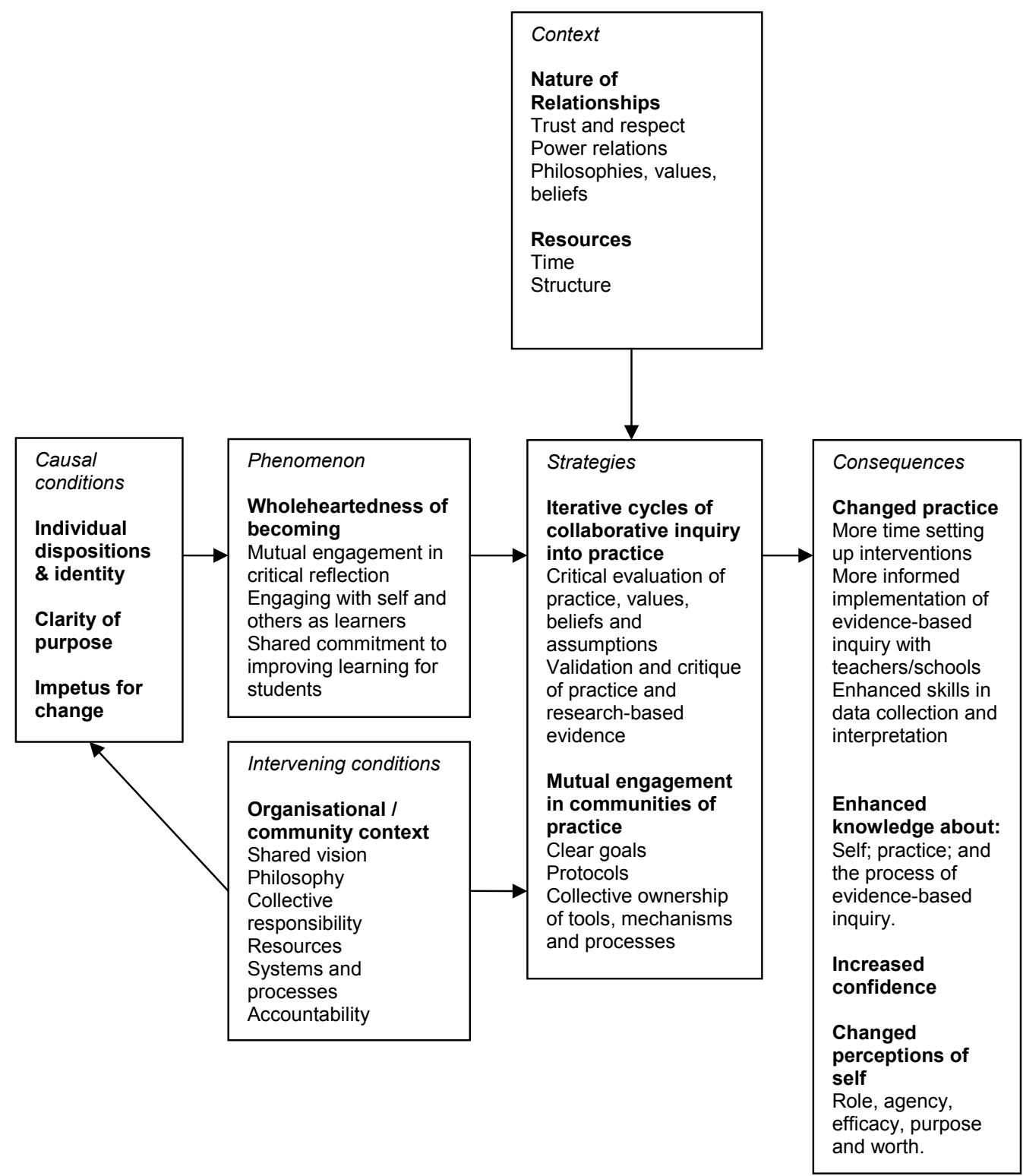

Figure 3.6: A coding paradigm for evidence-based inquiry into practice for inservice teacher educators

The purpose of the coding paradigm is to illustrate the way in which the main categories interrelate, and to locate the phenomenon "within a conditional structure and identify the 'how' or the means through which a category is manifested" (Strauss \& Corbin, 1998, p. 127). This enabled me to "relate structure with process" and "capture the dynamic and evolving nature of events" (p. 127). This process 
involved constant comparison of data by examining the categories and subcategories from the open coding process. In selective coding, the core phenomenon, wholeheartedness of becoming was identified, and all other categories were integrated within and around the core phenomenon.

During this stage, the key themes, which were derived from the qualitative data, were subsequently analysed using a variety of theoretical frameworks judged to be most appropriate to inform the phenomenon under investigation.

\section{Overarching theme}

Strauss (1987) provides a set of criteria for identification of a core category. It must be central with all other categories relating to it; it must appear frequently in the data with indicators pointing to the concept; the integration of all categories must be logical with no forcing of data; the description should be sufficiently abstract that it can be used to do research in other substantive areas; as the concept is refined, the theory grows in depth and explanatory power; the concept is able to explain variation as well as the main point made by the data.

The core concept of wholeheartedness of becoming satisfies these criteria. The many definitions of the term wholeheartedness convey a sense of commitment, determination, devotion, enthusiasm, sincerity and support, while the notion of becoming is used by Dall'Alba (2009) and others to convey the concept of transformation and growth:

A teacher is not something one becomes but rather something one is becoming. (Darling-Hammond \& Snyder, 2000, p. 528)

The ways in which the other key categories relate to the core phenomenon are illustrated in Figure 3.6. The stages in the development of the theoretical framework are illustrated in Figure 3.7. 


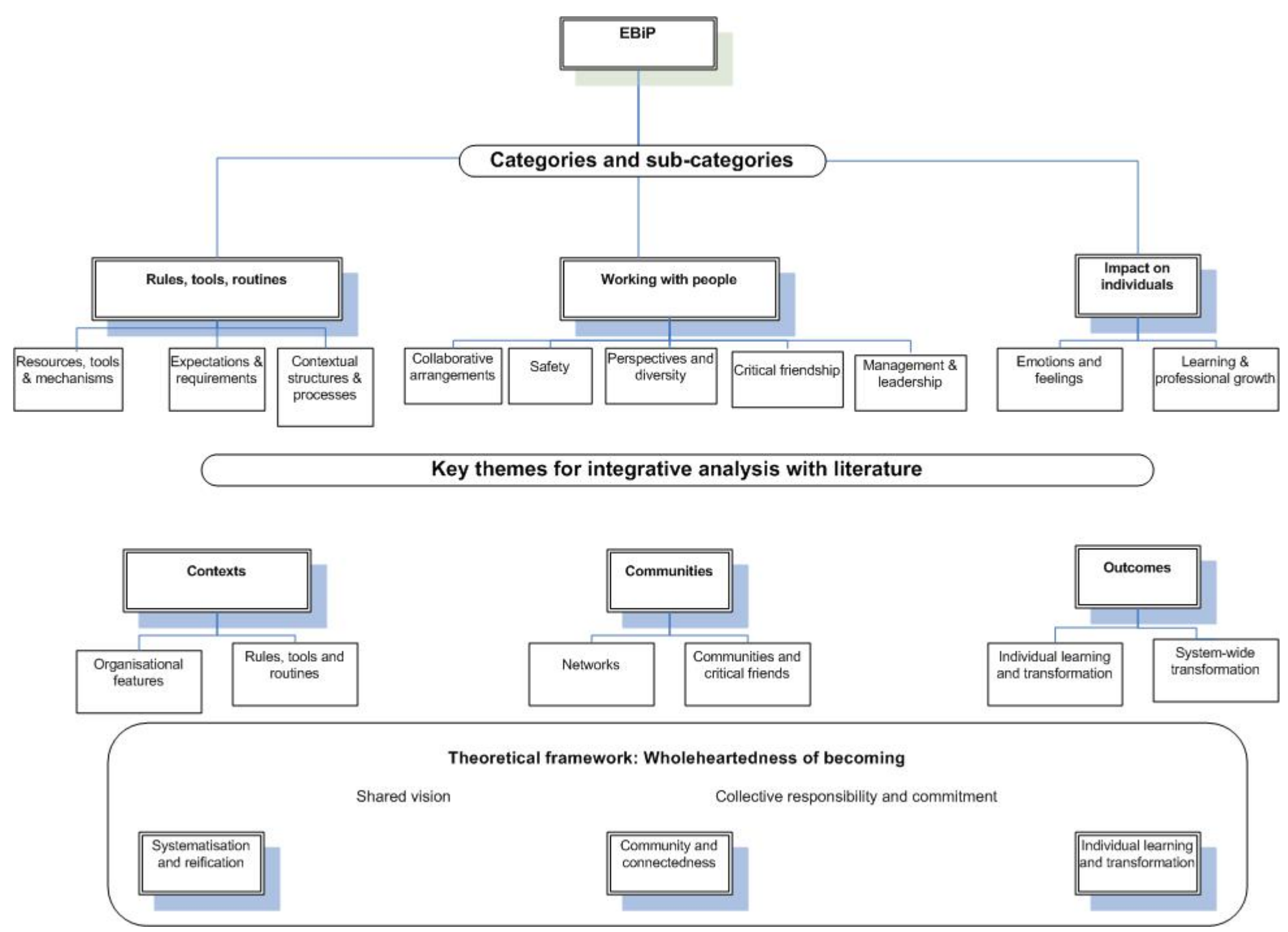

Figure 3.7: Stages in development of theoretical framework 
The phenomenon and the surrounding theory discussed in the concluding chapters of this thesis identify the ways in which the degree of wholeheartedness of becoming permeates and mediates professional learning and transformation through EBIP, whether the subject of learning and transformation is an individual, community, organisation or system.

\section{Theoretical frameworks}

The use of theoretical frameworks in grounded theory methodology is debated because of the emphasis on inductive analysis and rejection of the application of a predefined set of concepts to the data (Corbin \& Strauss, 2008). However, Corbin (in Corbin \& Strauss, 2008) asserts that the use of theoretical frameworks at various junctures can be helpful in extending and verifying findings, offering alternative explanations, and in providing insight and direction when developing theory. Within this study, while no theoretical frameworks were used in the inductive analysis in order to avoid imposition of preconceived concepts and categories, they were used after the initial inductive coding and analysis to help move the study "beyond the realm of the descriptive into the realm of the explanatory" (Bettis \& Mills, 2006, p. 68). Mills and Bettis (2006) describe the process and justification quite succinctly:

By working back and forth between the detailed data and the broader concepts of the framework, researchers and readers can highlight why the research can be relevant for other contexts and social settings. Qualitative researchers often talk about the continual comparisons and multiple iterations they perform with their data during analysis, but the theoretical framework is also part of this iterative process - the part that adds greater weight to the mundane data we gather and pore over. (p. 83)

In particular, while the theoretical perspectives of transformational learning (Dall'Alba, 2009; Land, 2010; Mezirow, 1990, 1991), and organisational and network theory (de Lima, 2010; Handy, 1981; Schein, 1980) enabled more in-depth analysis of data, the theoretical frameworks of activity theory (Engeström, 1987) and social learning theory (Wenger, 1998) were of particular value in integrating the contextual and interpersonal perspectives reflected within the data. These frameworks are used in the discussion of findings in Chapter 8 to enable the "intense, specific data collection and contextualized interpretations and conclusions to speak to broader issues and conceptual formulations" (Mills \& Bettis, 2006, p. 83).

\section{Chapter summary}

Case study and grounded theory methodology, with an emphasis on inductive analysis, was applied in this study to develop a theoretical framework for EBIP. The 
core phenomenon of wholeheartedness of becoming was identified and integrated with the other categories: systematisation and reification; community and connectedness; and individual learning and transformation. Theoretical sensitivity was evident with reference to theoretical perspectives and my own knowledge of the field. Theoretical sampling enabled identification of participants and data sources at different stages throughout the study to further inform some categories and provide greater depth of information.

The analysis progressed through three levels, incorporating stages of open, axial and selective coding, culminating in the development of a proposed theoretical framework for EBIP for inservice teacher educators.

For easy reference for the reader, a summarised list of participants and document sources is provided in Appendix M. 


\section{CHAPTER 4 \\ Evidence-based inquiry into practice}

\section{Introduction}

While chapters 5-7 report the findings from analysis of interview data, participant artefacts and document sources, chapter 4 illustrates the kinds of activities that the participants of this study (and of the INSTEP project) engaged in within EBIP. Drawing on the participants' interview and artefact data, and a range of document sources (denoted by square brackets to differentiate from standard references), this chapter describes some of the key activities that constituted EBIP. It is therefore designed to illustrate the kinds of contexts, evidence, criteria and processes that were experienced and used in EBIP. In the interests of protecting participants' identities, specific processes, tools and contexts are not directly attributed to study participants but referred to in a more general nature.

During data analysis, while categories were being developed, I prepared an individual profile of each participant. In order to present a personal snapshot of each individual, and their way of "being in the world" (Dall'Alba \& Barnacle, 2007, p. 681), I identified aspects of knowing, acting and being and presented these as the integral parts of the holistic self (Dall'Alba, 2005; Dall'Alba \& Barnacle, 2007). In the profiles, the following terms are used:

- knowing aspects of knowledge and theories of practice;

- acting the ways in which theories of practice, values and beliefs are enacted;

- being personal philosophies, values, beliefs and vision.

These 10 profiles were organised according to the emerging categories, and emailed to the participants as a means of member-checking my analysis and interpretation of interview data (Charmaz, 2006). The 10 profiles, therefore, give an impression of each participant's unique background, context and perspective. The profiles are provided in Appendix D.

\section{The process of inquiry}

All INSTEP participants were required to engage in EBIP within the context of their normal work with teachers, principals and schools. The process consisted of iterative cycles of inquiry represented in Figure 4.1 which builds on the cycle of 
inquiry for teachers and which was presented in the Teacher Professional Learning and Development Best Evidence Synthesis (Timperley et al., 2007).

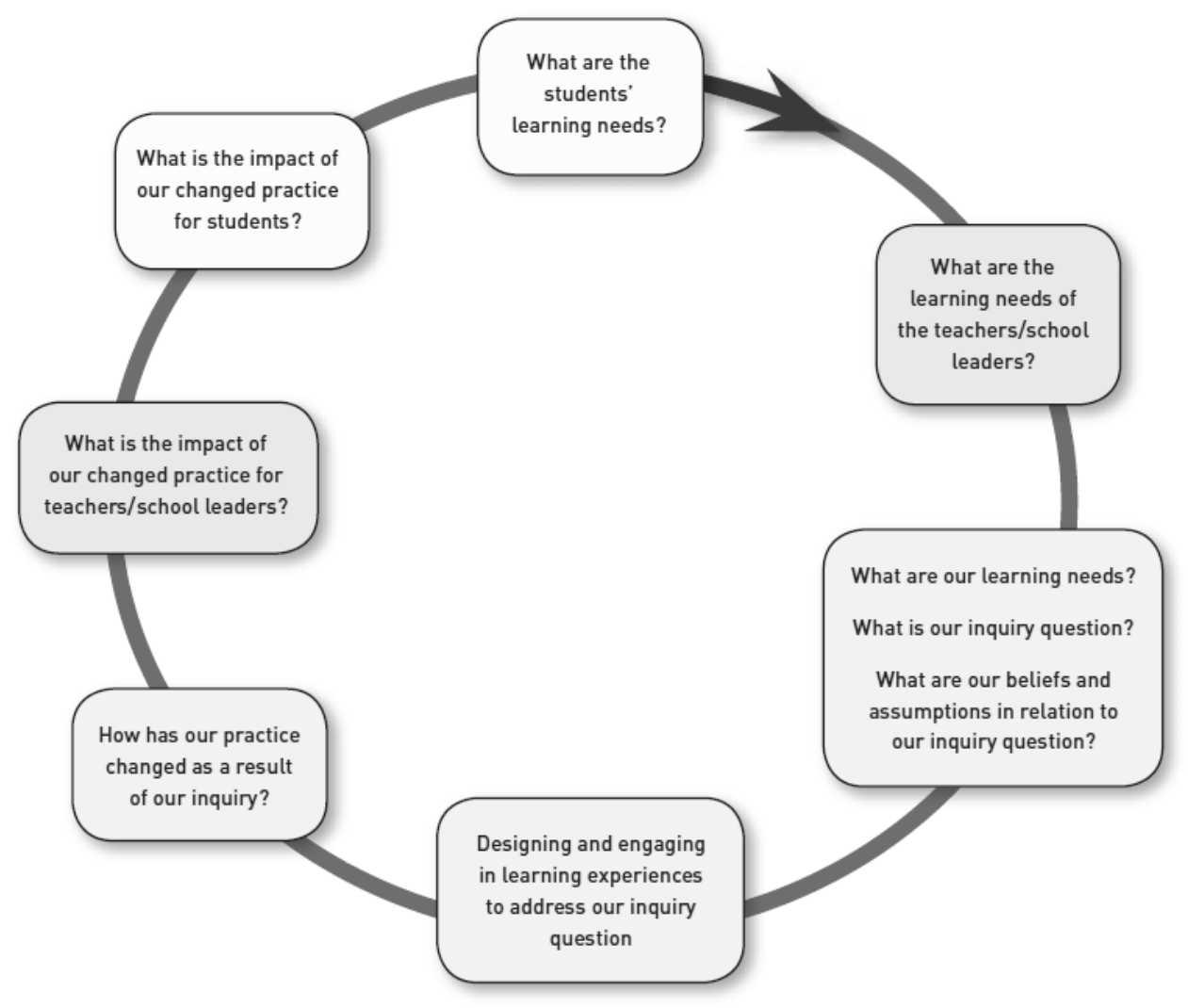

Figure 4.1: An Inquiry and Knowledge-building Cycle for Inservice Teacher Educators (Ministry of Education, 2008, p. 44)

The process incorporated identification of specific aspects of practice for investigation, collecting evidence of practice, and rthe impact of practice, collaboratively evaluating practice in the light of current research and theory, and surfacing values, beliefs and assumptions. Each of the NF groups developed their interpretation of the cycle and implemented it within their investigations. Figures 4.2 and 4.3 illustrate how two NF groups developed and used an action plan for inquiry for all ISTEs within the groups. Each of the action plans outlines a step-by-step process to guide ISTEs through inquiry into their practice. 


\section{Inquiry Plan}

Current statement/s or observation/s in relation to your personal values and beliefs. (Can be a general statement or a focus on a specific area.)

What aspect of your practice do you wish to examine?

Describe the context and methodology. (Stimulated recall; peer observation; transcripts...)

What evidence of your current practice will you bring to the next meeting? (Evidence should include

an artefact and some reference to theory/research which relates to the aspect of your practice.)

How will you prepare the artefact for the meeting with your critical friend/s? (Transcript/video excerpt; focus questions...)

What feedback did you receive from your critical friend/s?

How do you plan to act on the feedback?

Figure 4.2: Inquiry plan model [Document Source A (Lamont, 2011, p. 71)]

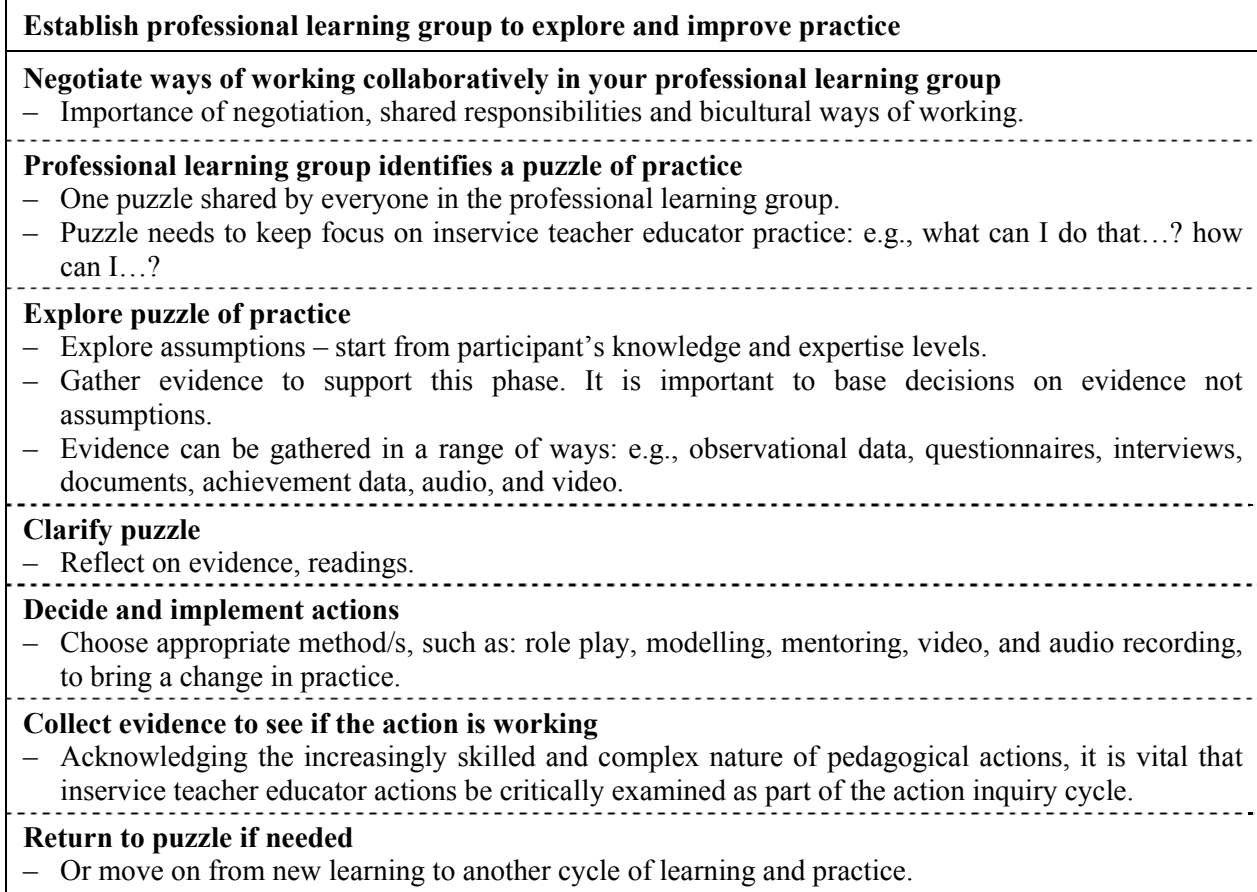

Figure 4.3: Overview of inquiry framework [Document Source A (McGee, 2011, p. 50)]

Due to the collaborative nature of inquiry, there was significant emphasis on the need for safe, risk-free collaborative environments for ISTEs to deprivatise practice and surface values, beliefs and assumptions. For most groups, there were explicit moves to develop shared protocols for meetings and interactions [Document Sources A, C (McGee, 2011; Mcllraith, Hope, Leslie, \& Pym, 2009)]. Some frameworks for protocols were based on the work of Stephen Brookfield (1995), Robert Garmston (Garmston \& Wellman, 1999) and Joan Dalton (Dalton \& Anderson, 2010). The next section identifies the aspects of practice which were the subject of EBIP for the study participants. 


\title{
Focus of inquiry
}

Some groups identified a collective puzzle of practice as in the professional learning groups in Figure 4.3, while others identified aspects of practice individually. For some ISTEs, identifying an aspect of practice was a challenge, as described in an excerpt from a progress report (Appendix G) which presents a transcript of a discussion among ISTEs in an attempt to identify an aspect of practice using a video clip. The ISTE, who was trying to identify an aspect of practice to investigate, is represented as $F 2$ in the transcript. She had some difficulty in identifying a problem with her practice when her colleagues could not suggest anything that could be improved upon, and considered it exemplary practice. In contrast to this, Anne identified her focus fairly quickly in her ISTE pod, when discussing a transcript of interactions with a teacher. She also found that she and her RTLB colleagues had similar problems of practice:

\begin{abstract}
We transcribed and we brought samples to our meetings and just discussed each other's ... conversations really ... a lot of us found ourselves doing all the talking in the conversations and ... asking questions and then answering them ourselves, - quite a lot of interrupting: that was one of my things. ... You know it's quite a lesson really to ... listen to yourself.
\end{abstract}

For the participants of this study the foci of inquiry were: learning conversations; being contextually responsive; relationships and interactions; feedback; and questioning. The next section describes some of the ways in which evidence of practice was obtained.

\section{Evidence of practice}

Study participants used a range of techniques to gather and present evidence of their practice to their peers including: video; audio; transcripts; observations; interviews with teachers; questionnaires; student voice and outcomes; journal reflections; and remembered stories.

The use of digital audio and video was fairly popular, although there were difficulties in becoming familiar with the technology. Subjects were challenged in becoming accustomed to being recorded, and then when viewing or listening to recordings. The following excerpt from an INSTEP report cited in Lamont (2009) describes the challenges:

The facilitator needs to be skilled in using digital media before attempting to record their interactions with teachers during professional development sessions. 
Relevant clips were selected, and edited. Facilitator skills in the use of the software, manipulation and management of large files are crucial, and take time to acquire. A training period was required.

Digital audio recorders enable smaller files to be collected. These are easier to manipulate, and less obtrusive during the PD session.

A range of transcription/analytical software is available and was considered, however time to become familiar with these was a barrier to their use.

Teachers readily gave permission to be recorded, but an element of selfconsciousness was noticeable initially. Some teachers repeatedly glanced in the direction of the camera and were reluctant to speak. Familiarity overcame these issues.

The facilitator was also self conscious. She was opening her practice for critique: a very revealing and initially, uncomfortable process.

The process of identifying what is relevant from amongst what has been collected is critically important and time consuming.

Phobias and fears were faced; the self consciousness of viewing ourselves on film was overcome. Hardware, software, digital audio, digital video, and close up inquiry are all now familiar friends. (p. 438)

Another group of ISTEs found that video-recorded conversations enabled a more accurate analysis than audio due to the ability to observe non-verbal cues [Document Source C (Mcllraith et al., 2009)]. Olivia noted the need for protocols for video recording in schools, including clarity around the ownership of the recordings, and privacy and confidentiality issues for students and teachers. Elaine also acknowledged her hesitancy in asking a group of principals if she could use video recordings, as she was aware of the sensitivities in such a group.

Transcripts of audio recordings were widely used. Some ISTEs had transcribing services while others transcribed recordings themselves. Olivia noted that it was useful for her to transcribe because it meant she paid very close attention to the recording, and therefore picked up the nuances. Evelyn noted that it is important to be selective about what you transcribe, otherwise you end up with far too much material. Careful selection of a smaller amount was more effective.

Elaine reported that remembered stories were used a lot in her organisation. Role play was then used to re-enact, evaluate and critique the situation. Handwritten notes of conversations were found to be effective by some, although it was difficult to give full attention to the direction of conversation while taking notes. Many, like Hannah, Anne and Olivia, used peer observation and feedback. Reflective journals were used by most participants. The following journal excerpt illustrates the power of journaling for self-monitoring of progress: 


\section{Reviewing the Video Recording}

It was time for me to finalise my notes, summarise my findings, write my report. I had videoed many of my regular meetings with the teachers I was assisting. Following each meeting, I would review the video and critique the development of my skills as an In-service Teacher Educator and my ability to implement the skills our group was working on. Along with this I would critique the power of the video as a reflective tool. I had already viewed this particular video, one of my most recent, and had rated the usefulness on this occasion as low. All the others had been high. Why the difference now? Time for another viewing. Had nothing of real importance occurred during this meeting?

I would watch with a more critical eye.

My previously recorded comments read:

The level of discussion was good with both parties contributing effectively. The ability to review did not provide new knowledge or insights, simply refreshed my mind, possibly clarifying decisions made. It served no more purpose than written notes would have achieved.

Yes, Low Value.

Now to view it once more, checking it against the skills I hoped to develop:

This meeting had flowed logically, clearly throughout. We had set and followed a co constructed agenda; there was no time wasting or deviations as we focussed upon our agreed task. We brought all our data together, explored possibilities arising from it and agreed upon a course of action. We established each person's role in the process, I summarised and confirmed our agreements; even remembered to take along some papers I had been asked to share!

I critiqued my skills as a communicator - "Did I interrupt? No. Did I slip into teacher mode and provide the answers, impose my views? No. Did I offer suggestions and remember to check in - and allow time for thoughts in response? Of course I did! I had even been honest and open about something I had felt uneasy about - that used to be hard for me to do. What about my listening skills? Seemed pretty good to me. This new viewing had shown me what I had already thought - it was an effective meeting and we had both gone away from it feeling ready to move on to tackle our assigned tasks.

So like I said - The video recording had served little purpose that time - it had just been an accurate recording of what had happened.

\section{AND WHAT HAD HAPPENED?}

YAHOO!!!!

This meeting had gone so well that I had thought there was nothing to be gained from the review! Why had it gone so well? - Because of the empowering skills I had developed. This video affirmed for me the effectiveness of the model I had been working on.

Let's change that rating! - From Low to SKY HIGH!

Sometimes you can overlook the good because you are so busy looking for the bad! (Report to Ministry of Education_1, 2007, P. 36-37)

Alison obtained feedback from teachers about a series of workshops by asking another ISTE to interview the teachers afterwards and take notes. Her focus was on being contextually responsive as opposed to practising design adherence. After exploring the meaning of the two terms with the teachers, the teachers were interviewed and the results analysed (Appendix $\mathrm{H}$ ). She considered it crucial to 
share her inquiry with the teachers and make her intentions very explicit. Student voice was obtained informally by talking with the students. Data on student achievement were used consistently by ISTEs. Alison observed that student achievement data were the most significant for her in terms of evidence:

Oh the most value ... was the student outcomes ... the difference we made to kids' achievement. It was phenomenal, and we actually had to get external people in to double check because we didn't think it would be that good and it was just mind blowing differences to the bottom group not just to the top group but - yeah and sustained. Like we've got four years of data, we've followed kids, so you know - sustained.

Hannah, Evelyn and Theresa all explicitly referred to gathering student achievement data. However, it was acknowledged within INSTEP that sustained improvement takes time, and that there were many other factors impacting upon teacher practice and student outcomes [Document Source D (Sankar, 2009)]. Within the short timeframe of INSTEP, therefore, key sources of evidence consisted of evidence of ISTE and teacher practice. The next section presents some of the analysis tools and frameworks that were applied in order to critically reflect on practice.

\section{Evaluation of practice}

A variety of frameworks, rubrics, schemas, and other analytical tools were used to monitor and evaluate particular aspects of practice. Some were developed by individuals or in critical friend pairs within the context of individual inquiries. Others were developed across organisations. The use of stimulated recall (Polio, Gass, \& Chapin, 2006) (using video to recall ISTE and/or teacher practice) was found to be of value in working with teachers, as well as to review ISTE practice. ISTEs described the ways in which feedback was focussed when reviewing audio and video recordings. Aroha's group used a basic framework of questions from the INSTEP project when viewing video:

We use the INSTEP framework the - What do you notice? What do you understand and what might you do differently or carry on doing and why? And the other question we often ask is - So how do you know it's effective?

The framework was based on the work of Paulo Freire (http://www.freire.org/). Another ISTE devised a series of questions (Figure 4.4) to focus attention on specific aspects of practice when listening to audio: 
1. Listen to the tape and notice the language I use:

i. Is it inviting?

ii. Am I giving him 'room' to answer my questions?

2. Listen to the tape and notice the questions. Pair Share:

i. In what ways are they concise and well worded? Offer suggestions for improvement.

ii. In what ways do they provide opportunities for the principal to respond?

iii. What openings are missed?

3. Listen to the tape and notice missed opportunities for challenge.

4. How might these be rectified?

Figure 4.4: Audio recording prompts [Document Source A (Lamont, 2011, p. 75)]

This means of focussing attention ensured that relevant aspects of practice were observed. Another pair of critical friends devised sculptural transcripts as a way of analysing conversations to illustrate the ways in which statements or questions opened up or closed down conversations. The sculptural transcript is a coding system for representing the development of dialogue by using visual representation of coding and indentation. An example of this visual portrayal of a conversation between an ISTE and a teacher is included in Appendix I. Methods of quantitative analysis were also applied within this particular pod to investigate common threads of interactions. The examples in Appendix $\mathrm{J}$ portray another means of analysing conversations. These examples illustrate the way in which a) a subjective/objective analysis of a transcript led to teacher learning; and b) a transcript of an intervention was the subject of reflection by a pod of ISTEs. The structure of the transcript analysis tool was informed by Annan, Lei and Robinson (2003).

An example of the way in which role play was used can be seen in learning case 3 in the INSTEP resource, Ki te Aotūroa [Document Source B (Ministry of Education, 2008)], where an ISTE and her colleagues "use role play and analysis of dialogue as tools to reveal the interpersonal model informing and guiding the interaction and to shape and practise a more effective model and approach" (p. 33). The role play model and approach is drawn from Argyris and Schön (1974).

Dalton and Anderson's (2010) work informed the development of the analysis framework in Appendix $\mathrm{K}$ which illustrates the ways in which ISTEs structured teacher feedback to gauge the balance of control of empowerment within an intervention. Other frameworks were also cited which were informed by Guskey (2000, 2002), Glickman (1981), Atkin (1996), and many others.

Some organisations developed frameworks and analysis tools to be used throughout the organisation for professional learning and appraisal. These were informed by the INSTEP principles of effective inservice teacher educator practice 
and the proposed theory of improvement (Ministry of Education, 2008), the New Zealand Teacher Council's registered teacher criteria, as well as many other sources. An example of such a framework used for professional learning and appraisal is provided in Appendix L. Study participants emphasised that these frameworks were a work in progress and were being continually reviewed and revised.

The participants' use of research and theory in EBIP is presented in the next section.

\title{
Research and theory
}

It is clear from the above examples that research and theory were used throughout EBIP to inform practice and critical reflection. Study participants valued the support from INSTEP NFs and RFs, and from the national management team in terms of providing recent and relevant references, and making them accessible. Eva expressed the integral nature of research and theory in her inquiry:

\begin{abstract}
It was absolutely up there because ... everything that I read influenced my design so when I started reading Carol Mutch and going about the process, when I started reading about her, what was it self... what did she call it... wasn't valuing self... something something self that she... and we went to the hui and it was in there too and she talked about it as well and that was absolutely key to my whole thing of that values and belief questionnaire that whole thing of the positioning of the teacher in the centre of their practice to look at what they are doing all those things. I think the Brian Annan and Lei reading around teacher talk - that gave me a framework to look at ways of identifying the talk within a conversation and how do I get to challenging talk so I think that was absolutely vital. I think that there were readings that I did around observations and I organised groups around that reading to frame it so all the reading I did helped me frame my thinking and helped... I thought well this is a researcher that's done this, this is proven, so therefore if I know this is proven I can build on that and take it forward in doing this and everything that I did was absolutely embedded in research reading.
\end{abstract}

Study participants reflected that they were now more inclined to source readings for themselves and use them with teachers. Hannah reported that the INSTEP resource (Ministry of Education, 2008) and the Teacher Professional Learning and Development Best Evidence Synthesis Iteration (Timperley et al., 2007) provided a wealth of readings and references that were used within professional learning groups in her organisation, and with teachers. Laura expressed the value of attending conferences and identifying related readings, while Evelyn reported using different strategies to explore readings with teachers. 


\section{Values, beliefs and assumptions}

Study participants acknowledged that learning and professional development through EBIP involved surfacing values, beliefs and assumptions. The collaborative engagement in the development of analysis frameworks and tools was in recognition of the need to obtain different perspectives and an objective approach to practice. Pods of ISTEs and critical friends acknowledged that they supported others by challenging practice, and were supported by being challenged about their own practice.

The complexities and implications of such an environment will be discussed in later chapters. The purpose of this section is to clarify the process of exposing the tacit nature of the participants' practice. Many INSTEP groups developed specific tools and strategies to support ISTEs in the articulation of their espoused theory - what they think they do (Argyris \& Schön, 1974). Then, when objectively analysing evidence of practice, the theories-in-use - what they actually do (Argyris \& Schön, 1974) - became evident. The espoused theories and theories-in-use were then considered and efforts made to align the two. Olivia explains how Julia Atkin's (1996) work provided support for such an activity:

I try to share as the training was going on, information and articles and I think one in particular they all found quite interesting was Atkin's circle and so we were all looking at our values for these principles in practice and how they aligned or didn't.

Anne also acknowledged the importance of "establishing what your values and beliefs are and then looking at whether the way you're working fits in with those". Most INSTEP groups addressed this explicitly with particular tools and strategies. For example, Atkin (1996) also informed the development of a questionnaire (Figure $4.5)$ in another group which was designed to help ISTEs articulate their values and beliefs. 


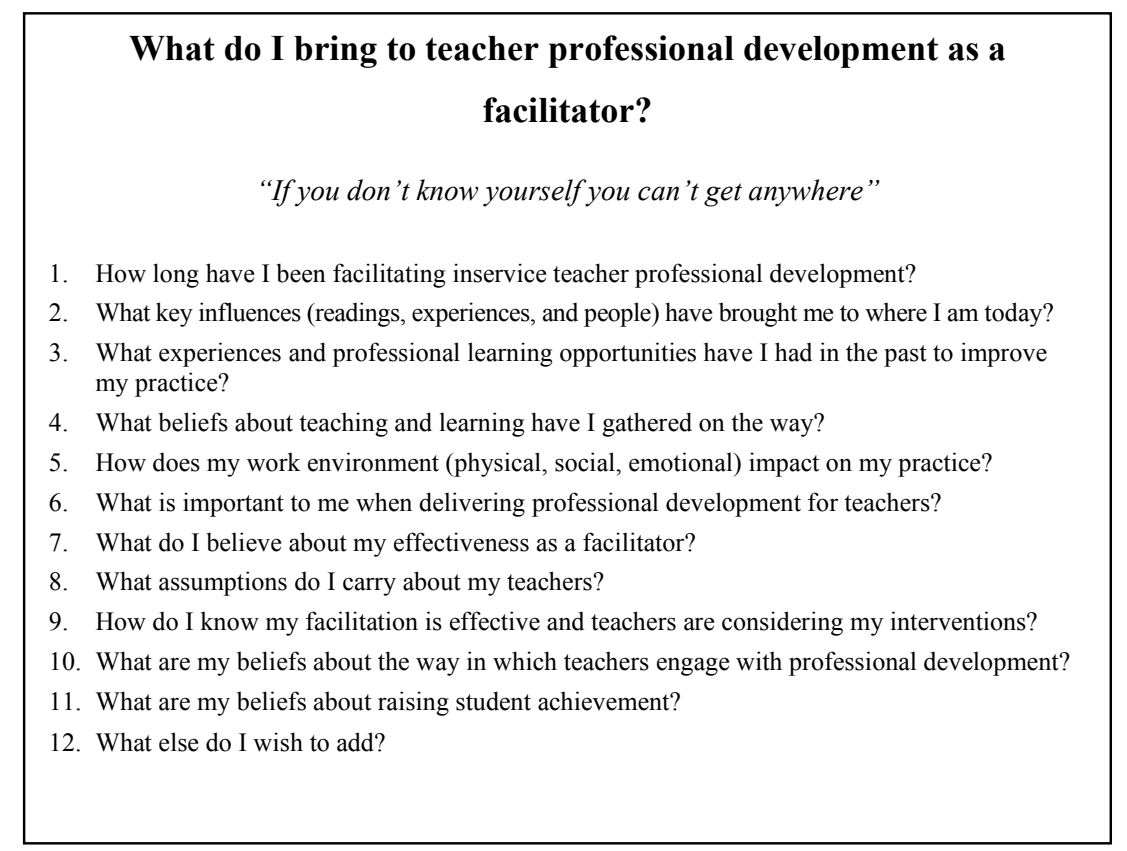

Figure 4.5: Values and beliefs questionnaire [Document Source A (Lamont, 2011, p. 70)]

Most study participants made reference to the importance of this process for teachers they were working with, and mirrored the same tools and strategies in their work in schools. One ISTE investigated the convergence of her ISTE pod's values and beliefs with those of the teachers she was working with. She found that neither made explicit reference to student learning outcomes. The findings are summarised below:

\section{Findings of this case}

Stella's research into her practice began with a personal inquiry into her values and beliefs. She shared these with her pod then took the question to 24 lead teachers. In her analysis of the similarities and differences between her values and beliefs and those of her teachers she found common threads. What was conspicuous by its absence was an articulation of student outcomes. This caused Stella to revisit her core belief that this premise underpinned her work.

What she found was:

- Across schools there is a similarity in teacher beliefs and values even when teachers were expressing these individually.

- When analyzing data sometimes what is significant is what is not there.

- At times the most important features of our practice are so firmly held we do not realise that we have to make them explicit in our delivery.

- References and links to student achievement need to be made explicit in workshop delivery

- The process of inquiry is a complex and winding road. Stella's findings grew from the larger picture and took her full circle to her initial idea linking her work with student achievement. 
- Emails were an effective way of being a critical friend, negotiating shared understandings and of having a record to trace the process

- There is value in making work with teachers transparent, explaining purpose and giving clear feedback.

As a result of this work Stella challenged the ISTEs around their focus on student achievement. She conducted a word search of a transcript of an ISTE meeting (20/4/07). This revealed that, out of 24,204 words student/s, child/children were mentioned 39 times; outcomes/achievement 7 ; teachers 119; and practice 64 times. This data could form the basis of further investigation. (Report to Ministry of Education_2, 2007, appendix H_3)

This investigation uncovered deep underlying assumptions on behalf of ISTEs and teachers, and resulted in more specific explicit attention to student learning outcomes in the professional development programme.

Surfacing values, beliefs and assumptions was integral to EBIP for ISTEs. Each of the study participants had an expectation that they would be challenged to align their espoused theory with their theories-in-use. Most of them had explicit tools and strategies in place which were designed to expose incongruities which were then addressed within collaborative, supportive environments.

\section{Chapter summary}

This chapter has given an overview of the tools, strategies and processes that study participants engaged in within EBIP. Most INSTEP groups developed explicit tools and mechanisms to identify a focus of inquiry, gather and critically analyse evidence of practice, and reframe their values, beliefs and assumptions with reference to research and theory. The rigour of the tools and mechanisms, combined with collaborative engagement in the process, helped ensure a degree of objectivity, with the necessary support and challenge. The following three chapters will report the findings from the key themes identified in the data analysis. The themes are: rules, tools and routines; working with people; and impact upon individuals. 


\section{CHAPTER 5 \\ Rules, tools and routines}

\section{Introduction}

This chapter reports on the operational contextual factors that mediated EBIP for participants. The category rules, tools and routines encompasses operational structures and processes, formal and informal expectations and requirements, and the resources, tools and mechanisms available to participants. The chapter will be reported in two phases: The INSTEP inquiry experience will report findings for factors which impacted upon individual participants' EBIP within the INSTEP project; and Beyond the boundaries of INSTEP will report findings for factors impacting upon individual participants' (and potentially other facilitators') EBIP external to, or since, the INSTEP project.

\section{INSTEP inquiry experience}

\section{Contextual structures and processes}

The inquiry approach embedded within INSTEP, combined with the management structure of the project, resulted in individual ISTEs being scaffolded by a variety of structures and processes to conduct collaborative EBIP [Document Source A (Baskerville, 2011; Lamont, 2011; McGee, 2011)]. These included series of meetings and interactions between and among NFs, RFs and ISTEs which all provided time and opportunities to discuss readings, share and reflect on practice, and provide and receive structured feedback.

Eva emphasised the benefits of building in "structures and processes that facilitate certain things along the way", and the value of the explicit nature and formalisation of the process of collaborative EBIP. She reflected on her INSTEP experience:

I think that the collaborations need to be formally organised. I know that they do happen but they happen on a very low level. But I think ... to take you right up there I think they have to be formally organised, that's what I would say about the process. I don't think that it's something that just happens coincidentally, I don't think it can. It was the formalisation of that [INSTEP] project that enabled us to go forward.

Eva valued the choice within critical friendships:

a choice as to who you align with or don't align with, because that emerges from the inquiry and it's something that we have to trust [to] emerge from the inquiry. 
She believed that alliances would emerge because of the conscientious professionalism of facilitators. Eva particularly valued the opportunity to develop a critical friendship with another RF, and is now clear about building in opportunities for critical friendship in her work. She also reported that it was crucial to set up rules and routines at the beginning of the collaborative process:

We took the time to set up those practices and protocols and rules, and we took the time to discuss those and identify them as a way of working, and agreeing to be willing and ready to work in that way.

She also valued the two levels of collaboration: the group of RFs and the one-onone critical friendships with the NF and one other RF. The meetings served different purposes:

So for example we'd have our whole group meetings ... all the RFs and [the $\mathrm{NF}]$ and in that time we would be looking at ... bigger picture stuff in a way, we'd be looking at the ways of working, ... a discussion around particular people's practice, or you know looking at something with a specific focus; whereas when I worked say with [the NF] on my own to discuss something or with [the other RF] I was looking at details within that. So for example it might be that I was looking at the values and beliefs questionnaire so I ... [took that to the NF], we nutted it through and then I took it away to work on it. Whereas the discussion in the bigger group in the RF pod would be around critiquing that, so it was like I was doing my designing if you like and the implementation within those smaller discussions and then the reflection and critique within the bigger group.

Evelyn valued the clearly articulated framework and purpose of INSTEP, within which there was flexibility and "licence to be as creative as you want it to be".

Aroha confirmed that her INSTEP pods agreed on protocols for group meetings, with clear guidelines for "the way the group works" because "we all agreed if you were going to start to look at practice you needed some kind of guidelines and some rules because otherwise it would just be a shambles, or people would get really defensive".

Hannah emphasised the importance to her of "the agency of choice and direction" which was afforded to her within a structure and framework. However, she also highlighted the need for such a structure and framework to be relevant to her day-today work. She valued the mechanisms and "structured time" available within INSTEP:

That was what made the difference for us. We had a structure within the learning group, we had structured tools that we were trying to work with and there was a focus, there was a real focus on the inquiry ... And I think we were modelling the things that we actually expect teachers to model. 
She observed that the deprivatising of practice and the surfacing of values and beliefs "was most evident in the very early phase of INSTEP" due to the systematic and structured approach, where there were "specific targeted activities to actually surface assumptions, beliefs and values".

Laura described the process her NF implemented with her INSTEP RF group in the exploration phase, which she later adopted with her own group of ISTEs. She considered that some aspects of management and organisation of meetings were crucial to the process of EBIP:

We had a process [in Phase 2] that was established by [the NF], and then I basically just lifted up that same process and applied it to the pod that I had been with [in Phase 3]. And that includes things like the times of meetings; the duration of the meeting. I always kept notes of what had happened at the meeting and mailed them out immediately, and with where we were going for the next meeting; what was required for the next meeting ... like a nurturing type contact with them all, and I felt that if I did that ... it just kept the whole thing moving. And from that point of view, it helped to keep us all focussed as well. And we knew where we were going.

She attributed the success and longevity of another community of practice to the fact that she used the same process as with the INSTEP pod:

I've used a lot of the same techniques that we've used in INSTEP ... it's exactly the same, because once you've got a model that works for a community practice, you know, you can bring it into another setting.

Anne and Olivia both valued the structure and regularity of the INSTEP pod meetings. Olivia referred to the INSTEP EBIP process as "the training", and she described the benefits:

That whole framework thing. It's like lots of things. Sometimes you need a model given to you to begin, so you know what it looks like then you can start making a few changes if you want - but initially ... when you learn anything new it has to be a good structure otherwise there's nothing - I think [the tutor] in our [RTLB] training always talked about: 'You can be given baubles but if you've got no tree to hang it on they're no good to you' ... it's a bit like that. The tree was really important and then you can start adding all those little things onto it later, but the regular getting together, the whole process that we went through, the devising of our question. Our question was to ask what a reflective practitioner is, so we knew what we were looking at, and that was a focus that all of us wanted to have in our group. So yeah the [INSTEP] training was brilliant and ... people need to really understand it.

She particularly valued "being supported; seeing it modelled; access to literature; training if you can access that; ... looking at your cases, and if they are not going how you want them to go, you know analysing it [with] somebody". 
Some participants reported that having a clear and shared vision of the purpose and nature of the INSTEP project helped them to locate their EBIP in the big picture. Evelyn, Eva and Alison reported a clear understanding of the purpose, roles, and protocols for ways of working within the INSTEP project, but did not comment at all on a wider organisational commitment to EBIP. Evelyn valued the clarity of the rationale and context of the INSTEP project: "Once you have established your fine minutes or hours or whatever you need ... going from the big picture. That's what [the NF] did: 'This is why we are doing [this]' - the purpose."

Eva believed that the ISTEs who came on board in Phase 3 had an advantage over the RFs in Phase 2, due to the development of the process by the RFs, and the clarity of the purpose of EBIP:

\begin{abstract}
They had that wonderful opportunity to look at us and the de-privatising of our processes when we presented our work to the [other] facilitators [in our organisation]. You know that was the key of it. They understood more so than we [RFs] did at the beginning, because they saw our process. We did [2 presentations] for them that [were] around our design of tools and things, so they had a much easier view of it than we did because we were invisible. We had nothing there. We didn't know what we were gonna decide and we didn't know how we were gonna to go about it. We ... designed the process; we lived the process, we presented a process to them that they might like to go through. So I think they actually were far ahead of us when they came into it than we were.
\end{abstract}

Both Olivia and Anne referred to these processes and structure as the "training", and considered that the shared understanding of the nature and purpose that was conveyed within the INSTEP "training" was crucial for them to take ownership and responsibility for collaborative EBIP.

In summary, The INSTEP project was designed and implemented in such a way that there were very clear and specific goals to be achieved by all INSTEP participants within a timeframe of clearly defined events and procedures. Participants valued the clear and explicit focus on EBIP, including the formalisation of a clear process for inquiry, agreed protocols for interactions, the regularity of, and explicit rationale for meetings, and a structure for collaboration at different levels. However, choice and flexibility were also valued: the choice to implement inquiry in an appropriate way for each pod and individual; and the freedom to choose critical friends.

\title{
Expectations and requirements
}

Each participant's EBIP was impacted upon by the immediate context and focus of the INSTEP project. The main focus of INSTEP ensured that all research 
participants had an expectation and requirement to collaboratively inquire into their practice within the INSTEP pods [Document Source D (Sankar, 2009)].

For all participants there were specific explicit expectations and requirements from each of their INSTEP pods. Alison reflected that she appreciated the deadlines and strict timeframe:

I like deadlines. I like knowing that this is due then and so having that - 'cos it could have been quite fluffy, it could have got lost. But having deadlines, having expectations, having requirements: ... it was diarised; it kept it ... on top.

She also indicated that having a great deal of respect for the RF was an incentive to meet the deadlines: "Our mana for [the RF] meant we just did it even if, you know, you were a bit sort of stressed getting it done we just did it".

Aroha reported that there was an expectation that all INSTEP participants in her organisation would transcribe video and share it with the pod. Anne cited expectations of "being prepared and having read articles and completion of any required tasks prior to meeting, for example, watching video clips and contributing to discussion" within her pod. Similarly, Laura reported that "the discipline for each meeting [was] you had to bring a problem of practice ... and you shared that with your group".

Anne recalled that being obliged to document her work in INSTEP had resulted in a greater awareness of the need to document her learning and development:

\begin{abstract}
We each had to do a case study and, you know ... I made sure I got everyone's comments and views on how things have gone and ... found out what the teacher's beliefs and attitudes and practices were, it was more because it was a case study for a project I was on, ... it was all documented. So I think probably the biggest difference is that I perhaps don't [now] document things as much as I did when I was doing the project but I do find that l've got a lot more to actually report on when I come to do my reports because l'm more aware of all this stuff.
\end{abstract}

She believed that the documentation at the initial stages of inquiry within INSTEP took her to a different level of practice:

Once you've recorded it all and documented it all initially - to look at what's there needs to be brought out of it - but then once that awareness is raised then you're practising at a different level probably ... it becomes about more now the way I work rather than something that I'm focussing in on too much. It's become more part of my practice.

The structures and processes outlined in the previous section incorporated an array of formal and informal expectations and requirements that participants were subject to within their EBIP process. Participants understood that they were expected to: 
meet deadlines and adhere to timeframes; document their inquiry process; share, and give feedback on, evidence of practice with peers; comply with agreed behaviour and protocols for meetings and interactions; and prepare for, and contribute to, meetings and discussions. In some cases, clarity and understanding of purpose promoted ownership of, and responsibility for, the process of EBIP, enhancing self-monitoring of goals and progress.

\section{Resources, tools and mechanisms for inquiry}

Access to resources impacted upon the ways in which participants conducted inquiry. NFs, RFs and ISTEs within the INSTEP project each had a specific allocation of funding for their time over the duration of their involvement in the project. They also had access to other resources from within their particular organisational contexts. In Phase 2 each of the NF pods developed their own approach to Phase 3 [Document Source A (Parsons \& Higgins, 2011)]. This included the exploration of potential tools and mechanisms ISTEs adopted to conduct systematic and rigorous EBIP. This section will report on resources, tools and mechanisms valued by research participants during the INSTEP project.

\section{Resources}

All research participants acknowledged that the availability of particular resources supported EBIP within the INSTEP project. The most common resource cited was time. Eight participants stated that the allocation of time was particularly beneficial. Alison's perception was that the time allocation "didn't really work in advisory" due to the constant and ongoing demands of working in schools, but that "didn't matter" because her pod "made a commitment to do it". Eva reflected on the importance of time allocation within INSTEP: "Time allocation was key; absolutely vital; the fact that there was time out for us to reflect was absolutely stunning; [a] totally privileged situation and greatly appreciated ... [within] the project".

Olivia appreciated having more time with teachers, but was aware of the need to "make it count". She appreciated the "time and space to do the in-depth questioning about what you're doing and why, and how effective it is". Laura highlighted the importance of having the time to obtain different perspectives on aspects of practice:

I keep coming back to that time thing. Sometimes we just need time to think it through and I think probably there are situations where one doesn't have the amount of time - and that's where you feel insecure: when you haven't had time to look up something or look at it from several points of view. 
Evelyn valued the "paid time" within the project, but, like Alison, acknowledged that she and her peers "did far more than we had allocation for".

Anne, Elaine and Eva all stated that easy access to audio and video recording equipment was valuable in terms of their INSTEP inquiry, while Eva made particular reference to the merits of having audio recordings transcribed, and having technological support readily available.

\section{Tools and mechanisms}

There were a variety of tools and mechanisms which were used at various stages, and for various purposes, in participants' INSTEP inquiries. They were used to: gather evidence; surface values, beliefs and assumptions; and share and evaluate practice.

All study participants used some combination of audio, video, transcripts and observation to capture evidence of practice. Elaine reported using video and/or transcripts, or simply remembering a situation and trying to re-create it using role play. Eva used video and stimulated recall with her peers and with her teachers. This provided a means of recalling and reflecting on events through the use of video recordings.

Seven participants reported the use of tools and mechanisms, such as questionnaires, interviews and computer applications to ascertain student or teacher voice. For example, Eva used a questionnaire to surface values, beliefs and assumptions. Her values and beliefs questionnaire, which was informed by Atkin (1996), originated as a tool adopted within her personal inquiry, but was further developed by her pod of RFs to be used with all ISTE participants during Phase 3 of INSTEP. Other mechanisms cited for gathering evidence were peer observations, teacher/student interviews, and learning journals.

All participants referred to using some form of framework or schema against which they could evaluate their practice and make a judgement on progress or improvement. Both Laura and Anne developed frameworks, based on Glickman (1981), to analyse their conversations with teachers, while Hannah's RF pod developed a framework of criteria as a tool to situate levels of ISTE practice. Similarly, Elaine's RF pod developed a schema to help "break down our practice into more criteria". This acted as a launch pad for the organisational development of a "different set of tools to look at our practice in different ways". 
Eva analysed her conversations with teachers, using a framework for critical reflection. She also used a system of focussed questions with her videos of practice to elicit feedback on different perspectives of her practice from colleagues acting as critical friends. Eva's values and beliefs questionnaire, along with video evidence, enabled close examination of her espoused theory and her theory in use:

The key for me was: is this actually what's happening in practice? So it was like what I called at the time my espoused theory - what I thought I was doing, and then actually looking at practice and seeing if that was what I was doing.

Eva transferred this process to her work with teachers in Phase 2:

Now I had 5 teachers to work with, so I was working with some frameworks to help us look at their practice, but in fact it was me helping me reflect on mine as well. ... So I used ... some readings, and made frameworks to ... help me to analyse my work. I used video recording and I used a questionnaire around values and beliefs and identified what the teachers valued and believed in the classroom, and then we looked at the concordance between that and their espoused theory and then recorded the conversation on film and then looked at it and to see if their theory in use actually was congruent with that espoused theory.

Aroha also reported analysing videos of practice with her pods. They modelled their analysis framework on an assessment tool, which was informed by the work of Paulo Freire (http://www.freire.org/paulo-freire):

\begin{abstract}
I think it was originated from Freire but we used the maths assessment tool for starting to give us some guidelines around looking at the video. You know - when we were starting to develop a framework and we used those words - What do you notice? What do you understand by what you are noticing and what might you do differently or change as a result of your understanding?
\end{abstract}

Theresa commented on the value of the analysis framework she used with her colleagues: "we all had a shared framework under which we were working, and we could give each other feedback against that". Elaine valued the explicit nature of the frameworks that she developed within INSTEP:

That's probably the other thing that INSTEP's done for us probably as we've, you know [our senior manager] would always talk [theory] but we actually in our job we developed that framework which ... for good or bad, really - we spent two and half years sharpening that up ... and for me that really allows you to kind of analyse your practice against something. Whereas before we had to ... [analyse it] against what's in [our senior manager's] head because we didn't have enough of it ourselves.

Hannah reported that she was using a framework of criteria in the aspect of leadership to evaluate her practice as a leader of professional learning. The framework was informed by Robinson's (2004) work, and by the Best Evidence 
Synthesis on leadership (Robinson et al., 2009). She also obtained feedback from managers and teachers on aspects of her practice. Hannah perceived that the framework of criteria was instrumental in focussing EBIP: "We had a structure within the learning group, we had structured tools that we were trying to work with and there was a focus, there was a real focus on the inquiry".

In summary, the key resource that participants valued in INSTEP was time: to critically reflect on practice; to explore different perspectives; and to spend with teachers. Accessibility of audio and video equipment was also valued, as was the facility for transcription.

Participants valued the tools and mechanisms that helped to make aspects of practice and espoused theory more explicit, and that facilitated their monitoring of changed and improved practice. Tools included video, audio and transcripts. Mechanisms were developed to: gather student and teacher voice before and after interventions; systematically and rigorously monitor and evaluate practice; and aid critical reflection and dialogue. Tools and mechanisms were acknowledged to be underpinned and informed by related research and theory.

The remainder of this chapter will report on rules, tools and routines that were located within the broader organisational, social and political contexts as opposed to specifically within the parameters of the INSTEP project.

\section{Beyond the boundaries of INSTEP}

\section{Contextual structures and processes}

Although the INSTEP project had a key focus with particular reporting requirements [Document Source D (Sankar, 2009)], each of the INSTEP NF pods had to operate within the particular management and operational structure of their organisational context. Some organisations regarded INSTEP as a one-off research and development project, while others adopted aspects of the INSTEP model throughout the organisation.

Although Eva's organisation did not adopt an organisational approach to EBIP, her response, based on her INSTEP experience, speculated on what that might have involved:

I think if you are wanting to get INSTEP-like [EBIP to] happen I think it has to be part of the time allocation or part of the organisation of the place. I think it 
has to be built in; I think time has to be given to it to make it a priority; and I think thinking time has to be given to it to make it happen. ... to get to the critical [reflection] - that's the hard stuff - of saying 'This is what I need to address' - you need formalised stuff. ... what I mean by formalising is the time allocation, the structures put in place, the organisational structures to be put in place to allow people to have that opportunity to reflect and deprivatise their practice; and saying 'This is important and therefore ... we are giving you the structures, we are supporting you to do this, we'll give you the choice of the groups that you want to work within but this must be done as part of your work'.

In 2008 Theresa reported that, within her organisation, it was accepted that all facilitators worked through a series of exercises, under the supervision of their senior manager, with the aim of improving practice:

We have these six archetypical kind of scenarios, problems or factors I guess and they're all on shared files, and at our own pace we work through those and when we think we've done one ... then we take it to [our senior manager] and he discusses with us and he gives us feedback as to whether we're kind of on the nail or not and then sometimes rework it, so we're kind of constantly getting feedback until he goes 'Yep, on with the next one.'

She also acknowledged that the organisation had always had "a strong theoretical basis" for examining practice. She accepted these activities and the deprivatising of practice as the norm in their workplace and "part of what we do". She described her acceptance of the process:

I guess l've got more comfortable with the process: examining your ... theories; examining the way you work; and I'm comfortable with getting feedback on that and people talking it through. Yeah, it's just what we do now.

However, Theresa expressed her need for more structure and framework around professional development rather than "one-off" events with no "real strong basis". She reflected: "the more you get into this, the more you realise that you need more structures". She also expressed the desire for organisational goals informing "the big vision" with "explicit systems ... and structures in place" for professional learning and development to "get that inquiry process at all levels stronger". She acknowledged, however, that formalising and regulating times when everyone can meet together could be problematic due to commitments such as planning and other meetings.

In 2010, Elaine explained that within her organisation, the process of developing a more rigorous approach to EBIP took approximately three or four years, and "it became more rigorous because of the research and development process within our organisation". She acknowledged that her experience within the INSTEP project influenced her to make the EBIP process more structured within her organisation, because it could not be done effectively on an "ad-hoc basis". She explained that 
there was now a system of team and individual goal-setting with the use of a template for professional development and appraisal. The first stages of the development of a more systematic approach was when she "tried to mimic within our organisation whatever we were doing in our [INSTEP] pod". She confirmed that all facilitators within her organisation now appeared to have a clear understanding of what is involved in EBIP. She also acknowledged that a number of factors impacted on the development of EBIP within her organisation including the focus on teacher inquiry in the New Zealand Curriculum (Ministry of Education, 2007).

Elaine described the organisational process she has been instrumental in developing:

What we do now is a far more rigorous process in that all of our stuff is tied to our appraisal, so our appraisal and personal learning are within the same document. So that's - and we all have done that quite consciously. And at the beginning of this year we set about it far more rigorously ... so, you set it up so you kind of appraise yourself, ... identify your needs, and come together and say, 'Ok, what common needs have we got?' from what we've identified from that self appraisal document ... So then we worked out a way of how we monitor that, so at workshops, and it's like, [for example] [one colleague] will video [another colleague], then they'll come back and talk about it. ... So we collectively pull together some of our learning ... So we just kind of had two iterative processes during term two, term three ... so it's a very, iterative process now.

In 2008, Hannah acknowledged the different approaches to professional learning and development within her organisation - organisational, collaborative groups, and individual - and the importance of bringing them together by attempting to embed a philosophy of organisational as well as individual learning:

We have been focusing on the individual, but now we're trying to focus on individual within context of output, within context of organisation and what does organisational inquiry look like ... how do you move the whole lot through organisational learning as well as individual learning and you can't always presume that individual learning will equal organisational learning ... or taking the whole - like creating a responsive effective service - you might have patches of that happening and - does everybody inquire into the right stuff? How do you ensure that people are inquiring into the right stuff to go in the right direction to move the entire service? ... It's about that collective whole, yeah, it's that coherency and consistency about moving forward. And you'll always have people on a spectrum but if somebody's focused over there and we're all focusing over here then somehow we need mechanisms to say 'come with us, come over here'.

She also acknowledged the need for a collaborative approach and structure to facilitate the management of the "double layers" of commitments in facilitators' day-to-day work:

Because if it's not there [the structure supporting the progression of what you do], people just slip away. With the best will in the world work overtakes what you think you might do with good intention. 
Hannah reflected on her experience of developing some strategies for the implementation of frameworks, tools and structures:

You need to make those explicit and never assume people will understand them the first time and you've got to keep coming back to it and reshaping it and revisiting it and putting it out in a different format.

In 2010, Hannah reflected on the journey towards organisational "coherency within professional learning" and the need for a degree of "formalisation" of "rules and procedures" to engender a "collective responsibility to move forward". She identified two key factors impacting upon the outcome: the reduction of meetings to four times a year "which had significant impact on people's practice and workings", and the informal and non mandatory nature of tools and mechanisms:

The tools are optional. And so it made it harder at times for the professional learning group leaders to actually assist people in movement because there were no formal tools and some people chose to use them and some people didn't. ... we tried very hard to bring about some buddying and peer observation but time constraints, financial constraints and again, the lack of, 'this is what we're going to do' from on high meant that it didn't happen. So - sort of systems issues as well as financial and time constraints. So without leadership, if you like, from [within] the learning pods it doesn't happen as well as it could because I think a lot of people say that they're reflecting and that they're doing this and doing that; [but] de-privatising practice doesn't happen unless you've got people on a regular basis coming with you, and you looking at other people, and sharing that in a collaborative space.

You need to have hard data and I think that's a result of the fact that ... it's not enough time, it's not regular enough. The lack of formalised you know: 'this is an institutional tool and you will all use it. It's not an optional extra', and having the resourcing to be able to have time and the buddying if you like. I mean that's stuff that is in the teacher professional development BES [Best Evidence Synthesis (Timperley et al., 2007)] isn't it? You've got to have some of those systemic things, you can't say - none of that is any different for us [facilitators] at all.

She added that the deprivatisation of practice had "diminished quite severely over time", and generally only those who worked together might observe others' practice, but there were "people who are never seen in practice".

Hannah's organisation had been influenced by Phase 2 of INSTEP, which had included two senior managers as RFs. As a result, facilitators were assigned to heterogeneous groups - with leaders - across the whole organisation, which had a focus on improving practice. The groups addressed themes, set at the beginning of each year, which were informed by current research including the Best Evidence Synthesis reports (Robinson et al., 2009; Timperley et al., 2007) and Ki te Aotūroa (Ministry of Education, 2008). Activities based on Ki te Aotūroa were being used to revisit some "targeted activities to ... surface assumptions, beliefs and values" (Hannah, 2010), that were implemented during the INSTEP project. This structure 
continued to be the basis of the ongoing professional learning programme. Although in 2008 Hannah reflected on a very supportive manager and rigorous inquiry within the INSTEP project, in 2010 she described a process that "doesn't happen as well as it could" due to "systems issues [and] financial and time constraints". She attributed this to management of the professional learning programme, and not having a formalised process in place:

\begin{abstract}
The other thing that changed quite dramatically was the fact that ... the director did not sanction ... [the] formal tool. ... I think a lot of people say that they're reflecting and that they're doing this and doing that. De-privatising practice doesn't happen unless you've got people on a regular basis coming with you, and you're looking at other people and sharing that in a collaborative space.
\end{abstract}

In 2010, Aroha reported that in her organisation there was a structure of five managers and 11 team leaders who supported and monitored facilitators as they developed professional learning portfolios. There was a clear process which was documented for all facilitators.

Individual facilitator progress was tracked and monitored quite explicitly, incorporating facilitator meetings with team leaders, and subsequent reports from team leaders to managers:

\begin{abstract}
Team leaders have been quite deliberate about monitoring that. In fact we get ... a report from our team leaders: So how many are on track to complete their PLP? How many have done their observation? How many have got an artefact? So we're actually keeping and monitoring the process quite closely. ... We are quite persistent really about what people should be doing.
\end{abstract}

Aroha added that the stringent monitoring by management has led, at times, to accusations of micro-management. When referring to the collaborative aspect of EBIP, Aroha confirmed that, although collaborative inquiry was an expectation, there was no formal structure to support that other than the curriculum teams; therefore collaborative reflection would happen within the context of the teams, which have approximately $10-12$ members. Aroha commented, however, that the regularity of manager and team leader meetings provided opportunities to monitor and support collaborative inquiry.

All three RTLB research participants cited the RTLB system of supervision as being conducive to EBIP. Three levels of supervision were identified: clinical supervision, where experts such as psychologists were consulted; professional/group supervision, which was regular supervision within and around a particular RTLB cluster; and peer supervision, which was a personal choice, and considered as peer 
support. Olivia considered that, in spite of these "different opportunities to be supported", there still needed to be "communities of support [built] ... at every level", similar to the INSTEP structure.

In 2008, Laura referred to the RTLB service as "an excellent model" to facilitate individual EBIP, and also to evaluate the way in which each cluster operates. She believed that the professional supervision system within the RTLB service was particularly beneficial for collaborative EBIP. However, she also believed that the lack of acknowledgement or focus from the Ministry on reflective practice for RTLB meant that there was no formalised system to maximise the potential of the structure:

\begin{abstract}
At the moment, there are little INSTEP groups going on, the one I'm talking about is happening out of time ... it's just something done in our own time; it's not part of the RTLB service - it's so crazy ... the most important thing that I would say is to elevate it; don't think of it as being something that's vague and of no consequence, that it needs to be elevated as a form of, well, a formal professional development and professional growth ... somewhere or other it needs ... a bit of status ... It needs to be legitimised $\ldots$ in terms of policies and things ... but it also needs a structured set-up and I think that INSTEP was a very good structure.
\end{abstract}

In 2010, Laura expressed concern about the changes taking place within the structure of the RTLB service. She was concerned that the cluster format, which consisted of working with a management committee of principals of the schools, was to be replaced by large groups of approximately twenty RTLB with an "external" manager.

Some participants commented on the extent of a shared vision of effective practice, which impacted upon the implementation of an EBIP process. In 2008, Theresa commented that she thought the vision was implicit within her organisation, but voiced the desire for a "shared vision" and more "explicit systems ... that big vision it's also how we're all working towards that and also [we need] some more systems and structures in place". Similarly, in 2008, Elaine described clear organisational expectations of having to conduct EBIP, but observed that she was unaware of a shared organisational vision:

I had the brief conversation with [my senior manager] about that ... and I said, 'you know when you think about it, I'm not sure I know what the vision for [this organisation] is' and he said 'Oh I think I articulate it all the time' and I said 'well if I don't think that, then you don't'. So that's quite interesting for him, because he thinks it's very obvious, but you know I don't. If you ask me to articulate our vision, I don't think I could at all.

In 2010, Elaine described the collaborative development of the processes for EBIP and appraisal across the organisation. In 2010, Hannah reported how the essence of the meaning of EBIP was "lost in translation" when senior managers conveyed 
the purpose of the professional learning initiative to the whole staff. She referred to the programme as being "the whole package ... of how professional development was conveyed and the professional learning for the team". She believed that the lack of preparation and lead-in resulted, for some, in a lack of commitment to the process of EBIP:

Because some groups weren't part of INSTEP they don't see the value of doing it this way [structured EBIP] and therefore less systematic and are not perhaps absolutely focused on the practice of facilitation as opposed to content of facilitation....

I'm sure INSTEP has ... scarred me for life, sort of thinking about practice really differently and thinking about organisational structures. ... It really has coloured the way I think about things. ... And that's what I based my whole premise about the learning groups and the learning formally about - but again, that was never - I didn't have the opportunity to present that and it [the purpose] wasn't presented to the whole team to sell why we were doing PD. ... the manager who decided they were going to inform people about how things there were going to run, didn't clearly articulate at all, the ... process, and why we were doing PD and why we were doing it this way. ... Not everybody was in it at the start. There were some real resisters at the start and they continue to be resisters. ... Sadly silent majority is very difficult to work with when you've got a very strong, vocal, extremely small minority. ... I do think we need to have a vision on how to get there and take those things into it otherwise we just tread water, and we haven't got time to tread water.

In 2010, Aroha described the development of their organisation's professional learning and appraisal programme, where the processes were collaboratively developed by the managers, while the facilitators had the opportunity to provide feedback and provide input throughout the development. The quest for "an inquiry based organisation", as stated in their organisation's strategic plan, included alignment of intensive professional development programmes, and seminars for managers and team leaders around challenging conversations, surfacing assumptions, and evidence-based decision making. This contributed to a performance management system which incorporated evidence-based reflection on practice. She also acknowledged that due to changes in management personnel, and an organisational readiness for a more reflective performance management system, the organisation was ready and willing to move forward:

Linda and I were kind of like holding the pen and it was that that ... allowed us to talk about what we needed to do next - so all the time we were looking for ways to raise the bar, basically. So INSTEP was the kind of trigger but then we kind of looked at - 'So what do we do from here?'

The organisational strategic plan, coupled with the readiness and willingness, enabled the timely experiences and ideas from the INSTEP project to contribute to the new system. 
She described the way in which she worked with her management team to implement the professional development and appraisal programme throughout the organisation. She highlighted the value of the collaborative and inclusive nature of the process:

One of the things I just want to make clear is that when we took it forward that wasn't just me on my own. I worked collaboratively with another manager, and all the management team contributed to how it ended up. So it was collaboration from the director and the management team around what it actually ended up looking like. Because I was just firing - well we both were - Linda and I were firing it out all of the time for feedback. It went to the team leaders as well and there's a focus group that's now looking at what we do for next year for our final year in terms of the whole document.

She also described the use of a questionnaire to get feedback from the whole organisation.

All RTLB participants recalled their commitment to the INSTEP project, but were aware that although, structures were in place for collaboration within the RTLB service, they were not maximising the potential for improving RTLB practice. Olivia observed that in order for the service to maximise potential from the INSTEP project and resources: "people would [need to] be informed about INSTEP. If it's to be maintained then it has to be rolled out in a much higher profile under more people". When asked about the impact of INSTEP on RTLB service provision, Anne commented that only "those RTLB involved in INSTEP have been influenced". Laura believed that a shared goal of publication had been a key incentive for her INSTEP pod to continue to meet:

and these guys were all saying, we're the only community of practice that's kept going, the rest have all fallen down. And we were exploring, why is this one, why are we still meeting, you know? And the main thing that we decided was that there was a goal, that we had something that we wanted to achieve and part of it was that presentation, and also where they'd all made a contribution to a paper that l've summarised and put together for Kairaranga which is our RTLB magazine.

In 2010, Olivia reported that, although her pod continued to meet beyond INSTEP, the purpose became blurred and "people were beginning to come with their own agenda". She lamented that the group was no longer meeting her needs, and that individuals did not have a shared understanding of the purpose of the meetings.

In summary, most participants reported that they considered the formalisation of structures and processes was necessary in order to promote a rigorous and systematic approach to EBIP by individuals. Both Elaine's and Aroha's organisations seemed to be ready and willing to further develop their existing programme of 
professional learning and appraisal for facilitators, and took steps to introduce explicit formalised systems and structures to support rigorous and systematic EBIP across the organisations. They also reported an inclusive approach and alignment with organisational goals and vision, as well as a system for monitoring and tracking individuals' progress. Both programmes were developed over a number of years, and were significantly influenced by the INSTEP project. Hannah's organisation was also influenced by the structure of INSTEP, and introduced a collaborative group structure across the organisation within their professional learning programme. However, it appeared that the lack of a shared vision and purpose and a consistent and cohesive approach resulted in more of an ad-hoc adoption of EBIP by individuals.

\title{
Expectations and requirements
}

The degree to which organisations, as a whole, were committed to EBIP across the organisation varied, and this was reflected in the expectations and requirements of facilitators. Study participants reported expectations and requirements in varying degrees of explicitness. Private provider participants reported explicit and implicit expectations of all facilitators to engage in EBIP, as did two university-based participants. The RTLB service was perceived by participants to make some implicit reference to the need for improvement of practice.

Anne reported that within the RTLB service, there was an expectation of personal goal-setting and monitoring, which she had integrated with her INSTEP inquiry, and although there was an expectation within the RTLB service "that you'll always be looking at your practice", there was no explicit requirement to produce hard evidence of practice. In an attempt to apply the INSTEP inquiry model to her and her colleagues' professional learning and appraisal, Olivia initiated her own approach:

\begin{abstract}
Our principal doesn't really take any interest in our appraisal system so what we've done this year we've chosen four of the eight dimensions for RTLB and chosen our own appraiser ... So, l've tried to talk a little bit about - maybe each dimension was around a case, a couple of cases ... to try and tell them about how I was trying to get the teacher to be more involved in decision making and problem solving and thinking about where we've come from, where we're going and why, and did that work and not work. But they haven't done the training so that didn't -, it was good, but it wasn't quite what I wanted either.
\end{abstract}

Olivia's reference to "the training" related to the INSTEP project, and the fact that her colleagues were not familiar with the INSTEP EBIP model and expectations. Similarly, Laura's interpretation was that "the role of RTLB doesn't require a reflective practitioner at the moment", and she felt "slightly off to the side of the RTLB service" because she was "advocating ...using ... and promoting" the INSTEP 
collaborative inquiry model. She felt that if the reporting systems incorporated reflective practice then she would feel more comfortable about her role.

Although Anne found that the detailed and structured format for RTLB reporting their cases was helpful for reflection because it "makes you stop and think ... about what you're doing and what you can do", Laura found the format and detail frustrating as it detracted from EBIP:

\begin{abstract}
What I do find is some of the constraints are coming from the Ministry as well and I find that really frustrating, that here l've been involved with this wonderful Ministry funded contract [INSTEP], but they still expect us to fill in forms and things that have got nothing to do with inquiry. ... It's just almost like two different ways of thinking. I find that really frustrating. I mean the reporting that we're doing at the moment, it's just, it's so time consuming, and it's just pieces of information that have got no relevance really, and nobody will even see this stuff and it's taking us hours and hours and hours and I find that really really annoying ... and it's not actually using my skills or the others' - I mean the others that are working in this way. It's actually almost making us - forcing us to go backwards instead of going forwards ... I think [the format for reporting] needs to show some appreciation of the need for reflection in our practice.
\end{abstract}

Similarly, Hannah found that the reporting format for the Ministry of Education funded provision was not as constructive as it could be, and expressed the desire for the reporting to incorporate aspects of professional learning:

So each of the [Ministry funded] contracts ... has an output schedule with indicators and so when I'm designing my work, I look at those outputs and indicators and for that particular year, devise the regional plan and the criteria for school selection for my particular area. ... I would like the Ministry to write into each output and contract the whole thing around building capacity and leadership and facilitation, and staff it for that so that we could output the work that we do around building capacity for advisors. I think that would be the singular most helpful thing that could happen 'cos then it's inside the contract. Everybody has to report against it; it would be consistent across the outputs and contracts; and that itself would bring cohesiveness to a service.

Hannah observed that although the Ministry of Education required quite specific reporting on outputs and practice of facilitators, the focus was on accountability rather than evidence of shifts. There was, therefore, "within [Ministry of Education funded provision] an expectation of change for improvement in [facilitator] professional learning but it's not necessarily measured in a tangible way ... because it's neither the university nor the [provider] issue". In 2008 Hannah reflected that within her organisation, although there was an expectation to include reflective dialogue in professional learning, it did not necessarily transfer to rigorous EBIP:

Well there is an expectation that you can talk about practice but it's at a talking level. Some people are engaging in [it] if you like 'informal[ly]', because they work, say a couple of AtoL [Asses to Learn] people work together they do some observations on each other and people who work in 
shared facilitation roles have done that, but if you're not working in a team and we have people who work in isolation, it's not happening naturally.

She indicated that formalisation of expectations would help ensure a more rigorous approach to EBIP. She considered that "the next step" towards that within her organisation would be to "allow the learning side of things to link to performance management in appraisal, because you could use evidence that you gather and use it on the other side of the coin if you like without trying to muddy the water between appraisal and learning".

Aroha reported on the expectations of all facilitators within her organisation's recently implemented professional learning programme: "every facilitator is involved in that there is an artefact of some description - either video or audio recording". She outlined some clear expectations of facilitators within the programme:

The INSTEP document, you know the framework towards ISTE practice, that's like our Bible. Everybody in this organisation has a copy. In induction we spend a day looking at some of the videos from that. ... That's invaluable. We still refer to that all the time around challenge of practice. In fact people have actually got to identify out of that and the Best Evidence Syntheses - either the quality teaching one or the professional learning one - what areas they're targeting and how does that connect to those two documents? So there's an assumption in this organisation that those two documents are well read and are kind of - like your toolkit for effective facilitator practice.

She also reflected on the reason for making some expectations more explicit:

I spent a lot of time sharing what it might look like and when we came across a stumbling block that people didn't want to give their artefacts in, or didn't want to talk about them, that's when we strengthened the whole piece in front of the professional learning profile. So people could say 'Okay, so this is what I'm expected to do in this organisation'

Aroha provided a rationale for integrating EBIP with appraisal:

We were originally doing ... appraisals where people [facilitators] were nominating ten schools and they would be sent a link that they had to fill in electronically and then give some comments to the facilitators. It wasn't giving us what we wanted. We'd have evidence of a facilitator in deep trouble and not giving schools what they wanted and yet when we got the ten feedbacks ... it said that this person was fine, so there seemed to be a mismatch between what people described as effective facilitation and what we were getting in terms of feedback from school. So that kind of indicated to us that we had to think about this whole notion differently.

So now you can't actually progress up the pay salary scale unless you complete ... a professional learning profile and in it you have to have all the things like your artefacts, you have to have completed all the output statements ... your hours are looked at.

That accountability is there but the main focus of this particular document is critical inquiry into how we're doing our job. 
Although Aroha ascertained that the main focus was critical inquiry, she also indicated the necessity to balance a tension between learning and appraisal:

We've changed it probably from its initial inception, the document has probably changed two or three times ... And last year was a significant change in terms of the accountability piece. We strengthened that because we felt that it possibly wasn't giving us enough information to say 'This person had actually met the key requirements of the position'. So it was one thing to be saying 'Okay l'm examining my practice and I'm getting better' but if you're still not delivering your outputs there was a mismatch.

Within Elaine's organisation there was always a clear expectation to reflect on practice using evidence such as video and role play: "So at that organisational level ... when you come into [this organisation] it is expected that you're going to reflect on your practice". However, these expectations did not at the time translate into accountability or performance measures. In 2008, Elaine expressed her perceived need for documented accountability within EBIP within her organisation:

[My senior manager] and I were talking about this yesterday ... I really hate the idea of kind of that reflective journal thing, but if you knew that each month you had to say 'This is what I've done and I've written something down to show it', you know it's that accountability of actually doing it, whereas we don't have any formal accountability. ... if you've some accountability, you know like ... the thing about monthly something or other, so that you don't just go 'Well I haven't got time to do that'.

In 2010, Elaine outlined some very clear expectations and requirements of each facilitator within her organisation, and made it clear that it was now "a far more rigorous process" and that there had been a conscious effort to link personal learning and appraisal with expectations of facilitators to identify team and individual goals and monitor progress with a critical friend, and with Elaine, at regular intervals. She indicated that her colleagues valued the process and accountability aspect as it helped make their learning explicit:

\footnotetext{
One of the main comments of people at the last meeting ... was: the process we've used; that iterative process, has forced people to get stuff done. It [has] put accountability in, which we had before but not anywhere near as clearly, and they said 'We actually can see the progress we've made because of that accountability.' It's like - we do it with teachers, we do it with leaders, but I don't think we do it well enough with ourselves before, and I think people agree with me that they're always 'oh, we're too busy to do that'. ... We don't accept that from teachers, we can't accept it from ourselves.
}

In summary, RTLB participants reported that, although there was an implicit requirement by the service to set personal goals and monitor practice, there was no requirement to document or report professional learning and growth. It appeared that reporting formats for RTLB and Ministry of Education funded services focussed on 
accountability measures with little or no reference to professional learning and growth. In fact, the reporting process was perceived to detract from building facilitator capacity.

Elaine and Aroha's organisations had each implemented explicit formalised programmes which incorporated aspects of professional learning and appraisal. Each of the programmes required facilitators to identify and provide evidence of aspects of practice, engage in critical reflective dialogue, and document their professional learning and growth. Both organisations had systems in place to monitor individual facilitators' progress that were explicitly linked to appraisal. Considering Aroha's, Elaine's and Hannah's organisations, it appeared that implicit expectations, even with structures in place, were insufficient to ensure rigorous EBIP, and it seemed to be the case that without the element of appraisal, and the explicit requirement to critically reflect on practice, it would not happen.

\section{Resources, tools and mechanisms for inquiry}

\section{Resources}

While individuals were impacted upon by the resourcing allocated within the INSTEP project, they were also operating within the broader context of particular organisational, social and political environments. Some participants related their situation during INSTEP, while others reflected and speculated on broader aspects of resourcing that supported, or might have supported, EBIP in general. The factor of time was once more predominant in terms of resourcing.

Laura appreciated the autonomy within the RTLB service in terms of being able to allocate time within her workload, but also referred to the lack of acknowledgement by the service that reflection on practice takes time, and that her INSTEP pod was continuing to meet beyond the project but it was "done in our own time; it's not part of RTLB service". Anne indicated that more time would be advantageous "to spend on ... cases and relationships", and acknowledged that there is almost always pressure on time allocated to each case, due to there usually being a backlog of cases.

Both Elaine and Theresa acknowledged that formalising times for all facilitators to meet and share practice was problematic due to the conflicting demands of practice in schools and other meetings and commitments. Elaine reported that all facilitators agreed that a more effective way forward was to ensure that two full days per term

were blocked out and dedicated to reflection on practice. Eva found that using travelling time with a colleague working off site in the same school was an effective 
way to maximise a critical friendship and reflect on practice, but voiced concerns about sustaining EBIP in that environment:

Physically we've got time to drive up to this place and come back in the car so we will have time which is a key factor that ... needs to be built in because I think that's the thing that is most inhibitive of [being a] reflective practitioner and [having a] critical friendship. This time [that has to be built in] ... the negative is that ... how long can I sustain that, you know, working in this way on my own and ... will it become embedded in my practice sufficiently to be part of what I do; and I think it might, I'm not sure ... but it's always going to be the time factor, the availability of somebody else to be working with.

In 2008, Hannah had similar concerns about sustaining a process for reflection on practice:

I firmly believe that for our practice to improve we need a collaborative approach; a collaborative structure - but also a designated time to do it and not just time to meet in a PD structure but time to observe and reflect and get feedback; and that's one of the things that's very lean in any situation I think. And, that's the thing that worked for us from the start of INSTEP until this stage, because we're coming to the stage now where there's no money and no time really. It means that you have to work - or how do we embed it into a system when you can't staff learning groups and you can't staff ... observations [which have] got to be embedded in your day-to-day work, when in actual fact your day-to-day work is to shift the teacher practice and so there's all those double layers of things that make it difficult to manage.

She observed that if there is not "a designated time to [reflect on practice] within your workload then you've got to squeeze it in somewhere". She believed that one of the challenges to being a reflective practitioner is the increasing demand for "things to be done in that unallocated time that are pushing the boundaries a wee bit".

Hannah acknowledged that "while there is time set aside for PD [professional development], the organisational PD is the thing that takes a bit of a priority" due to the "obligation to have an effective service as a whole". However, she believed that "there has to be some acknowledgement that growth and capacity has to be funded ... it can't be self-sustained. ... You've got to have a structure, you've got to have resourcing and you've got to have the capacity to do that."

Aroha voiced concerns that, due to the competitive contractual nature of inservice teacher education and the changing political climate over the next few years, conflicting priorities might, in the future, impact negatively on the organisation's ability to allocate sufficient time to the aspect of EBIP within their professional learning and appraisal programme:

Given that we've only got one more year before our contract ends, and that we're faced with a number of different ways of having to work in 2012, where does ... the professional learning profile, fit? Does it have to accommodate 
those different ways of working? So we're just starting to think about what will happen. ... [another manager] has already said maybe we need to strengthen this accountability piece even more, because, otherwise we won't survive. You know, it's all very well having people doing all this lovely reflection, maybe we're spending too much time on that and maybe we need to claw back some time in terms of getting people out there doing their work. So there's a whole lot of issues that we're just starting to grapple with, but I can't give you a single answer... That's the political climate, that's the organisation that we operate within, as well. So there are a number of constraints that are probably going to have some measure and impact. I've already said to [the other manager] l'd be really reluctant to lose them, the inquiry has been the basis of everything we do, we have to think about how we do that and resolve the issues in the constraints that have been put on us.

Aroha and Elaine indicated that the INSTEP resource Ki te Aotūroa (Ministry of Education, 2008) was a valuable one and well used within their organisations. Anne and Olivia acknowledged the value of the resource, but observed that it is not well acknowledged, used or readily available within the RTLB service. Olivia remarked on the lack of knowledge of the INSTEP project or resource within the service:

INSTEP - the whole word has gone out of anything to do with learning now with the new RTLB things. They are talking about conversations - and I can't quote you some of the references, but just recently there was something came on the RTLB site and they were talking about conversations with teachers as part of the behaviour kit that's just come out, but my brief look, I actually didn't instantly recognise any references to people that we've used in INSTEP and there was certainly no reference to INSTEP itself, and I was quite disappointed.

\section{Tools and mechanisms}

Some organisations took a broad approach and developed tools and mechanisms designed to support EBIP throughout the organisation. In 2010 Elaine, Hannah and Aroha reported that their organisations went on to develop organisation-wide tools and frameworks for all facilitators to use to analyse and improve practice. Elaine reported that the development of their framework for analysis is an ongoing work in progress which began with the schema developed within the INSTEP pods. Their most recent framework incorporating appraisal and learning was informed by Ki te Aotūroa (Ministry of Education, 2008).

Hannah reported that a framework of criteria had been developed across a range of aspects of practice:

There was no methodology and there's no means to actually say 'ok I think I'm here. Let's test that hypothesis and then what do I have to do to actually get better at that?' and then what does that look like when you're better. So that was ... [why the criteria were] developed across those different principles.

However, in 2010, Hannah reported that the framework of criteria was not sanctioned by management as a tool for the whole organisation, and therefore remained a non- 
mandatory tool that was used fairly inconsistently by facilitators. It was therefore difficult to evaluate shifts in practice: "it made it harder at times for the professional learning group leaders to actually assist people in movement [of practice]". She reported that although there was a process in place for collaborative professional learning, they did not have the "tools and the teeth to actually make further progress".

In 2010, Aroha reported that there was a comprehensive system in place in her organisation for appraisal and professional learning, and each facilitator maintained a professional learning profile. There were clear and explicit mechanisms in place to support EBIP:

so they actually have to say: what is their inquiry about; how are they going to gather this data; and how does it connect to the work that they are doing. So there's quite a critical piece of setting up. ... The document ... has got some very critical messages in about how you set it up; who you talk to; what stages. I've got a timeline. As a management team, each year we've kind of looked at it and said 'Okay so what are the other things we need to add in, or how do we need to do this?'

She also reported that managers and team leaders closely monitored the process with the use of a tracking sheet.

In terms of resourcing within the broader context of organisations, it was evident that time was crucial to the implementation of EBIP. Participants emphasised the importance of structured, formalised time for meetings and collaborative reflection on practice. Concerns were raised over the sustainability of collaborative EBIP if time was not acknowledged or built into a facilitator's workload. The INSTEP resource (Ministry of Education, 2008) was well used within Hannah's, Elaine's and Aroha's organisations. Its value was acknowledged by the other participants, although there was no explicit reference to its use.

Since INSTEP, Elaine and Aroha's organisations had developed systems for professional learning and appraisal, and Hannah's had developed a system for professional learning, incorporating the establishment of professional learning groups across the organisation. Both Elaine and Aroha reported a clear organisational framework for EBIP with tools and documentation to support it. Hannah reported that her organisation had established a system for collaboration, but no formalised framework, tools or process for EBIP. 


\section{Chapter summary}

Within the INSTEP project and beyond, the clearly defined processes, structures and requirements enhanced and supported individual engagement in EBIP. The formalisation of processes and structures, and mandated requirements were necessary if systematic and rigorous EBIP was to take place. A clear and shared vision of purpose for EBIP enhanced engagement by encouraging individuals' ownership of, responsibility for, and commitment to, the process.

Participants acknowledged that the formal requirement to report on, and document, EBIP was valuable and necessary, and helped ensure a systematic and rigorous approach. The lack of acknowledgement of professional learning and growth in the reporting of RTLB and Ministry of Education funded services was perceived to detract from, and devalue, the process of EBIP.

Within the INSTEP project, and within the two organisations that developed programmes for professional learning and appraisal, there was a variety of resources, tools and mechanisms that were formally adopted and made available to support EBIP for individual facilitators. Facilitators from the other organisations reported using tools and mechanisms developed during INSTEP, but none appeared to be used since in a systematic or rigorous manner.

The availability of time was a key factor mediating individuals' and organisations' capacity to adopt EBIP. The provision of time was valued within the INSTEP project, and it was acknowledged by all participants to be a major influence on whether or not individuals or organisations would be able to sustain their commitment to EBIP. The INSTEP resource (Ministry of Education, 2008) appeared to be well used within the three organisations that had adopted professional learning programmes, but not in the others. This chapter has reported the ways in which various contextual factors, expectations, tools and resources impacted upon individuals' EBIP. The following chapter will report the key findings in relation to working collaboratively with others to inquire into practice. 


\section{CHAPTER 6 \\ Working with people}

\section{Introduction}

This chapter will report on the variety of factors impacting on participants' collaborative EBIP, during and since the INSTEP project. The first section will give an overview of the range of formal and informal contexts the research participants engaged in. Subsequent sections will report on the factors that were reported to be key aspects of collaborative EBIP: trust, respect and safety; perspectives and diversity; and management and leadership. The final section will report on two aspects of critical friendship that were deemed to be important for deprivatising practice and surfacing values and beliefs.

\section{Collaborative arrangements}

Within research participants' professional learning and development, they were engaged in a range of formal and informal collaborative arrangements within the INSTEP project, and within the broader context of their work with all stakeholders. These contexts ranged from one-on-one interactions with peers, to organisational, regional and national meetings and professional interactions. Participants reflected on specific aspects of collaborative arrangements that influenced their EBIP. Collaborative EBIP was a key aspect of the INSTEP project (Sankar, 2009), so it was an expectation that project participants would deprivatise and reflect on practice with peers and/or mentors. Some participants reported their personal experiences within the INSTEP context. Others reported their ongoing experiences of EBIP within the context of their practice and/or an organisational framework for professional learning. The purpose of this section is to provide an account of the range of collaborative contexts within which participants engaged, and some of the ways in which these contexts impacted upon participants' EBIP.

RTLB research participants described the structure of the service, which is based on clusters of schools within the broader regional and national RTLB representation. They referred to termly RTLB regional meetings that consisted of guest speakers that Laura described as "boring" and "quite irrelevant". She perceived the purpose of these meetings to be quite different to a "community of practice" where practitioners aim to improve their practice. Anne reported that the regional RTLB group also had annual gatherings, where facilitators would present examples of "things that they've 
done during the year that have been successful", and where she presented her INSTEP work. Laura noted that the group supervision facility and cluster management structure within the RTLB service was instrumental in evaluating practice as a cluster group.

The RTLB participants referred to a number of stakeholder groups that they work with, where they discuss and justify their practice. Such groups included psychologists, field workers in schools, occupational and speech therapists, Group Special Education, teachers, parents and caregivers. Anne reflected on the need to be able to justify her decisions and actions when working with stakeholders:

There certainly is the need for you to be involved; to be quite clear about what you do and the way you're doing it; and to help other agencies ... in schools ... who are also involved with the same students, so you have to be, you know [aware of] what you add into the pot, and so that certainly makes you think about what you're doing and, so that's part of the organisation I guess.

During Phase 3 of INSTEP, all RTLB research participants met within their INSTEP pod of five ISTEs and an RF. However, the value of the pod meetings was perceived differently by the participants. Anne and Laura valued the more "intimate" environment within the smaller pod of six, as opposed to the larger cluster or regional RTLB service meetings. Laura enjoyed the "little clique ... of people who like to talk about things at this level ... where we all talk about videoing and how it's changed the way we interact with our teachers". Similarly, Anne enjoyed hearing others' ideas, within the smaller group, and felt affirmed by hearing that other RTLB ISTEs faced similar challenges in their practice to her own:

\begin{abstract}
Hearing that their concerns and their challenges and their self-reflection were so similar to mine was very reinforcing, - that you know, you're not the only one out there ... and just picking up so many ideas from each other too, because you can, you know, you're working with the same team and you're going along the same lines for a few years, you, even though we're doing PD [professional development] - we do meet up as a big group - it's not always easy to have that intimate [interaction]
\end{abstract}

In contrast, Olivia perceived that more in-depth reflection had the potential to take place in schools in which she was working, or in the base school, rather than in the INSTEP pod meetings, and that collaborative EBIP was probably more effective for three other members of the INSTEP pod because they worked closely together within the same cluster. She reflected on the fact that, although she would prefer to have collaborative critical reflection with the colleagues with whom she works closely, they were not involved in INSTEP, so they had not had the "training" and were not familiar with the process and purpose of collaborative EBIP as she 
understood it. In 2008, Olivia reported that she had made some attempts of her own to keep her colleagues abreast with the INSTEP project, but had limited success, and was met with the response 'Don't try to INSTEP me!'. In 2010 she reported that she wanted to include them in the INSTEP pod meetings:

[At the next meeting] I want it around looking at an INSTEP [transcribed] conversation of mine, but I want my colleagues [from my base school] to be invited to the meeting. I sort of vaguely suggested that once before and they [the INSTEP pod] felt it was better just to keep our little group, but that's collegiality on one level and, like [one pod member] and [another] work together, so they probably have a very in-depth conversations with each other, but I don't think that happens with the others [pod members]. I'm sure it doesn't, and so I don't have anyone really to sit and do that with.

Elaine reflected that she formed quite close, ongoing relationships with her pod of five RFs in Phase 2 of the project, only two of whom she had known previously, although they had not continued collaborative EBIP as a group: "we - that group, formed a very close relationship over that [INSTEP] time and delved into each other's practice, and we kept in contact for quite a while afterwards". She also formed good relationships with ISTEs she worked with, although she deprivatised practice with only one or two selected individuals within her organisation. In 2008, she expressed the difficulty of deprivatising her practice, because she worked on her own with groups of school principals. In 2010, she reported that since her last interview in 2008, she had sought individuals to help her critique videos of her practice:

I've got several videos of mine which I talk to [my senior manager] about ... maybe it was after our last conversation [2008 interview], but I talked to [my senior manager] and he said 'Well, just use me'. ... We work as - kind of buddies and ... I've used [colleague X] because we work on some things together; we work with a cluster together, so I've taken some video - and she's got good expertise in the stuff I want to get better at. So we use different people for different expertises. You might have: this goal I might be working with [colleague X]; and that goal l'm working with [my senior manager].

Although Elaine's organisation had implemented a system for professional learning and appraisal, including collaborative EBIP, there was freedom of choice as to who each facilitator worked with to deprivatise practice. Elaine reported working effectively in an ongoing way within a group of three facilitators within her organisation to share evidence of practice.

In 2008, Theresa described the way in which her organisation would do some things collectively, but break into smaller clusters to deprivatise practice:

We work on some things together, and then we break up into little clusters and work on things - or even partners - so, according to who's ready to work on a little problem in practice or inquiry, we break out and, we have our little teams ... about two or three. So sometimes we work as a whole team 
but that's mostly around where have we got to: let's look at some more theory; let's look at something collectively together; a problem practice together or something together, and then we normally break into little groups ... I guess the way we work in little groups is - and people have decided this for themselves - is when they show their video, they would rather just be in a small group.

Alison experienced being one of a large pod of 12 ISTEs during Phase 3 of INSTEP. The pod consisted of the whole of her curriculum team. She recalled that the large pod of 12 "was pretty much a waste of time" and that it had to be broken down into smaller pods of three or four. She became "really frustrated" in the large pod because "people were doing a whole lot of talk and no action". She found the smaller pods much more effective.

Alison reported that the smaller sub-pods were self-selected, and happened to align geographically, so members worked in schools in the same geographical area. Although Alison shared a workspace with all other 12 ISTEs in her pod, she considered the geographical sub-pods to be more effective in terms of having "quality conversations" than being in close proximity in the base organisation. Alison observed that in the smaller pods:

More people feel more confident about saying what they want to say, whereas when you are working in a group of 12 you can easily not hear from eight people, and you know they've all got really valuable things to say, so you wanna be hearing from them, but the actual number reduces their confidence.

Within INSTEP, Eva particularly valued having a trusted relationship with one other RF as a critical friend, where she deprivatised practice and surfaced values and beliefs. In 2010, Eva described her participation in a number of different communities, such as her national and organisational curriculum teams, and preservice teacher education student and tutor communities. She reflected on the different levels of discussion and critique that took place within them, and that the "really important conversations" took place "on the side with colleagues that I trust, so they are more intimate - perhaps one-on-one or whatever". Taking that experience forward into her practice, she now makes a conscious effort to incorporate opportunities for those quality one-on-one conversations:

I'm going into a research project shortly and there will be a chance for me to have a critical friend, so I'm planning very much what I want that critical friend to look at; the means by which they work, what we're going to reflect on and, how that impacts on my practice and what I take forward ... That will enable me to be more effective in my reflection with a critical friend. 
Eva asserted that although, in her opinion, there should be a formalised process for EBIP, there should always be a choice regarding critical friendship for evaluating practice.

Evelyn considered that in her ongoing practice, it was "fantastic PD [professional development]" to be able to work as a pair [of facilitators] because of the opportunity for personal professional growth and the resulting benefit for schools. However, she acknowledged that labour and cost factors inhibited this practice.

In 2008, Hannah reported that at the beginning of Phase 3, her organisation assigned facilitators to structured learning groups across the organisation, with five groups participating in the INSTEP project. Professional learning was organised within the group structure and included learning experiences such as guest speakers followed by discussions around the implications for practice.

In 2010 Hannah reported that, although she was a leader of one of the learning groups in her organisation, she did not believe that participation in the group served her as well as some other "communities of practice" that she belonged to. She perceived that those facilitators in her organisation that had not participated in INSTEP did not see the value of systematic and rigorous EBIP, and were "not perhaps absolutely focused on the practice of facilitation as opposed to content of facilitation". She also reported that, although she met with another one or two colleagues at least twice a term to reflect on practice, organisational changes had overtaken their focus and they "dropped the ball" on their learning. She regretted that professional learning had become a casualty of organisational and political change.

During Phases 2 and 3 of INSTEP, Aroha led five RFs and their respective ISTEs within her organisation to engage in collaborative EBIP. In 2010, she described the system that her organisation had implemented, since INSTEP, for all facilitators' professional learning and appraisal. There was a layered structure of managers, team leaders and facilitators, where each team leader was responsible for approximately 12 facilitators. She described a clear structure for the management team and team leaders to meet to discuss the programme:

The way we've structured our organisation, the [collaborative critical inquiry] will happen within teams. So there's a literacy team with a team leader, there's a mathematics team with a team leader, there's an ESOL [English as a Second Language] team and so on. And those conversations ... would happen within those teams. The critical conversations that happen between the management team - there's a structure for that but there's also - we meet every second week 
with our team leaders as well. So there's a structure across the organisation to have those kinds of conversations ... because often the focus is: So what's going on in terms of the professional learning profiles? What are some of the challenges? How can we help? So it happens through the structure that we've instigated across the organisation - because as you can appreciate we're not as big as we were, but we've still got a number of people, and for us to have groups like the INSTEP group would be impossible. ... So the team leader structure allows those kind of collaborative groups ... to occur.

Although participants engaged in a wide range of professional interactions, those reported to be most conducive to effective EBIP were those smaller, more intimate groups of two to three colleagues who were self-selected and met more informally as part of their ongoing work in schools, or within the context of the INSTEP project or organisational framework for appraisal and professional learning.

Anne, Laura and Olivia continued to meet in their INSTEP pods after the project had concluded, although they perceived their effectiveness for EBIP quite differently. Elaine, Hannah and Aroha reported that, since INSTEP, their organisations had implemented a structure for collaboration within their professional learning programme, although the arrangements for collaborative EBIP varied considerably. More details of these implementations were provided in the chapter on rules, tools and routines. After INSTEP Evelyn, Eva, Alison and Theresa were left to their own devices to continue with collaborative EBIP within the context of their individual working environment.

The next sections of this chapter report on the key mediating factors impacting upon participants' engagement in collaborative EBIP. They are: safety; perspectives and diversity; management and leadership; and critical friendship.

\section{Safety}

There were many references to aspects of safety within a collaborative environment where individuals are exposing their practice, values and beliefs. Some pods adopted formal or informal protocols for meetings in order to minimise risk. Most participants reported the need for trust and respect in such an environment. There were also instances of power relations and competition impacting upon collaborative EBIP.

\section{Protocols}

Most participants reported the implementation of some protocols or ways of working with other people. In 2008, Eva reflected that a shared "understanding [of] some 
protocols [and] ways of working", as well as clarity of project objectives were "embedded within the way of working" of her INSTEP pods. She also reflected on the "support and energy" that came from such a community. She was very explicit regarding her RF pod's understandings of protocols and ways of working:

We agreed how we would work; we agreed what was important to us and we had quite a discussion around what we needed individually to be safe, and as a consequence what, as a group, we needed, to feel that we could trust those who we were working with, and that we could trust them to reveal our own practice. ... if that hadn't have happened, I wouldn't have shared. ... We took the time to set up those practices and protocols and rules and we took the time to discuss those and identify them as a way of working and agreeing to be willing and ready to work in that way. I think we resolved some of those things in the process. ... And I think that's critical to setting up the beginning of the processes: establishing those rules and routines; absolutely vital.

Laura recalled that, in her ongoing INSTEP pod, there were protocols related to respect for others such as punctuality and organisation, while she was less explicit regarding protocols for safety of individuals:

Things like the time, you know, people don't - we know what time it's going to be and what time it's going to finish ...it would be considered quite ill mannered to leave before the meeting is finished, you know, things like that. We guard the time and we block it out and that's all there is to it. ... if everybody can't attend then we would reschedule the meeting ... the thinking behind it is that, if you're missing a person you're basically missing that perspective.

When working within her INSTEP pod, Anne reported that each member felt "okay about opening up" because there was an informal "confidentiality" understanding that "what was said in the group, stayed in the group".

Aroha was very clear about specific protocols, based on literature (Dalton \& Anderson, 2010; Garmston \& Wellman, 1999) that were developed within her pods for ways of working together:

I'll go back to the Dalton and Garmston stuff ... we read it and we thought 'Okay this is a really good guide for what we should be developing in terms of our protocols for the way the group works', because we all agreed if you were going to start to look at practice you needed some kind of guidelines and some rules because otherwise it would just be a shambles or people would get really defensive. So Dalton's work around collaborative conversations and productive conversations was really useful for kind of guiding us through that process. It wasn't just reading it and talking about it. $\ldots$

She described the way in which the same protocols were adopted within the organisation's professional learning and appraisal programme, and cited one 
example of the ways in which instances of unprofessional behaviour were addressed:

One of my team leaders ... never said anything in the leadership team meetings. One of the times I said to her 'So, why don't you say anything, because I know you've got some really good ideas?', and she said 'I can't get a word in edgewise'. So we both decided that we would watch what happens, to see why she wasn't able to put forward her ideas, and one of the things that happened was that there were some dominant people. So once we worked out who was being dominant, we were able to say: 'On the norms of collaboration, we agreed that we would listen to contributions, and if people weren't able to [contribute], we would invite those contributions from those who hadn't been forthcoming'. And we weren't doing that. So it was taking us back. The norms of collaboration allow us to [go] back and have those conversations, not about you personally, but about what we've agreed to. That's been a really powerful framework for us to operate.

She reported that the protocols also allowed her team leaders to challenge her to justify some of the things she was saying in the meetings, and she summarised one of the protocols that facilitated that challenge:

\begin{abstract}
We're very good now at paraphrasing, it's become part of the way we do things. So we try not to use the words like 'however' and 'but', because the minute you say 'but', that means you're disagreeing and you're not paraphrasing and you're not checking out what that person actually meant. So the norms ... are quite powerful and are used deliberately within our conversations to check what people are saying, and how they're saying it.
\end{abstract}

She also observed that, once team leaders adopted protocols within the leadership team, they carried them forward to the context of their curriculum team meetings, so they would all "agree to take an inquiry stance [and] ... have no put-downs". Within that context all ideas were accepted and critiqued: "When somebody puts forward an idea we either comment on it; paraphrase it ... we don't say 'that that's a dumb idea'". She perceived that, as a result of the protocols, the curriculum team meetings were "running much more smoothly". She reported that Garmston's seven laws of collaboration (Garmston \& Wellman, 1999) and Dalton and Anderson's (2010) work had informed the organisation's leadership charter and enabled them to develop protocols for ways of working together. She described how it impacted upon their leadership meetings and prompted questions:

So are we putting an idea on the table? Whose idea is it? Have we listened? - those kinds of things. That's been really useful. And every now and then we forget and somebody jumps up in the leadership team meeting and just puts "norms" up on the board. And we all go, oh, right. But we've all got little stickies ... So, you know: What are you doing? Why are you doing it? And is it effective?

Research participants adopted protocols with varying degrees of rigour and formality. For example, Eva's were very explicitly discussed and agreed within a 
group context; Aroha's were developed fairly rigorously across the organisation and were derived from relevant literature and professional development; Laura's were based on aspects of organisation and punctuality; while Anne recalled an informal agreed understanding of behaviour to protect confidentiality within the group.

\section{Trust and respect}

Seven participants cited the need for trust and respect within a group if they were deprivatising practice and surfacing values and beliefs.

One of the things that Eva considered most crucial to collaborative EBIP was that of trusted relationships:

[I valued above all] collegial relationships development. And to a degree, that there are unguarded conversations, and there is a trust that goes with those relationships that you know things won't be repeated, or you could really say what you think. And I think that is an absolute gift in the workplace.

She also considered that trustful, respectful and caring relationships with teachers were crucial, in order to be able to support teachers in improving their practice.

In 2010, Eva reflected on the trusted relationship she had with her NF and another RF in her INSTEP pod:

I felt that [the NF was] a friend and colleague which went much deeper, so my immediate trust of [the NF] was far deeper, but I did have that level of trust with [the other RF] as well going into it [INSTEP] so I can see why our work advanced; because there was that relationship prior that was built on trust.

I would say that that [critical friendship with the RF] was one of the most significant developments [of INSTEP] because I think it came out of a mutual respect for each other's work.

She described how her professional relationship with another RF in the pod advanced due to "good conversations and such genuine respectful interactions", but that the same opportunities were not there for them to work together so closely.

Eva also reported that other facilitators within the organisation were impressed by the trust and respect that the RFs demonstrated for each other when they presented their work:

I think we [the RFs] were an inspiration to the other advisors when we presented our work, $\ldots$ and I remember them all saying about our relationships; what they noticed about the trust between us, and about the sense of having done something together, and the strength of that, and I think they were really impressed, and I think we had a lot of respect from some colleagues because of that. 
She also acknowledged that there would always be those people who would not value or respect those types of relationships:

Of course there were those colleagues that didn't value that sort of thing so they're not going to respect it anyway and that's okay, you are not going to change that but I think they still acknowledged the work we did was good work.

Eva also articulated the "sense of trust and respect" that developed "out of anticipation" for a small group of three in her pod of ISTEs in Phase 3:

I think ... there was a sense of trust that developed; a sense of respect that developed ... from anticipation. I mean those three came with anticipation to show their work to the others and have a good discussion.

Evelyn reported that she valued the "rich opportunity" of working with another RF whom she trusted and respected, and that she considered it to be one of the best forms of professional development. Theresa indicated that she was more comfortable deprivatising practice in a small self-selected group situation, and appreciated having the choice of who to share with. Alison considered that respect, resonating from "an underlying friendship" with a colleague, would be essential in order to work closely with them to collaboratively critically reflect on practice.

Hannah reported that she respected those who were observing and giving feedback on her practice, and that she trusted that they would provide constructive criticism because of their common understanding of her work context:

I guess I have enough trust and respect for the people that were observing, that I knew that it would come back to me in such a way that it would not be destructive ... they would be acting as a critical friend, but not being overly critical. ... It wasn't in the sense of an appraisal situation, it was a learning situation. ... I respect their ways of operating and their opinions.

In 2010, Laura reported that she was comfortable sharing problems of practice with the INSTEP pod that continued to meet, although the process was not as structured as it had been during INSTEP:

And at the beginning [of INSTEP] it was sort of like, you know, well what's your problem of practice, you'd sort of, like, do that. But now, it's just become an automatic thing. You sort of save up your problem and bring it $\ldots$ to the group. And there's no reason to sort of structure it, it just is now, it's just a comfortable place to bring that problem of practice.

In 2008, Elaine reported an increased "level of trust in each other's opinion" within her organisation since her INSTEP work, and the fact that others' feedback is as valued as their senior manager's, which had not always been the case. 
Even with protocols in place, Eva explained how she felt compromised by some who did not reciprocate her trust and take the risk of deprivatising practice:

I aligned myself with people who I knew were working and as committed as I was, and the ones who weren't as committed; of course I supported them because that's what the relationship's about; but I didn't trust them to the same degree, I lost respect for two people in the project - of circumstances around them not taking risks.

The development of trust and mutual respect were positively influenced by a familiarity with colleagues and their practice, while a situation of mistrust and lack of respect arose from no reciprocity in exposing practice and taking risks. The next section cites examples where power relations and competition impacted upon the process of collaborative EBIP.

\section{Power relations and competition}

All of the NF and RF participants adopted leadership roles with their colleagues within the context of the INSTEP project. This presented dilemmas for some, as they found themselves working in a leadership context with peers and those in more senior positions or roles within their organisation or other organisations. The competitive nature of inservice teacher education providers and restructuring within some organisations presented instances of individual or organisational competition which impacted upon collaborative EBIP. This section reports the views of six participants who perceived that aspects of power relations and competition impacted negatively upon collaborative EBIP.

With reference to the learning groups within her organisation, and the need for a safe, risk-free environment, Hannah noted that, even with protocols in place, the presence and contribution of some organisational leaders was not conducive to a risk-free environment for collaborative EBIP:

Some people feel very uncomfortable with some elements of leadership and
being able to talk about their practice ... general advisors who are
uncomfortable with some leaders in the group. So chose not to talk as freely
as they normally would have. ... and there would have been an instance of
probably one other senior person who would shut down a conversation. And
so that negated [critical reflection on practice] - and even though we had
protocols for discussion and protocols for behaviours within each group, that
didn't matter.

Within Phase 3, Eva led a pod of five ISTEs to conduct collaborative inquiry into their practice. She recollected the tension for her in being in a leadership role with her peers, some of whom were considered to be senior advisors in schools, and acknowledged that each of the smaller sub-pods of three and two within her pod 
required different forms of leadership and degrees of direction. She attributed this, in part, to the "different power relations within those two groups", of which she was "very conscious".

Alison observed that some members of her large pod were "the bosses" within her organisational department, and had opposing philosophies of practice. She noted that, although it was not possible within such an environment to have "quality conversations", INSTEP gave her permission to practise in the way that she believed:

But what was really fascinating was the four people who were in the 'do it to them' group were the bosses. So INSTEP actually allowed us to say 'Well okay you might be the boss ... but l'm allowed under this project to do it this way' ... which was really good. I hadn't thought of that before ... but it was a real clash, it was really tricky. It actually brought things to the fore that needed to be discussed but they didn't... you just... it was just impossible to ... have those [discussions]. I mean I'm talking a scripted workshop; I'm talking: say this; listen for these responses; and then say that. It was just horrendous.

She therefore deprivatised practice and surfaced values and beliefs within the context of a smaller group of ISTEs with whom she worked and could relate to.

Elaine, Olivia and Evelyn considered that some elements of individual and organisational competition inhibited collaborative EBIP. In 2010, when Elaine was reflecting on her leadership experience in Phase 4, she described the situation as "fraught" because of the way in which her role was perceived by some other inservice teacher education provider organisations. The competitive nature of inservice teacher education provision caused some ISTEs to disengage, and resulted in elements of resistance with others:

You're working with seven providers who are competitors, even though we're working on the same thing; we're still competitors and there was that huge resistance of 'Who are you to try and tell us how to do our PD [professional development]'. Plus they were already working within their own organisations. So, it had some good effect, but not huge, and none of those relationships were built in any bigger way. But within [my organisation] I guess, I had much closer relationships because I'm doing a lot of that work with people individually.

Olivia indicated that within the RTLB environment there is an "element of competitiveness" which is a barrier to "genuine in-depth discussions and conversations" that typify the notion of "collegiality" she was seeking in a colleague. Evelyn noted that the restructuring within her university introduced an element of competition for positions within the organisation, which impacted negatively upon EBIP: 
They [ some members of the pod] weren't happy with other people's successes, and I think that's maybe the university environment - because if you're being successful, maybe that's because somebody else isn't ... whereas to be a good advisor you need to really be collegial. ... I think it was personalities [that made it difficult] ... but it was exacerbated by the competition that existed in jobs.

Power relations impacted upon participants in a variety of ways. For Eva, her dilemma was how to work in a leadership role with two colleagues who were considered to be more senior than the others; Hannah observed the impact of senior colleagues on the freedom of others to expose practice and surface values and beliefs; while Elaine had difficulty leading her inter-organisational group which consisted of colleagues in senior positions in other organisations who were in competition with her organisation. Both Evelyn and Olivia experienced individual competition within their pods, due to the nature of their role and context of the organisation. A summary of the dimensions of aspects of safety reported in this section is presented in Table 6.1. 
Table 6.1: Aspects of safety

\begin{tabular}{|c|c|c|c|c|}
\hline & Why is it important? & How is it developed / manifested? & What does it look like? & Who are the key players? \\
\hline Protocols & $\begin{array}{l}\text { Provided safe environments for sharing and } \\
\text { critiquing ideas and exposing vulnerabilities; } \\
\text { Promoted respect for individuals and } \\
\text { organisational functionality; } \\
\text { Promoted confidentiality. }\end{array}$ & $\begin{array}{l}\text { Rigorous formal } \\
\text { agreements/contracts; } \\
\text { Informal tacit understandings; } \\
\text { Developed within groups and } \\
\text { organisations. }\end{array}$ & $\begin{array}{l}\text { Clarity of objectives; } \\
\text { Shared understanding of } \\
\text { guidelines/rules/norms of } \\
\text { working/interacting/conducting } \\
\text { conversations. }\end{array}$ & $\begin{array}{l}\text { ISTEs in groups; } \\
\text { Facilitators in organisations. }\end{array}$ \\
\hline $\begin{array}{l}\text { Trust and } \\
\text { respect }\end{array}$ & $\begin{array}{l}\text { Mediated safe environments for deprivatising } \\
\text { practice, values, beliefs, philosophies; } \\
\text { Supported professional development. }\end{array}$ & $\begin{array}{l}\text { Deeper levels developed with close } \\
\text { colleagues and friends; } \\
\text { Arises from opportunities to work } \\
\text { together; } \\
\text { Developed and enhanced through } \\
\text { anticipation/expectations/valuing } \\
\text { others/mutual risk and vulnerability } \\
\text { /close working relationships. }\end{array}$ & $\begin{array}{l}\text { Evident and modelled to others } \\
\text { through interactions/relationships; } \\
\text { Unguarded confidential } \\
\text { conversations; } \\
\text { Comfortable and reciprocal; } \\
\text { Trust in others to provide } \\
\text { constructive criticism. }\end{array}$ & $\begin{array}{l}\text { Individuals who value trust and } \\
\text { respect; } \\
\text { Colleagues and friends who work } \\
\text { closely together/have an } \\
\text { understanding of each other's work; } \\
\text { Some groups and self-selected } \\
\text { peers; } \\
\text { Teachers, NFs, RFs and ISTEs. }\end{array}$ \\
\hline $\begin{array}{l}\text { Power } \\
\text { relations and } \\
\text { competition }\end{array}$ & $\begin{array}{l}\text { Relevant for NFs and RFs in professional } \\
\text { development leadership roles; } \\
\text { Informed and impacted upon leadership } \\
\text { strategies; } \\
\text { Impacted upon quality } \\
\text { conversations/interactions/ relationships. }\end{array}$ & $\begin{array}{l}\text { Intra-organisational } \\
\text { restructuring/hierarchical positions; } \\
\text { Inter-organisational contestable } \\
\text { environment. }\end{array}$ & $\begin{array}{l}\text { Tensions in relationships and } \\
\text { interactions; } \\
\text { Lack of } \\
\text { trust/engagement/commitment; } \\
\text { Resistance; } \\
\text { Limited ability to celebrate others' } \\
\text { success; } \\
\text { Inhibitive of deprivatising practice, } \\
\text { values and beliefs, and engaging in } \\
\text { quality conversations. }\end{array}$ & $\begin{array}{l}\text { Everyone except those in trusting } \\
\text { and respectful working relationships. }\end{array}$ \\
\hline
\end{tabular}




\title{
Perspectives and diversity
}

Six participants commented on the benefits of having different perspectives. Some appreciated individual perspectives on theirs and others' practice, while others valued different organisational perspectives.

Although Evelyn reflected that perhaps the "common ground" of "fundamental basic beliefs" might be a necessity for a critical friendship to be effective, she thought the differences in other respects "gave it a sort of an edge" in terms of analysis and interpretation of, and responses to practice. She also reflected on the value of her pod presenting their INSTEP work to other facilitators in her organisation, and the way in which that process encouraged her "to think about things in a different way and take on other perspectives ... turning your world view around a different way". Alison also noted that in terms of her own critical reflection on practice, she found it necessary to talk things through with someone who had a different perspective. Eva appreciated perspectives that aligned with hers, and also learned from those that were different:

\begin{abstract}
You have an understanding of their work and they have an understanding of yours ... the similarities; and you can work on those similarities to find common ground, and you can look at their differences and see if that is something that you want to pursue and look at because you admire it or if it's something that you would like to work to protect yourself from. ... both of those perspectives are fantastic as a reflective practitioner. So you're looking at somebody else's journey and saying 'Well that will save me going down there' or 'that's the place I want to go down' and that too, is an excellent gift from people that you work with.
\end{abstract}

In 2008, both Theresa and Elaine, as NFs, appreciated the inter-organisational INSTEP community. Elaine made the point that, although the other organisational groups she worked with within INSTEP had "slightly different underpinning theories", and came from different perspectives, they all had a common understanding of EBIP and had similar values, She reflected on the group of NFs in the INSTEP project:

As one of the national facilitators I think the learning was huge, because we all came from such different theory bases, backgrounds, ways of working, but that was kind of a constant struggle we were involved in at the time. Trying to get inside each other's heads and find out what that was about. And I think that was - looking back, was good for all of us because you kind of think your way's the best, then you realise there are other ways that impact on things just as well. So within that group, I think that was fantastic even though it was quite hard at times.

Elaine also noted the contribution of external experts, and the importance of considering their perspectives: 
We talk with different people, you know, that kind of drags you off into different directions. We still work with other groups that keep you on your toes and thinking about other things: ... a good example; we had Ruth Sutton who has been in the country for a couple of weeks. And she spent a day with our team, and I spent about four days with her overall, but she brings ... another whole perspective that makes you sit up again and think, 'Oh yeah, I remember reading that ages ago, I must pull that out and look at it again'. So I think we constantly now don't just look inside ourselves, we work with other groups and other people to keep that kind of fresh thinking. Otherwise we're only a small team and if you don't do that you can just become too insular.

Theresa also articulated that other organisational perspectives on EBIP were valued:

We all bring things to this [organisational] group but then it's important to have other outside ... groups to actually - that's what l've learnt through INSTEP - is that the importance of listening to other people's ways of working, other people's theories.

In Phase 4, Theresa led a project with other inservice providers throughout New Zealand. She valued the sharing of ideas and experience:

It was really useful talking to [another INSTEP organisation] 'cos they're about at that point too and so are the other [INSTEP organisation] team we looked at, so it's quite useful; like the three of us as teams thinking that through 'cos we share some of it: ... 'Oh we're using this little bit of theory for this and this' or 'this is how we're going about it when we watch our videos'; 'this is how we're building up a little tool for that'.

Theresa made the point that maintaining those inter-organisational relationships was important, while Elaine emphasised the importance of ongoing communication and collaboration for her organisation because it was a "small company".

Hannah reported that when her organisation adopted a structure of professional learning groups, that they were across two campuses, of "mixed gender, mixed region, mixed work stream, experienced, and newly inducted people" in a deliberate move to "foster that growth across the board". She reported that facilitators seemed to value and "talk about the range of expertise ... [and] different perspectives" that were brought to each group. She observed that shared leadership within her group helped ensure that all members of the group were encouraged and supported to contribute, whether they were very experienced or new to the facilitator role.

When reflecting on the development of an organisational system for professional learning and appraisal, Aroha commented on the need for a shared belief in, and commitment to, EBIP as well as the challenge that comes from different perspectives: 
I don't think we would have got as far as the whole - if all of us hadn't believed that it was important, and being supported by [the senior manager] either, because you would have been fighting an uphill battle. So I think the fact that we're all talking the same language, and when we don't we check it out. And we all come from quite different perspectives, so that's useful. You're not going 'yes that's a good idea'. We're willing - I think we have quite a high trust relationship, so we're able to challenge each other when we need to - so that all contributes to your learning.

Laura, Evelyn and Alison cited examples where perspectives were so diverse that they presented barriers rather than benefits to EBIP. In some cases, pods of RFs or ISTEs were brought together, and their diversity of perspectives was so great that individuals had difficulty in identifying with the group.

Laura considered that her pod of RFs in Phase 2 consisted of such diversity of roles and responsibilities, that she struggled to relate to them:

We're a very different group of people and it was hard to find a common thinking, very hard, you know with some people from the Ministry and people ... who were delivering the maths curriculum for instance and it was quite hard to sort of feel that your contribution was even understood.

Evelyn reflected on her role as a leader in Phase 3, within a large INSTEP pod, when she "couldn't get the whole team to gel". She believed that the diversity of roles within the organisation, individual characteristics, and the fact that the organisation was in the process of change, all impacted negatively on the functioning of the pod:

That experience with the [INSTEP] team was quite demanding ... we had stars, and I think that there are people who work with the team, and there are people that are stars, and we had three that clashed - so that was quite difficult keeping that within bounds. ... I think they [the stars] saw other people as a threat, or they couldn't listen to other people.

She also acknowledged that some members of the pod had "different values", and commented on the impact this had on the meetings: "for instance that team [the INSTEP pod] wouldn't have said anything they weren't pleased with...they wouldn't have shared that". However, she reported that there was "real value" once the large pod was broken down into smaller pods of two or three. In some cases, she acted as an intermediary and paved the way for critical reflection:

I was able to get people who weren't working together to work together say in twos ... or maybe three; so that was a real value and that's carried on where I couldn't get the whole team to gel - but it worked within pods. ... I would bring them together so that was like - if there'd been a problem with two of them and I listened, and then put the other point of view, and then got them together and said 'This is something - l'd like you to talk it over', and I sort of chaired it and they got on really well after that. 
Alison observed that some members of her large pod came from directly opposing philosophies in terms of what was considered to be effective facilitator practice:

We had some real dilemmas because as a group we were telling teachers that they needed to base their decisions for their [curriculum] teaching and learning programmes on what assessment data showed them. But then I felt we were going in as a group and rolling out this set PD [professional development] that had nothing to do with the teachers' own assessment data or beliefs or anything else. ... Some people [in the INSTEP pod] thought that [the scripted workshop] was a really good idea. ... my thinking was these people [teachers] are professionals, they are teachers, they can make decisions about what they believe is best for them. ... But some people on the team [INSTEP pod] thought that they [the teachers] weren't able to make decisions for themselves as learners and it was our [the facilitators'] responsibility to tell them what do to.

On the whole, individuals valued different perspectives within the context of inquiring into their practice and developing a system of professional learning, as it supported them to consider practice, values and beliefs in a more balanced way. Some also valued different perspectives of knowledgeable experts, and ISTEs from other organisations. Others found that the diversity of perspectives was too great in terms of role, context, personality or educational philosophy.

\section{Management and leadership}

During INSTEP, both NFs and RFs were operating in a leadership capacity with their pods. Participants commented on the leadership qualities of their NF and RF that impacted upon their EBIP. Some also commented on management structures or influences within their organisations.

Alison indicated that respect for her RF in Phase 3 was a motivating factor in the inquiry process: "Our mana for [our RF] meant we just did it even if ... you were a bit sort of stressed getting it done. We just did it yeah. Without [our RF] it would have gone to custard, it just wouldn't... I don't think it would have happened".

Although Aroha was a manager within her organisation, she regarded herself very much a learner within the INSTEP pod, and seemed inclusive in her approach. When reflecting on her role as an NF with her INSTEP pod of RFs within her organisation, she described it as "a learning partnership" on a "level playing field" rather than mentor or manager: "there was no way I knew how to do everything and neither did they, so we were discovering things together basically, and had some pretty intense debates around video, and what we thought was happening, and why we were saying things about what we saw". 
Hannah recalled one of the leaders in her professional learning group modelling

"being a learner herself", and being interested and inclusive:

I have been fortunate to have a [leader] who's very clear in her role around leading learning, but also being a learner herself, and she demonstrates that within the group and encourages us all in what we do and remembers to make that connection next time we come together. So when she ... sees you two months down the track it's around 'how did you get on with such and such?' So she does that reconnecting ... and seeks feedback on her facilitation ..., which is really powerful because then she's modelling the same sort of process and using different tools to help her do that and it puts those tools on the table. 'So, what do you think about this as a mechanism?' and 'This is what I learnt from what you said last time, does that still fit?' So, being around people who lead by example really helps.

Laura commented on the inclusive practice modelled by her NF, with a diverse pod of RTLB:

I needed, the first year, to see [the NF] modelling how to operate as a leader and as a very very collaborative sort of, honouring everybody's contribution leader, because we're a very different group of people ... I needed to see the way that [the NF] did that and the way that she helped each of us to sort of come to the fore at various times of the year, during the year.

She also noted how shared leadership of her ongoing pod meetings worked "really well", and that it had introduced "new thinking and new dimensions" to their group.

Laura commented on the value of her managers within her RTLB cluster having similar values and beliefs:

I'm just lucky that I have a principal that acknowledges that that's the way that I like to work. And he supports me ... and he, himself, would work this way. But I can see that if I was in another cluster maybe, who had a different sort of principal, I may well have to work in a different way if I wanted to function, or stay in that place. ...he's really interested in leadership and management and inquiry, so he sees ... the way that I'm working - it fits well with the way that he thinks. It sits well with his values and beliefs. So I'm very lucky, it's part of the reason I'm still working here and still working with him, because it's very easy to work with somebody when you share the same values and beliefs. ... Our management committee is a fantastic management committee, this is made up of all of our principals, and there's many a time when all of us are really glad that we work in a cluster where we have supportive principals who do think the same way as we do. [l] keep coming back to this inclusion thing because it's the binding thing that keeps us all in the [regional] cluster, working the way it is you know, because the principals in this particular cluster believe in inclusion, so now all the time trying to support us to offer that, which is what the RTLB service is all about.

Aroha observed the impact of the RFs, as leaders of their pods of ISTEs, understanding and modelling the process of inquiry. She reported that if the RFs were confident in conducting inquiry into their practice, it followed that their pod was 
effective in inquiry, whereas in those pods where the RF was not so confident, the process was not so successful.

There were also aspects of leadership which were reported to be detrimental to EBIP. All of the instances were cases where senior management in organisations impacted upon the perceived value and commitment to EBIP. In Eva's case, senior managers within her organisation, including those who were not directly involved with the INSTEP project, had an impact on the value attached to EBIP. Eva recalled the impact on her of such a situation:

I think the management support might have been higher profile and I think that could have perhaps given more value to the project. I don't know but I was thinking, you know, we never saw our manager at all. Our head of school came to one of the [presentations] and we got some brief feedback there, but there was never a sense of real interest. I was never stopped in the corridor and asked how it was going and I think that would have made a big difference to have that kind of interest.

Theresa also reported frustration with others in her organisation who were not taking responsibility for aspects of EBIP. In 2008, she expressed that she would have liked to have seen "other people driving things a little more in the company", with respect to sourcing literature and EBIP. Elaine acknowledged that her immersion in the INSTEP project as an NF helped her prioritise these sorts of activities, whereas others were in "different places" and "not thinking like that".

Eva perceived that the lack of engagement, and early withdrawal from INSTEP of two senior managers within the organisation, may have impacted upon the commitment of another two ISTEs in her pod who were "perceived as leaders in the school system". She described her dilemma:

Now those two [ISTEs] were tentative about coming on board with the process. I don't know whether they didn't want to de-privatise their practice, or they didn't value the project or whether they'd been in discussion with other leaders in our faculty who had ... withdrawn from the project. I don't know, but there was a reluctance there to actually participate and I had to work really hard to find a context for them that they could find meaningful. So when I slotted it in to them being critical friends to look at their practice together and de-privatise it together in conversation around workshops they said they'd do it and that was the only context in which they would.

In 2008, although Hannah reported a close working relationship with her senior manager, who supported her to deprivatise her practice, she also acknowledged, from her experience in working with departments in schools, that "you might have all the will in the world by the HOD [Head of Department], but if the middle or senior management are constraining that, we'll go nowhere in a hurry". Ironically, in 2010, 
Hannah observed the same phenomena within her own organisation where senior management "did not sanction" some of the tools as part of the process of EBIP. This resulted in, what she perceived to be, a lack of rigour and commitment to the professional learning programme across the organisation: "So without leadership ... it doesn't happen as well as it could".

Key leadership qualities that supported EBIP included being: like-minded; encouraging; challenging; inclusive; a knowledgeable expert; interested; and timely. It was also acknowledged that having leaders who organised and modelled the inquiry process was an important contributing factor, as was being able to source relevant literature. The negative aspects of leadership arose more from organisational management than individual leadership qualities.

\section{Critical friendship}

All participants commented on the value of working in small groups to deprivatise practice, and most established close working relationships with one or two colleagues, which they termed as critical friendships. This section reports on two of the aspects that were most valued in such a relationship: challenge and likemindedness.

\section{Challenge}

Nine participants expressed the opinion that being challenged by a colleague within the context of EBIP was of particular value. Participants were challenged within INSTEP to consider their values and beliefs in the light of evidence of their practice. Eva noted that there should always be an opportunity to reciprocate challenge within such an environment, while Hannah and Theresa noted the reciprocity of valuing each other's contribution to the process:

[The lack of respect] was around the fact that this person was very quick to challenge me, but never took the opportunity for me to respect and reciprocate that challenge, so again that came down to an equity issue for me. (Eva 2008)

So, it's having somebody who's willing to value you enough to put the hard stuff on the table in front of you and talk it through and work with you. (Hannah 2008)

The more we worked together, there was a more idea of, challenging practice, that idea of collegiality; the idea of refining against something that we knew was making us stronger. (Theresa 2010) 
Theresa and Elaine were very clear about the fact that personal values, beliefs and assumptions were being challenged:

What we do as a group is, we just take, we take each other further all the time and what we're really focussing on now is ... that aspect of examining theories, values, those sorts of things, and we thought ... we were doing it but we realised [we're not]. (Theresa 2008)

If you've a totally different theory from me about teaching then no matter what feedback I give you, it's just going to be a brick wall 'cos your just going to take it and discard it: 'nah that doesn't work', but people don't say that, so we're kind of listening for those little cues that people say ... and now trying to kind of go 'Okay, what did you mean by that?' so that you can keep on ... if you don't in the end examine each other's beliefs and stuff you won't get anywhere. (Elaine 2008)

\section{Evelyn appreciated colleagues challenging her for evidence of her assertions:}

it goes back to the 'Oh I'm doing well' and 'That was a good lesson', and having somebody say 'How do you know? Where's the evidence? Show me'. They are sort of pushing you really to prove it, and if isn't there you have to go back. I think that's the main thing - that the critical friend is making you actually firm up what you think.

Others were aware that they really valued the probing questions that challenged and prompted them to think things through in more depth:

I think too in the small pods with the ISTEs ... they knew there were gonna be questions posed on a level that would take them deeper. (Eva 2010)

I want people to ask me the hard questions but nobody really did, they were too nice: Why did you do that and did it work? Why not? What would you do differently, you know what process did you follow? If it didn't [work] what did you do with the teacher? What were the conversations like? What, how often did you meet? ... I thought my supervision would be a good place but it hasn't worked really. ...she's a lovely person but it hasn't challenged me. (Olivia 2008)

\section{Some also acknowledged that they expected and accepted elements of dissonance} or discomfort within the challenge:

[critical friends would] challenge you; they'd say what you didn't want to hear; they'd ask really good questions rather than tell you how to fix it. (Alison 2010)

It's sort of great - no it's not always great what you do - 'cos she [the critical friend] can be challenging as well and she'll challenge [for example] ... if l've said something ... [she'll say]: 'Why do you think that?' (Anne 2008)

I had a sense that I was never going to make any progress unless somebody put the hard stuff on the table, and there's been at least one conversation with my manager where he put some hard stuff on the table and it made a huge impact. (Hannah 2008) 
Olivia also identified that different perspectives challenged her to explore her practice more thoroughly:

Now as a reflective practitioner I don't want to do it by myself, I want to share with others and have their input to challenge and make me think about things that I may not have thought about.

All participants except Laura indicated that they valued aspects of challenge regarding their practice, values, beliefs and assumptions. Challenge took the form of probing and prompting questions, offering different perspectives, and considering hard evidence to evaluate espoused theory against theory in action. Some acknowledged the dissonance and discomfort that can be expected with such a challenge, and others referred to the importance of reciprocity of trust, respect, and willingness to take risks and expose practice. Laura made no reference to challenge.

\section{Like-mindedness}

Those participants who cited some form of close professional interactions with colleagues indicated that being able to relate to their peer was important in terms of providing a safe environment where vulnerabilities could be exposed. Participants cited different types of commonalities they looked for in trusted critical friendships. The aspect of like-mindedness was expressed in different ways.

Six participants, including Alison and Laura, were able to identify something in common with their colleagues with whom they shared and deprivatised practice:

So the people who thought similar to what I was thinking went this way and the people who thought similar to what they were thinking went that way. (Alison 2010)

I really did feel like I was having to make adjustments all the time [within the RF pod]. But eventually, I found a common ... thread that ... was fine. And, I've become quite close friends with all of them really. (Laura 2010)

I relied on my colleagues hugely and was with like-minded people. (Laura 2008)

When referring to her pod of ISTEs in Phase 3, Anne acknowledged that, although each RTLB worked in different ways, and she valued that diversity, they all had a common understanding of their role and work context:

We can discuss; ... do peer supervision; we each know what everyone's talking about, because all work in those schools ... we all knew each other's jobs and that's interesting because we're all individuals, we all work slightly differently. 
Some expressed similarities in their values and beliefs, although their work contexts and areas of expertise were different. Within Phase 2 of INSTEP, Evelyn found richness and great satisfaction working with another RF to critique practice. She noted that although they were from completely different curriculum areas with different pedagogical approaches, their educational values and beliefs were in alignment:

\begin{abstract}
I don't know whether it would work as a critical friend if somebody ... had different ... fundamental basic beliefs. I think you have to have some sort of common ground like that, but in every other respect we were completely different, and that gave it a sort of an edge because we had to interpret each other's responses
\end{abstract}

Eva identified characteristics she shared with her critical friend such as "a mutual respect for each other's work" and that they were both "real inquirers into practice ... [and] reflective practitioners". She perceived that they "connected on an intellectual level" and explained "We both really liked ideas; we both really liked breaking ideas; reconstructing ideas; reformulating where we were going. ... We both had inquiring minds". Eva noted that because she was now clear about her values and beliefs, she was "aware of the alliances that I want and the alliances that I don't want" and she wished to align herself with "similar people".

Others identified commonalities in work contexts and ways of working. Eva acknowledged that she and her critical friend each had an understanding of the other's work. Laura reported that her reflections took place within the context of her work while "preparing material and delivering it". She valued meeting regularly with a group of RTLB colleagues who could "look at the way that we worked". She identified that she valued having someone she could relate to in her particular field, and who has "been through the same sorts of experiences".

Aroha shared an office with one colleague who, although was not involved in INSTEP, "lived and breathed it" with her. Another colleague she was able to identify with because he had a "handle on this whole notion of inquiry".

Hannah was aware she would not like to deprivatise her practice with anyone who was not familiar with her context of practice:

I would not like to expose too much of the soft underbelly to somebody that was unknown really, who didn't know at least a little bit about the context in which I work. 
Anne noted that other RTLB ISTEs were able to identify common problems of practice due to their similarities in contexts of working with teachers and schools that had particular expectations of RTLB:

\begin{abstract}
Most people were open about their own faults when it came to what they discovered in their audio recordings, and there were some definite patterns that we all had ... RTLB don't come in as the expert, we come in as part of the team. But there is often an expectation from the schools that we are expert and we have to try and ... get over that in a way, but there is certainly - when you're meeting with younger teachers - there is an expectation that you're gonna come up with some ideas, and so a lot of us found ourselves doing all the talking in the conversations ... asking questions and then answering them ourselves.
\end{abstract}

Eva was aware that she aligned herself with those who had a similar commitment and work ethic:

I aligned myself with people who I knew were working and as committed as I was ... If I see somebody who's really like me, trying to find answer for this student in the classroom or to raise achievement for students, or to find a way of working that's going to improve someone's life then yes, I work beside that person.

At the simplest level, like-mindedness was interpreted as similarities in ways of thinking and personal professional characteristics. A common understanding of the process of EBIP was also considered important, as was work ethic. Most predominant was the mutual understanding of each other's roles and contexts of work, as well as alignment of professional values and beliefs. The element of support in critical friendships was defined in different ways. For example, Olivia explained that she was not seeking support in terms of affirmation of her practice, but support in terms of being challenged.

\title{
Chapter summary
}

When working with others within the context of EBIP, participants reported a variety of ways in which they engaged with each other and prepared for trusting and respectful environments. They reported that trust, respect and diversity were of particular value when deprivatising practice and surfacing values and beliefs in the context of EBIP. Within the context of professional relationships with colleagues to evaluate practice, participants noted that challenge and like-mindedness were key elements of such a relationship. Participants respected and responded to leaders who were inclusive, modelled the inquiry process and had similar values and beliefs. In contrast, senior managers within organisations had the potential to undermine authentic engagement in EBIP by facilitators if they did not demonstrate value or respect for the process. Participants experienced aspects of fear and risk when they 
were expected to deprivatise practice within larger groups with very diverse philosophies and personalities, or where power relations and competition negated trust and respect. The next chapter will report on the impact of EBIP upon individual participants' learning and professional identity. 


\section{CHAPTER 7 \\ Impact upon individuals}

\section{Introduction}

This chapter will report the ways in which individuals perceived that engagement in the process of EBIP impacted on their emotional wellbeing, and professional learning and identity.

\section{Emotions and feelings}

The first section reports the approach and response to participants' involvement in the whole INSTEP project and process of inquiry. Subsequent sections relate more specifically to participants' emotions, feelings, professional learning, and growth experienced when engaging in collaborative EBIP.

\section{Approach and response to inquiry}

Most participants were eager to participate in the INSTEP project, although both positive and negative reactions were reported from the experience.

Laura was attracted [to the INSTEP project] by "the fact that it was professional people going to explore something; explore an idea". She was motivated to inquire into her own practice:

\footnotetext{
I actually found that quite unique. l'd never ever been involved with anything that was looking at the way that I practised. ... There's always been somebody else looking at the way that I was practising.
}

Elaine delighted in the "aha" moments: "I could have done it like that", and found it "really satisfying" to be working with others who helped her to identify ways in which she could "actually do it better". She recalled that her pod was "really keen to look at ... their own practice" in a consistent way using an inquiry model.

Anne was very positive about engaging in EBIP, and "felt quite excited about the prospect of doing things differently". Theresa was encouraged by, and valued, making changes in her practice. She explained that she had become "more comfortable with the process: examining your ... theories; examining the way you work". She was also more comfortable getting feedback on her practice from others and with "people talking it through", and noted that "It's just what we do now". She 
was encouraged by successes in her changed practice, and overcame fear by embracing it:

It's just so so valuable to try out new things and then just go 'Wow that really works!' It's really really encouraging, ... there's a lot of fear around approaching some things because you think it's going to be hard but ... it's generally not, and to me that is the biggest learning for me, is just to dive in, and sometimes you'll make a mistake, but most of the times you don't. Most of the time you have really good outcomes for both of you.

Hannah acknowledged that looking upon the process as a learning experience helped to ease her nervousness. Eva reported that she was excited and motivated at the prospect of collaborative EBIP:

I think there was a lot of excitement and I think I held onto that all the way through the project actually because I saw innovative opportunities to keep that passion going ... and just finding ways that reflected who I was and what I bring ... to the [INSTEP] project, and ... I think these self motivators are very instilled in my practice and so I think that passion stayed with me all the way through the project.

She explained that she had prepared herself to engage in collaborative EBIP:

So I arrived there ready and willing; did the reading; had the conversations; and I think I was there understanding what it was about and what risks I might need to take; what opportunities I might need to look for, and really get involved right from the start.

Hannah acknowledged some apprehension but "didn't want to put it [EBIP] off”. She reported being "certainly encouraged by some of the commentary [on her practice] and challenged by the other". She recalled her "nervous anticipation" when she deprivatised her practice:

I had a sense that ... before I started using some really hard data and external to myself, there was a sense of 'Well I think everything's going okay, but I'm not $100 \%$ sure', and then I was very nervous, because I was one of the few people that got an external observer to come and look at my practice, and I thought this could go very pear shaped very quickly; because if I'm not doing what I think I'm doing l've got to go back and re-evaluate, so there was a bit of if you like nervous anticipation around that.

Alison was keen to have the opportunity to "look beyond your head; look beyond content". Aroha reported that being more acutely aware of the impact of her practice on others meant that she had since become more nervous about facilitating large groups of people.

Eva was enthusiastic and prepared, happy and excited to deprivatise her practice, and experienced a very effective and rewarding critical friendship with another RF when engaging in EBIP. However, she related experiencing frustration and 
disappointment at different stages throughout the project. The first was her pod's inability to give her feedback that would take her forward in her practice:

I think I was frustrated because l'd been so excited about it and l'd put some effort into working out the questions I wanted them [pod members] to reflect on; working out the snips I wanted them to see, and I had spent a lot of time framing that, and so I was probably a little frustrated and maybe even a wee bit disappointed.

The second was when she observed that some others in her pod were not willing to expose their practice to the same extent as she did:

There were moments of frustrations when I could see that others weren't taking the risks in their learning that I was taking ... after a little while I became disappointed for them mainly, that they weren't able to take that risk ... I was very disappointed that they hadn't met me in that way and ... there were some people - I never saw their practice at all.

The third was when she felt a sense of anger that other members of her pod were not committing time and effort to collaborative [EBIP]:

And so, and that taps into a very deep seated sense of equity I have which is terrible, and good, you know, it can be a thorn in my side at times ... but I was very well aware that I had to manage that. That was my stuff, and I had to manage that within the project, but I did find that there were times when I don't think the frustration ever got to really harsh anger - but it certainly was building through the project. I was aware that it was, and I was trying to channel that into other things.

Finally, she was appalled when two senior managers from the organisation disengaged from the project:

I think the other thing that really gutted me was when two of the managers middle managers - withdrew from the project, I think that was shocking. It was immoral, appalling and I don't want to go there in discussion 'cos it just makes me angry - that level of hypocrisy. ... I never voiced that but it really rocked my boat. I couldn't believe that they weren't seeing this as an opportunity to take all our advisory service forward to something really fantastic.

Olivia was also keen, enthusiastic and excited at the prospect of working collaboratively in an ongoing way to improve her practice, but for her, the experience did not meet her needs or expectations:

I didn't really have that community, and the idea of our INSTEP group continuing was so that we could build that collegiality, but ... for me it hasn't happened. It's gone off on a tangent and it doesn't meet my needs anymore.

Olivia did not feel that her practice was examined in depth in a collaborative environment, and that she did most of it on her own. She felt that her "only hope" was to get her "colleagues [in her cluster] on board" with EBIP. 
Alison "got frustrated" with her large pod: "It drove me nuts!", because there was not the opportunity to have quality interactions and move forward. Laura acknowledged a feeling of uncertainty when deprivatising her practice:

I'm not very sure of the outcome when I start to look at my practice and even sometimes even discussing it with a colleague, you know, I'm not quite sure where it's going to go.

She valued the connection with her everyday work, and the "involvement with other people", although she also acknowledged the potential for dissonance and discomfort:

What you discover, you may not like, and you have to be in the right frame of mind to be able to cope with that, or [work with] the right group of people. If you're not prepared to find things that you don't like, you needn't go into inquiry.

In summary, participants seemed to be aware of, and welcomed the aspect of challenge involved in improving their practice, and they approached EBIP in a positive way. Those who reported negative reactions to the experience were disappointed and frustrated by a failure of others to contribute to EBIP in ways that were expected.

\section{Dissonance and personal challenge}

All participants acknowledged that the process of EBIP could be, and was at times, a challenging and difficult experience. There was some dissonance and discomfort in the realisation that their practice was not quite what they had perceived, and that changes were difficult to make. Elaine expressed the difficulty in grappling with the realisation that she was not as familiar with her role as she thought: "that's quite hard when you're in a position where you feel as if you've kind of got a lot of knowledge about your role and then you realise you don't". She also observed that it was "a constant struggle" to consider other perspectives on aspects of practice when "you kind of think your way's the best, then you realise there are other ways that impact on things just as well", although she considered the collaboration to be "fantastic even though it was quite hard at times."

Anne and Laura reported that they found the experience of collaborative EBIP challenging. Because some aspects of Anne's practice had become "ingrained", she found that some changes were not easy to bring about:

One of my sort of philosophies I remember when I was doing the training, ... was that you meet people where they're at, whether it's children or teachers or whatever and then you would, you know acknowledge what's happening 
to them and then kind of move on from there and I think somehow I found that next step a little bit difficult: moving on; ... being able to challenge. For me it was easy just to come up with the solutions.

Hannah's peers drew her attention to her tone and language when working with them:

Sometimes when I'm frustrated with people that I work with - and it's particularly within the organisation as opposed to outside the organisation ... I have a very abrupt manner and people know that I'm really frustrated with them, which is not always a bad thing, but if that actually inhibits you working as a team member then you need to sharpen up on that.

This direct challenge to the way she operated and worked with peers was a revelation, and she wondered why no-one had pointed it out to her before:

Why hadn't somebody told me that decades ago? ... So, that's the sort of learning I think: around not only professional knowledge and understanding, but personal interactions with people, because if that was being demonstrated with teachers - which I'm nearly $100 \%$ sure it's not - then that would be a real concern. But, I wasn't aware that it was creeping into my work, my work within the institution.

Hannah became more acutely aware of the direct impact of her practice on others when she was confronted with the dissonance that her intervention brought about with a teacher she was working with:

I felt we were making reasonable progress until one day I got to the school and the teacher came in and said, just sat down and said 'I haven't done anything' [and I said] 'Why is that?', and, the conversation was very one sided, and he left the room in tears. I hadn't said anything overly critical ... I just was gently trying to prod what was happening. ... I went away feeling quite sick about the whole thing, but it was at the stage where that teacher had nowhere else to go so I guess l'd almost backed him into a corner where he had to make a decision about whether he could actually stump up and do this stuff or put his hand up and say 'I can't deliver what is needed to deliver for these kids and I'm failing'. ... I came away with that very big sense of unease .... so there were a couple of people external to me that I talked it through with, and that's when I decided I really needed somebody else to have a look at my practice.

Hannah summarised her personal challenge and journey as the realisation, through collaborative EBIP, of the value of making connections and building relationships when working with people.

Eva also realised the significance of being able to deal with a teacher's sense of dissonance during an intervention:

One teacher chose respect [to evaluate], then I used stimulated recall to go in and check that out, and he was blown out of the water to find actually there wasn't respect in his classroom. At that time there was a lot of stuff happening that was against what he valued, so it was really challenging. 
Anne, Evelyn, Laura and Olivia all realised that they talked too much when working with teachers, and it was impacting upon the outcomes of their interventions. Anne related to other ISTEs in her pod who were "asking questions [of the teachers] and then answering them ourselves". She observed that she was "cutting across what the teacher was saying and not giving them space". She reflected that it was "quite a lesson ... to listen to yourself". Similarly, Evelyn recalled her feelings of shock and dismay when she reviewed evidence of her practice, and was aware that she had some misconceptions about the way she worked:

So I would say 'No I let teachers talk' but I was doing all of it. I was also sort of killing them with kindness in a way because I didn't want them to feel embarrassed or ill at ease so I would fill in any spaces. But when you actually analyse the transcript that was really bad because there is undisputed proof ... and then looking at the sort of questions I was asking and the responses they elicited. ... You can be quite delusional like me saying 'Oh no I don't do all the talking' ... it's how we see ourselves and how we really are.

Similarly, regarding her approach and conversations with teachers, Laura acknowledged that she was often "talking too much ... feeling sorry for them [teachers]" and was "sympathetic to the point where I [said] heaps and heaps and heaps of unnecessary stuff". Olivia reflected that past interventions perhaps failed due to her tendency to provide solutions and resources at the expense of identifying and responding to teachers' needs:

For me the challenge is to always remember that it's not me again bringing up all these good ideas cause they're so good. It's 'What ... are they really wanting?' and 'What is going to work for them?' and maybe sometime in the past when an intervention really wasn't that successful it was because I owned it.

Olivia realised that she was so intent on moving things along, that she was not listening to what the teacher was saying, and therefore was not responsive to the teacher's needs. She was concerned that since INSTEP she had probably "reverted a little bit back to 'let's get this moving' and spending a little bit less time [in conversation with the teacher]". Theresa acknowledged that she focussed too much on delivery and "just launching into something, expecting everybody to know what's in my head", and was now working on trying to "go slowly", although it was still a challenge for her. Olivia was also aware that she might be more enthusiastic and committed with teachers to whom she could relate, than with those to whom she could not relate:

In the job you find that teachers, [who] had a similar personality to you, make more referrals back to you, and ... I've lots of the warm fuzzy, fluffy teachers because I like a bit of that. You perpetuate the same way of doing things and then when you get a teacher who's completely different you know, not very nice really, but I might have thought 'Oh, this is going to be hard work' and put less effort into it. 
Aroha observed that some facilitators in her organisation "really struggled" when they were confronted with evidence of their practice that did not align with how they believed they practiced: "So there was often a mismatch, and that's quite difficult ... to be suddenly confronted with a piece of evidence that's saying something completely different to the way you thought you came across".

Alison became aware that what she was being asked to deliver within the Ministry of Education contract was out of alignment with her own values and beliefs and what was generally accepted to be effective practice:

I felt a real dilemma between what we were telling teachers to do, but we weren't doing it. So that's why the contextual responsive became my focus with my ... group [of teachers] because I thought 'Well do I ... tell them all this stuff and then roll out a workshop that l've already decided is best for them?' ... It was completely different to what we were [saying] ... what we were saying was a fundamental thing that teachers should be doing; we were not doing as teachers of teachers.

In summary, one of the most common problems of practice reported here was that of not being attentive to teacher voice, resulting in practice that was not responsive to the needs of the teacher or school. Being confronted by evidence of practice, which was contrary to what participants perceived it to be, brought about an uncomfortable sense of disequilibrium through the realisation that practice was not as effective as it could or should be, and that it was contrary to personal values and beliefs about effective practice.

\section{Confidence and affirmation}

Five participants reported increased confidence and affirmation in relation to their practice. Anne reported that she had more confidence (through being more informed) to give herself time at the beginning of an intervention to dialogue with stakeholders: "it's all very valuable that we do all this stuff before we dive in because if you dive in too soon you might be looking at the wrong thing".

Eva's increased confidence throughout the process of EBIP meant that she was much more proactive in seeking others' advice:

I have no problem in seeking out people's advice if I think they know something that I want know: l'll go and ask them now, whereas I wouldn't have dreamed of it before.

She reported that through her increased confidence, she had given herself permission to be selective in her choice of peers with whom she worked: 
What I'm seeing the biggest impact is who I align myself with to work with now. I am far more choosy and I have the confidence to be more choosy about who I work with. And if I look at somebody and I think they're looking at what's in it for them, I won't work with them. But if I see somebody who's really like me, trying to find answer for this student in the classroom or to raise achievement for students, or to find a way of working that's going to improve someone's life then yes I work beside that person.

Hannah reported much more confidence in subject knowledge and facilitation skills: "I think I'm a much more confident facilitator now". As a result, she ascertained that she had gained courage and assertion in her research work, and in communicating and justifying her practice and beliefs:

I think I've got more courage to do things. I'm much more courageous. I had never written ethics or proposals or anything like that, and I thought that was well outside my capacity, but I don't think that any more, but it was the courage to take the step. And I'm far more courageous about articulating what it is I think we need to do, and why we need to do it; ... being really staunch about it; ... being a stroppy wee moo really; and having that unswerving belief that at the moment we are doing the right thing. ... I will put my beliefs on the table. ... l'll be very upfront about those sorts of beliefs and values.

Although Laura had increased confidence in her decision-making, she was tentative in acknowledging that she was a more confident practitioner, stating that she still "sought people who thought the same way, to have enough confidence ... to keep going" and that her confidence can be impacted by "something that comes in and rocks you to bits". She did feel affirmed that she did a good job, although she accepted her fallibility:

You can't actually be right all the time and ... there are times when you do get it wrong, but that's okay; you can still get up and feel it; you can still do a good job, but you got it wrong that time.

Overall, Laura reported that "there's a lot more affirmation [in EBIP] than there is scariness". Anne was comforted to hear that other ISTEs faced similar difficulties in their RTLB role, and was affirmed to hear others' problems of practice were similar to hers:

We could each relate to what the other was saying as well. It was like lots of nodding and affirmation going on that, even when you were being quite hard on yourself and in some ways that, I guess we all, you know we were relieved to hear other people saying that they struggled with their job and um it's not an easy job, you know.

Hannah's experience reaffirmed for her that relationships and "making connections with people" played an important part in facilitation. 
For Alison, her teaching philosophy and the process of developing her practice were affirmed, including considering hard evidence gleaned from "conversations with the teachers about what they felt their needs were [and] looking at students' achievement data".

In summary, increased confidence resulting from engagement in EBIP took the form of the courage of conviction to ways of working. Participants felt more informed and confident in their decision-making and actions with regard to their practice. For some, existing practice was affirmed as being effective; while others were affirmed in the knowledge they were not alone in their problems of practice.

\section{Fear and discomfort}

Six participants cited elements of risk or feelings of fear that they had experienced or witnessed while working with others in the context of collaborative EBIP. Alison accepted a certain level of discomfort and acknowledged that there would always be a "certain amount of risk when you ask people to ... look into their practice, or examine why they do what they do, or look at the outcomes of what they do" because "you might find out that you are crap at something you thought you did quite well". Similarly, Hannah acknowledged that the experience "wasn't overly safe and comfortable", but she managed it because it was "something to get my teeth into; something concrete that I know that I need to do".

In 2008, Laura had articulated that she found self-reflection on her practice "scary" because of the complexity of her role in working with stakeholders:

In our field, it can be ... quite difficult, because ... we're sort of in the middle of everything and ... things can get skewed, so that your practice gets really threatened. ... I'm just thinking back over this last week, l've had some really really hard meetings where l've had to think really hard about how I worded something, because there are principals there, there's Special E [Education], there are parents and in this particular case the court is involved as well; so when you're asked your opinion about something, one has to be thinking about how it's going to be received by all of those people and plus staying loyal to the principal of the school that you happen to be in, so there are times when self-reflection is pretty scary.

She reported feelings of fear and insecurity, and never feeling complacent, particularly in the context of change and time constraints:

I was very frightened ... I had a constant feeling of being insecure, and particularly because everything that I was doing was involved with special education and there were so many changes happening. 
She revealed that, although she found it difficult to share evidence of practice within her RF pod in Phase 2, she was comfortable to do so with her NF, whom she regarded as a mentor. She was very aware of her vulnerability when deprivatising practice, and indicated that it would have to be with someone she could relate to and trust.

Anne was contradictory in that, although she acknowledged that at times she felt "quite threatened", she also said that she "felt quite safe to say "Look, you know I made a complete mess of that', or 'Just listen to me interrupting' or whatever". Her pod consisted of people she knew but had not worked closely with, and she regarded them as "a friendly crowd" and "a supportive team".

Elaine indicated that deprivatising practice "to the level that's kind of expected [within the organisation]", and within the context of a larger group, was quite fearful due to the risk of others being judgmental:

We're all very different here ... [it's difficult because] you're just not too used to ... exposing your practice to the level that's kind of expected here I think ... would that be what the fear is? ... we still have a fear of each other in some ways. I mean I don't think this applies to me and [a colleague] but with other people - that they may judge you on your practice, so you're not willing - some of us aren't willing to expose our practice totally to other people because ... they judge you rather than helping ... and that's why those small group things work really well because the people you're working with, you're quite, happy to expose yourself to.

Theresa was "a bit nervous" and felt quite fearful and daunted by exposing her practice from the perspective of a facilitator "rather than from something that you were very safe in as a teacher". She described her initial experience of the INSTEP project "a quagmire for a while" trying to incorporate theory and collaborative EBIP. She acknowledged that the nervousness eased with time as the experience became more familiar.

Eva "felt exposed" because she was "taking those risks" but was grateful that she "had the courage to keep taking them" because she recognised it was about her learning. She felt she had to "keep the impetus going" to progress her learning. Interestingly, Olivia reported that she never felt at all threatened exposing her practice, and thought that was due to teaching in Special Education for many years and sharing and critiquing her practice with specialists and teacher aides.

In summary, it was generally accepted that engagement in EBIP involved a certain amount of risk, and that it would be an uncomfortable process. Feelings of fear and 
exposure through engagement in EBIP arose as a result of working with others who were not considered to be trusted colleagues, or there was a fear of being judged. Feelings of fear and insecurity in RTLB practice arose as a result of ongoing change in the service, and working within an environment where decisions on practice constantly require to be justified to stakeholders. One participant reported no fear or threat due to the fact that she had, in a previous role, become accustomed to working in an environment of collaborative EBIP.

\section{Learning and professional growth}

This section reports aspects of learning and professional growth reported by participants as a result of engaging in EBIP over a period of time. Learning was interpreted as new knowledge and changed practice, including commitment to ongoing professional development. Professional growth included heightened awareness of self and role, clarification and articulation of teaching and learning philosophies, and enhanced sense of self-efficacy and agency.

\section{Knowledge and practice}

All participants reported increased knowledge and changes in practice with teachers and schools and/or changes with regard to systematically implementing EBIP to improve their practice.

\section{Knowledge}

Seven participants reported that they were better informed through reading more theory and research. Elaine broadened her knowledge about other theories she had not considered before, although she found it difficult "coming to grips with the ... dense ... and complex theory", while Theresa acknowledged that familiarisation and accommodation of new theory was a "slow process". Hannah's practice and development of skills in leadership were informed by reading the Best Evidence Synthesis on leadership (Robinson et al., 2009). Anne appreciated being able to "back up" her decisions with reference to theory, while Olivia gained a better understanding of the importance of using literature to inform her practice. Similarly, Eva "found meaning" within the concept of "research-led teaching", which she had not valued previously.

Five participants reported that they had a better understanding of ways to go about improving their practice. For Elaine, the whole process of EBIP was clarified. She 
indicated that her "understanding and application" of EBIP had "improved a thousand percent" and she was learning in "different ways ... at different levels".

Hannah identified that she had increased knowledge about her practice "at two levels": with teachers in schools, as well as in a leadership role with her peers.

Eva's raised awareness of the potential and opportunity for learning through collaborative inquiry meant that she would "jump at any collaborative projects", because she recognised the value in collaboration:

I knew in the collaboration there would be learning for me, and there would be somebody else to stand outside my practice to encourage and inform me. ... I just jumped at it [a collaborative project] because I knew that this is what collaborative inquiry is about; these are the opportunities. ... I recognise opportunities now because l've been through the process; because l've got my perspective of what it did for me; I know where I need to look and what opportunities I need to offer and get feedback from [in order] to ... improve.

She felt that because of the knowledge gained through her EBIP experience, she could "understand some of the places to stop and look at my practice, and what to look for when I stop at those places". Similarly, Olivia gained an increased awareness of the potential to constantly improve her practice, and the process by which to do it:

[EBIP] has increased my awareness that ... you can't stand still; you can always improve; you can always change; there's always different things to do and you can never think you've arrived at 'ah-hah, l've got it'; that it's always on the move ... INSTEP allowed me to put a framework around what I was trying to do and help formalise it a lot more, and I think doing the transcripts at the beginning was really important and that needs to be done; not all the time but an ongoing thing, so that you can keep reviewing what you're doing.

Evelyn learned quite simply that she did not have to transcribe everything; a small amount was sufficient to evaluate practice.

\section{Practice}

All of the seven participants who continued their role as ISTEs to 2010 described specific changes to their facilitation practice with teachers and leaders in schools. Eva and Alison cited changes in the way that they worked with preservice students in their role as teacher educators.

Changes in practice in schools were reported by participants at two levels. Firstly, changes in facilitation skills within schools was noted including: more conscious and systematic gathering of evidence of teacher and facilitator practice; efforts to be 
more contextually responsive to teacher/school needs; giving more time to interventions; and specific attention to development of relationships with clear communication between teachers/schools and facilitators. Secondly, they were aware of changes in their practice in terms of implementing EBIP within their own practice and promoting and supporting it in schools with teachers.

The most significant change of practice with teachers and leaders in schools was that of gathering evidence of teacher and facilitator practice. Hannah reported that her data gathering and analysis were "much sharper now," while Anne ensured "better outcomes for cases" by taking more time for gathering information, and using "more robust evidence" of practice. Laura considered that the use of video for gathering evidence of her practice, and that of teachers, had changed the way she interacted with teachers, and that her ongoing ISTE pod was "using video a lot more freely and openly". Theresa felt she was much better equipped, in her new role, to encourage her fellow teachers to "think about how to improve their practice and to see the influence of that on their children's progress ... through [using] hard assessment information ... and student voice". Evelyn observed that she was "much better at gathering evidence at the beginning and at the end [of an intervention]", and was using e-mail to "ask them [the teachers] provocative things" to surface beliefs and assumptions prior to working with them. She considered that the use of e-mail in this way gave teachers "time to think about that sort of thing". Elaine considered her practice had improved in terms of gathering evidence:

We [in our organisation] were always very evidence focussed originally, that's always been ... our thing with [this organisation]: evidence is crucial; gathering evidence; so I guess all I can really think of is we've become better at it. Thinking about ... what are those valued outcomes and what evidence do we have of how well ... [the teachers are] doing. Let's start with that, rather than sometimes doing stuff, and then gathering evidence later.

Anne, Elaine, Aroha and Hannah suggested that they had become more responsive to teachers' needs through more attentive questioning and listening to teacher voice. Hannah noted that she insisted on gathering information of claims about teacher practice and student performance rather than rely on what schools were saying:

When I'm designing any intervention with teachers I do a lot more of the ground work around, 'so tell me about how this will work in your department?' and 'if we did this, how would you see that working?' So, I do a lot more around the information gathering before we start deciding what the action is; and having the hard and fast evidence. So, when an HOD [head of department] says 'we don't do anything; our students are no good at this' I say 'well let's have a look at student work. Let's see which elements are missing'; so we're actually looking at evidence rather than a gut reaction. 
Anne acknowledged "giving the teacher plenty of space to talk; to hear her". Elaine considered that her organisation was better at "starting from where they [the teachers] are at ... and then trying to move people on, and measuring how much we move them on". Similarly, Aroha noted the change in her practice with regard to questioning:

I question a lot more; I check what l'm hearing. I ... probably try not to rush into things, because there's always something underneath that might not be surfaced initially. So, I think - checking; I think we've all learnt to question.

Olivia and Laura acknowledged changes in practice relating to giving more time to interventions and implementing ways of ensuring they were listening to teachers in order to be more responsive to their needs. Olivia took more "quality time" through a heightened awareness of "others and their needs", while Laura used "a lot of meetings" with teachers to establish needs. Olivia was conscious of "taking it more slowly"; giving "people time to go away and think about something"; and also of giving more time to reflect on her decisions.

Laura, Olivia, Evelyn and Hannah acknowledged changed practice in relation to communicating and establishing relationships with peers, teachers and schools with whom they were working. Laura was implementing communication techniques such as using "different opening sentences" to prevent her from "falling into the trap of ... [being] far too sympathetic and far too ... scared of rocking the boat with people". Olivia had "toned down" her tendency to provide solutions, and focussed more on "being the facilitator" within specific contexts, while Evelyn reported being much better at "keeping quiet and letting teachers do the talking". Hannah had "taken on board" feedback in relation to her tone and manner when interacting with peers, and found that had made a "significant difference" to her interactions as a member of a team.

Elaine, Eva and Alison cited changes in deliberate efforts to improve their own practice and implement EBIP, as well as supporting and encouraging teachers in schools to engage in EBIP.

Eva described, in detail, some of the changes she had adopted to monitor and evaluate her practice. She reported that she was more rigorous in inquiring into her practice by: planning processes for critical friendship; clarifying her objectives; developing data gathering tools to use at the beginning of interventions; developing frameworks to evaluate practice; being more honest with herself; maintaining a 
reflective journal; and being proactive in seeking feedback and advice. She summarised the experience:

And because I had this kind of contextually responsive process, I was ... confidently clearer at implementing where I wanted to [go]. So my work probably was more refined and more direct, and because of that the teachers responded to that, and they were keen to work in that way too, and they could see the value of it, and some of them had had dialogue with the other teachers that were involved and they could see the benefits of what we'd done as well.

Elaine reflected that she used EBIP much more rigorously than before, and had become proactive in identifying aspects of her practice for improvement:

It kind of crystallises things for me that I think I'm not good at and I need to get better at. I actually think about it rather than ... before you might just think, 'ah I should really get better, I really don't think I'm very good at that' but now you actually think of ways of gathering some evidence and talking to people about it, and actually doing that better ... we actually go out and video something we're working on, which is different.

Similarly, Alison identified her more proactive, rather than reactive, approach to improving practice.

Elaine and Eva reported changes in the ways in which they supported and encouraged EBIP by teachers in schools. Elaine stated that the EBIP cycle that was implemented within her organisation was also one that she would adopt in schools with teachers and leaders, but that it had been improved:

I think the other thing that we're really nutting out is that whole inquiry cycle and ... how well are we actually using that with our teachers. ... We use that ... evidence-based inquiry cycle all the time with our teachers, and students, and leaders. ... we always had in our work with teachers ... what we used to call an intervention logic, which really is just an inquiry cycle, start with evidence, blah de blah. But what we've done is sharpened it up.

It works the same at all levels. So basically, we do it for ourselves as an ISTE [inservice teacher educator] saying these are the things I need to get better at because I got this list of things that make a good ISTE [inservice teacher educator] and then at the same time you've got things about what makes good leaders, what makes good teachers, what makes good students, and you're using the same process as them. So ok, you've got this, this, and this. Evaluate yourself against these. Now what do you need to work on? So it's the same across all, we consciously try and keep the same process with all levels of organisations.

Eva valued using a questionnaire (that she had developed for ISTEs to use) to help surface teachers' values, beliefs and assumptions.

Hannah, Anne, Evelyn and Laura also acknowledged promoting and supporting EBIP with teachers in schools. Anne and Laura reported the effectiveness of using 
video to support teachers to review their practice. Evelyn was trying to promote a system of critical friendship within schools:

That whole contract of critical friend would be great if they were doing it within their school. I'm trying to get that established, but at the end of this year every teacher will review their successes and their learning needs from the data, and then what I'm hoping is that they will then say 'I've been really good with this. This is what l'd like to work on' and they will find somebody in their school that's got the reverse so that they can [work together as critical friends].

She also reported trying to get schools to identify, through self review and student voice, aspects of teaching and learning in need of improvement:

I try and get them to have done self-review before I go in, and have written down what's important to them and things like that, so I can have those conversations with them before I go in: they've talked to their children about what they value in [curriculum area]

Similarly, Hannah described how she used her experience with EBIP to influence her work with teachers in schools:

Certainly, having an inquiry cycle has impacted greatly ... getting people to use a systematic way of approaching implementation of change in the faculties and departments and classrooms: processed inquiry. Actually: 'So what is it we want to change? Why do we want to change it? How do you know? What are the systems here?' That's coming through loud and clear in everything I do. And then all the artefacts ... you can see the teachers working with me have got these elements in it.

In summary, most participants reported being more knowledgeable and better informed about their practice and role through reading relevant research and theory. They also found that enhanced knowledge of collaborative EBIP enabled them to adopt more rigorous and systematic processes to improve their own practice, as well as support EBIP in schools with teachers. As a result, participants were more aware of their own practice, the potential for improvement, and how to go about evaluating and improving it.

Changes to practice were reported by all participants, including those whose roles had changed since INSTEP. The most significant changes were in skills of facilitation such as gathering and analysing evidence including student data, improving communication and listening skills, and taking more time to identify needs and design interventions that were more responsive to school and teacher needs. Participants also reported that they were more proactive, systematic and rigorous in implementing processes to improve their own practice, as well as when supporting teachers to take ownership and responsibility for improving their practice in schools. 


\section{Professional growth and identity}

Seven participants indicated that engagement in EBIP brought about changes in their perceptions of themselves and/or their role and performance as inservice teacher educators. Some indicated changes in their philosophies of practice and sense of self-efficacy and agency.

\section{Perceptions of self and role}

Olivia, Laura, Eva, Elaine and Hannah all reported an increased awareness of themselves, their role and the ways in which they worked. Eva had identified who she was "as a person", and her way of "viewing the world", including the lens through which she perceived things, and biases she might bring to the data she was analysing. She also had an awareness of her ability to critique literature and position herself and her views:

I would say my ability to read literature, to integrate it with my views; seeing what I wanted to influence and actually saying 'no that's not where I want to go', and rejecting some as well. I'm starting to ... position myself in relation to that a bit better.

She also acknowledged that she was able to identify with the role of a valued researcher:

I'd say that's another outcome of the work with INSTEP: the willingness and readiness to take on research projects, and respond to people's invitations to be researching with them is stronger because I think probably INSTEP made me realise I have got something to offer; it validated who I was as an individual; it gave me a sense of identity within research and that combined with my Masters at the same time meant that yes, I do like this work; I could do this work. ... There is the brain in here that could work in this way.

She identified with "conscientious professionals", and her worth became explicit to her:

I think that's another aspect of the project that really stood me on my ground. I am a professional. I'm a blinking good professional. I'm really rigorous in my practice - always have been - but this [EBIP] made it explicit to me and for that I will always be grateful.

Eva was also more aware of the impact of her practice on others, and of her growing ability to be explicit about the way she worked:

I think that it is explicit now that I realise I want to improve my practice all the time, because if I improve my practice that impacts on the people that I'm working with. I'm better at what I do; being able to talk about what I do; then it makes it easier for them, and I'm realising the incredible significance of a role model who can make things explicit. 
She noted that through her increased confidence, she had granted herself permission to be selective about her work and colleagues, and not be too "worried about what other people think".

Laura and Olivia both reported an increased awareness of the ways in which they operated. Laura realised she liked to work in "collaborative consultation" with the teacher, which was quite different to some RTLB facilitators who were more inclined to provide solutions and resources:

Because, you often see other people working like that and you think 'oh my gosh ... they're working hard'. But the way that I like to work now is more of a, coming in with an open mind really, and not having an agenda, but expecting that the situation is going to have input from the teacher as well as me, is a much, much more sustainable approach. And I actually feel we both grow from it. So now, I'm quite firm about this is the way that I work.

Olivia was more aware that previously she had been inclined to provide solutions and resources because she "liked doing it so much" and "had no reason to ... do it differently" until she was confronted by the evidence of her practice:

I've always been a bit concerned about being the teacher's friend. I think l've [since] seen that a little bit differently. It has its pluses and minuses though. It's not really about being a friend ... it's making a difference ... it's about me being the facilitator not the person that comes up with the ideas ... I sometimes saw myself as a sales person, l've got all these fantastic ideas and I just want everyone to do them because they are so good. So I don't really do that any more. I just bite my tongue a bit sometimes. So probably I come in less with my own agenda, because I know just what to do to solve this, this is the sales thing, yeah so I'm very aware of that and I work really hard to not be quite so enthusiastic, and I'm also a bit of a rescuer. I love making resources and things like that so instead of doing that, I'm more putting it with the teacher: what do they think might work in this situation and 'why do you think that might work?' and 'how would you do it?' and 'what might it look like?', and then I can say 'would you like me to laminate it?' - so definitely, moderation for all those things.

She also ascertained that her enhanced sense of professionalism enabled her to look more objectively at her practice:

Instead of just looking superficially [at practice] ... there have to be reasons why; so the improvement in my professionalism will be: you know you can't cry about something or get overly excited. You've really got to look at what does it really mean and what's the person saying, so that part of professionalism as well.

Elaine became aware of her changed perception of her role from being a facilitator and a learner, to a leader of learning, where the use of research was more accepted as part of their role:

We've become confident at leading that learning, not just at learning to do our own jobs better - which is something definitely has happened; but actually been confident to lead a [learning] conversation with a group other 
people ... and we consciously try to lead the learning better too, so it's a never ending kind of spiral isn't it? ... I think for me l've got a lot better at looking at different research; bits of research and reading other literature a lot more than I used to ... I remember [when] we first started in INSTEP, we used to say, 'you know, we're the practitioners, we're not the ...' but I don't ... think like that anymore.

Theresa also acknowledged that she had become a leader of learning, as well as a learner.

Hannah reported that she became much more aware of her own professional identity, and the way in which she worked:

Now that I know more about how I operate, I can judge whether that works in a particular situation. ... So I'm also thinking about ... Oh so they think that identity for teachers is this. What does that mean for my identity, and what does that mean for the identity of the teachers that I'm working with. And so I was always, if you like, processing.

She also recognised that "the agency of choice and direction" was important to her as a practitioner, and she valued the structure and framework that allowed her that.

\section{Philosophies of practice}

Some participants reported a heightened awareness of their philosophies of practice, and their alignment with the ways they worked. Eva became much more aware of her values and beliefs through EBIP, which had "an impact on the underpinning philosophy" of her practice. She found that she was more able to identify with the philosophy of research-led teaching, which she had previously not been able to relate to:

This whole thing of research-led, teaching: we're so resistant to it, but I actually think that this stuff is very strong, so I probably changed my attitude towards the whole philosophy of research-led. I can see that it does have value whereas before it was like: 'Oh yeah here we go'. It was like I found the meaning in it for me, so that sits better with me because I like to have congruence between my values and my workplace and if there isn't a congruence I just really struggle and it presents in different ways.

She described the impact that research-led teaching had on her practice, and she acknowledged that the INSTEP project, combined with her MEd study, had contributed to her developing philosophy:

I think that I probably got a clarity in my teaching that has been reinforced by research-led teaching. ... I've gotta acknowledge too: my Masters - it went alongside this. It wasn't just INSTEP, but having those two processes concurrently has really enabled me to see the value of research-led teaching and how it works and how I can support my research ... how it comes into my teaching, and how I can use that in a way that makes the process clearer and unpack what things to unpack with the students ... in terms of effective teaching in the classroom. So I think those pathways are more explicit. 
Laura experienced an alignment of her values and beliefs with her adapted practice, and reported that she had renewed confidence and assurance:

I think, all of a sudden l've felt like this was what was really comfortable for me, and, I felt strong enough to keep working in this way. Whereas, there was a time when I often used to feel guilty if I was not ... fetching and carrying and taking all the resources and basically putting them in front of the teacher. ... And in fact, my employing principal has acknowledged that [different way of working] too.

She described feelings of affirmation and strength at the realisation of the alignment of her practice with her philosophy of teaching:

I think it's affirmed, and strengthened. ... INSTEP definitely just felt so comfortable, as soon as I started to understand what it was all about, it just fitted so well with the way that I wanted to be, and the way that I wanted to work.

However, in 2010 Laura expressed concern that the proposed new model for RTLB was challenging her whole values and beliefs system, as it appeared to be moving away from "collaborative consultation with teachers" to "Ministry directed practice".

Hannah found that her "beliefs and values around effective pedagogy" were clarified, and this enabled her to inform and articulate her practice in relation to "underpinning theories" from the INSTEP project dimensions of practice (Ministry of Education, 2006) and her own "framework for operation" such as the "principles of andragogy".

\section{Self efficacy and agency}

Anne, Eva, Hannah and Laura experienced an enhanced sense of self-efficacy and agency as a result of engaging in EBIP. Although Anne stated that self-efficacy was difficult to achieve in the RTLB environment because of the difficulty of measuring outcomes, she reported a greater sense of self efficacy from having more certainty in her values and beliefs, and from being "more informed", and being able to back up her practice with research. Eva reported an increased awareness that her work was "of value" and she had more confidence in her practice:

It's about growing in my sense of who I am, what I do, and the fact that what I do is good work; it's very good work, whereas before I thought it was work, I hadn't realised, I hadn't put a kind of value on it and I don't know if that's a good or bad thing, but it has certainly improved things for me.

Hannah acknowledged that her work within her organisation had allowed her "to work within a national community of practice where those skills are being utilised". Laura reported making "much better choices", and "feeling more confident" about 
these choices. She reported that she felt assured that she had "credibility" in her work:

I guess credibility is the thing, or efficacy really in a way, is the thing that we always, well I'm always concerned about ... from our work anyway, it has to be; you have to ... feel that the time that the teachers are spending with you is worthwhile, so I guess that's one of things that I'm thinking about in terms of my practice.

In relation to professional growth and identity, participants reported a greater awareness of themselves, their perspectives and the ways in which they worked. Enhanced feelings of professionalism included self-efficacy, agency, and the ability to view their own practice objectively. Self-efficacy and agency seemed to be enhanced through clarification of values, beliefs and assumptions and increased knowledge of research and theory, enabling a clearer articulation of underpinning philosophies of practice. Some had developed changed perceptions of themselves and their roles, and were able to identify with the role of researcher or leader of professional learning, as well as that of a facilitator. For some, the closer alignment of their values and beliefs with their roles led to a clearer sense of identity and purpose.

\section{Chapter summary}

All participants appeared to be ready and willing to embrace the challenge, and engage in EBIP. They welcomed the experience as an opportunity for professional learning and growth. There was some frustration and disappointment expressed as a result of others not reciprocating effort and risk.

Dissonance was experienced by participants when evidence of practice revealed it to be less than what it was perceived it could or should have been, or when it was not aligned with the participants' values and beliefs.

Increased confidence occurred when participants felt better informed about their practice, including knowledge of related research and theory. Increased confidence was manifested in clearer convictions of ways of working.

Fear arose from deprivatising practice with colleagues who could not be trusted to be non-judgemental, and from working in an environment that was subject to frequent change. 
Enhanced knowledge of the process of EBIP enabled more systematic and rigorous approaches to improving practice.

Changes to facilitation practice included improved gathering and analysing of evidence, improved communication and listening skills, and more attention to being responsive to school and teacher needs. Processes adopted to improve participants' and teachers' practice were more proactive, systematic and rigorous.

Professionalism was enhanced through a heightened and more objective awareness of self and practice; a greater sense of self efficacy and agency, and a more transparent articulation of philosophies of practice and underpinning theories. For some, their professional identity had grown to incorporate the role of researcher or leader of professional learning. 


\section{CHAPTER 8 \\ Discussion of findings}

\section{Introduction}

In Chapters 4-7, the broad categories and sub-categories, which were inductively derived from the data through grounded theory methodology, were reported without further analysis. This chapter discusses the key findings with reference to literature. Relationships among the categories are identified, and three key themes derived: contexts, communities, and outcomes of EBIP. These themes are subjected to further analysis and discussion in relation to existing theoretical frameworks, and key contributors to literature in the respective fields of knowledge. They inform the resulting theoretical framework which is presented in Chapter 10. The development of categories, themes, and the emergent theoretical framework is illustrated in Figure 3.7. Throughout this chapter, participant quotes are used as illustration. In some cases, quotes which have been presented in earlier chapters are re-presented in this chapter as they are considered to illustrate particular aspects of in-depth analysis and discussion. The chapter begins with an introduction to the key elements of EBIP.

\section{EBIP: What does it consist of?}

The process of EBIP for inservice teacher educators within INSTEP was based on an action inquiry approach (Kemmis \& McTaggart, 1988; McNiff, 2002; Reid, 2004) and consisted of an iterative process of deconstructing, evaluating and critiquing practice against personal professional values, beliefs and assumptions. The inquiry and knowledge building cycle for inservice teacher educators is illustrated in Figure 4.1.

Within INSTEP the actual process of inquiry was developed and implemented in different ways by each of the ISTE pods, and encompassed a range of approaches such as action research, critical dialogue, observations and learning journals (Reid, 2004; Robinson \& Lai, 2006). Examples of different approaches are cited in Document Sources A, B and C (Lamont, 2011; McGee, 2011; Ministry of Education, 2008a). Participants valued the explicit nature of the inquiry cycle which involved rigorous reflection within a collaborative environment. They also reported that they valued the structures and processes that were in place to support EBIP within INSTEP such as evaluation frameworks, timeframes, collaborative arrangements, and reporting and monitoring requirements that helped to maintain focus and priority. 
The aspects of reflection and incorporation of evidence of practice were central to all inquiries within INSTEP. This section will discuss these two aspects and the ways in which they were manifested within the INSTEP project.

\section{Reflection within inquiry}

Forde et al. (2006) report that research has shown that reflection improves confidence, increases thoughtfulness, increases acceptance of ambiguity in practice, and increases the likelihood of improving practice through a systematic approach. However, these findings focus on the individual practitioner, and are based on perceptions of improvement and not objective judgements (Forde et al., 2006). As discussed in Chapter 2, there are many different perceptions of what constitutes reflection, and one of the difficulties is arriving at a definitive model. For example, Korthagen's (2001) definition of reflection as "the mental process of trying to structure an experience, a problem, or existing knowledge or insights" (p. 58) seems simplistic, while Brookfield (1990) acknowledges that his phases of reflection centring on "the recognition and analysis of assumptions" (p. 177) are not only challenging, but also "psychologically explosive" (p. 178). Reflexivity is differentiated from reflection, and involves a degree of introspection questioning values, beliefs and assumptions about practice and the interactions, connections and relationships that surround it (Cunliffe, 2004; Kemmis, 2009; Ryan, 2005).

Forde et al. (2006) and Zeichner and Liston (1996) caution that the act of engaging in reflection does not automatically translate into a better or good practitioner, and that it depends on the rigour, depth and nature of reflection. In spite of the difficulties in attributing actual outcomes to reflection (Ministry of Education, 2008a; Timperley et al., 2007), it has become "an almost unquestioned element" of professional practice and learning; so much so that it is considered unacceptable or unprofessional not to engage in reflection (Forde et al., 2006, p. 72).

Participants in this study engaged in systematic and rigorous reflection on practice which incorporated: deprivatising and making practice explicit; surfacing and examining personal professional beliefs, values and assumptions; engaging in critical dialogue; and reframing practice and underpinning theory to improve teacher practice and student outcomes. They adopted rigorous and systematic procedures to gather valid evidence and engage in critical dialogue around practice. They changed their practice in specific ways to be more responsive to client needs, and were better informed about their underpinning theories and the ways in which they practised. Although most did not continue with such a systematic and rigorous 
approach to inquiry beyond INSTEP, they reported being more proactive and objective in relation to their practice as a result of reflection. This is similar to Cordingley's (2004) findings where teachers who did not necessarily continue with a rigorous research-based approach were more "passionate about retaining a problematizing approach to their practice" (p. 85) in an ongoing way.

It is important to distinguish at this point, the difference between what might be interpreted as a mechanistic or technicist approach to inquiry (Moore, 2007), as conveyed in the inquiry cycle in Figure 4.1, and the enculturation of a philosophy of inquiry by individuals and organisations, which can contribute to educational change and reform (Cochran-Smith, 2005; Reid, 2004). Embedded within each of the individual INSTEP projects was a shared and explicit understanding of a process for inquiry that would be adopted by individuals [Document Source A (Higgins, Parsons, \& Bonne, 2011)]. These processes were underpinned by theoretical perspectives of reflection and inquiry such as Schön (1983), Argyris and Schön (1974), McNiff (2002), Kemmis and McTaggart (1988), and Atkin (1996). Although the processes and terminology varied, the principles were the same for all participants.

An individualistic approach, although valid for individual practice, has been the subject of criticism when it does not embrace or address external socio-political or cultural contexts of practice:

\begin{abstract}
Changing the individual is not enough: if we are to improve learning for pupils in our schools then we must focus on change at school level, and this is a complex process. Any process of individual reflection, change and development needs to take account of the cultural factors at work in institutions such as schools and hospitals, and to take account of how the individual's professional identity meshes with that culture or otherwise. (Forde et al., 2006, p. 79)
\end{abstract}

An individualistic approach is criticised for being too insular and introspective (Cochran-Smith, 2005; Reid, 2004; Zeichner \& Liston, 1996), and not leading to sustained, system-wide change and improvement. Reid (2004) argues that unless educational institutions "model and support inquiry" (p. 8) individual efforts will be inhibited. He also argues that EBIP requires "an institutional and system-wide environment of trust" (p. 7).

Reflection, as defined in Chapter 3 of this thesis, incorporates rigorous and systematic reflection over time, is informed by evidence, and can incorporate any or all of the three levels identified by van Manen (1997): technical-practical, interpretative, and critical. Critical reflection involves examining values, beliefs and 
assumptions, and consideration of the broader sociocultural and political factors mediating teaching and learning. Reflection considers any or all of the following:

- the content and process of teaching and learning (the immediate contexts, actions, and purposes within the teaching and learning situation);

- established research and theory;

- personal practical theories and theories-in-use;

- the broader sociocultural and political contexts and consequences that influence practice.

All participants of this study engaged in reflection on practice as defined above, except that there was more of an awareness of the broader sociocultural and political contexts and consequences, rather than incorporating evidence of them within the process of reflection. There was certainly more of a focus on evaluating evidence of practice, surfacing values and beliefs, and reframing theories-in-use to align with espoused theory (Argyris \& Schön, 1974). The reflection practised by the participants, therefore, although rigorous and systematic, is probably in line with the insular and introspective individualistic approach which is less likely to lead to sustained system-wide change and improvement.

During INSTEP, participants engaged collaboratively in reflection on practice within a variety of communities. Only two participants continued to reflect on practice in a rigorous way beyond INSTEP, and that was within the context of organisational professional learning and appraisal initiatives. Rigorous reflection, therefore, did not continue outwith the organisational support and framework provided by the INSTEP project and the provider organisations.

The next section discusses the consideration of evidence in EBIP.

\section{Evidence}

The aspect of evidence is a crucial one, since judgements of improvement are dependent upon evidence of the outcomes, and one of the key challenges in education lies in directly linking changes in inservice teacher educator practice with improved outcomes for students (Ministry of Education, 2008a; Timperley et al., 2007). There are a multitude of mediating factors influencing teacher practice and student learning, and the impact of changes on student learning may only be evident over a long period of time. This section discusses how the selection and treatment 
of evidence is significant in terms of making judgements of practice and informing learning and professional growth. It begins by discussing the relevance, sufficiency and veracity of evidence as articulated by Thomas (2004).

\section{Relevance of evidence}

Thomas (2004) discusses the process of identifying relevant evidence within "informational noise" (p. 4). He acknowledges the social context and the legitimacy of peers within a professional community judging the quality and value of evidence. The participants in this study undoubtedly engaged in a variety of professional communities within the INSTEP project and beyond, to debate, critique and agree on the relevance and validity of types of evidence such as artefacts from practice and research and theory. Some also developed processes which were designed to filter out extraneous information, and focus only on pertinent aspects of video, audio or transcript artefacts. Within INSTEP it was the collective responsibility of the INSTEP communities to arrive at a consensus on the relevance of evidence and the criteria for judgement of effectiveness.

\section{Sufficiency of evidence}

In relation to the sufficiency of evidence, Thomas (2004) asserts the need for corroborating evidence and information. He considers that sufficiency of evidence is particularly important "in determining the status of one's evidence in moving beyond information, and in particular for drawing distinctions between the status of the beliefs one holds" (p. 6). In this study, participants used a range of corroborating evidence of practice such as video, audio, transcripts, teacher and student voice, and student outcomes. They also used information about the context of their practice, relevant research and theory, and statements of personal values and beliefs. Participants therefore considered a variety of research and practice-based evidence as well as their personal philosophies of teaching and learning.

\section{Veracity of evidence}

Thomas (2004) also emphasises the importance of corroborating evidence in establishing trustworthiness. Within INSTEP, participants engaged in professional communities where consensus was reached on types of evidence that would be required for EBIP, and in some cases, the ways in which practice and researchbased evidence would be interpreted and critiqued. The aspect of challenge, which was particularly valued by participants, served to provide different perspectives and question the legitimacy of practice and research-based evidence, as well as personal philosophies and assumptions. The veracity of evidence was attended to 
by participants within their INSTEP communities where there were structures and frameworks for critical dialogue with respect to evidence.

Thomas (2004) proposes that corroborative evidence is necessary if it is to impact upon rational belief and acquisition of new knowledge. He presents a continuum of types of evidence (see Figure 8.1).

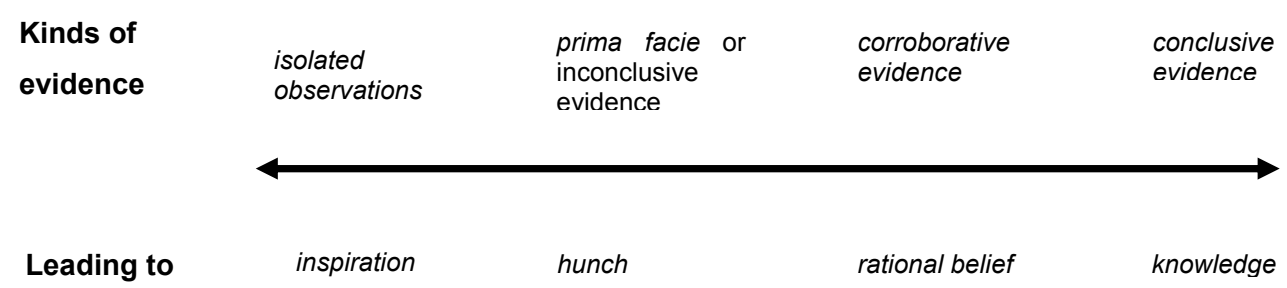

Figure 8.1: A continuum of sufficiency (Thomas, 2004, p. 8)

Thomas asserts that much of this gathering of evidence and moving along the continuum is tacit and subconscious. It is also worth noting, that in an educational context, when considering evidence, there will be no conclusive evidence of the impact of inservice teacher educator or teacher practice, and that corroborative evidence is the best that can be achieved (Ministry of Education, 2006, 2008a; Thomas, 2004; Timperley et al., 2007). Thomas (2004) and Cordingley (2004, 2008) emphasise the significance of tacit knowledge gained through this process, and acknowledge the potential difficulty for teachers in reconciling their tacit knowledge with knowledge from research and theory. The increase of rigour along the continuum is also reflected in the dimensions of reflection proposed by Zeichner and Liston (1996). The processes discussed in this section go some way towards responding to Pring's (2004) appeal for "reflections about notions of evidence outside experimental research - for example in craft and personal knowledge - and consideration of how that evidence can be systematically marshalled and used" (cited in Thomas, 2004, p. 17).

Within INSTEP, the participants of this study approached the consideration of evidence rigorously and systematically as recommended by Hargreaves (1996). They determined validity by developing and implementing processes which "involved rigorous attempts to examine and eliminate alternative interpretations of the evidence" (Robinson \& Lai, 2006, p. 65). These processes incorporated a range of tools and mechanisms including, for example, critical dialogue, triangulation, peer feedback, learning conversations, and stimulated recall, within environments where respect and rigour were consciously and deliberately nurtured and applied (Ministry of Education, 2008a; Reid, 2004; Robinson \& Lai, 2006). 
Having engaged in planned and explicit processes to examine practice and research-based evidence alongside their personal professional philosophies, participants reported a heightened awareness of their practice and its impact upon others, and the ability to articulate more specific and distinct links between their practice and underpinning research and theory. In this way, their progression along the continuum in Figure 8.1 ensured that elements of rigour and relevance were addressed (Schön, 1983), their espoused theory became more aligned with their theories in use (Argyris \& Schön, 1974), and new knowledge was constructed by bridging the gap between episteme and phronesis (Loughran, 2006). This study evidences the benefits and value of collective ownership of, and responsibility for, the process of validating and judging both research and practice-based evidence.

Participants in this study engaged in rigorous and systematic evidence-based inquiry into their practice. The collaborative approach enabled groups of practitioners to debate the relevance and validity of different types of practice and research-based evidence and to develop tools and mechanisms of evaluation. The degree to which rigour was applied in relation to relevance, veracity and sufficiency of evidence was variable dependent upon the particular community context. For all participants during INSTEP, the project provided the structure and expectation of systematic rigour in reflection. However, for most of the participants beyond INSTEP, there was no such community within which to debate evidence of practice. Aroha and Elaine were the exceptions as they were involved in organisational systems with particular frameworks within which to conduct EBIP. Hannah and the RTLB participants continued to be engaged within communities, but they reported less rigour and systematisation. Evelyn, Alison, Eva and Theresa were not engaging in rigorous and systematic EBIP, but reported a heightened awareness of the need to adopt a problem-solving approach.

This section has discussed the processes involved in participants' critical reflection on, and reframing of their practice, beliefs values and assumptions. The following sections include discussion of the findings in relation to community and organisational contexts.

\section{Contexts}

Within INSTEP each of the individual participant inquiries took place within the broader contexts of the INSTEP project and their respective provider organisations. This afforded a variety of infrastructures, requirements and expectations. This section will discuss the impact of these broader contexts on EBIP with particular reference to the influence of formal and informal systems, processes and 
expectations. This discussion draws on the relevant aspects of organisational theory to clarify the variety of contexts.

\section{Organisational features}

Schein's (1980) definition of an organisation as "the planned coordination of the activities of a number of people for the achievement of some common, explicit purpose or goal, through division of labour and function, and through a hierarchy of authority and responsibility" (p. 15) would apply to the INSTEP project and any inservice teacher education provider organisation.

Within INSTEP there were expectations, responsibilities and requirements of individuals and communities, which were embedded within the project framework. They were: to engage in inquiry and critical dialogue; to agree and abide by protocols for collaboration; to meet deadlines and prepare for meetings; to gather valid evidence of practice; and to support colleagues in critical reflection [Document Sources B, D (Ministry of Education, 2008a; Sankar, 2009)]. Due to the contractual nature of INSTEP, there was an obligation of RFs and ISTEs to monitor and report on the progress of their inquiry. Throughout the INSTEP project, the level and nature of the requirements were similar for each of the participants. However, beyond INSTEP, only two participants continued with a rigorous and systematic approach to EBIP. They were from organisations that adopted professional learning and appraisal programmes which had monitoring and reporting expectations and requirements of all facilitators within the organisation.

Schein (1980) differentiates between three different types of organisations: formal, informal and social. The formal organisational aspect of INSTEP and provider organisations are "fundamentally a pattern of roles and a blueprint for their coordination" (p. 16), such as the infrastructures, systems and processes that enable the operationalisation of organisations. Within INSTEP and provider organisations there were also embedded informal and social organisations. Informal organisations are those activities, interactions and relationships that take place within every formal organisation in pursuit of the goals of the organisation "which are not called for by the blueprint" (p. 16). Social organisations incorporate activities, interactions and relationships that arise implicitly and spontaneously within communities and that do not necessarily have an explicit aim or goal. While formal organisations exist independently of people as a blueprint for operationalisation, social and informal organisations are dependent upon, and have particular people, relationships and interactions at their core. 
This study found that the formal organisation of INSTEP provided a framework for operation with explicit aims, and a clearly defined hierarchical infrastructure with leadership and management structures, and accountability measures for communities and individuals. INSTEP's system of "vertical and horizontal networks of practice" [Document Source A (Parsons \& Higgins, 2011, p. 2)] incorporated aspects of formal, social and informal organisational features. Networks of practice, which were a major feature of the design of INSTEP, are recognised as being effective for the promotion and sustainability of educational change and innovation (Chapman \& Aspin, 2003; Earl \& Katz, 2010) as they are "able to function at the meso-level to strengthen interconnections and spread innovation across all levels - the micro, meso and macro-levels" (Chapman \& Aspin, 2003, p. 654, cited by Higgins \& Parsons, 2011).

While the formal organisational structure of INSTEP determined resourcing, strategic priorities, infrastructure, management, and accountability measures, the networks of practice at all levels consisted primarily of dimensions of social and informal organisations. These took the form of the interactions, activities and relationships inherent within and across the communities consisting of the INSTEP management team, NFs, RFs and ISTEs. The contractual obligations and expectations were clear at a formal level, but there were also implicit expectations at all levels. Psychological contracts and forces have a significant impact on the functionality of organisations (Cooper \& Robertson, 2001; Handy, 1981; Schein, 1980). Psychological contracts are implicit, subtle and unwritten expectations at all levels within organisations. Psychological forces "operate in organizations towards the establishment of informal patterns which influence and alter the formal ones" (Schein, 1980, p. 32). This complex interplay of implicit expectations and unseen forces impacts upon, and is influenced by, personal motivations, values and beliefs, power relations, and the broader socio-political contexts of each organisation or community (Cooper \& Robertson, 2001). These forces were evident within INSTEP, for example, when Alison expressed her thoughts in relation to uneven relationships of power within her pod:

So INSTEP actually allowed us to say 'Well okay you might be the boss ... but I'm allowed under this project to do it this way' ... which was really good. I hadn't thought of that before ... but it was a real clash, it was really tricky.

Within INSTEP and beyond, although there may have been an implicit expectation, or psychological contract to demonstrate professional growth by reflecting on practice, this was not always reflected, or clearly articulated in the policy and practice of the formal organisation, as explained by Hannah: 
Well there is an expectation that you can talk about practice but it's at a talking level. Some people are engaging in [it] if you like 'informal[ly]', because they work, say a couple of AtoL [Asses to Learn] people work together they do some observations on each other and people who work in shared facilitation roles have done that, but if you're not working in a team and we have people who work in isolation, it's not happening naturally.

Psychological contracts and forces pertaining to respect, commitment, reciprocity, and mutual trust operated at many levels within and across INSTEP communities of NFs, RFs and ISTEs. These contracts and forces impacting upon participants were often dissonant, with conflict between the perceived values and expectations of the organisation and those of the learning community or individual. The organisations were sometimes perceived not to value the kinds of activities, interactions and relationships that were prioritised and valued within INSTEP. Eva described her reactions:

I think the management support might have been higher profile and I think that could have perhaps given more value to the project. I don't know but I was thinking, you know, we never saw our manager at all. Our head of school came to one of the [presentations] and we got some brief feedback there, but there was never a sense of real interest. I was never stopped in the corridor and asked how it was going and I think that would have made a big difference to have that kind of interest.

Laura described her feelings of guilt when she felt she was not meeting implicit expectations:

I think, all of a sudden I've felt like this was what was really comfortable for me, and, I felt strong enough to keep working in this way. Whereas, there was a time when I often used to feel guilty if I wasn't like fetching and carrying and taking all the resources and basically putting them in front of the teacher. ... And in fact, my employing principal has acknowledged that [different way of working] too.

McGee [Document Source A (2011)] highlighted the imbalance of available and sufficient time against expectations of ISTEs within the INSTEP project. Beyond INSTEP, most of the study participants reported similar concerns. Laura and Eva express the tensions in regard to time allocation:

At the moment, there are little INSTEP groups going on, the one I'm talking about, is happening out of time ... it's just something done in our own time, it's not part of the RTLB service - it's so crazy. (Laura)

physically we've got time to drive up to this place and come back in the car so we will have time which is a key factor that ... needs to be built in because I think that's the thing that is most inhibitive of [being a] reflective practitioner and [having a] critical friendship. This time [that has to be built in] ... the negative is that ... how long can I sustain that, you know, working in this way on my own and ... will it become embedded in my practice sufficiently to be part of what I do, and I think it might, I'm not sure. ... but it's always going to be the time factor, the availability of somebody else to be working with. (Eva) 
There was also a perceived mismatch between implicit expectations to improve practice and accountability measures, such as the output driven nature of Ministry of Education funded and RTLB services' reporting requirements which did not acknowledge learning, professional growth and improvement of practice. Laura and Hannah both believed that reporting requirements should acknowledge professional learning and growth:

What I do find is some of the constraints are coming from the Ministry as well and I find that really frustrating, that here l've been involved with this wonderful Ministry funded contract [INSTEP], but they still expect us to fill in forms and things that have got nothing to do with inquiry. ... It's just almost like two different ways of thinking. (Laura)

So there's more and more being squished into that time which would be the time that you would naturally sit down and ... reflect on your work ... I would like the Ministry to write into each output and contract the whole thing around building capacity and leadership and facilitation, and staff it for that so that we could output the work that we do around building capacity for advisors. I think that would be the singular most helpful thing that could happen 'cos then it's inside the contract. Everybody has to report against it; it would be consistent across the outputs and contracts, and that itself would bring cohesiveness to a service. (Hannah)

Those participants who did not continue with EBIP beyond INSTEP still expressed a commitment to an inquiry approach to practice, but were hampered or discouraged by the lack of focus, acknowledgement and resourcing at an organisational level.

One aspect of INSTEP that was particularly valued was the rationale and infrastructure including the alignment of the organisational/community goals, and systems, processes and accountability measures that gave value to, and legitimised, the activities, interactions and relationships inherent within a culture of inquiry. Olivia and Eva, for example, identified the need for formalising the process:

INSTEP allowed me to put a framework around what I was trying to do and help formalise it a lot more. (Olivia)

I think that the collaborations need to be formally organised. I know that they do happen but they happen on a very low level. But I think ... to take you right up there I think they have to be formally organised, that's what I would say about the process. I don't think that it's something that just happens coincidentally, I don't think it can. It was the formalisation of that [INSTEP] project that enabled us to go forward. (Eva)

Forde et al. (2006) state that the social and informal dimensions of an organisation are crucial: to the functionality of the organisation; to the organisation's capacity to achieve its objectives; and to the development of individuals' professional identities as educators. Schein (1980) asserts that psychological contracts and forces mediate personal motivation and the development of professional identity and sense of 
worth. Integration of goals and expectations can reduce these conflicting messages and enhance communication and mutual understandings within the organisation.

In this study, these social and informal organisational features that were so prominent in the professional learning and growth of the participants in INSTEP, and allowed flexibility and autonomy within the framework, were not able to be sustained without being embedded within the overarching features of the formal organisation. This was evidenced in Hannah's organisation where collaborative inquiry was perceived to be of value, and collaborative structures were in place, but the lack of formalised processes and a coherent vision of purpose resulted in an ad hoc and loose approach to inquiry, where environments of trust, respect and safety were not prioritised or supported.

The INSTEP project incorporated formal, informal and social aspects of an organisation. This enabled an environment of theory competition, with shared understandings, distributed leadership, collective ownership and responsibility, the expectation of challenge, and the valuing of diversity (Robinson \& Lai, 2006; Timperley \& Parr, 2005). This study confirms that environments of theory competition, incorporating networks of practice such as those established within INSTEP, require to be situated and integrated within a formal organisational framework if they are to benefit from, and build on, the social and informal dimensions of such communities. In this way, practitioners will be supported in the improvement of their practice and their professional growth, where implicit and explicit expectations, resourcing, and policy are in alignment within a coherent and shared vision of purpose.

This section has foregrounded the importance of the alignment of formal policy and infrastructure with the informal and social dimensions of organisational operation. The following section discusses the value of systems, tools and mechanisms within EBIP.

\section{Systems, tools and mechanisms}

Research illustrates that collaborative models of professional learning are able to support and promote learning and professional growth (Little \& McLaughlin, 1993; McLaughlin \& Talbert, 2001; Timperley et al., 2007; Wenger, 1998b; Wilson \& Berne, 1999; Wyatt-Smith et al., 2008). However, there is little research into the processes and mechanisms that facilitate the formation and sustainability of collaborative communities of learning (Given et al., 2010; Grossman, Wineburg, \& Woolworth, 2001; Little, 2003; Wilson \& Berne, 1999). Recent research (Given et al., 
2010), focussing on processes and mechanisms to promote collaboration, reports that collective engagement in processes of documentation and acts of "going public" (such as presenting to peers, and sharing work):

- mediated tensions;

- acted as catalysts to learning and development; and

- supported teachers in articulating their practice, sharing power and validating the process.

INSTEP participants considered that the process of engaging in authoring journal articles or presenting at seminars or conferences enhanced and enriched learning and added value to the process. Such activities afforded collaborative engagement with participants' learning and progress, as well as validating their efforts. For example, this was the case for Eva:

\begin{abstract}
I think we [the RFs] were an inspiration to the other advisors when we presented our work, $\ldots$ and I remember them all saying about our relationships: what they noticed about the trust between us, and about the sense of having done something together, and the strength of that, and I think they were really impressed, and I think we had a lot of respect from some colleagues because of that.
\end{abstract}

Given et al. (2010) and Wyatt-Smith et al. (2008) assert that tools to guide collaborative work and make teaching and learning explicit, facilitate an inclusive culture, and are vital to the change process. They also observe that ownership of processes and routines within a leadership framework can shift power dynamics and allow a degree of autonomy. The participants of this study individually and collectively engaged in developing frameworks for evaluation, protocols for interactions, inquiry cycles, and explicit tools and mechanisms for deprivatising and critiquing aspects of practice and values, beliefs and assumptions. Most participants commented on the value of the tools and frameworks they developed. They were able to claim ownership of the specific tools and mechanisms they were using, which were informed by research and theory. For example, Aroha commented on the development of an evaluation framework:

I think it was originated from Freire but we used the maths assessment tool for starting to give us some guidelines around looking at the video. You know - when we were starting to develop a framework and we used those words - 'What do you notice? What do you understand by what you are noticing and what might you do differently or change as a result of your understanding?'

Verdonschot (2006) advocates deliberate efforts to create circumstances that enable innovation, such as the development of meta-cognitive and reflective skills. Little (1982) identifies that norms of collegiality and continuous improvement were 
prevalent in adaptable schools. Such norms include expectations of shared discussion, planning and designing, where analysis, evaluation and experimentation are regarded as "tools of the profession" (p. 339). The contractual nature of the INSTEP project meant that there was an expectation that participants would meet regularly with colleagues, engage in critical dialogue, and document and present their progress in different forums and formats. There was explicit attention to metacognitive and reflective skills embedded within the inquiry cycles that were developed by the pods, and in the INSTEP resource materials Ki Te Aotūroa (Ministry of Education, 2008a).

Participants in this study engaged collectively in developing tools and mechanisms to make their learning and practice explicit, and to facilitate critical reflection and dialogue. The contractual nature of the project, and the leadership framework within which it operated, conveyed clear expectations of INSTEP participants, while autonomy and flexibility afforded individual and collective ownership of the learning process. While it was reported that the particular tools and mechanisms were necessary and valuable for critical reflection and documentation, research literature and the findings of this study indicate that it is not simply the tools and mechanisms, but the collaborative engagement in their development that adds value to the process. The following section discusses the aspect of collaborative structures and communities.

\section{Community}

Over the past two decades there has been a growing awareness of the benefits of collaborative approaches to professional learning (Cochran-Smith, 2005; Cordingley et al., 2005; Darling-Hammond \& Bransford, 2005; Forde et al., 2006; Lave \& Wenger, 1991; Little \& Horn, 2010; Stoll, Fink, \& Earl, 2003; Wenger, 1998b; Wilson \& Berne, 1999). One of the key elements in the design of the INSTEP project was the incorporation of collaborative EBIP. This was afforded by the networked infrastructure of the project, and the formation of professional learning communities at multiple levels of operation [Document sources A, D (Parsons \& Higgins, 2011; Sankar, 2009)]. Hadar and Brody (2010) assert that although communities of practice "are created from existing social networks in organisations ... they require focus and leadership in order to flourish" (pp. 1642-1643). Four out of six key elements identified by Sankar that enabled the INSTEP project to achieve positive outcomes, related to aspects of networking and collaboration: 
- leadership by a core group of national facilitators

- inquiry/action research within communities of practice

- management by a project team located within the Ministry

- additional support through research mentors, online communities, international speakers. [Document Source D (Sankar, 2009, p. 26)]

Within INSTEP a variety of networking and collaborative arrangements were designed, and evolved, which included multiple layers of participation. They included: the Ministry of Education (MoE) project management team; NFs, RFs, ISTEs, and their provider organisations; the wider community of inservice teacher educators; sector representatives as stakeholders in New Zealand education; and leaders, teachers and students in schools (see Figure 8.2).

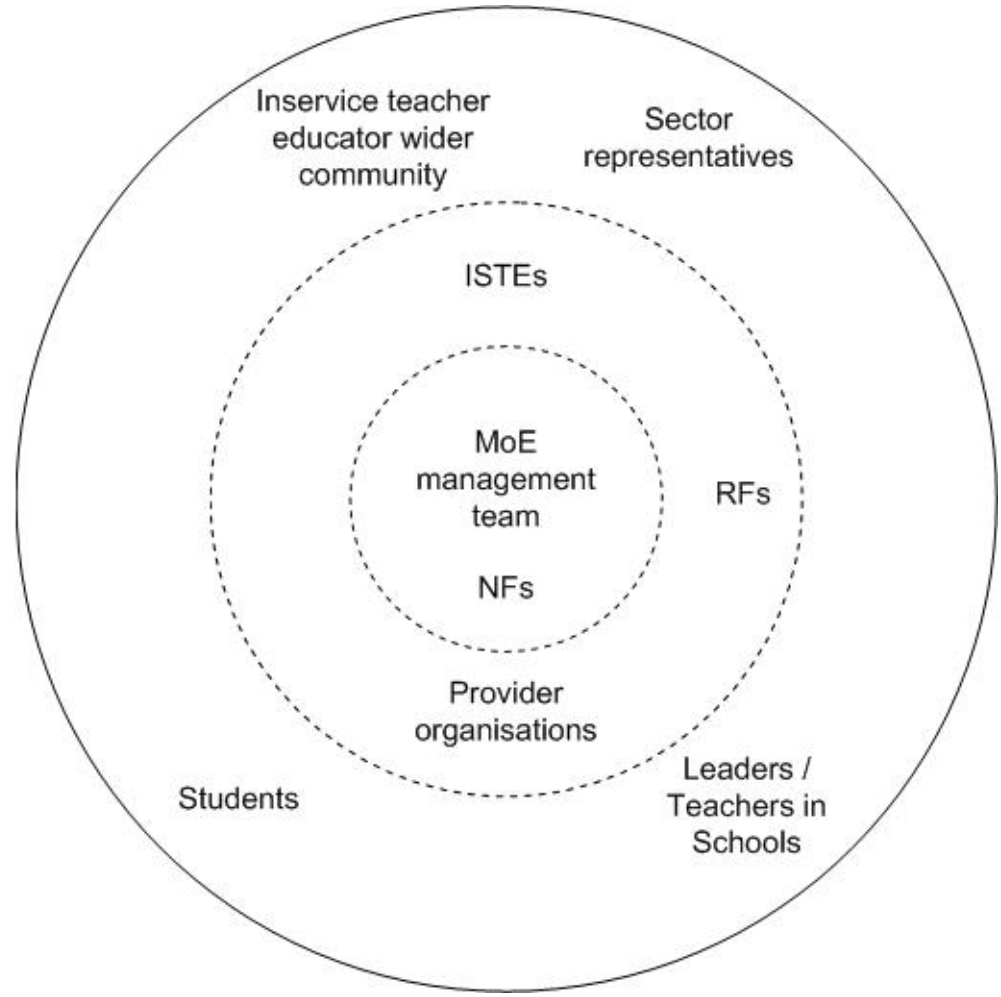

Figure 8.2: INSTEP community

(adapted from Sankar, 2009, p. 18)

In Figure 8.2 the concentric circles give some indication of key involvement of INSTEP participants during different phases (for example, the inner two circles represent key players during Phases 1 and 2). The many arrangements were not as centrifugal as the circular diagram suggests, as there were formal and informal interactions and activities throughout, at all levels from the centre of the circles to the outermost periphery, as suggested by the porous lines. Participation and collaboration was multi-layered and dynamic, consisting of any combination of individuals within the INSTEP community at different times throughout the duration 
of the project [Document Sources A, B, D (Ministry of Education, 2008a; Parsons \& Higgins, 2011; Sankar, 2009)].

As discussed earlier in this chapter, the formal organisation of the INSTEP project provided an operational infrastructure incorporating collaboration, management and accountability. The flexible research and development feature of the project [Document source A, D (Parsons \& Higgins, 2011; Sankar, 2009)] allowed the spaces within which interactions, activities and relationships formed the social and informal organisational elements which were integral to the aims of the project [Document sources B, A (Higgins \& Parsons, 2011; Ministry of Education, 2008a)]. These social and informal elements incorporated complex collaborative arrangements of networks, communities and critical friends. This section will discuss the key findings of the study with regard to these collaborative environments for professional learning.

The two key components of this section - networks and communities - are treated in the following paragraphs as distinct, but complex interwoven dimensions of the ways in which the collaborative environment of INSTEP fostered capacity building and sustainability of learning and professional growth. In order to clarify the distinction, and explore each of the dimensions more fully, two theoretical lenses will be applied. The theoretical frameworks of activity theory (Engeström, 1987) and communities of practice (Wenger, 1998a, 1998b) are effective for analysing both the contexts and cultural impact of the environment, and the interactions, relationships and complex patterns of participation within a collaborative learning environment (Barab, Schatz, \& Scheckler, 2004; Levine, 2010). The first lens of activity theory (Engeström, 1987) provides a conceptual framework for analysis of the multi-layered and dynamic networks as the system and context within which collaborative EBIP took place. Activity theory is a useful frame for the analysis of the design of collaborative environments (Barab et al., 2004), and for examining how and why activities develop in the ways that they do (Levine, 2010). The second lens - the concept of communities of practice (Wenger, 1998b) - is used as a conceptual framework to investigate "the organic systems that emerge[d] through interactions among members, not because some designer made it so" (Barab et al., 2004, p. 42). The application of Wenger's (1998b) social theory of learning allows closer examination of how, why, and to what extent individuals engaged with each other. 


\section{Networks}

In recent years there has been an increased focus on the implementation of intraand inter-institutional networks within education to effect sustainable change and improvement (Bell et al., 2006; Church, Crowe, Plummer, \& Worrall, 2005; Stoll et al., 2003; Wyatt-Smith et al., 2008). Although there is little doubt that networking can be energising and empowering, where individual values and identities are valued, and it can enhance professional development and motivation (Hofman \& Dijkstra, 2010; Sachs, 2000, 2003), there has been little systematic research into the effectiveness of educational networks (de Lima, 2010; Earl \& Katz, 2010; Little \& Veugelers, 2005). Earl and Katz and de Lima take approaches that inform the features and dimensions of educational networks.

De Lima (2010) asserts that networks are "moving systems that may be constantly rebuilt and shaped by the actions and interactions of their members" (p. 9), and he proposes dimensions of six network concepts that afford a more comprehensive approach to research into educational networks. De Lima's dimensions are: genesis, composition, structure, substance, dynamics, and effectiveness (see Table 8.1).

Table 8.1: Key dimensions for the analysis of networks in education (de Lima, 2010, p. 11)

\begin{tabular}{|c|c|c|c|}
\hline Dimension & Sub-dimension & Type & Description \\
\hline \multirow{2}{*}{ Genesis } & & Emergent & $\begin{array}{l}\text { Spontaneous, voluntary, generated through } \\
\text { "grassroots" processes }\end{array}$ \\
\hline & & Externally sponsored & $\begin{array}{l}\text { Conceived and promoted by outside agents as an } \\
\text { instrument for their own agendas }\end{array}$ \\
\hline \multirow{2}{*}{ Composition } & & Individual-actor & Comprised by individuals \\
\hline & & Collective-actor & $\begin{array}{l}\text { Comprised by groups, organizations, institutions, } \\
\text { etc. }\end{array}$ \\
\hline \multirow{6}{*}{ Structure } & \multirow{2}{*}{ Density } & Dense & Most possible relations are activated \\
\hline & & Sparse & Few of the possible relations are activated \\
\hline & \multirow{2}{*}{ Centralization } & Decentralized & $\begin{array}{l}\text { No particular actor or set of actors is relatively } \\
\text { prominent }\end{array}$ \\
\hline & & Centralized & $\begin{array}{l}\text { One actor or a small set of actors are the focus of } \\
\text { most of the network's relational activity }\end{array}$ \\
\hline & \multirow[b]{2}{*}{ Connectedness } & Strongly connected & Most actors are strongly connected to one another \\
\hline & & Fragmented & $\begin{array}{l}\text { Subgroups of actors within the network are weakly } \\
\text { connected or unconnected to one another }\end{array}$ \\
\hline \multirow{2}{*}{ Substance } & & Single-purpose & Devotes most of its activity to a single purpose \\
\hline & & Multi-purpose & Devotes its activity to several purposes \\
\hline \multirow{2}{*}{ Effectiveness } & & Effective & Achieves its declared aims \\
\hline & & Ineffective & Fails to achieve its declared aims \\
\hline \multirow[t]{2}{*}{ Dynamics } & & Goal-directed & $\begin{array}{l}\text { All relations between network members are } \\
\text { structured in order to achieve network-level goals; } \\
\text { an administrative entity plans and coordinates the } \\
\text { activities of the network as a whole }\end{array}$ \\
\hline & & Serendipitous & $\begin{array}{l}\text { Evolves haphazardly from the interactions of } \\
\text { individual actors, without guidance from any } \\
\text { central network agent }\end{array}$ \\
\hline
\end{tabular}


Since the INSTEP community consisted of a multitude of complex networking arrangements with different players and motivations, de Lima's dimensions have been superimposed on an activity theory system in order to highlight the complex mediating factors of the networks. The findings of this study, therefore, in relation to the networked infrastructure, will be discussed according to de Lima's framework of six key dimensions of network concepts, and the principles of activity theory.

The principles of activity theory are:

- activity what sort of activity am I interested in?

- $\quad$ subject who is involved in carrying out this activity? Who are the players?

- object why is this activity taking place? What are the motivations?

- tools by what means are the subjects carrying out this activity?

- community what is the environment in which activity is carried out?

- rules

are there any cultural norms, rules and regulations governing the performance of this activity?

- division of labour who is responsible for what, when carrying out this activity and how are the roles organised?

- Outcome what is the desired outcome from this activity? (Engeström, 1987; Mwanza, 2002).

Each activity system exists within, and is related to, networks of other systems, within which subjects (individuals or sub-groups) direct activity towards an object. The activity is mediated by cultural norms, the environment, roles and responsibilities, and strategies and resources (Hill, Capper, Wilson, Whatman, \& Wong, 2007). Figure 8.3 illustrates a generalised activity system for the INSTEP networks which could be applied to the range of individual or collective subjects (ISTE, teacher, INSTEP project community, provider organisations, sector) sharing the same general objects: the objectives of the INSTEP project (to improve ISTE practice, explore approaches to professional learning, and support leadership and ongoing improvement within the sector). The mediating factors and outcomes of the activity vary dependent on the subject. 


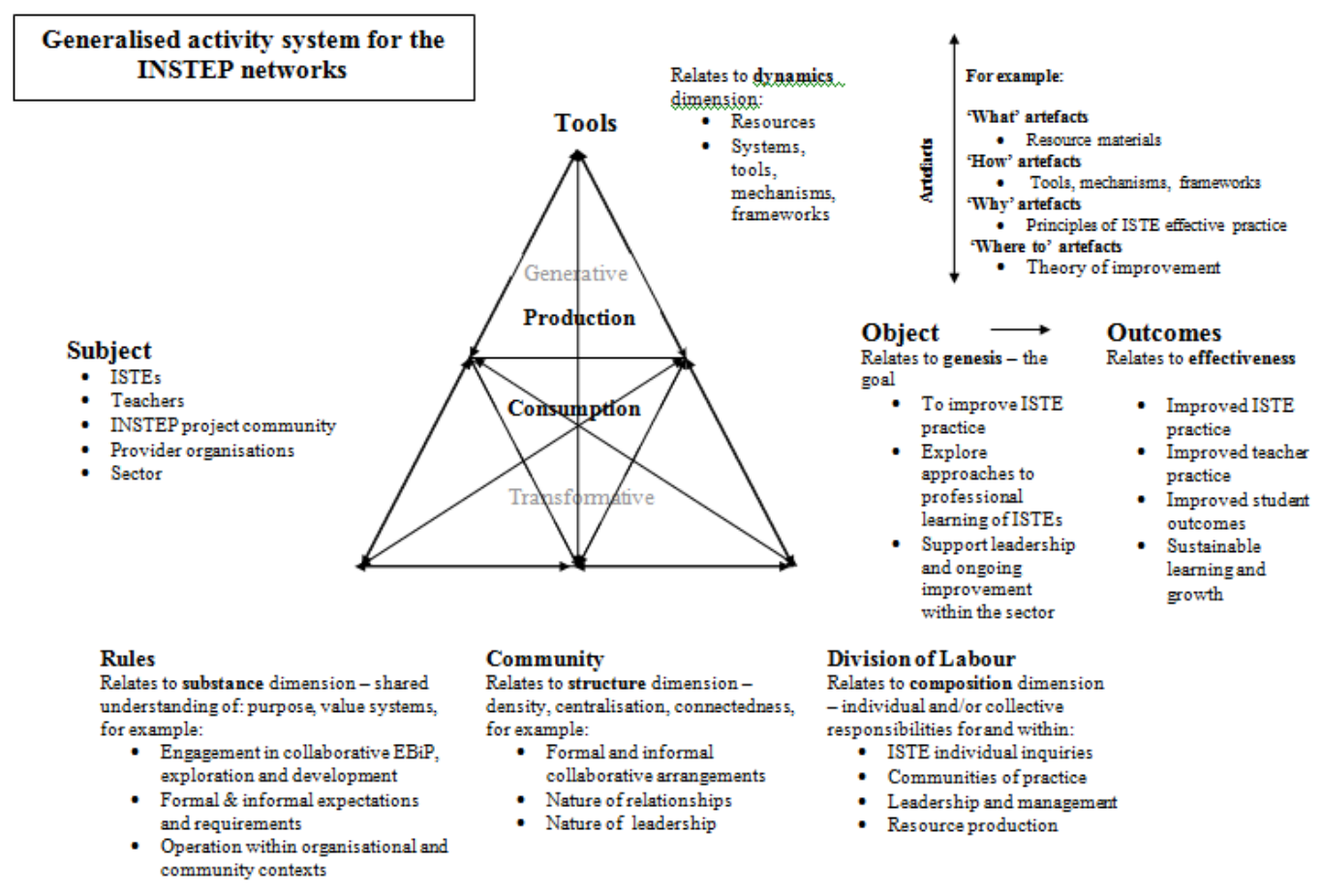

Figure 8.3: Generalised activity system for INSTEP networks

The activity theory principles are represented as nodes in the activity system diagram in Figure 8.3 which are also mapped to de Lima's (2010) framework. The activity system is constantly in motion and there is incessant shifting between the nodes of the activity. Activity is not static, but continuously evolves. Subjects continuously (consciously or subconsciously) adapt and transform tools, rules, communities and divisions of labour (Mwanza, 2002). For example, within INSTEP, what starts off as an ISTE inquiry can become a learning case within the artefacts or tools as a resource for future reference. This incessant movement reflects the dynamic nature of networks as described by de Lima (2010).

The networked infrastructure of INSTEP will now be discussed within the context of de Lima's framework and activity theory, and will inform the dynamic contexts within which participants were operating.

\section{Genesis: the reasons and motivations behind the creation of networks}

Genesis relates to the object of the activity system. Although each of the individual and collective subjects shared the objectives of the INSTEP project, there were a variety of specific motivations, within the general objects of the activity system that were dependent on the subject. Within the INSTEP project community, the management network including the project management team, NFs and RFs was explicitly and directly extrinsically motivated with the aim of achieving the project 
objectives. However, for ISTEs, there were also emergent intrinsically motivated arrangements during and beyond INSTEP, such as the RTLB ongoing meetings, the continued critical friendships with some participants, and particular connections made between and among participants for different purposes during and after INSTEP. For example, Laura's shared responsibility for the development of a conference paper, ISTEs' shared authorship of publications [Document sources $C$ and $E$ (Baskerville \& Goldblatt, 2009; Mcllraith et al., 2009)], and Eva's and Elaine's reports of engaging within different communities for different purposes. Although the motives for the formal organisational INSTEP network were extrinsic, there were other emergent intrinsic incentives and motivators evidenced for certain individuals or groups. The varied activities and outcomes, therefore, were mediated by the particular goals and motivations of the subjects of the activity system.

\section{Composition: individual and/or collective actors}

Composition reflects the division of labour in the activity system, which was complex and intertwined within INSTEP. There were mixed-level individual and collective networks in operation simultaneously throughout INSTEP, dependent on the subject and object in the activity system. There were collective networks of national NF groups with activity directed towards resource production and national seminars [Document sources B, D (Ministry of Education, 2008a; Sankar, 2009)]. Individual members of pods engaged in critiquing and evaluating practice, developing tools, mechanism and frameworks [Document source A (Baskerville, 2011)], and designing and implementing the projects within NF pods [Document Source $C$ (Mcllraith et al., 2009)], with activity directed towards evaluating and improving individual practice. Beyond INSTEP, there was little evidence of any individual or collaborative networks in operation apart from those reported by the three organisations that had adopted professional learning programmes.

Regardless of the subject, the object (and therefore the network activity) did not prevail at any level outwith the formal organisational project community or professional learning programme.

\section{Structure: whole system or individual members' structural properties and locations - density, centralisation and connectedness}

Structure relates to community in the activity system. Participants reported a high level of interaction within different communities of practice throughout the project (communities of practice are discussed fully in the next section of this chapter). Interaction and relationships included: leadership, as reported by Elaine; mentorship 
[Document Source A (Davey, Ham, Stopford, Calender, \& Mackay, 2011; Thornley \& McDonald, 2011)]; critical friends [Document Source A (Baskerville, 2011)]; planning and reporting meetings [Document sources A, D (Lamont, 2011; Sankar, 2009)]; national seminars where NF pods shared their progress; and collaborative development of resources [Document sources B, D (Ministry of Education, 2008a; Sankar, 2009)].

It seems that with ISTEs as the subjects of the activity system, the environment was one of formal and informal collaboration incorporating a range of types of relationships. For ISTEs, therefore, there was a high degree of density during INSTEP, where many relationships were activated.

Although the project manager, NFs and RFs had specifically designated leadership roles, the patterns of relationships and communications were not necessarily always centred around them, due to the evolution of communities of practice within collaborative inquiry. Participants therefore fulfilled the role of interacting with, and relating to, many others within a collaborative learning environment. This was perhaps due to the diversity of participants' knowledge, experience and expertise, and the fact that the role of an inservice teacher educator is one of a leader of learning, which incorporates the professional responsibility to engage in professional learning communities. The patterns of relationships and communications therefore did not always reflect a high degree of centralisation, for example as Elaine describes:

\begin{abstract}
We work as - kind of buddies and ... I've used [colleague $\mathrm{X}$ ] because we work on some things together; we work with a cluster together, so l've taken some video - and she's got good expertise in the stuff I want to get better at. So we use different people for different expertises. You might have: this goal I might be working with [colleague X]; and that goal I'm working with [my senior manager].
\end{abstract}

It is not possible within this study to ascertain the degree of connectedness within all levels of the INSTEP networks, and this varied dependent on the subject and object in the activity system. The NFs were connected within the framework of regular meetings and common requirements of milestone reporting and resource production. Elaine reported valuing the connectedness of the NF group in Phase 1, although acknowledged that it was challenging to begin with. A similar experience was reported by Laura within her RF group. However, Alison, never felt connected to her larger pod of ISTEs, but did connect with her self-selected sub-group. The findings of this study would indicate that it takes time to achieve a sense of connectedness: for diverse individuals to relate to each other and recognise the 
value of the relationships and perspectives. This study also found that opposing philosophies of practice and uneven relationships of power and influence can act as a major impediment to the connectedness of a network.

In terms of subjects other than ISTEs within the activity system, there is insufficient evidence within this study to inform the nature and extent of relationships and interactions and the aspects of network structure. For example, although there was regular engagement with sector representatives as a means of keeping them informed and obtaining feedback [Document Source D (Sankar, 2009)], there is no further evidence of networking and community. Similarly there is no evidence of provider organisations engaging in networking activities.

\section{Substance: what interactions are about - missions, purposes, values, social norms, conceptions and perspectives}

Substance relates in some ways to the rules of the activity system. In Phase 1 of the INSTEP project, the purpose and aims of the project were shared and discussed in detail within the NF management team. The specific requirements and expectations of engagement evolved from these discussions, due to the research and development nature of the project [Document Source D (Sankar, 2009)]. Specific rules of engagement and the focus of the interactions varied according to the subject of the activity system. For example, the NF management team had a focus on negotiating meaning and developing resources [Document Source B (Ministry of Education, 2008a)], while individual ISTEs' activities were more focussed on their individual inquiry [Document Source G (Lamont, 2011)]. The substance of the interactions for participants within the INSTEP community was clearly evident within the requirements and expectations of engagement, arising from a shared understanding of purpose and shared value system.

There was insufficient evidence in this study to determine the extent to which shared understandings of purpose and cultural norms were established, or how activities were directed for subjects other than ISTEs.

\section{Effectiveness: evidence of impact upon members and those with whom they interact}

Effectiveness relates to the intended outcomes of the activity system. Both this study and Sankar's report [Document Source D (Sankar, 2009)] found that individual ISTEs had made significant changes to their practice. They also developed their knowledge and understanding of: their practice; the impact of their practice on 
teachers and students; and what constitutes effective inservice teacher educator practice. There is no doubt from the findings of this study that the small group and critical friend networks were effective for evaluating and critiquing research and practice evidence, and surfacing values and beliefs. However, this study found that rigorous EBIP was not sustained by eight out of 10 participants. The main reasons cited for this were the unavailability of critical friends or colleagues for collaborative inquiry, and lack of time for reflection. It is also worth noting the absence of a framework within which to operate (for all participants except Aroha and Elaine), which had been particularly valued during INSTEP, as observed by Hannah:

That was what made the difference for us. We had a structure within the learning group. We had structured tools that we were trying to work with and there was a focus: there was a real focus on the inquiry.

It seems that the networks at the ISTE and RF level were effective in improving individual practice, knowledge and attributes, but were not, or could not easily be sustained beyond INSTEP. In addition, Sankar (2009) reported that the "impact of INSTEP on the sector appears to have been minimal suggesting more needs to be done in this regard" (p. 57). Sankar's case study participants perceived that greater impact on the sector could only be achieved with "significant involvement from the Ministry" (p. 57). Sankar observed:

There are a number of reasons for this: first, the sector includes private and publicly funded providers with different interests and motivations. This impacts on the extent to which cohesion is possible and feasible as the providers operate in a contestable environment. Secondly, the sector is made up of a number of disparate groups who have strong regional presence and leadership does not rest with any one group in the sector. This means that any attempts to bring about cohesion at a national level will require a collective effort from a group of committed players who proactively lead the sector for change. (p. 57)

Sankar's observation has implications for an activity system with the sector or provider organisations placed as a subject. The outcome is mediated by the principles of the activity system and the interplay of network dimensions. This study suggests that insufficient attention may have been given to these principles and dimensions in relation to ongoing improvement within the sector and provider organisations, and that the focus may have been primarily individual ISTEs as subjects of the activity system.

The relative flexibility of the project, combined with the clear infrastructure and explicit objectives, afforded clear direction with a degree of autonomy with the potential for network members to take ownership of, and responsibility for, their role within the project. The explicitness of the processes, goals and expectations of 
INSTEP supported and promoted collaborative EBIP, while the project management team coordinated aspects of overarching design, implementation and resource development. Multiple and dynamic layers of networking activities were implemented to meet a variety of goals, and were mediated by varying degrees of intrinsic and extrinsic motives and incentives. The networks were dynamic and they hosted, and often gained from change and development over time in the serendipitous and goal-directed relationships and interactions. The design and implementation of the networked structure for INSTEP was mostly effective in achieving individual ISTE goals, and the INSTEP project community goals of improving (individual) ISTE practice, and exploring approaches to professional learning. However, the network structure may require more consideration in relation to the principles of the activity system and the dimensions of network concepts, when the provider organisations and sector are placed as the subjects of the activity system. This has implications for sustained learning and growth at the organisation and sector level as highlighted by Sankar (2009).

The following section looks more closely at the interactions, relationships and activities that were characteristic of the communities of practice within the networked infrastructure of INSTEP.

\section{Dynamics: how they develop over time}

Dynamics relates to the tools of the activity system. There were multiple purposes for the networks of communities of practice within INSTEP, as illustrated in Processes of Inquiry and Ki te Aotūroa [Document Sources A, B (Higgins et al., 2011; Ministry of Education, 2008)]. The dynamics of all networks within INSTEP could be said to be goal-directed, as they existed within the confines of the contractual agreement with fixed aims and objectives. However, over time, as participants took more responsibility and ownership of their role within the INSTEP networked community, the flexibility of the research and development nature of the project allowed individuals to make choices about what to share and contribute, who to interact with, and when [Document Source D (Sankar, 2009)]. The informal and social aspects of the organisation allowed "network trajectories [to] develop haphazardly from the interactions of individual actors" (de Lima, 2010, p. 10). In some instances, such as in Laura's RF pod in Phase 2, developing relationships within a diverse group of individuals took time. In others, such as Alison's pod in Phase 3, the perspectives were too diverse for meaningful interactions to take place. Feelings of tension due to ambiguity of the purpose of INSTEP were eased over time through interactions within networks at different levels. For example Elaine, 
Laura and Eva expressed a sense of being in a "quagmire for a while" (Laura), each at different phases of the project. There is some evidence, therefore, that the networks evolved and changed over time, and were both serendipitous and goaldirected. The evolution of the networks was mediated by resources such as time allowance and access to support. The networks also mediated, and were mediated by, resources, tools, mechanisms and frameworks that were developed in an ongoing way by INSTEP participants.

\section{Communities of practice}

Communities of practice are in evidence throughout society. According to Wenger (1998a, 1998b), within a community of practice, formal or informal groups of practitioners interact regularly with the intention of getting better at what they do through interacting with each other. They engage with each other through negotiation, discussion, theorising, joint activities, shared practice, and sharing information. Although not always formally recognised or intentionally formed, communities of practice have intentionality at their core, and a shared domain of interest. Members are committed to the domain, and they have a shared competence and sense of purpose that identifies them as a community. They are bound together by what they do and what they learn within the community of practice (Wenger, 1998a, 1998b). In this way, members have "shared histories" of learning within which "practices evolve", where "[h]istory in this sense is neither merely a personal or collective experience nor just a set of enduring artefacts and institutions, but a combination of participation and reification intertwined over time" (Wenger, 1998b, p. 87).

INSTEP propagated a myriad of communities of practice within the overarching project community, which was intentionally institutionalised (Wenger, 1998b) within a framework of clearly defined goals. As discussed in the previous section, members of the large INSTEP community of practice, which was populated from all sectors in Figure 8.2, engaged in all of the activities outlined above, to some degree. For example, within the networked infrastructure: all NFs engaged with the project management team, RFs, ISTEs, stakeholder groups, and communities of practice

within their own organisations; RFs and ISTEs engaged with each other in different communities of practice ranging from one-on-one critical friendships to national INSTEP seminars; at the boundaries of the community of practice, stakeholders engaged in regular meetings and discussion [Document source D (Sankar, 2009)], and students engaged in learning experiences [Document Source A, B (McDonald \& Thornley, 2011; Ministry of Education, 2008a)]. 
Wenger's (1998b) concept of a community of practice is the lens that will be applied in this section in order to investigate more fully the nature of these communities, and the ways in which individuals engaged within them. Wenger asserts that participation and reification are integral to a community of practice, and seamlessly combine to bring meaning and learning. Participation is the mutual engagement in the activities and interactions of the community, while reification is the evolution of shared meanings and concepts, documents, instruments and processes that support and shape participation (Wenger, 1998b).

Within INSTEP, there were varying degrees of participation and reification over time. Wenger (1998b) asserts that the two elements cannot be considered in isolation; that they are "seamless" (p. 62), but that both are necessary and need to be balanced:

Participation is essential to repairing the potential misalignments inherent in reification. When the stiffness of its form renders reification obsolete, when its mute ambiguity is misleading, or when its purpose is lost in the distance, then it is participation that comes to the rescue. (p. 64)

Eva experienced this imbalance when members of her pod attended meetings and critiqued her practice, but were not mutually engaging with her in terms of reciprocating the risk and deprivatising their practice, also when senior managers within her organisation regarded INSTEP simply as another Ministry funded project and did not engage with the community:

Our head of school came to one of the [presentations] and we got some brief feedback, there but there was never a sense of real interest. (Eva)

Similarly, according to Wenger (1998b), reification is just as essential:

[W] hen the informality of participation is confusingly loose, when the fluidity of its implicitness impedes coordination, when its locality is too confining or its partiality too narrow, then it is reification that comes to the rescue. (p. 64)

Hannah experienced this when attempts were made within her organisation to ensure participation in professional learning communities without the reification such as procedures, tools and shared understanding of purpose:

The tools are optional. And so it made it harder at times for the professional learning group leaders to actually assist people in movement because there were no formal tools and some people chose to use them and some people didn't.

The feelings of uncertainty and ambiguity of role and purpose expressed by some participants at the beginning of the project were perhaps due to the imbalance, at 
that time, of participation and reification. There was definitely willingness for participation, but, partly due to the research and development nature of the project, reification took time to evolve and develop, as perspectives and understandings were shared and negotiated.

Both Elaine's and Aroha's organisations were making explicit efforts to balance participation with reification, by embedding EBIP into their organisations' appraisal and professional learning programmes, within an inclusive environment, with shared visions of purpose, collaborative processes, accountability measures, and the implementation of agreed tools and mechanisms. Similarly, the INSTEP project incorporated the two elements by having a central focus on autonomous collaborative inquiry within the context of the implementation framework, structure, tools, mechanisms and resources. Key concepts and foci pertaining to inservice teacher education were shared and negotiated in order to derive the principles of effective inservice teacher education and the theory of improvement for inservice teacher educators (Ministry of Education, 2008a). Tools and mechanisms were also debated, trialled and developed; regional pods and a senior management team enabled and supported mutual engagement; and accountability was inherent for every participant within the project, including the project leaders. There were deliberate attempts, therefore, to balance participation and reification within the INSTEP project, and within Elaine's and Aroha's organisations.

Wenger (1998b) is a key contributor of knowledge in the field of communities of practice. He identifies three dimensions of communities of practice within an enabling environment: mutual engagement; a joint enterprise; and a shared repertoire (see Figure 8.4). These dimensions provide a framework for further analysis and discussion of the complex mediating factors within the INSTEP communities of practice that will be discussed in this section. 


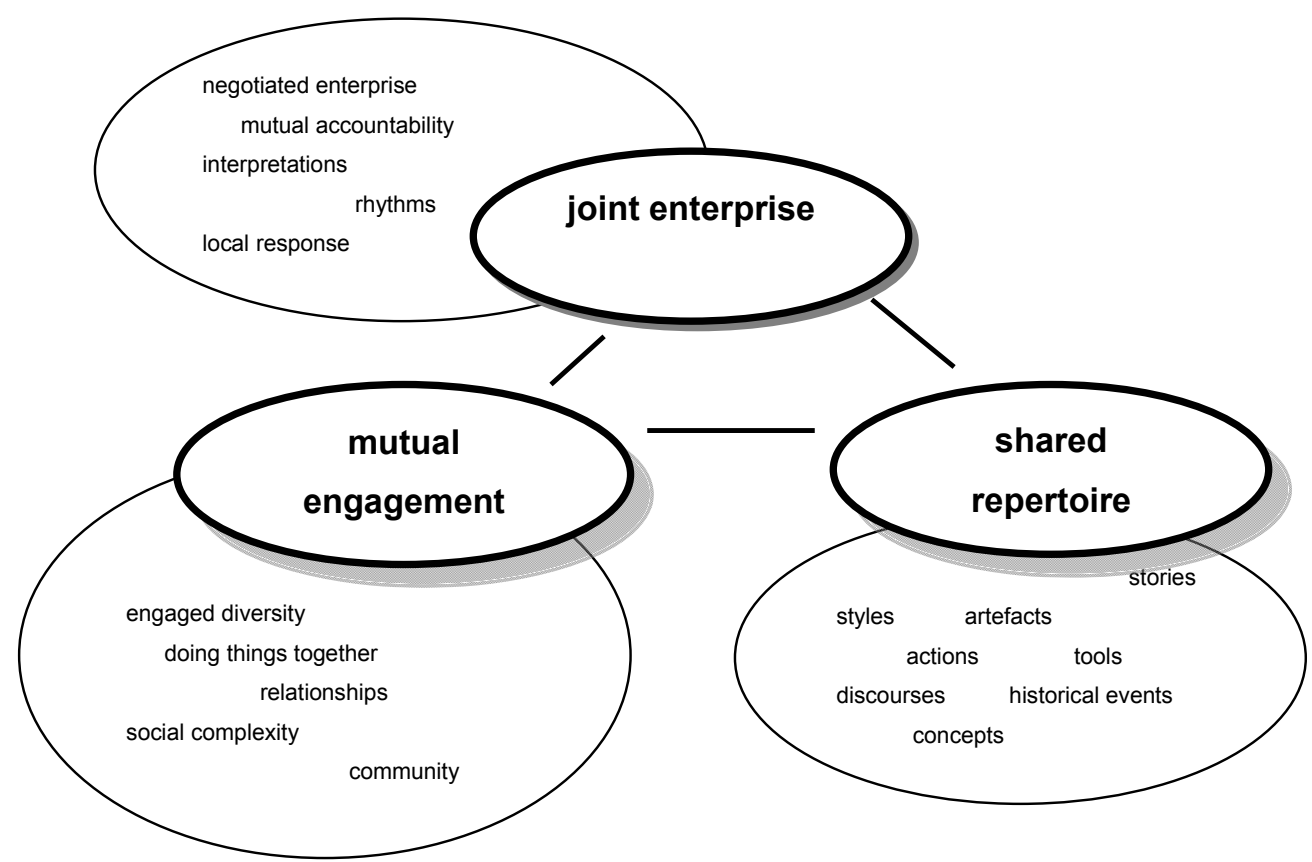

Figure 8.4: Dimensions of practice as the property of a community (Wenger, 1998b, p. 73)

The enabling environment for the INSTEP community of practice was manifested in the infrastructure and framework, with a focus on collective participation, which created time and space for activities and interactions, the development of relationships, the forming of alliances, and tolerance of diversities. This was reflected in Eva's observations:

You need formalised stuff. ... what I mean by formalising is the time allocation, the structures put in place, the organisational structures to be put in place to allow people to have that opportunity to reflect and de-privatise their practice, and saying 'This is important and therefore ... we are giving you the structures, we are supporting you to do this, we'll give you the choice of the groups that you want to work within but this must be done as part of your work'.

The first of Wenger's (1998b) dimensions is mutual engagement, where diverse and complex relationships are formed within an enabling environment. According to Wenger, connectedness and interpersonal relationships are key components of mutual engagement, and can include tensions and challenges within environments of alliance and competition, and power and dependence. Engagement can evoke emotions ranging from pleasure to pain, anger to tenderness, trust to suspicion, and many others.

Within INSTEP, the forming of relationships and communication with others were key components within the pods. Key factors mediating mutual engagement were: trust and respect; safety; challenge; diversity; and mutual understanding of role and 
context of practice. Feelings of vulnerability, of being judged, and lack of respect for some colleagues inhibited the deprivatising of practice and surfacing of values, beliefs and assumptions. Tensions were evident when participants had difficulty relating to a group of diverse individuals where there were instances of opposing philosophies of practice, uneven relationships of power and competition, incompatible personalities, and lack of trust. Evelyn explains:

I think it was personalities [that made engagement difficult] ... but it was exacerbated by the competition that existed in jobs.

However, mutual engagement allowed negotiation of perspectives, theories and practice, as Elaine described:

So sometimes we work as a whole team but that's mostly around where have we got to: let's look at some more theory; let's look at something collectively together - a problem of practice together, or something together, and then we normally break into little groups.

Although participants valued their practice being challenged, mutual vulnerability, and value and respect for each other's work were necessary components for a safe environment within which challenge could take place. Deprivatising practice, therefore, was generally more difficult in larger groups. However, communities of practice at all levels valued the discourse where concepts, theoretical perspectives and ways of working were explored and debated, as evidenced in Theresa's statement:

We all bring things to this [organisational] group but then it's important to have other outside ... groups to actually, - that's what l've learnt through INSTEP - is that the importance of listening to other people's ways of working, other people's theories.

Some communities included members who were not INSTEP project participants, such as teachers, stakeholders, principals and other inservice teacher educators, but who were on the boundary of the INSTEP community of practice, and shared the purpose of improving teacher practice to enhance student outcomes. There were instances where those on the boundary were not fully participating members of the community, therefore did not mutually engage, such as Olivia's colleagues: "Don't INSTEP me!", and the facilitators in the provider organisations that Elaine worked with in Phase 4:

You're working with seven providers who are competitors, even though we're working on the same thing, we're still competitors and there was that huge resistance of 'Who are you to try and tell us how to do our PD [professional development]'. Plus they were already working within their own organisations. So, it had some good effect, but not huge, and none of those relationships were built in any bigger way. (Elaine) 
Other study participants engaged successfully in relationships or activities at the boundaries of the INSTEP community for particular purposes. For example, in Phase 2 Hannah was involved in professional learning groups across her organisation, Eva was involved in presenting work to facilitators within her organisation, and Laura, Eva and others collaborated to publish papers for conferences or journals. Mutual engagement took a variety of forms, and centred on the shared vision and purpose, whether that took the form of exploring perspectives, publishing a journal article or conference paper, deprivatising practice, or any other purpose.

The second dimension Wenger identifies is that of a joint enterprise which incorporates "a collective process of negotiation". This dimension brings members together "in a negotiated response to their situation and thus belongs to them in a profound sense, in spite of all the forces and influences that are beyond their control" (1998b, p. 77). This process allows members to define their reality as a response to (but not defined by) external resources and constraints. This promotes a sense of ownership of, and responsibility, for the process.

Key activities within this dimension for participants were negotiation of shared meaning, reaching consensus on ways of working, and establishing measures of accountability. Study participants engaged in shaping their individual and collective perspectives and roles within the project, as Laura recalled:

We're a very different group of people and it was hard to find a common thinking, very hard, you know with some people from the Ministry and people ... who were delivering the maths curriculum for instance and it was quite hard to sort of feel that your contribution was even understood.

Aspects of leadership impacted upon activities within this dimension. Leaders who were respectful, inclusive, interested, encouraging and challenging were more likely to nurture, promote and support a joint enterprise. The relative flexibility within the INSTEP project allowed space for creativity and autonomy of particular individuals and groups: "There was licence to be as creative as you want it to be" (Evelyn).

Wenger (1998b) asserts that accountability is a key feature of this dimension. He claims that:

Those relations of accountability include what matters and what does not, what is important and why it is important, what to do and not to do, what to pay attention to and what to ignore, what to talk about and what to leave unsaid, what to justify and what to take for granted, what to display and what to withhold, when actions and artefacts are good enough and when they need improvement or refinement. (p. 81) 
As discussed in the earlier section on peer validation of evidence, and the development of tools and mechanisms for inquiry, the process of negotiation within the pods fostered an environment of mutual accountability. Mutual accountability, although it became integral to the practice of the INSTEP communities of practice, was not always explicit as in the INSTEP infrastructure or Elaine's or Aroha's organisations, but took the form of implicit shared understandings, such as Alison's acceptance of accountability through respect for her RF, or the expectations of challenge and justification of evidence as articulated by Olivia and Evelyn. Participants negotiated and agreed upon structures, timeframes, and ways of working including reporting processes and protocols for interactions. In this way, participants engaged in a joint enterprise with shared understandings of roles and expectations, and an enhanced sense of shared responsibility.

The third dimension identified by Wenger (1998b) is a shared repertoire. The shared repertoire includes the implicit and explicit joint development of resources such as tools, routines, ways of working, and concepts and vocabulary that bring meaning to the community and its practices. The identity of the community and its members is implicitly and explicitly negotiated and understood within the shared repertoire (Wenger, 1998b).

Key activities for ISTEs within this dimension were very explicit: the development of $K i$ te Aotūroa (Ministry of Education, 2008a) as a resource for inservice teacher educators, including a proposed theory of improvement, principles of professional learning and practice, an inquiry and knowledge-building cycle for inservice teacher educators, and learning cases. ISTEs also developed a variety of tools and mechanisms to aid EBIP [Document source A (Baskerville, 2011)], and some also published in academic books, journals and conferences [Document sources A, C, E, and F (Baskerville \& Goldblatt, 2009; Higgins et al., 2011; Lamont, 2009; Mcllraith et al., 2009)].

Olivia and Laura's reference to "the training" reflects the shared repertoire of the INSTEP community which was lacking in trying to take the EBIP approaches forward into the broader RTLB service community. This shared repertoire was also not in evidence when Hannah acknowledged that those facilitators in her organisation, who were not involved in INSTEP, did not engage with the purpose and processes of rigorous EBIP.

Wenger (1998b) states that it is within the shared repertoire that ambiguity and different perspectives are addressed, and that the context is one of dynamism and interaction. This was evidenced by Elaine's experiences within her NF pod: 
As one of the national facilitators I think the learning was huge, because we all came from such different theory bases, backgrounds, ways of working, but that was kind of a constant struggle we were involved in at the time. Trying to get inside each other's heads and find out what that was about. And I think that was - looking back, was good for all of us because you kind of think your way's the best, then you realise there are other ways that impact on things just as well. So within that group, I think that was fantastic even though it was quite hard at times.

This is in line with Wenger (1998b, p. 84) who claims that agreement is not a "precondition" or "outcome", but that differences and misunderstandings are opportunities to explore new meanings.

In Hannah's case, the imbalance of participation and reification in her organisation resulted in there being little space for negotiation and discussion around shared understandings and new meanings; therefore there was no shared repertoire of EBIP among facilitators in her workplace. The shared repertoire of INSTEP was evident in the resource Ki te Aotūroa, including: the principles of effective practice and the theory of improvement (Ministry of Education, 2008a); the multiple inquiry cycles; negotiated processes such as protocols for interaction; the national seminars; and regular NF, RF, ISTE and management team meetings. The findings reported in this section are summarised in Table 8.2.

Table 8.2: Dimensions, activities and mediating factors of INSTEP communities of practice

\begin{tabular}{|c|c|c|}
\hline Dimensions & Activities & Mediating factors \\
\hline $\begin{array}{l}\text { Mutual } \\
\text { engagement }\end{array}$ & $\begin{array}{l}\text { Contributing to formal and informal } \\
\text { meetings, interactions and } \\
\text { communications } \\
\text { Forming relationships within different } \\
\text { groups for different purposes } \\
\text { Investing time and effort in collaboration } \\
\text { (e.g. readings, preparation for meetings) } \\
\text { Deprivatising practice }\end{array}$ & $\begin{array}{l}\text { Trust and respect } \\
\text { Safety } \\
\text { Understanding of role and } \\
\text { context of practice } \\
\text { Challenge } \\
\text { Diversity }\end{array}$ \\
\hline $\begin{array}{l}\text { Joint } \\
\text { enterprise }\end{array}$ & $\begin{array}{l}\text { Sharing and critique of research and } \\
\text { theory } \\
\text { Planning collaborative approaches } \\
\text { Exploration of data gathering and } \\
\text { evaluation tools and mechanisms } \\
\text { Validation of evidence of practice }\end{array}$ & $\begin{array}{l}\text { Framework and } \\
\text { infrastructure } \\
\text { Time and space } \\
\text { Leadership } \\
\text { Flexibility and autonomy }\end{array}$ \\
\hline $\begin{array}{l}\text { Shared } \\
\text { repertoire }\end{array}$ & $\begin{array}{l}\text { Development of resources as an } \\
\text { outcome, including principles, learning } \\
\text { cases and proposed theory of } \\
\text { improvement } \\
\text { Development of tools and mechanisms for } \\
\text { EBIP } \\
\text { Publications and presentations for peers, } \\
\text { academic journals and conferences }\end{array}$ & $\begin{array}{l}\text { Collective ownership } \\
\text { Shared understandings } \\
\text { Common goals }\end{array}$ \\
\hline
\end{tabular}


The participants of this study engaged in multiple INSTEP-focussed communities of practice. There were complex relationships formed within a variety of environments, with some evidence of mutual engagement, joint enterprise and shared repertoire which was rewarding, challenging, generated a "social energy" (Wenger, 1998b, p. 84 ), and contributed to the practice and learning of individuals. Critical friendships too, developed over time. These are discussed in the next section.

\section{Critical friends}

The term critical friend encompasses a wide range of situations from one-on-one relationships, to one person working with a group of people, which can involve anything from a group of peers and colleagues working together to support improvement of practice, to trained personnel in school improvement projects with the assigned role of critical friend (Swaffield, 2008). Key features of critical friendship are: opportunities to challenge and be challenged (Ainscow \& Southworth, 1996; Bambino, 2002; Swaffield, 2008); mutual trust and advocacy of the work (Costa \& Kallick, 1993; Swaffield, 2002); provision of alternative perspectives (Ainscow \& Southworth, 1996; Dimmock, 1996); and shared values (Swaffield, 2005). MacBeath (1998) acknowledges the complexities and challenges inherent in critical friendships including issues of trust, acceptance, power relations, and dispositions to learning. Swaffield's (2008) definition of a critical friend is one that would apply to the critical friendships experienced by the participants of this study. She defines a critical friend as one who is both supportive and challenging, and:

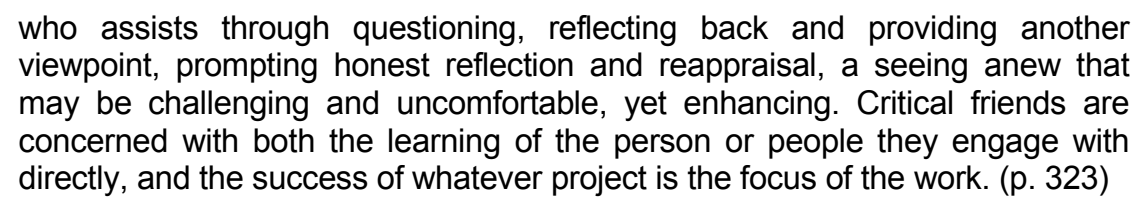

Most participants in the study identified critical friendship as being one of the most valuable aspects of the project. This discussion will explore the aspects of the particular critical friendships that developed within the contexts of the INSTEP communities of practice.

Within the context of the INSTEP wider community of practice, critical friends contributed to the joint enterprise and shared repertoire by engaging in the activities in Table 8.2. However, it is the mediating factors within the dimension of mutual engagement that define critical friendship as a particular and unique type of community of practice. Swaffield (2007) identifies trust as a key feature of critical friendships, and the element of trust was highlighted by the participants of the study. Gibbs and Angelides (2008) explore this aspect in more detail, and introduce the 
term "competence of trust" which is "the confirmation of - usually rationalexpectations" (p. 219). They ascertain that when actions are trusted, that trust arises from a perceived adherence to social conventions and adoption of particular values. They cite Williamson (1998) who says that understandings are: "rooted in the tacit agreements with others about how that world is constituted and its function" (p. 23).

This was confirmed in this study, where a "competence of trust" was fostered within critical friendships where participants had a mutual understanding of practice and context, and had identified aspects of like-mindedness in terms of ways of working and having similar values and beliefs. Within critical friendships, diversity was valued, and different perspectives were sought. Evelyn observed the basis of her critical friendship:

I don't know whether it would work as a critical friend if somebody ... had different ... fundamental basic beliefs. I think you have to have some sort of common ground like that, but in every other respect we were completely different, and that gave it a sort of an edge because we had to interpret each other's responses.

The mediating factors within the dimension of mutual engagement in Table 8.2 had a positive influence on the critical friendships within INSTEP. Critical friends within this study: were self-selected from within their community of practice; valued reciprocal challenge and alternative perspectives; had a mutual understanding of role and context of practice; were mutually trusting and respectful; had reciprocity of vulnerability; and adopted explicit protocols to ensure a risk-free collaborative environment. Although they differed in terms of disciplines, teaching approaches and experience, they identified that they were like-minded in terms of values, beliefs and teaching philosophies, and some were affirmed by similarities in problems of practice.

There were no instances of tensions or conflicts, such as uneven relationships of power and trust, as identified by MacBeath (1998). All aspects of the mutual engagement of critical friends within this study were reported as positive and beneficial. This is not really surprising since the aspects of relationships and social complexity reside within the dimension of mutual engagement. However, it is also worth noting that the term critical friend was selectively applied by participants to relationships and interactions that were valued and perceived as successful within the INSTEP experience, and critical friends, in this respect, were not assigned but selected.

The mediating factors of mutual engagement afforded positive, constructive and authentic environments within which practice could be deprivatised, and values, 
beliefs and assumptions could be surfaced and examined. Mutual engagement of critical friends, situated alongside the dimensions of shared repertoire and joint enterprise within the INSTEP community, contributed to a rigorous and systematic approach to individuals' EBIP. It is worth reflecting on Wenger's (1998b) focus on all three dimensions and considering the impact that activities within the joint enterprise and shared repertoire had on the process of forming critical friendships. In this study, engagement in all three dimensions was certainly instrumental in setting the scene for critical friendships to be nurtured and developed.

The following section discusses the implications of EBIP on individuals and the wider system.

\section{Outcomes}

\section{Individual learning and transformation}

Within this study, all participants reported some changes in practice, and increased knowledge about themselves, their practice or research and theory. Some reported changed perceptions of their role as facilitators, and an increased sense of agency and efficacy, while a few indicated more in-depth transformations in their perceptions of themselves and their roles. Beijaard et al. (2000) believe that teachers' professional identities impact upon their self-efficacy, professional growth, and their capacity to implement change, and that people feel threatened in the face of change that influences their identity. In engaging in collaborative EBIP which involved close scrutiny of personal values, beliefs and assumptions, alongside an expectation of change in practice, participants of this study were aware of the potential risk and threat, but most embraced the experience as a challenge and a learning experience, acknowledging both the tension and opportunity (Forde et al., 2006). Even with the preparation and lead-in within a community of colleagues facing similar challenges, participants still reported feeling some degree of threat and uncertainty at some stage.

Most participants emerged with enhanced perceptions of self-efficacy and agency, and a clearer sense of identity and purpose. They attributed this to a greater awareness of self, aligned with being more informed through research and theory. They acknowledged environments of mutual engagement, respect and trust, within the INSTEP communities, as recommended by Sachs (2001) for the nurturing of professional identity. The findings of this study concur with the benefits of inquiry in 
relation to professional identity, as discussed by Forde et al. (2006): participants' engagement in EBIP enabled them to be more open-minded and open to change; be better equipped to deal with puzzles and problems of practice; to value theoretical aspects; and make links between established theory and their own theories in use.

Within this section, I present a conceptual framework for learning and transformation derived from some of the key contributors to the professional discourse in the field of transformative learning, and from the findings of this study. I then discuss the findings in relation to the conceptual framework.

In the conclusion of the literature review chapter, I differentiated between transformation and the contexts that provide opportunities and possibilities for transformation. I concluded that learning and/or transformation would be optimised within such contexts, and that transformation was not necessarily the goal of professional learning and development.

The key elements in the process of learning and transformation of the holistic self where ontology and epistemology are inseparable (Dall'Alba, 2009) - derived from the literature and the findings of this study are:

- the sense of self, incorporating knowing, acting and being;

- the openness, readiness and willingness to challenge and be challenged, and cope with ambiguity;

- professional discourse and social engagement within the space of possibilities for transformation; and

- the need for environments of trust, respect and mutual commitment to, and responsibility for, learning.

Figure 8.5 presents a conceptual framework for the process of becoming, where the individuals' frames of reference and ways of knowing and being, are shifting, resulting in the crossing of a threshold into a newly formed, and continually emerging, sense of self. This continuous cyclical process is referred to by Thomson (2001) as "receptive spontaneity" (p. 256), and is summarised by him as follows: "Genuine education leads us back to ourselves, to the place we are, it teaches us to dwell there, transforming us in the process" (Thomson, 2001, p. 254 italics in original). 


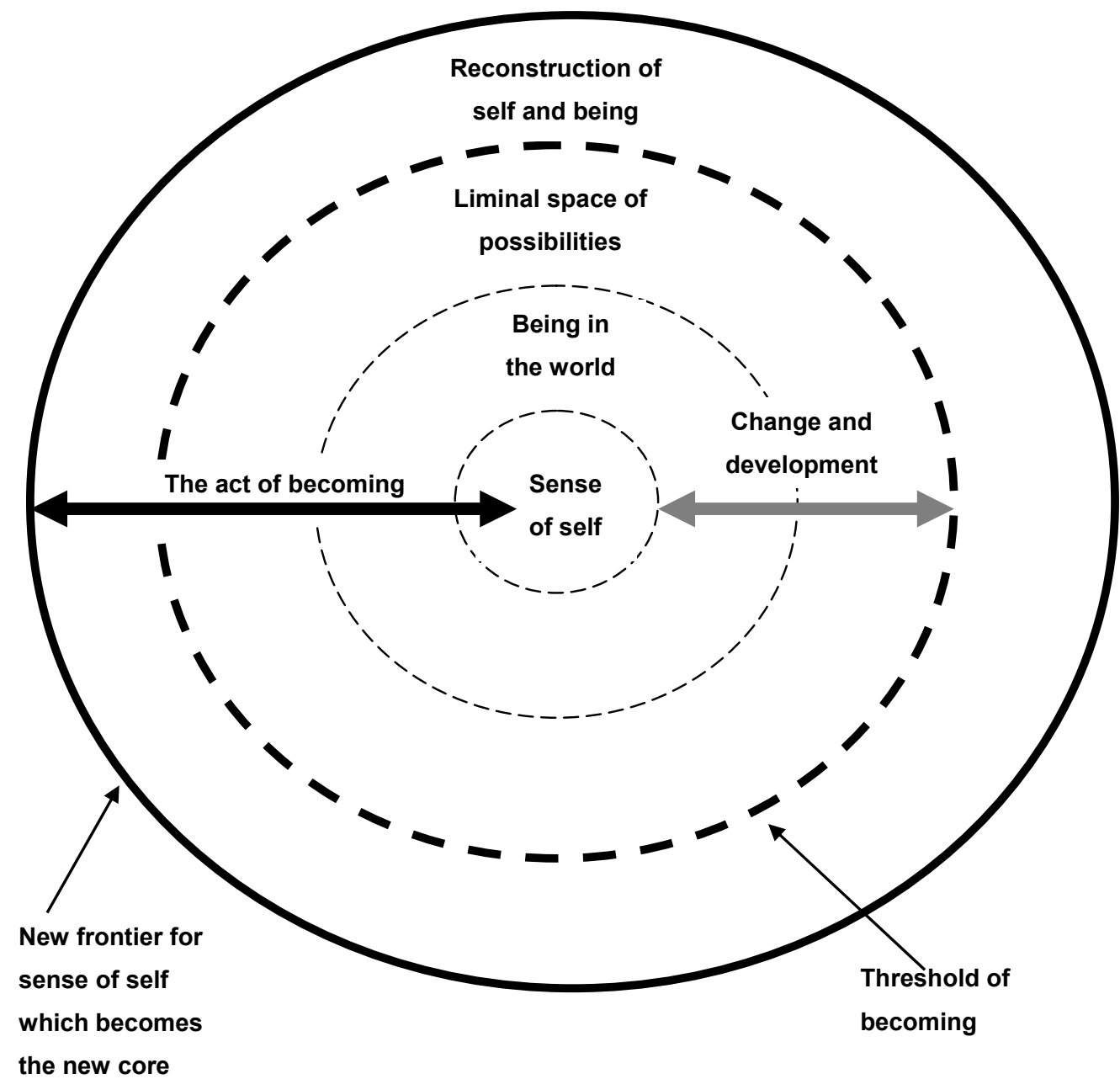

Figure 8.5: A conceptual framework for the process of becoming

The findings of the study will now be discussed with reference to the key elements identified above, and the framework illustrated in Figure 8.5.

\section{The sense of self (what we bring of ourselves)}

This is the inner core of an individual, and the way the world is interpreted. It is the cumulation of histories of experience, knowledge, values and beliefs. It is a stance; a worldview. The sense of self also includes dispositions to learning, and personal and professional identity. It is what each individual brings to their being in the world.

Participants in this study were diverse in terms of their knowledge, expertise and dispositions. Changes to professional identity ranged from participants perceiving their role as inservice teacher educators differently, to perceiving themselves as leaders and researchers. Participants conveyed their values and beliefs, and perceptions of their roles as inservice teacher educators at different points within the process of professional growth. For example, Hannah recognised that "self 
motivators" were "very instilled" in her practice; Eva was conscious of her "very deep-seated sense of equity"; Olivia acknowledged that she would be continually growing and developing her professional self. Some participants were very clear and explicit in expressing the reconstruction and transformation of their sense of self. Eva expressed her new-found perspective of herself as a researcher:

I'd say that's another outcome of the work with INSTEP: the willingness and readiness to take on research projects, and respond to people's invitations to be researching with them is stronger because I think probably INSTEP made me realise I have got something to offer; it validated who I was as an individual; it gave me a sense of identity within research and that combined with my Masters at the same time meant that yes: I do like this work; I could do this work. ... There is the brain in here that could work in this way.... I think that's another aspect of the project that really stood me on my ground. I am a professional. I'm a blinking good professional.

Similarly Elaine acknowledged her paradigm shift:

I've got a lot better at looking at different research - bits of research and reading other literature a lot more than I used to ... I remember [when] we first started in INSTEP, we used to say, 'you know, we're the practitioners, we're not the [theorists or researchers]' but I don't ... think like that anymore.

Olivia perceived her role differently:

I've always been a bit concerned about being the teacher's friend. I think l've [since] seen that a little bit differently. It has its pluses and minuses though. It's not really about being a friend ... it's making a difference ... it's about me being the facilitator not the person that comes up with the ideas.

Both Elaine and Theresa acknowledged that they now regarded themselves as "leaders of learning", and were confident in that role. Hannah acknowledged the impact that the INSTEP project had on her way of thinking:

I'm sure INSTEP has ... scarred me for life, sort of thinking about practice really differently and thinking about organisational structures. ... It really has coloured the way I think about things.

Most participants indicated some shift in their perspective: their ways of seeing the world, and each experience was unique to the individual. Those who did not express such changes in their sense of self, acknowledged: changes in practice; enhanced knowledge of theory, themselves, and/or their practice; and/or increased confidence and sense of agency. Although this resulted in learning, growth and improvement, the sense of self remained unchanged.

\section{Being in the world (and how we are who we have become)}

This is an individual's frame of reference; their way of being and knowing; the enactment and embodiment of their role incorporating their values, beliefs, and 
assumptions. It includes a repertoire of knowledge and skills at a point in time, and means of dealing with contexts and situations of practice. The being in the world offers the continuity and security of the familiar, within which improved practice, increased knowledge, and increased confidence can take place within a context of "average everydayness" (Dall'Alba, 2009, p. 35).

Each participant expressed their being in the world in terms of their role at any particular time. Anne recognised that her practice had become "ingrained", and she found change difficult:

One of my sort of philosophies I remember when I was doing the training, ... was that you meet people where they're at, whether it's children or teachers or whatever and then you would, you know, acknowledge what's happening to them and then kind of move on from there and I think somehow I found that next step a little bit difficult: moving on.

Theresa reflected on her response to collaborative inquiry:

I guess l've got more comfortable with the process: examining your ... theories; examining the way you work, and I'm comfortable with getting feedback on that and people talking it through. Yeah, it's just what we do now.

Olivia attempted to apply EBIP to her work with colleagues:

Our principal doesn't really take any interest in our appraisal system so what we've done this year we've chosen four of the eight dimensions for RTLB and chosen our own appraiser ... So, l've tried to talk a little bit about maybe each dimension was around a case, a couple of cases ... to try and tell them about how I was trying to get the teacher to be more involved in decision making and problem solving and thinking about where we've come from.

Being in the world was also impacted upon by contextual and sociocultural factors which impacted upon each individual's capacity to enact or embody their sense of self. This was evidenced by Hannah when she "dropped the ball" on her learning due to organisational and political change. Olivia also expressed frustration at not being able to enact her sense of self due to the lack of an environment where colleagues would challenge her. Laura lamented that her new-found comfort with her practice was threatened by the forthcoming restructuring of the RTLB service.

\section{Liminal space of possibilities (to become what we are 'not yet')}

It is within this space that there exist possibilities to become ("what we are "not yet") (Dall'Alba, 2009, p. 36), and possibilities and opportunities to change the sense of self. These possibilities and opportunities for change and transformation are present in engagement with others, in an environment of mutual commitment and 
responsibility for learning. Individuals' own dispositions to learning and their contexts of practice and learning can determine the extent to which opportunities are seized, and possibilities explored.

Elements of risk and challenge are features of this space. Dispositions to learning, such as resilience, resistance, perseverance, openness, willingness and wholeheartedness determine readiness for learning, and thus the potential for change and transformation. This is a space in which the sense of self can be confronted and challenged, and professional identities re-appraised (Forde et al., 2006). Constraints and limitations are also manifested in this space within the context of each individual's being in the world. Factors of organisational structure, power and competition mediate the opportunities and possibilities available to individuals.

Learning and change can take place, and are accommodated within the existing frame of reference. Increased confidence and improved performance can become part of being in the world, without necessarily changing the sense of self. There is also the potential within this space, therefore, to change and grow professionally without necessarily undergoing transformation.

The INSTEP project and framework provided a myriad of liminal spaces of possibilities: spaces "for strangeness" (Barnett, 2005, p. 795), where participants were supported to form communities of collaborative EBIP. These collaborative environments were explicit in their efforts to be inclusive, respectful and risk-free, in order to maximise opportunities and possibilities for individual learning and transformation.

All study participants reported some degree of challenge or discomfort within this space. Laura "had a constant feeling of being insecure". Elaine articulated fear within this space: "we still have a fear of each other in some ways". Eva "felt exposed", and at risk when she was deprivatising her practice. Theresa was aware of the collective responsibility to challenge each other: "The more we worked together, there was a more ... challenging [of] practice; that idea of collegiality". Evelyn was appreciative of the challenge, by her peers, for evidence of her claims of effectiveness.

Dispositions to learning mediated each individual's capacity to cope with ambiguity, change and transformation, and thus their journey towards the threshold of becoming (who we are 'not yet'). Eva conveyed a readiness for learning, and sought and embraced the opportunities within this space: 
So I arrived there ready and willing; did the reading; had the conversations; and I think I was there understanding what it was about and what risks I might need to take; what opportunities I might need to look for, and really get involved right from the start.

Hannah's approach was to embrace the experience of EBIP as one of learning. Theresa valued trying out "new things", and was optimistic in the face of challenge:

There's a lot of fear around approaching some things because you think it's going to be hard but ... its generally not, and to me that is the biggest learning for me, is just to dive in, and sometimes you'll make a mistake, but most of the times you don't. Most of the time you have really good outcomes for both of you.

Although Eva embraced the opportunities within the liminal space, she articulated the need for faith and resilience to overcome an apparent indifference to the value of EBIP conveyed by senior management within her organisation. Hannah also perceived that the attempt to create such liminal spaces within her organisation post-INSTEP were thwarted by a lack of reification combined with uneven relationships of power within the professional learning groups.

The extent to which participants identified possibilities and embraced opportunities to learn and grow were mediated by each individual's dispositions towards learning, as well as their contexts of being in the world, such as organisational infrastructure and support, and the existence of safe and risk-free environments. The extent to which elements of risk-taking were positive and productive experiences was mediated, therefore, by the collective responsibility to challenge, learn and grow within a collaborative environment of mutual vulnerability, trust and respect.

\section{Threshold of becoming (what we are 'not yet')}

This threshold represents each individual's emergence into different ways of knowing and being. Complete emergence over the threshold is generally a point of no return, as there can be no unlearning and perceiving the world as it was previously perceived. However, emergence can take place over time, and is subconscious. There may be a process of emerging where the threshold is straddled, with one foot in each way of knowing. This would bring about what Land (2010) refers to as "glimpses of an untraveled world: not yet entered". The emergence through the threshold takes time.

Hannah's reflection of the INSTEP experience having "scarred" her "for life" indicates the irreversibility, for her, of emerging over her threshold. Eva became a researcher: once over the threshold, she perceived her role with different eyes. 
Elaine and Theresa's journey resulted in their regarding themselves as leaders of learning within the sector of inservice teacher educators. Their perception of their role, although still including their role as inservice teacher educators, had expanded.

\section{Reconstruction of self and being (in the world)}

This is a period of continual readjustment, where practice is realigned with values, beliefs and assumptions. This is an adjustment of perspective and worldview and a reassessment of how to enact this new perspective of being in the world.

This was the period which brought tentativeness and uncertainty for some participants, while they tried to align their espoused theory with their theory-in-use. Elaine found it difficult to reposition herself:

That's quite hard when you're in a position where you feel as if you've kind of got a lot of knowledge about your role and then you realise you don't.

Olivia was very conscious of the efforts she was making to align her espoused theory with her theory-in-use:

I sometimes saw myself as a sales person, I've got all these fantastic ideas and I just want everyone to do them because they are so good. So I don't really do that any more. I just bite my tongue a bit sometimes. So probably I come in less with my own agenda, because I know just what to do to solve this, this is the sales thing, yeah so I'm very aware of that and I work really hard to not be quite so enthusiastic, and I'm also a bit of a rescuer.

Anne reported the struggle in changing the way she worked because her practice and knowledge had become so ingrained: "it's difficult to teach old dog new tricks".

This period is also a time of excitement and innovation. This is where the unfamiliar becomes familiar, towards a reconstruction of being in the world. Hannah was passionate about her new found courage:

I'm much more courageous. I had never written ethics or proposals or anything like that, and I thought that was well outside my capacity, but I don't think that any more, but it was the courage to take the step. And I'm far more courageous about articulating what it is I think we need to do, and why we need to do it; ... being really staunch about it; ... being a stroppy wee moo really, and having that unswerving belief that at the moment we are doing the right thing. ... I will put my beliefs on the table. ... I'll be very upfront about those sorts of beliefs and values.

Eva was excited when she realised that her experience of EBIP within INSTEP had transformed her teaching and her work with student teachers and teachers:

I think that it is explicit now that I realise I want to improve my practice all the time, because if I improve my practice that impacts on the people that I'm 
working with. I'm better at what I do; being able to talk about what I do, then it makes it easier for them, and I'm realising the incredible significance of a role model who can make things explicit.

This period is one of discovery and new beginnings, and leads to a new frontier for redefining the sense of self, and a reconstruction of being in the world.

\section{New frontier for the sense of self}

This frontier becomes the renewed sense of self, with enriched histories of experience and knowledge, and changed perspectives of the world and being within it. This continuous process reflects the notion of "folding of past into present, into future [ensuring] continuity with change in our lives, while opening up a range of possible development trajectories" (Dall'Alba, 2009, p. 39).

\section{Change and development}

This is a continual process of gaining new knowledge, and changing and improving practice within the individual's existing frame of reference (being in the world). This can lead to enhanced performance and increased confidence, but does not impact upon the sense of self and perceptions of the world. It stops at the threshold of becoming, therefore is not a transformative learning experience.

\section{The act of becoming}

This is the process, unique in its degree of completeness and fulfilment for every individual, of:

- continuous enacting being in the world;

- coping with ambiguities and challenge;

- engaging in critical reflection and discourse;

- exercising dispositions to learning; and

- reconstruction of sense of self.

Borders that are crossed are not necessarily distinct and well defined, and it is not necessarily a linear process.

All participants in this study reported changes in their practice and knowledge informing their existing frame of reference (being in the world). Some reported transformative learning, where their perspectives and worldview had changed, and they crossed a threshold into who they had now become: a renewed sense of self and being in the world, with new challenges and opportunities in an ever expanding cycle of learning and professional growth. It is clear that in order to optimise the potential for 
transformational learning, individuals must demonstrate dispositions such as wholeheartedness, openness and responsibility as identified by Dewey (1933), but these characteristics must also pervade the liminal spaces of possibilities within learning communities and learning organisations. The next section will discuss the implications for organisational and system-wide transformation.

\section{Organisational and system-wide transformation}

Sankar [Document Source D (2009)] reports that, as a result of INSTEP, some ISTEs had a major impact on their organisations, including the development of professional learning and appraisal programmes. Other impacts, Sankar reports, include reviews of management structure, induction programmes, and the use of professional development days. However, in spite of the individual shifts in knowledge, skills and attitudes, and the aforementioned organisational changes, Sankar expresses concern about the sustainability of such shifts, and about building capacity at system level. She asserts that in order to achieve sustainability in inservice teacher educator practice, provider organisations need to change systems, structures and processes to promote and accommodate new learning and professional growth. She reports that even within the aforementioned organisational impacts, "[a] closer examination of these structures and systems reveals that within these broader institution-wide changes, in most instances the inquiry on practice related issues still tends to be individually, 'l' focussed" (p. 56). She highlights this as an issue and urges inservice teacher education providers to take collective responsibility for the improvement of the quality and effectiveness of inservice teacher educator practice:

[O]ver time the focus needs to extend beyond individual improvement to
explore how ISTEs can contribute to lifting the quality of the services
provided by their institution as a whole. This requires ISTEs to escalate the
inquiry to include practice issues that face the entire organisation. It also
allows the organisation to tap into the tacit knowledge of advisors to
collectively reflect on aspects of their service including issues such as
prioritisation and decision-making processes regarding selection of schools;
aligning professional delivery to regional needs; gathering evidence of
success (p. 56).

She concludes by observing that unless these issues are addressed, individual inquiries into practice will have no impact on shifts within inservice teacher education provision.

Cochran-Smith (2005) argues that a narrow version of evidence-based practice fails to take account of the responsibility of educational policymakers and analysts to improve outcomes for students, is outcomes based, and places too much emphasis on the role of teachers and teacher educators without consideration of broader 
political and sociocultural influences. She argues that the new teacher education should be "constructed as a policy problem and a political problem ... based on evidence plus ... and driven by learning" (p. 14 italics in original). She presents a scenario for the future of teacher education where teachers, teacher educators, educational institutions, researchers and policymakers are informed by a "wealth of critical and theoretical inquiry":

\begin{abstract}
We now have many routes and pathways into teaching, but all of them have the core components necessary for teachers to learn to teach in the service of students' learning. These components were identified through dialogue within the profession and in the public arena. Quantitative and qualitative evidence was considered alongside arguments about teaching as an ethical and moral activity. There were debates about ideas and ideals for our society. Many people came to agree that, particularly in light of changing demographics, education that promotes basic skills and critical thinking for everybody was necessary to preserve our democracy.
\end{abstract}

Teacher education scholars and practitioners in all routes and pathways now collect evidence about their work. But because the focus is on learning opportunities as well as learning outcomes, policymakers pay attention to resources as well as test scores and performance measures. Social justice and equity are common words in the discourse because they are seen as worthy outcomes in and of themselves and as the foundations of a successful education system. (p. 15)

This scenario depicts critical inquiry taking place at multiple levels of complexity throughout the educational system, with collective vision of, and responsibility for, improvement of practice and educational reform. Similarly, Kemmis (2009, p. 37) highlights the need for reflexive pratice at organisational levels:

... changing practices requires changing things frequently beyond the knowledge and control of individual practitioners, and frequently outside the individual practitioner's field of vision (though also, sometimes, right under their noses). Changing these things requires forms of collective change and forms of collaborative discussion and inquiry to change not just what practitioners know and think and say and do and how they relate to others, but also the practice architectures, constituted by mediating preconditions, which surround and support them, and sometimes place them in impossible and unsustainable conditions (discursively, materially, economically, socially and politically, and personally).

Prpic's (2005) tri-view model of reflexive practice incorporates individual introspective reflection in the first stage (intra-view); discussion, sharing and being challenged in the second stage (inter-view); and consideration of the wider organisational or community contexts in the final stage (trans-view). She considers that the final stage contextualises the first two stages, and that new knowledge in this stage may give rise to sustainable change as it acknowledges collective priorities (Roebuck, 2007). 
The findings of this study confirm Sankar's (2009) report that change and improvement were not sustained beyond INSTEP for the majority of study participants, or their organisations. Participants in this study reported that without the "bigger picture" (Evelyn, 2010) of community and organisational infrastructure, frameworks, and common vision of purpose of EBIP, it was more difficult to sustain a process for continuous improvement of practice as deemed necessary for inservice teacher educators (Loughran, 2006; Ministry of Education, 2006, 2008a; Timperley et al., 2007). Olivia expresses the necessity of conceptual and organisational frameworks:

You can be given baubles but if you've got no tree to hang it on they're no good to you ... it's a bit like that. The tree was really important and then you can start adding all those little things onto it later.

Only two of the participants of this study continued to be involved in rigorous and systematic EBIP beyond INSTEP, and that was within institutionalised professional learning and appraisal programmes adopted by their organisations. Although some RTLB participants had continued to meet as a group, there was no evidence of rigour being applied to EBIP:

And at the beginning [of INSTEP] it was sort of like, you know, well what's your problem of practice, you'd sort of, like, do that. But now, it's just become an automatic thing. You sort of save up your problem and bring it ... to the group. And there's no reason to sort of structure it, it just is now, it's just a comfortable place to bring that problem of practice. (Laura)

There was a similar situation in Hannah's organisation, where there was a professional learning programme, with certain implicit expectations, but no "tools and teeth" to apply rigour. For Hannah and the RTLB participants, the sharing of evidence of practice was no longer required or deemed necessary, and appeared to be reduced to a "cosy chat" (Hannah) about problems of practice, which served more as a therapeutic exercise than one of challenge and dissonance. Most others reported the difficulty of sustaining rigorous EBIP in isolation, and of identifying colleagues for critical reflection and mutual commitment within an environment that did not prioritise or resource a system for EBIP in professional learning. Evaluation of McGee's INSTEP project [Document Source A (McGee, 2011)] highlighted the necessity and benefits of an organisational infrastructure within which EBIP was prioritised and embedded. However, in spite of establishing an organisational framework, McGee reported challenges of sustainability once the organisational priorities and commitment shifted to Ministry funded projects that took precedence due to the contestable environment of inservice teacher education provision. 
Both Sankar's (2009) evaluation and this study found that formalisation and institutionalisation, at different levels, contributed to the process of professional learning within the INSTEP project. The INSTEP framework formalised and institutionalised the process of EBIP, locating individual inquiry within the broader context of the project goals and infrastructure. Similar to learning communities described by Wyatt-Smith et al. (2008) for teacher professional learning, INSTEP had a shared vision of purpose, was "multi-layered and dynamic", and provided "a supportive environment for opening spaces for critical conversations" (p. 18). The project also incorporated systems and procedures for monitoring and reporting progress, as well as having a shared understanding of expectations and requirements [Document Sources A, B, C (Higgins et al., 2011; Mcllraith et al., 2009; Ministry of Education, 2008a)]. Within the formal infrastructure, the INSTEP networks of communities performed the function of professional peer validation of evidence, shared ownership of, and responsibility for the development of tools and processes, and engaged in critical dialogue [Document Sources A, C, E (Baskerville \& Goldblatt, 2009; Higgins et al., 2011; Mcllraith et al., 2009)]. These findings would favour Cochran-Smith's vision of a future teacher education (2005), and confirm the assertion by Forde et al. (2006) that individual practitioners need the support of organisations to develop professionally:

It is important, then, to look at wider contexts for professional development: how to implement policy but retain ownership of teaching work; how to improve individual practice within the school as an organization; how to ensure that reflection leads to sustained efforts to improve learning for all pupils. It may be that to focus on individual teacher development is to miss the opportunity to think about what the school can do to further pupil learning and to encourage the professional development of its teachers. (p. 79)

Although Forde et al. are discussing teacher professional development, this would also apply to teacher education organisations and communities. Some participants in this study noted the lack of a shared vision and understanding of EBIP. Olivia and Laura referred to this organisational dimension as "the training" that was not evident in other communities.

Hannah also attributed lack of rigour in her organisational professional learning programme to the failure of leadership in conveying the purpose of EBIP within the professional development programme. Although Aroha's and Elaine's organisations seemed to be making explicit moves to embed formalised processes within their professional learning and appraisal programmes, and establish a shared vision of the nature and purpose of EBIP in professional learning, no claims can be made in this study about sustainability and system-wide educational change. That would 
have to be the focus of another study. However, in terms of individual inquiry, both participants were engaging in rigorous EBIP in a continuous way, and reported that other facilitators within the organisations were supported to do the same.

It seems that the INSTEP project was effective in promoting and supporting EBIP, and was effective in bringing about some learning and changes in practice for all study participants. Participants expressed increased knowledge and understanding, changes to ways of working, and changes to their sense of self including altered perceptions of themselves, their role and their professional identity. It also seems that organisational contexts including resourcing and infrastructure mediated the capacity of participants to engage in EBIP, since only two maintained EBIP beyond the INSTEP project, and that was within the context of organisational professional learning initiatives.

\section{Chapter summary}

The process of EBIP incorporated reflection including:

- deprivatising and making practice explicit;

- surfacing and examining personal professional beliefs values and assumptions;

- engaging in critical dialogue; and

- reframing practice and underpinning theory to improve teacher practice and student outcomes.

This resulted in varying degrees of learning and transformation for study participants. EBIP, however, could only be sustained in a rigorous and systematic manner, when it was supported within formal, informal and social organisational contexts. This enabled the collective ownership and responsibility for learning, incorporating collective negotiation and development of shared meanings, tools, mechanisms and frameworks, which systematised and reified EBIP. In this way, the goals of individual EBIP were located within an overall infrastructure incorporating a shared vision, and alignment with strategic priorities and resourcing.

This study indicates that sustainability of change and improvement of practice within system-wide educational reform may be more likely to be achieved by individuals working coherently within organisations and educational systems that value and adopt a culture of inquiry that:

- nurtures safe, collaborative environments and opportunities for learning where vulnerabilities can be exposed; 
- minimises the impact on learning, of power relations and contestable environments; and

- offers challenge, support and diversity of perspectives.

The next chapter presents the research findings in relation to the research questions. 


\section{CHAPTER 9 \\ Revisiting the research questions}

\section{Introduction}

This chapter summarises the research findings with reference to the research questions that informed the study and the development of the resulting theoretical framework. The research questions were:

1. What are the personal, cultural, social and organisational contextual factors that mediate EBIP for inservice teacher educators?

2. What are the processes, interactions and activities that constitute effective EBIP for inservice teacher educators?

3. What is the impact of EBIP upon inservice teacher educators' learning and sense of professional identity?

\section{Personal, sociocultural, and organisational factors}

There were three key factors found to mediate EBIP for inservice teacher educators. They were: resourcing; systematisation and reification; and dispositions to learning. Although they are reported here as distinct elements, they were complex and interwoven, and found to impact in all three domains of personal, cultural, social and organisational contexts. As articulated in the previous chapter, the INSTEP project was regarded as an organisational context, as were the participants' provider organisations.

\section{Resourcing}

The aspects of resourcing that mediated EBIP were: time, infrastructure, and access to technology. The provision of time was considered the most significant. Since the multi-layered framework of networked communities of INSTEP featured quite significantly in supporting EBIP, the infrastructure served more as a resource for the inservice teacher educators than as an aspect of systematisation. The following three aspects of resourcing were therefore most significant.

- The provision of time for:

- rigorous reflection;

- collaboration; 
○ the development of tools and mechanisms;

$\circ$ reviewing literature; and

○ peer support.

- The prominence of an infrastructure or operational framework offering:

○ opportunities for leadership; and

o the development of a variety of collaborative arrangements such as networks, communities of practice, critical friendships and mentoring.

- Ease of access to technology such as video/audio recorder for gathering evidence of practice.

The above aspects of resourcing, in particular, the provision of time, significantly impacted upon ISTEs' capacity to engage in EBIP. Without such resourcing, ISTEs found it difficult, and at times, impossible, to engage authentically and wholeheartedly in EBIP.

\section{Systematisation and reification}

Aspects of systematisation and reification served both to support the pragmatics of EBIP, and provide a means of negotiating and operationalising concepts such as the principles and the proposed theory of improvement for inservice teacher educator practice (Ministry of Education, 2008a). The following aspects of systematisation and reification were found to impact upon EBIP:

- Operationalising of EBIP at various levels from individual cycles of inquiry to the collective development of evaluation frameworks, processes, tools and mechanisms to support EBIP;

- Clarity of the purpose of individual EBIP, and its situation in the wider frame of coherent goals, resourcing, and strategic priorities of the community and the organisation;

- Collective negotiation and development of valid tools, mechanisms and frameworks, informed by relevant literature, to support the identification and evaluation of aspects of practice;

- Established processes for documenting and sharing professional learning and growth;

- Measures of accountability in place, with clarity of expectations of individuals, communities and organisations. This includes reporting mechanisms which incorporate aspects of professional learning and growth; 
- Nurturing of collegial spaces of challenge, trust and respect, which are risk free and safe; and where explicit strategies are put in place to minimise the impact of power relations and contestable environments;

- Provision for a degree of flexibility and autonomy within an operational framework with clear goals and shared visions of implementation.

The above aspects of systematisation and reification served to establish a multitude of communities of practice incorporating shared understandings and ownership, and negotiation of systems and frameworks within which to operate.

\section{Dispositions to learning}

The following five dispositions to learning apply to individuals, communities of practice, and organisations, and were found to be key factors in promoting and supporting learning through EBIP:

- Courage to surface values, beliefs and assumptions; to embrace challenge and dissonance; and to mutually engage in deprivatising practice and exposing vulnerabilities;

- Mutual commitment to learning that is enacted in deliberate and explicit efforts to critically reflect on and justify contexts, practice, values, and beliefs, incorporating evaluation of evidence of practice, and literature, with a view to enhancing education for all;

- Embracing and valuing diversity and alternative perspectives, and appreciating and valuing others' work and contexts of practice;

- Taking ownership of, and responsibility for, the learning of self and others, incorporating self-directed learning and monitoring of progress. This incorporates setting goals for improvement of practice that align with a shared vision of enhanced performance and learning for inservice teacher educators, teachers and students. It also incorporates accepting collective responsibility for ensuring and maintaining the safety of liminal spaces for critical reflection on practice;

- Valuing leadership qualities that are inclusive, respectful, encouraging and challenging;

These dispositions were evident for study participants and their communities of practice. They were also evident within INSTEP as a community or organisation. Courage and commitment were demonstrated by the way in which the management 
team engaged in defining the nature and implementation of the project, within the research and development context, to meet its aims. Similarly, the external evaluation of INSTEP (Sankar, 2009) was designed to appraise the structures and processes of the project and their contribution to the aims, and to identify the impact of the project upon participants. The flexibility of the project and the networked communities of practice allowed autonomy, and promoted collective ownership and responsibility for learning. The design of the project facilitated shared leadership and allowed leaders to emerge and grow, while enactment of the principles of inservice teacher educator learning and practice (Ministry of Education, 2008a) reflected the value of diversity and leadership qualities.

Although this study offers some insights into the dispositions of some provider organisations, identifying the extent to which each organisation demonstrated these dispositions was not within the remit of this study. This would require further research.

It seems, therefore, that the impact of resourcing, systematisation and reification of EBIP was evident in the development of collectively owned tools, mechanisms, systems and processes that located EBIP within individual, community and organisational goals and infrastructure, and that reflected the cohesion of policy and resourcing. These factors afforded an operational framework, which, while allowing for flexibility and autonomy, incorporated liminal spaces of challenge, trust and respect within risk-free, safe environments. Individual, community and organisational dispositions to learning were key influences on participants' EBIP. Such dispositions included: mutual commitment to learning; courage to deprivatise practice and embrace challenge and dissonance; valuing diversity and particular leadership qualities; and taking ownership of, and responsibility for, learning.

The following section summarises the processes, interactions and activities that individuals engaged in within EBIP.

\section{Processes, interactions and activities}

There were three key dimensions identified within the processes, interactions and activities of EBIP for inservice teacher educators. These dimensions - reflection, monitoring and reporting, and communities of practice - are summarised in this section. 


\section{Reflection}

The core activity of EBIP for individuals involved rigorous reflection within a variety of communities of practice. All participants engaged in collaborative, planned, intentional reflection incorporating:

- the identification of problems of practice from their contexts of work;

- examination and deconstruction of practice;

- surfacing values, beliefs and tacit knowledge;

- questioning taken-for-granted assumptions; and

- evaluation of evidence of practice and established research and theory.

Rigour in participants' reflections was evident in:

- the proactive, and often systematic identification of problems of practice situated within authentic contexts;

- clearly defined structures and processes to support collaborative EBIP, such as collaborative arrangements and timeframes;

- the development and implementation of negotiated tools and mechanisms such as questionnaires, interviews and stimulated recall, to gather valid evidence and surface values, beliefs and assumptions;

- the steps taken to ensure a safe and risk-free environment for reflective dialogue, such as agreement on protocols for ways of working, shared leadership, and autonomous selection of peers for deprivatising practice; and

- the degree of challenge that was expected and embraced within negotiation of meaning and inquiries into practice.

Reflection, therefore, incorporated a variety of processes, interactions and activities that contributed to a systematic, rigorous and collaborative approach to EBIP. Such rigorous reflection incorporated systematic approaches including measures of accountability, such as monitoring and reporting. The ways in which aspects of monitoring and reporting were manifested are addressed in the following section.

\section{Monitoring and reporting}

Documenting and sharing learning experiences facilitated and supported the inquiry process and enhanced rigour in reflection. Individual reflections were embedded within systems consisting of: 
- explicit expectations and requirements for monitoring and reporting progress, including negotiated processes, tools and mechanisms;

- collectively negotiated and established tools and mechanisms for gathering evidence, surfacing values and beliefs, and evaluating practice.

Monitoring and reporting, therefore, added rigour and validity to participants' EBIP, and promoted and supported self-regulated learning.

While all ISTEs were required to share their progress and report on their inquiries, many also contributed to publications such as conference presentations, journal articles and book chapters. The participants of this study reported that the process of writing and preparation to share knowledge and experience in public forums enhanced and validated the learning experience.

\section{Communities of practice}

Mutual engagement within communities of practice took place at multiple levels for a variety of purposes. Larger, more diverse communities, which were determined by the project structure, were engaged in:

- negotiating shared meanings and exploring different perspectives;

- debating and agreeing on ways of working;

- developing evaluation and reporting tools and mechanisms; and

- discussing and evaluating research and theory.

Smaller groups of critical friends engaged in deprivatising and critiquing practice within a mutually vulnerable environment of trust, respect and challenge, where alternative perspectives were sought and valued. Critical friends tended to be self-selected on the basis of similar philosophies, and mutual understanding of contexts of practice.

Within the communities of practice, collective ownership and responsibility for learning was promoted through the enactment of the principles for inservice teacher educator practice (Ministry of Education, 2008a); in particular, the development of collaborative relationships, being contextually responsive, and providing and building leadership.

The variety of processes, interactions and activities that constituted EBIP for study participants incorporated systematic reflection within a variety of communities of practice, and took place within an overarching operational framework incorporating 
processes for inquiry, and monitoring and reporting progress. Some examples of the processes, interactions and activities are presented within the learning cases in Ki te Aotūroa (Ministry of Education, 2008), and serve as a resource for inservice teacher educators.

The following section summarises the impact of EBIP on individual participants.

\section{Impact upon learning and professional identity}

As discussed in an earlier chapter, a holistic view of professional learning renders ontology and epistemology as inseparable, where learning involves the integration of knowledge and understanding, ways of working, and sense of self (including professional identity). Within this study, participants identified the ways in which their knowledge and understanding, ways of working, and their sense of self were impacted. These three aspects of learning are summarised in this section.

\section{Knowledge and understanding}

Study participants reported enhanced knowledge and understanding of theoretical perspectives, and of the way in which these increasingly informed and underpinned individuals' practice.

Knowledge and understanding of EBIP and of approaches to the improvement of practice were extended, as was appreciation of the potential for improvement.

There was an increased awareness of personal assumptions, values and beliefs, and the way in which these influenced practice. There was also an increased awareness of the impact of practice upon others.

\section{Ways of working}

Participants reported particular changes in facilitation skills such as:

- giving more quality time to interventions;

- practising being more attentive to teachers' needs through appropriate questioning, listening and pausing;

- $\quad$ paying particular attention to developing relationships; and

- communicating more effectively. 
They also reported improved data gathering skills with conscious, systematic gathering of robust evidence.

In terms of improving their own practice, participants reported taking a more proactive, objective and problem-solving approach to their practice, incorporating:

- increased clarification of objectives;

- more planning for collaboration;

- proactively seeking feedback and advice; and

- the development of data gathering tools and mechanisms.

The inquiry cycle was adopted more systematically and rigorously with teachers, with mechanisms in place to surface teachers' values, beliefs and assumptions, and strategies to promote teachers' and schools' self-review and identification of needs.

Practice was better informed, justified by theoretical perspectives, and there was more proactive and productive sourcing of relevant literature.

An awareness of values, beliefs and assumptions led to modification of particular tendencies which were deemed to negate effective intervention, such as the tendency to provide solutions rather than promote a problem-solving approach.

All study participants, therefore, were aware of changes in their ways of working as a result of EBIP. Some involved the use of particular tools and techniques to improve facilitation skills, while others adopted changes in approaches to their practice with teachers and schools, and to their efforts to improve their own practice.

\section{Sense of self}

Some participants reported increased confidence through clarity of practice and the linking of evidence to improved teacher practice and enhanced student outcomes.

Some experienced an increased sense of agency and credibility through the realisation that their work was of value. This also led to feelings of affirmation and strength.

Some were reaffirmed that their role as inservice teacher educators was to support and promote teacher learning, as opposed to providing resources and ready-made solutions. 
Others experienced changes in their perceptions of themselves, their identity, and their role. Some were able to identify more clearly with the role of a researcher and creator of knowledge. Others expressed new perceptions of themselves as leaders of learning with their peers.

The changes within the sense of self, therefore, ranged from feelings of affirmation and an increased sense of self-efficacy and agency, to participants perceiving their world, and their role, quite differently.

The impact on participants' learning and professional identity incorporated all three dimensions of knowledge and understanding, ways of working, and sense of self. However, for each individual, the interplay of the dimensions resulted in different learning outcomes. On one level, there was increased confidence, self-efficacy and agency through improved practice and increased knowledge and understanding, where participants improved their practice within their existing perceptions of being in the world. On another level, some participants experienced a transformation of their sense of self. They perceived themselves, and their role, quite differently and therefore reconstructed their being in the world. The mediating conditions and implications of such learning and transformation are presented in the following summary.

\section{Chapter summary}

It seems that participants' learning and transformation as a result of engaging in EBIP are dependent on their capacity to engage in rigorous reflection within communities of practice. This capacity is significantly mediated by the contextual factors: dispositions to learning; resourcing; and systematisation and reification. Similarly, the capacity to enact new learning and transformation may also be significantly mediated by these contextual factors. However, the impact of those factors upon sustained and enacted learning and transformation would require further research, as would the impact on the capacity for individuals to influence organisational and system-wide learning and sustained change. This study was limited to the participants' experiences, mediating factors, and the impact of their engagement in EBIP within the INSTEP project. The next chapter presents the conclusions, limitations and implications of the study. 


\section{CHAPTER 10 \\ Conclusions, limitations and implications}

\section{Introduction}

This chapter presents the conclusions of the study, the limitations and implications for further research. The chapter begins with a proposed theoretical framework for EBIP for inservice teacher educators.

\section{Theoretical framework}

The theoretical framework is derived from the literature and the findings of the study. There are three interdependent and interconnecting elements: individual learning and transformation; community and connectedness; and systematisation and reification. They are embedded within the framework of Wholeheartedness of becoming. The use of the term wholeheartedness conveys a sense of commitment, determination, devotion, enthusiasm, sincerity and support, while the notion of becoming conveys the concept of learning and transformation. The term wholeheartedness of becoming therefore reflects all components of the learning community or organisation working in harmony towards learning and transformation in striving to bring about improvement of inservice teacher educator practice, improved teacher practice, and enhanced learning outcomes for students.

\section{Wholeheartedness of becoming}

The proposed theoretical framework for EBIP for inservice teacher educators is illustrated in Figure 10.1.

The framework represents wholeheartedness in terms of:

- shared vision of purpose;

- a collective commitment to learning for the enhancement of student learning;

- the interdependence and interconnecting nature of the core components of EBIP:

$\circ$ individual learning and transformation

- communities and connectedness

- systematisation and reification. 


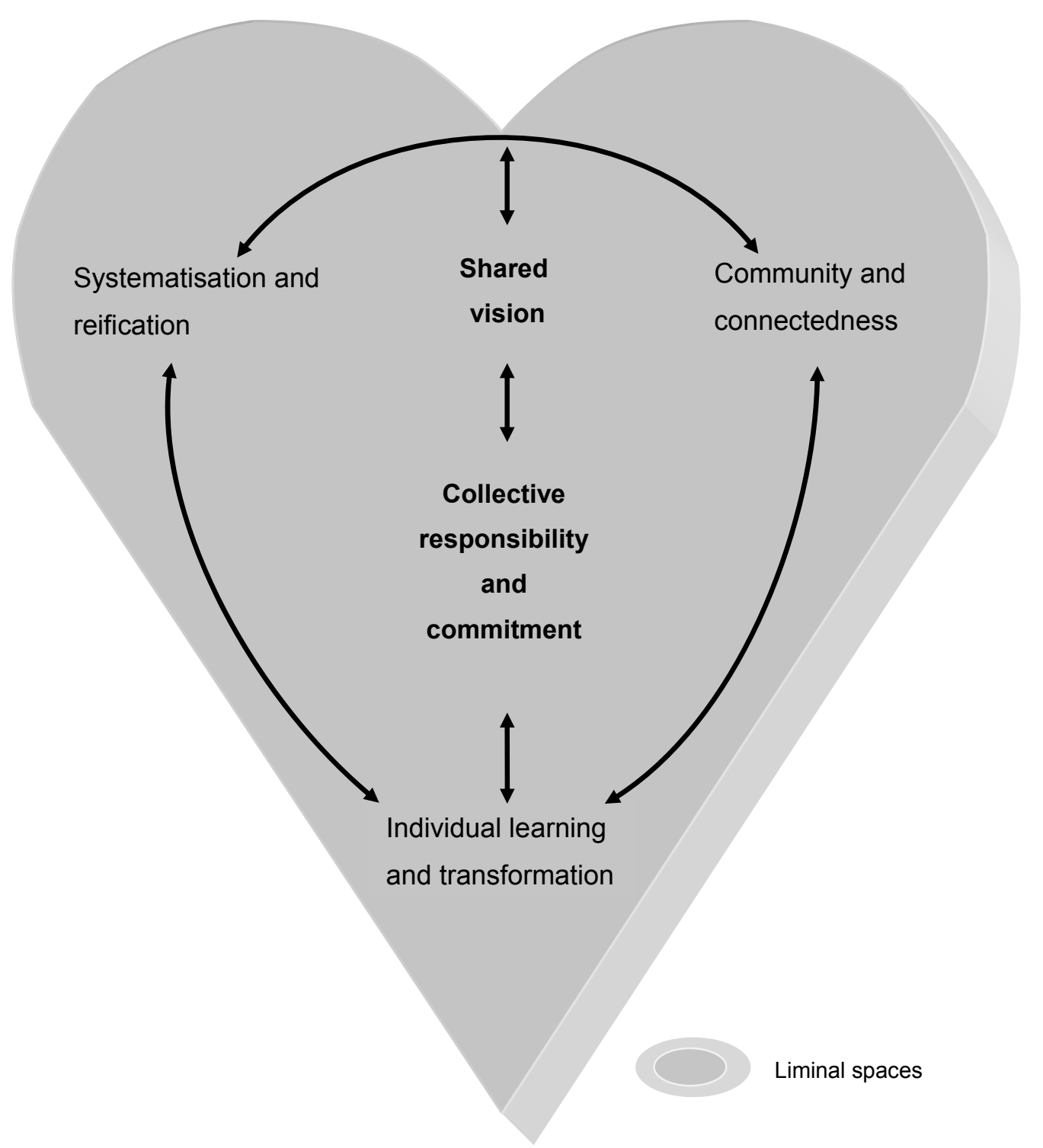

Figure 10.1: Proposed theoretical framework: The wholeheartedness of becoming

\section{Shared vision of purpose}

A clear and shared vision of the purpose of EBIP is the means by which signals are transmitted, conveying the value and priority placed on EBIP for the individual, community, organisation or system. The shared vision is a medium for intrinsic and extrinsic motivation and incentive to mutually engage in EBIP. It is therefore an energising force in the reification of EBIP.

\section{Collective responsibility for, and commitment to, learning}

Collective responsibility for, and commitment to, learning are evident when:

- deliberate steps are taken to ensure safe, risk-free collaborative environments;

- interactions are open, honest and respectful; 
- individuals take responsibility for their own and others' learning;

- $\quad$ systems, tools, mechanisms and resources are developed by, and for use within collaborative communities of practice; and

- communities, organisations and systems demonstrate dispositions to learning including:

○ courage;

○ commitment;

- promoting ownership and responsibility for learning;

○ valuing diversity and other perspectives; and

$\circ$ valuing leadership qualities that are inclusive, respectful, encouraging, and challenging.

\section{Individual learning and transformation}

Individual learning and transformation is optimised through:

- Reflection:

$\circ$ on the content and process of teaching and learning (the immediate contexts, actions, and purposes within the teaching and learning situation);

$\circ$ on established research and theory, personal practical theories and theories-in-use; and

- which is informed by evidence, including the broader sociocultural and political contexts and consequences which influence practice.

- engaging in critical dialogue in a variety of contexts incorporating challenge, different perspectives, evaluation of practice and theory, and collaborative development of systems, tools and mechanisms to support EBIP; and

- dispositions to learning including:

- courage;

- commitment;

o owning and taking responsibility for learning;

○ valuing diversity and other perspectives; and

○ valuing leadership qualities that are inclusive, respectful, encouraging and challenging. 


\section{Community and connectedness}

Community and connectedness are in evidence through:

- mutual engagement in communities of practice and critical friendships, allowing for mutual vulnerability and alignment with like-minded peers, as well as opportunities for exploring different perspectives and negotiating understandings;

- liminal spaces that are supporting and challenging, and that promote a trusting and respectful collaborative environment within which uneven relationships of power and competition are minimised;

- an operational infrastructure enabling networks of formal and informal collaborative arrangements; and

- opportunities for leadership demonstrating qualities of inclusiveness and respect, while being encouraging and challenging.

\section{Systematisation and reification}

EBIP is systematised and reified through:

- collective responsibility for negotiating and developing tools, mechanisms and frameworks to enact a shared vision of EBIP;

- an operational framework with clear expectations of individual, community, organisation or system within a shared vision of EBIP; and

- incorporation of strategies for monitoring and reporting progress which are aligned with strategic objectives and resourcing in relation to EBIP.

Figure 10.1 proposes a theoretical framework within which individual, community, organisation or system learning and transformation can be optimised, and contribute to change and improvement. All components of the system are interconnected and interdependent. The consequences of only some of the components being in operation can present barriers to learning and transformation for an individual, community, organisation or system, or result in the inability to enact learning and transformation due to limiting and constrictive contextual factors. The following sections present the conclusions, limitations, and implications of the study.

\section{Conclusions}

This study has investigated EBIP as an approach to the professional learning and development for inservice teacher educators. Within the educational context in New 
Zealand, EBIP is advocated as a way of working for teachers and inservice teacher educators. There are many different approaches to the professional learning and development of teachers and inservice teacher educators. The remit of this study was not to justify EBIP as a valid approach, although the findings may be relevant for consideration in such a debate. Rather, this study was based on the assumption that EBIP is a valid model for the professional learning and development of inservice teacher educators. Its purpose was to investigate the nature and contexts of EBIP for a group of inservice teacher educators who engaged in this approach within the context of the government-funded INSTEP project.

\section{Factors}

The study found that factors impacting upon EBIP for inservice teacher educators striving to improve their practice were:

- individual and organisational dispositions to learning;

- opportunities for collaborative arrangements which afforded a variety of formal and informal communities of practice within safe, trusting, respectful and challenging environments;

- leadership qualities and opportunities;

- negotiation of a collective vision and purpose for EBIP;

- systematisation and reification of EBIP;

- alignment of policy, strategic priorities and resourcing in relation to EBIP; and

- collective ownership and responsibility for learning.

\section{Reflection}

Systematic and rigorous reflection featured as a core component of EBIP for inservice teacher educators. Such reflection incorporated:

- deprivatising practice;

- surfacing values beliefs and assumptions;

- mutually engaging in communities of practice that were trustful and challenging;

- evaluating practice against frameworks of criteria informed by relevant research and theory; and

- considering a range of evidence of the content and processes of immediate teaching and learning environments as well as the broader sociocultural and political contexts influencing practice. 


\section{Outcomes}

Systematic and rigorous engagement in EBIP, which was located and supported within the INSTEP project community, resulted in shifts in participants' knowledge, practice, and, in some, perceptions of themselves and their role as educators.

\section{Evidence}

Evidence of improved teacher practice and improved student learning outcomes as a result of participants' EBIP was not included in this study due to the difficulty of attributing particular behaviours and outcomes to inservice teacher educator practice. This study considered the ways in which evidence of practice was validated and deemed appropriate for evaluation of practice. Improvements in practice were therefore judged using particular tools and frameworks designed for that purpose, such as stimulated recall and a variety of evaluation criteria for particular purposes.

While teachers are immersed in opportunities to obtain a variety of types of evidence of student learning to inform the effectiveness of their teaching, inservice teacher educators are further removed from evidence of improved teacher practice and enhanced student learning. In the absence of immediate feedback and evidence of effectiveness, participants in this study used a variety of types of evidence of their practice for reflection within a cycle of EBIP.

\section{Sustainability}

EBIP was found not to be sustainable by participants outwith the formal, informal and social organisational contexts and resourcing afforded by the INSTEP project and provider organisations.

\section{Limitations of the research}

Transferability of the study to the sector of inservice teacher educators is limited as the findings are based on only 10 participants who engaged in EBIP within the INSTEP project. There was an assumption that all participants were familiar with, and had a shared understanding of, the concept of EBIP. This group of 10 participants was therefore a very selective group, and not necessarily a representative sample of inservice teacher educators. Document sources were also written by INSTEP participants and researchers. 
Evidence of student learning outcomes was not included in the study, so the impact of EBIP on students was not investigated. Instead, judgements of inservice teacher educator practice were based on frameworks of criteria that were collaboratively developed for that purpose.

As the researcher, although I took steps to maintain a relatively objective stance, I could not guarantee an objective perspective, as I also had participated in the INSTEP project. In addition, seven out of 10 participants were known to me personally as a result of participation in the INSTEP project or in the contexts of work within the university environment. Interviews, therefore, may have been influenced by prior relationships.

This study did not consider the validity of EBIP as an effective approach to inservice teacher educator professional learning and development, but was based on the assumption that it was a valid approach for inservice teacher educators striving to improve their practice.

\section{Implications for future research}

This study found that although there are trends towards collaborative approaches to teacher professional learning and development, there is little research into the processes inherent in such models. There is a need for further research into contexts and processes of such models in order to establish what is effective and why. Not only would this inform the role and professional learning needs of inservice teacher educators, but would, in turn, inform approaches to their professional learning and development.

There is a lack of research into the role and professional learning requirements of inservice teacher educators, particularly in an environment where approaches to teacher professional learning and development are moving from transmission models to collaborative approaches incorporating individual ownership of, and collective responsibility for, learning. This has implications for the changing role, and knowledge required, of inservice teacher educators.

This study has investigated the black box between inservice teacher educator professional learning and development, and improved inservice teacher educator practice illustrated in Figure 2.2. The nature and validity of evidence used for making judgements of improved practice is a crucial dimension, since evidence of enhanced 
student learning is linked only by a chain of influence, and therefore not directly attributable to inservice teacher educator practice. There is therefore a need to investigate alternative valid means of judging effectiveness of practice for inservice teacher educators.

This study found that although individual participants experienced improvements in practice, enhanced knowledge, and impacts on their sense of self, the possibilities for enactment of their learning and development were often constrained by their immediate and broader contexts of practice. There is a call for investigating the consequences of individual inservice teacher educator learning and development, and the ways in which this can contribute to coherent system-wide improvement in student learning.

\section{Chapter summary}

This chapter has presented a theoretical framework for EBIP which has been derived from the literature and the findings of the grounded theory analysis of data. The framework is analogous to the structure and function of components of the heart, with all components being interconnected and interdependent. The wholeheartedness of becoming is enacted when all components function in unison. The framework represents the ways in which the degree of wholeheartedness of becoming affords professional learning and transformation through EBIP, whether the subject of learning and transformation is an individual, community, organisation or system.

This study has cast some light on the processes and contexts of EBIP for inservice teacher educators. It has highlighted the crucial role of working with peers in a variety of trusting and challenging collaborative arrangements, and the important role that organisations and communities play in terms of establishing coherence of policy, strategic priorities and resourcing, and the systematisation and reification of EBIP. The nature and validity of evidence of practice for consideration in reflection for inservice teacher educators is an important one, since there is no direct link between evidence of effectiveness in terms of improved teacher practice and enhanced student outcomes. Inservice teacher educator practice is only linked to student outcomes by a chain of influence.

This study has highlighted the need for further research into the processes and contexts of collaborative approaches to professional learning and development, particularly in light of the changing role and professional learning and development 
needs of inservice teacher educators. It recommends further investigation into ways in which individual learning for inservice teacher educators can contribute to systemwide improvement in student learning. Finally, in the absence of direct links to improved student achievement, it urges exploration of a range of tools and mechanisms that would provide valid sources of evidence of inservice teacher educator practice that could be used to make judgements on effectiveness.

I will conclude with Senge's (1990) view of a learning organisation which reflects the substance of the theoretical framework which was the product of this study:

At the heart of a learning organization is a shift of mind - from seeing ourselves as separate from the world to connected to the world, from seeing our problems as caused by someone or something "out there" to seeing how our own actions create the problems we experience. A learning organization is a place where people are continually discovering how they create their reality and how they can change it. (p. 12,13) 


\section{References}

Ainscow, M., \& Southworth, G. (1996). School improvement: A study of the roles of leaders and external consultants. School Effectiveness and School Improvement, 7(3), 229-251.

Annan, B., Lei, M. K., \& Robinson, V. (2003). Teacher talk to improve teaching practices. SET: Research Information for Teachers, 1.

Argyris, C., \& Schön, D. (1974). Theory in practice: Increasing professional effectiveness. San Fransisco: Jossey-Bass.

Atkin, J. (1996). From values and beliefs about learning to principles and practice. Incorporated Association of Registered Teachers of Victoria (Seminar Series No. 54. Melbourne). Retrieved from www.learningtolearn.sa.edu.au/ Colleagues/files/links/ValuesBeliefs.pdf

Bambino, D. (2002). Critical friends. Educational Leadership, 59(6), 25-28.

Barab, S., Schatz, S., \& Scheckler, R. (2004). Using activity theory to conceptualise online community and using online community to conceptualise activity theory. Mind, Culture and Activity, 11(1), 25-47.

Barnett, R. (2005). Recapturing the universal in the university. Educational Philosophy and Theory, 37(6), 785-797.

Baskerville, D. (2011). Organisation and design of analytical tools to identify effective teacher educator practice. In J. Higgins, R. Parsons \& L. Bonne (Eds.), Processes of inquiry: Inservice teacher educators research their practice (pp. 11-28). Rotterdam: Sense.

Baskerville, D., \& Goldblatt, H. (2009). Learning to be a critical friend: From professional difference through challenge to unguarded conversations. Cambridge Journal of Education, 39(2), 205-221.

Beijaard, D., Verloop, N., \& Vermunt, J. (2000). Teachers' perceptions of professional identity: An exploratory study from a personal knowledge perspective. Teaching and Teacher Education, 16(7), 749-764.

Bell, B., \& Gilbert, J. (1996). Teacher development: A model from science education. London: Falmer Press.

Bell, M., Jopling, M., Cordingley, P., Firth, A., King, E., \& Mitchell, H. (2006). What is the impact on pupils of networks that include at least three schools? What additional benefits are there for practitioners' organisations and the communities they serve? Nottingham: National College for School Leadership.

Berg, B. L. (2004). Qualitative research methods for the social sciences (5th ed.). Boston: Pearson.

Berg, B. L. (2009). Qualitative research methods for the social sciences (7th ed.). Boston: Pearson Education.

Berger, J. (2004). Dancing on the threshold of meaning: Recognising and understanding the growing edge. Journal of Transformative Education, 2(4), 336-351.

Bernard, W. T. (2000). Participatory research as emancipatory method: Challenges and opportunities. In D. Burton (Ed.), Research training for social scientists. London: Sage. 
Bettis, P., \& Mills, M. (2006). Liminality and the study of a changing academic landscape. In V. Anfara Jr. \& N. Mertz (Eds.), Theoretical frameworks in qualitative research (pp. 59-71). Thousand Oaks, CA: Sage.

Bogdan, R., \& Biklen, S. (1992). Qualitative research for education. Boston: Allyn and Bacon.

Bolam, R., \& McMahon, A. (2004). Literature, definitions and models: Towards a conceptual map. In C. Day \& J. Sachs (Eds.), International handbook on the continuing professional development of teachers (pp. 33-63). Maidenhead: Open University Press.

Boud, D. (2000). Sustainable assessment: rethinking assessment for the learning society. Studies in Continuing Education, 22(2), 151-167.

Braun, V., \& Clarke, V. (2006). Using thematic analysis in psychology. Qualitative research in Psychology, 3(2), 77-101.

Brockbank, A., \& McGill, I. (2007). Facilitating reflective learning in higher education (2nd ed.). New York: Open University Press.

Brookfield, S. (1990). Using critical incidents to explore learners' assumptions. In J. Mezirow (Ed.), Fostering critical reflection in adulthood (pp. 177-193). San Francisco: Jossey-Bass.

Brookfield, S. (1995). Becoming a critically reflective teacher. California: JosseyBass.

Brookfield, S. (2000). Transformative learning as ideology critique. In J. Mezirow (Ed.), Learning as transformation (pp. 125-148). San Francisco: Jossey-Bass.

Brookfield, S. (2006). Critical thinking materials. Retrieved January 29, 2008, from http://www.stephenbrookfield.com/

Bryman, A. (2001). Social research methods. Oxford: University Press.

Campbell, A., McNamara, O., \& Gilroy, P. (2004). Practitioner research and professional development in education London: Paul Chapman.

Chapman, J., \& Aspin, D. (2003). Networks of learning: A new construct for educational provision and a new strategy for reform. In B. Davies \& J. WestBurnham (Eds.), The handbook of leadership and management (pp. 653-659). London: Pearson Education.

Charmaz, K. (2000). Grounded theory: Objectivist and constructivist methods. In N. Denzin \& Y. Lincoln (Eds.), Handbook of qualitative research (2nd ed., pp. 509-535). Thousand Oaks, CA: Sage.

Charmaz, K. (2005). Grounded theory in the 21st century. In N. Denzin \& Y. Lincoln (Eds.), The Sage handbook of qualitative research (pp. 507-535). Thousand Oaks, CA: Sage.

Charmaz, K. (2006). Constructing grounded theory. Thousand Oaks, CA: Sage.

Charmaz, K., \& Bryant, A. (2007). The Sage handbook of grounded theory. Thousand Oaks, CA: Sage.

Cheetham, G. (2005). Professions, competence and informal learning: Graham Cheetham and Geoff Chivers. Cheltenham: Edward Elgar.

Cheetham, G., \& Chivers, G. (1998). The reflective (and competent) practitioner: A model of professional competence which seeks to harmonise the reflective practitioner and competence-based approaches. Journal of European Industrial Training, 22(7), 267-276. 
Cheetham, G., \& Chivers, G. (2000). A new look at competent professional practice. Journal of European Industrial Training, 24(7), 374-383.

Cheetham, G., \& Chivers, G. (2001). How professionals learn in practice: An investigation of informal learning amongst people working in professions. Journal of European Industrial Training, 25(5), 248-292.

Church, M., Crowe, V., Plummer, G., \& Worrall, N. (2005). What does network practice tell us about the impact of networking and collaboration? Nottingham: National College for School Leadership.

Churchman, R., \& Hall, C. (1997). The nature of professional knowledge. Extract from Unit Standards and professional education: a question of compatibility. Victoria University Wellington: UTDC Academic Development Series.

Cochran-Smith, M. (2005). The new teacher education: For better or for worse? Educational Researcher, 34(7), 3-17.

Cochran-Smith, M., \& Lytle, S. L. (1999). Relationships of knowledge and practice: Teacher learning in communities. Review of Research in Education, 24, 249306.

Cooper, C., \& Robertson, I. (Eds.). (2001). Organizational psychology and development. Chichester: John Wiley.

Corbin, J., \& Strauss, A. (2008). Basics of qualitative research: grounded theory procedures and techniques (3rd ed.). Thousand Oaks, CA: Sage.

Cordingley, P. (1999). Constructing and critiquing reflective practice. Educational Action Research, 7(2), 183-191.

Cordingley, P. (2003). Research and evidence-based practice: Focussing on practice and practitioners. In L. Anderson \& N. Bennett (Eds.), Evidenceinformed policy and practice in educational leadership and management. Milton Keynes: Open University.

Cordingley, P. (2004). Teachers using evidence: Using what we know about teaching and learning to reconceptualise evidence-based practice. In G. Thomas \& R. Pring (Eds.), Evidence-based practice in education (pp. 7787). Maidenhead, Berkshire: Open University Press.

Cordingley, P. (2008). Research and evidence-informed practice: Focussing on practice and practitioners. Cambridge Journal of Education, 38(1), 37-52.

Cordingley, P., Thomas, S., \& Firth, A. (2005). The impact of collaborative continuing professional development (CPD) on classroom teaching and learning Research evidence in education library. London: EPPI-Centre.

Costa, A., \& Kallick, B. (1993). Through the lens of a critical friend. Educational Leadership, 51(2), 49-51.

Creswell, J. (2003). Research design: Qualitative, quantitative and mixed method approaches (2nd ed.). Thousand Oaks, CA: Sage.

Creswell, J. (2007). Qualitative inquiry and research design: Choosing among five approaches (2nd ed.). Thousand Oaks, CA: Sage.

Creswell, J. (2008). Educational research: Planning, conducting and evaluating quantitave and qualitative research (3rd ed.). Upper Saddle River, NJ: Pearson Education.

Crockett, M. D. (2002). Inquiry as professional development: Creating dilemmas through teachers' work. Teaching and Teacher Education, 18, 609-624. 
Cunliffe, A. (2004). On becoming a critically reflexive practitioner. Journal of Management Education, 28(4), 407-426.

Dall'Alba, G. (2005). Improving teaching: Enhancing ways of being university teachers. Higher Education Research \& Development, 24(4), 361-372.

Dall'Alba, G. (2009). Learning professional ways of being: Ambiguities of becoming. Educational Philosophy and Theory, 41(1), 34-45.

Dall'Alba, G., \& Barnacle, R. (2007). An ontoligal turn for higher education. Studies in Higher Education, 32(6), 679-691.

Dalton, J., \& Anderson, D. (2010). Professional communities and pedagogy in action. Retrieved 20 December, 2010, from http://www.plotpd.com

Darling-Hammond, L. (2000). How teacher education matters. Journal of Teacher Education, 51(3), 166-173.

Darling-Hammond, L., \& Bransford, J. (2005). Preparing teachers for a changing world. San Francisco, CA: Jossey-Bass.

Darling-Hammond, L., \& Snyder, J. (2000). Authentic assessment of teaching in context. Teaching and Teacher Education, 16(5-6), 523-545.

Davey, R., Ham, V., Stopford, M., Calender, S., \& Mackay, J. (2011). Mentoring reflective practice in inservice teacher education. In J. Higgins, R. Parsons \& L. Bonne (Eds.), Processes of inquiry: Inservice teacher educators research their practice (pp. 89-115). Rotterdam: Sense.

Day, C. (1995). Qualitative research, professional development and the role of teacher educators: Fit for purpose. British Educational Research Journal, 21(3), 357-369.

Day, C. (1999a). Developing teachers: The challenges of lifelong learning. London: Falmer.

Day, C. (1999b). Teachers as inquirers. In C. Day (Ed.), The challenges of lifelong learning. London: Falmer.

Day, C. (2007). School reform and transitions in teacher professionalism and identity. In T. Townsend \& R. Bates (Eds.), Handbook of teacher education (pp. 597-612). Dordrecht, The Netherlands: Springer.

Day, C., \& Sachs, J. (2004a). International handbook on the continuing professional development of teachers. Maidenhead: Open University Press.

Day, C., \& Sachs, J. (2004b). Professionalism, performativity and empowerment: Discourses in the politics, policies and purposes of continuing professional development. In C. Day \& J. Sachs (Eds.), International handbook on the continuing professional development of teachers (pp. 3-32). Maidenhead: Open University Press.

de Lima, J. (2010). Thinking more deeply about networks in education. Journal of Educational Change, 11, 1-21.

Denzin, N. (1970). Sociological methods: a sourcebook. New York: Aldine.

Dewey, J. (1933). How we think. Chicago: Henry Regnery.

Dimmock, C. (1996). Dilemmas for school leaders and administrators in restructuring. In K. Leithwood, J. Chapman, P. Corson, P. Hallinger \& A. Harts (Eds.), International handbook of educational leadership and administration (pp. 135-170). Dordrecht: Kluwer. 
Earl, L., \& Katz, S. (2010). Learning about networked learning communities. School Effectiveness and School Improvement, 21(1), 27-51.

Engeström, Y. (1987). Learning by expanding: An activity-theoretical approach to developmental research. Helsinki: Orienta-Konsultit.

Eraut, M. (1994). Developing professional knowledge and competence. London: The Falmer Press.

Eraut, M. (2004). Practice-based evidence. In G. Thomas \& R. Pring (Eds.), Evidence-based practice in education (pp. 91-101). Maidenhead, Berkshire: Open University Press.

Evans, L. (2008). Professionalism, professionality and the development of education professionals. British Journal of Education Studies, 56(1), 20-38.

Forde, C., McMahon, M., McPhee, A. D., \& Patrick, F. (2006). Professional development, reflection and enquiry. London: Sage.

Fraser, C., Kennedy, A., Reid, L., \& McKinney, S. (2007). Teachers' continuing professional development: Contested concepts, understandings and models. Journal of In-service Education, 33(2), 153-169.

Fullan, M. (2001a). The NEW meaning of educational change (3rd ed.). New York: Teachers College Press.

Fullan, M. (2001b). Leading in a culture of change. San Francisco: Jossey-Bass.

Fullan, M. (2006). The future of educational change: System thinkers in action. Journal of Educational Change, 7, 113-122.

Fullan, M. (2007). Understanding change. The Jossey-Bass reader on educational change (pp. 169-181). San Fransisco, CA: Jossey-Bass.

Fullan, M., \& Hargreaves, A. (1992). Teacher development and educational change. London: Falmer Press.

Garmston, R., \& Wellman, B. (1999). The adaptive school: Developing and facilitating collaborative groups. Norwood, MA: Chrisopher-Gordon.

Gibbs, P., \& Angelides, P. (2008). Understanding friendship between critical friends. Improving schools, 11(3), 213-225.

Given, H., Kuh, L., Leekeenan, D., Mardell, B., Redditt, S., \& Twombly, S. (2010). Changing school culture: Using documentation to support collaborative inquiry. Theory into Practice, 49(1), 36-46.

Glaser, B. (1978). Theoretical sensitivity. Mill Valley, CA: Sociology Press.

Glaser, B. (1992). Basics of grounded theory analysis. Mill Valley, CA: Sociology Press.

Glaser, B., \& Strauss, A. (1967). The discovery of grounded theory: Strategies for qualitative research. Chicago: Aldine.

Glickman, C. (1981). Developmental supervision: Alternative practices for helping teachers improve instruction. Association for Supervision \& Curriculum.

Goodson, I. F., \& Hargreaves, A. (2003). Educational change and the crisis of professionalism. In I. F. Goodson \& A. Hargreaves (Eds.), Professional knowledge, professional lives. Maidenhead, UK: Open University Press.

Griffiths, M., \& Tann, S. (1992). Using reflective practice to link personal and public theories. Journal of Education for Teaching: International Research and Pedagogy, 18(1), 69-84. 
Grossman, P., Wineburg, S., \& Woolworth, S. (2001). Toward a theory of teacher community. Teachers College Record, 103(6), 942-1012.

Groundwater-Smith, S., \& Dadds, M. (2004). Critical practitioner inquiry: Towards responsible professional communities of practice. In C. Day \& J. Sachs (Eds.), International handbook on the continuing professional development of teachers (pp. 238-263). Maidenhead: Open University Press.

Grundy, S., \& Robison, J. (2004). Teacher professional development: Australian experience. In C. Day \& J. Sachs (Eds.), International handbook on the continuing professional development of teachers (pp. 146-166). Maidenhead: Open University Press.

Guskey, T. (2000). Evaluating professional development. Thousand Oaks, California: Corwin Press.

Guskey, T. (2002). Does it make a difference? Redesigning professional development. Educational Leadership, 59(6).

Habermas, J. (1991). The theory of communicative action. Boston: Beacon Press.

Hadar, L., \& Brody, D. (2010). From isolation to symphonic harmony: Building a professional development community among teacher educators. Teaching and Teacher Education, 26(8), 1493-1710.

Hammersely, M. (1992). What's wrong with ethnography? Methodological explorations. London: Routledge.

Hammersley, M. (2002). Educational research policymaking and practice. London: Sage.

Handy, C., B. (1981). Understanding organisations. Aylesbury, Bucks: Penguin Books.

Hargreaves, A. (2000). Four ages of professionalism and professional learning. Teachers and Teaching: History and Practice, 6(2), 152-182.

Hargreaves, D. (1991). A common sense model of the professional development of teachers. In J. Elliot (Ed.), Reconstructing teacher education. London: Falmer Press.

Hargreaves, D. (1996). Teaching as a research-based profession: Possibilities and prospects (Annual Lecture). London: The Teacher Training Agency.

Hargreaves, D. (2000). The production, mediation and use of professional knowledge among teachers and doctors: A comparative analysis. Knowledge management in the learning society (pp. 219-236). Paris: OECD.

Heidegger, M. (1962/1927). Being and time (J. Macquarrie \& E. Robinson, Trans.). New York: SCM Press.

Hesse-Biber, S., \& Leavy, P. (2006). The practice of qualitative research. Thousand Oaks, CA: Sage.

Higgins, J. (2008). Synthesis of the outcomes of the inservice teacher education practice (INSTEP) project. Wellington: Ministry of Education.

Higgins, J., \& Parsons, R. (2011). Generating new knowledge through a systemlevel network. In J. Higgins, R. Parsons \& L. Bonne (Eds.), Processes of inquiry: Inservice teacher educators research their practice (pp. 179-188). Rotterdam: Sense.

Higgins, J., Parsons, R., \& Bonne, L. (Eds.). (2011). Processes of inquiry: Inservice teacher educators research their practice. Rotterdam: Sense. 
Hill, R., Capper, P., Wilson, K., Whatman, R., \& Wong, K. (2007). Workplace learning in the New Zealand apple industry network: A new co-design method for government "practice making". Journal of Workplace Learning, 19(6), 359376.

Hoban, G. (2002). Teacher learning for educational change. Buckingham, UK: Open University Press.

Hofman, R. H., \& Dijkstra, B. J. (2010). Effective teacher professionalization in networks? Teaching and Teacher Education, 26, 1031-1040.

Holstein, J. A., \& Gubrium, J. F. (2005). Interpretive practice and social action. In N. Denzin \& Y. Lincoln (Eds.), The Sage handbook of qualitative research (pp. 483-506). Thousand Oaks, CA: Sage.

Hoyle, E. (1975). Professionality, professionalism and control in teaching. In V. Houghton (Ed.), Management in education: The management of organisations and individuals. London: Ward Lock Educational in association with Open University Press.

Hubbard, R., \& Power, B. (1993). The art of classroom inquiry. Portsmouth, NH: Heinemann.

Ingvarson, L., Meiers, M., \& Beavis, A. (2005). Factors affecting the impact of professional development programmes on teachers' knowledge, practice, student outcomes and efficacy. Education Policy Analysis Archives, 13(10), 120.

Jonassen, D. H. (2000). Computers as mindtools for schools: Engaging critical thinking. Columbus: Prentice-Hall.

Jones, E. (2007). A portfolio for assessment of the practice of special education resource teachers. Wellington: Victoria University.

Kegan, R. (2000). What "form" transforms? A constructive-developmental approach to transformative learning In J. Mezirow (Ed.), Learning as transformation (pp. 35-70). San Francisco: Jossey-Bass.

Kelle, U. (2007). The development of categories: Different approaches in grounded theory. In K. Charmaz \& A. Bryant (Eds.), The Sage handbook of grounded theory (pp. 191-213). Thousand Oaks, CA: Sage.

Kemmis, S. (2009). Understanding professional practice: A synoptic framework. In B. Green (Ed.), Understanding and researching professional practice (pp. 1938). Rotterdam: Sense.

Kemmis, S., \& McTaggart, R. (1988). The action research planner. Victoria, Australia: Deakin University Press.

Kennedy, A. (2005). Models of continuing professional development (CPD): A framework for analysis. Journal of In-Service Education, 31(2), 235-250.

Killon, J., \& Todnew, G. (1991). A process of personal theory building. Educational Leadership, 48(6), 14-16.

Korthagen, F. (2001). Linking practice and theory: The pedagogy of realistic teacher education. Mahwah NJ: Lawrence Erlbaum.

Lamont, M. (2009). Enhancing professional learning for the improvement of practice of inservice teacher educators: Professional learning for inservice teacher educators. The International Journal of Learning, 16(16), 431-444. 
Lamont, M. (2011). An environment of collegial reflective dialogue for inservice teacher educators. In J. Higgins, R. Parsons \& L. Bonne (Eds.), Processes of inquiry: Improving inservice teacher education practice. Rotterdam: Sense.

Land, R. (2010). Threshold concepts and troublesome knowledge. Unpublished Seminar, Victoria University.

Laurillard, D. (2002). Rethinking teaching for the knowledge society. Educause Review Retrieved October 5, 2003, from http://www.educause.edu/ir/library/ pdf/erm0201.pdf

Lave, J., \& Wenger, E. (1991). Situated learning: Legitimate peripheral participation. Cambridge: Cambridge university Press.

Levine, T. H. (2010). Tools for the study and design of collaborative teacher learning: The affordances of different conceptions of teacher community and activity theory. Teacher Education Quarterly, 37(1), 109-113.

Lincoln, Y., \& Guba, E. (1985). Naturalistic inquiry. Newbury Park, CA: Sage.

Little, J. (1982). Norms of collegiality and experimentation: Workplace conditions of school success. American Educational Research Journal, 19(3), 325-340.

Little, J. (2003). Inside teacher community: representations of classroom practice. Teachers College Record, 105(6), 913-945.

Little, J., \& Horn, I. S. (2010). Attending to problems of practice: Routines and resources for professional learning in teachers' workplace interactions. American Educational Research Journal, 47(1), 181-217.

Little, J., \& McLaughlin, M. (1993). Teachers' work, individuals, colleagues, and contexts. NY: Teachers College Press.

Little, J., \& Veugelers, W. (2005). Big change question: Professional learning and school-network ties: Prospects for school improvement; Networks of teachers or teachers caught in networks? Journal of Educational Change, 6, 277-291.

Loughran, J. (1996). Developing reflective practice: Learning about teaching and learning through modelling. London: Falmer Press.

Loughran, J. (2006). Developing a pedagogy of teacher education: Understanding teaching and learning about teaching. London: Routledge.

MacBeath, J. (1998). 'I didn't know he was ill': The role and value of the critical friend. In L. Stoll \& K. Myers (Eds.), No quick fixes: Perspectives on schools in difficulty (pp. 118-132). London: Falmer.

Martinez, K. (2008). Academic induction for teacher educators. Asia-Pacific Journal of Teacher Education, 36(1), 35-51.

McDonald, T., \& Thornley, C. (2011). The measure of success: Resolving conflicts in professional learning using evidence of student learning. In J. Higgins, R. Parsons \& L. Bonne (Eds.), Processes of inquiry: Inservice teacher educators research their practice (pp. 29-44). Rotterdam: Sense.

McGee, A. (2011). Building collaborative professional learning within an organisation. In J. Higgins, R. Parsons \& L. Bonne (Eds.), Processes of inquiry: Inservice teacher educators research their practice (pp. 45-62). Rotterdam: Sense.

Mcllraith, G., Hope, C., Leslie, S., \& Pym, C. (2009). INSTEP: Learning about practice: A dynamic inquiry. Paper presented at the New Zealand Association for Research in Education. 
McKinney, S., Carroll, M., Christie, D., Fraser, C., Kennedy, A., Reid, L. et al. (2005). AERS: Learners, learning and teaching network project 2 - progress report. Paper presented at the Scottish Educational Research Association Annual Conference.

McLaughlin, M. W., \& Talbert, J. E. (2001). Professional communities and the work of high school teaching. Chicago: University of Chicago Press.

McNiff, J. (2002). Action research for professional development: Concise advice for new action researchers. Retrieved August, 2004, from http://www.jeanmcniff. com/booklet1.html

Merriam, S. B. (1998). Qualitative research and case study applications in education. San Francisco: Jossey-Bass.

Meyer, J. H. F., \& Land, R. (2006). Threshold concepts and troublesome knowledge: Issues of liminality. In J. H. F. Meyer \& R. Land (Eds.), Overcoming barriers to student understanding: Threshold concepts and troublesome knowledge (pp. 19-32). New York: Routledge.

Meyer, J. H. F., Land, R., \& Baillie, C. (Eds.). (2010). Threshold concepts and transformational learning. Rotterdam: Sense.

Mezirow, J. (1990). Fostering critical reflection in adulthood. San Francisco: JosseyBass.

Mezirow, J. (1991). Transformative dimensions of adult learning. San Francisco: Jossey-Bass.

Mezirow, J. (1994). Understanding transformation theory. Adult Education Quarterly, $44,222-232$.

Mezirow, J. (2000a). Learning to think like an adult: Core concepts of transformation theory. In J. Mezirow (Ed.), Learning as transformation (pp. 3-33). San Francisco: Jossey-Bass.

Mezirow, J. (Ed.). (2000b). Learning as transformation. San Francisco: JosseyBass.

Mezirow, J., \& Taylor, E. W. (2009). Transformative learning in practice: Insights from community, workplace, and higher education. San Francisco, CA: Jossey-Bass.

Mills, M., \& Bettis, P. (2006). Organizational identity and identification during a departmental reorganization. In V. Anfara Jr. \& N. Mertz (Eds.), Theoretical frameworks in qualitative research (pp. 73-84). Thousand Oaks, CA: Sage.

Ministry of Education. (2005). Making a bigger difference for all students: Schooling strategy 2005 - 2010. Retrieved March 28, 2008, from http://www.minedu.govt.nz

Ministry of Education. (2006). Towards a framework for professional practice: INSTEP. Retrieved April 28, 2007, from www.minedu.govt.nz/goto/instep

Ministry of Education. (2007). The New Zealand curriculum for English-medium teaching and learning in years 1-13. Wellington: Learning Media.

Ministry of Education. (2008a). Ki te Aotūroa: Improving inservice teacher educator learning and practice. Wellington Learning Media.

Ministry of Education. (2008b). The literacy and numeracy strategy. Retrieved March 17, 2008, from http://www.tki.org.nz/r/literacy_numeracy/num_projects_e.php

Ministry of Education. (2008c). National assessment strategy. Retrieved April 1, 2008, from http://www.tki.org.nz/r/assessment/strategy_e.php 
Moore, A. (2007). Understanding the social self: The role and importance of reflexivity in schoolteachers' professional learning. In B. Townsend \& R. Bates (Eds.), Handbook of teacher education (pp. 571-583). Dordrecht: Springer.

Morse, J. M. (2007). Sampling in grounded theory. In K. Charmaz \& A. Bryant (Eds.), The Sage handbook of grounded theory (pp. 229-244). Thousand Oaks, CA: Sage.

Moseley, C., \& Ramsay, S. (2005). Teaching portfolios in teacher education: Effects of program-wide mentoring on elementary pre-service teachers' perceptions. Current Issues in Education Online, 8(23). Retrieved from http://cie.ed.asu.edu/volume8/number23/

Mwanza, D. (2002). Conceptualising work activity for CAL systems design. Journal of Computer Assisted Learning, 18, 84-92.

NZTC. (2007). Graduating teacher standards. Wellington: New Zealand Teachers Council.

NZTC. (2010). Registered teacher criteria. Wellington: New Zealand Teachers Council.

OECD. (2000). Knowledge management in the learning society. Paris: OECD.

OECD. (2003). New challenges for educational research. Paris: OECD.

Parsons, R., \& Higgins, J. (2011). Improving inservice teacher education practice. In J. Higgins, R. Parsons \& L. Bonne (Eds.), Processes of inquiry: Inservice teacher educators research their practice (pp. 1-10). Rotterdam: Sense.

Perkins, D. (2006). Constructivism and troublesome knowledge. In J. H. F. Meyer \& R. Land (Eds.), Overcoming barriers to student understanding: Threshold concepts and troublesome knowledge (pp. 33-47). New York: Routledge.

Polanyi, M. (1967). The tacit dimension. New York: Anchor Books.

Polio, C., Gass, S., \& Chapin, L. (2006). Using stimulated recall to investigate native speaker perceptions in native-nonnative speaker interaction. Studies in second Language Acquisition, 28, 237-267.

Pring, R. (2004). Conclusion: Evidence-based policy and practice. In G. Thomas \& R. Pring (Eds.), Evidence-based practice in education. Maidenhead, Berkshire: Open University Press.

Prpic, J. (2005). Managing academic change through reflexive practice: A quest for new views. Research and Development in Higher Education, 28, 399-406.

Rebore, R. W., \& Walmsley, A. L. E. (2007). An evidence-based approach to the practice of educational leadership. Boston: Pearson Education.

Reid, A. (2004). Towards a culture of inquiry in DECS. Retrieved April 27, 2007, from www.decs.sa.gov.au/corporate/files/links/OP_01.pdf

Reinharz, S. (1992). Feminist methods in social research. New York: Oxford University Press.

Robinson, V. (2003). Teachers as researchers: A professional necessity? SET: Research Information for Teachers, 1, 27-29.

Robinson, V. (2004). New understandings of educational leadership. SET: Research Information for Teachers, 3, 39-43.

Robinson, V., \& Lai, M. (2006). Practitioner research for educators: A guide to improving classrooms and schools. Thousand Oaks, CA: Corwin Press. 
Robinson, V., Hohepa, M., \& Lloyd, C. (2009). School leadership and student outcomes: Identifying what works and why: Best evidence synthesis iteration. Wellington, NZ: Ministry of Education.

Robson, C. (2002). Real world research (2nd ed.). Oxford: Blackwell.

Roebuck, J. (2007). Reflexive practice: To enhance student learning. Journal of Learning Design, 2(1), 77-91.

Rose, E. (2006). An introduction to grounded theory method. Unpublished Seminar, Victoria University.

Ryan, T. (2005). When you reflect are you also being reflexive? Retrieved March 05, 2012, from http://www.nipissingu.ca/oar/PDFS/V812E.pdf

Sachs, J. (2000). The activist professional. Journal of Educational Change, 1, 77-95.

Sachs, J. (2001). Teacher professional identity: Competing discourses, competing outcomes. Journal of Education Policy, 16(2), 149-161.

Sachs, J. (2003). The activist teaching profession. Buckingham, Philadelphia: Open University Press.

Sankar, M. (2009). Evaluation of the inservice teacher education practice project (INSTEP) (Report to the Ministry of Education). Wellington, NZ: Ministry of Education.

Schein, E. H. (1980). Organizational psychology (3rd ed.). Englewood Cliffs, NJ: Prentice-Hall.

Schön , D. A. (1983). The reflective practitioner. New York: Basic Books.

Schön, D. (1987). Educating the reflective practitioner. San Francisco: Jossey-Bass.

Schwartzman, L. (2010). Transcending disciplinary boundaries: A proposed theoretical foundation for threshold concepts. In J. H. F. Meyer, R. Land \& C. Baillie (Eds.), Threshold concepts and transformational learning (pp. 2144). Rotterdam: Sense.

Senge, P. (1990). The fifth discipline: The art and practice of the learning organization. New York: Doubleday.

Shulman, J. H. (1992). Case methods in teacher education. New York: Teachers College Press.

Shulman, J. H., \& Shulman, L. (2004). How and what teachers learn: A shifting perspective. Journal of Curriculum Studies, 36(2), 257-271.

Shulman, L. (1999). Taking learning seriously. Change, 31(4), 11-17.

Shulman, L. (2004). The wisdom of practice. San Francisco: Jossey-Bass.

Silverman, D. (1993). Interpreting qualitative data. London: Sage.

Stake, R. (1995). The art of case study research. London: Sage.

Stake, R. (2005). Qualitative case studies. In N. Denzin \& Y. Lincoln (Eds.), The sage handbook of qualitative research (3rd ed., pp. 443-466). Thousand Oaks CA: Sage.

Stake, R. (2008). Qualitative case studies. In N. Denzin \& Y. Lincoln (Eds.), Strategies of qualitative inquiry (3rd ed., pp. 119-149). Thousand Oaks, CA: Sage.

Stoll, L. (2000). School culture. SET: Research Information for Teachers, 3, 9-14. 
Stoll, L., Bolam, R., McMahon, A., Thomas, S., Wallace, M., Greenwood, A. et al. (2005). What is a professional learning community? A summary., Professional learning communities: Source materials for school leaders and other leaders of professional learning. United Kingdom: National College for School Leadership.

Stoll, L., Fink, D., \& Earl, L. (2003). It's about learning (and it's about time): What's in it for schools? London: RoutledgeFalmer.

Strauss, A. (1987). Qualitative analysis for social scientists. New York: Cambridge University Press.

Strauss, A., \& Corbin, J. (1990). Basics of qualitative research: Grounded theory procedures and techniques. Newbury Park, CA: Sage.

Strauss, A., \& Corbin, J. (1998). Basics of qualitative research: Techniques and procedures for developing grounded theory (2nd ed.). Thousand Oaks, CA: Sage.

Swaffield, S. (2002). Contextualising the work of the critical friend. Paper presented at the 15th International Congress for School Effectiveness and Improvement (ICSE). Retrieved from http://www.leadershipforlearning.org.uk/hcdimages/docs/swaffield.pdf

Swaffield, S. (2005). No sleeping partners: Relationships between headteachers and critical friends. School Leadership and Management, 25(1), 43-57.

Swaffield, S. (2007). Light touch critical friends. Improving Schools, 10(3), 205-219.

Swaffield, S. (2008). Critical friendship, dialogue and learning in the context of leadership for learning. School Leadership and Management, 28(4), 323-336.

Taylor, E. W. (1997). Building upon the theoretical debate: A critical review of the empirical studies of Mezirow's transformative learning theory. Adult Education Quarterly, 48(1), 34-59.

Taylor, E. W. (2009). Fostering transformative learning. In J. Mezirow \& E. W. Taylor (Eds.), Transformative learning in practice: Insights from community, workplace, and higher education (pp. 3-17). San Francisco, CA: Jossey-Bass.

Taylor, P. (1996). Researching drama and arts education paradigms and possibilities. London: Falmer Press.

Thomas, G. (2004). Introduction: evidence and practice. In G. Thomas \& R. Pring (Eds.), Evidence-based practice in education (pp. 1-18). Maidenhead, Berkshire: Open University Press.

Thomas, G., \& Pring, R. (2004). Evidence-based practice in education. Maidenhead, Berkshire: Open University Press.

Thomson, I. (2001). Heidegger on ontological education, or: how we become what we are. Inquiry, 44(3), 243-268.

Thornley, C., \& McDonald, T. (2011). Individualised professional learning: Mentoring leaders of school-based inquiry projects. In J. Higgins, R. Parsons \& L. Bonne (Eds.), Processes of inquiry: Inservice teacher educators research their practice (pp. 117-131). Rotterdam: Sense.

Timperley, H. (2008). Teacher professional learning and development. In I. A. o. Education (Ed.) (Vol. 18). Geneva: IBE Publications Unit.

Timperley, H., \& Parr, J. (2004). Using evidence in teaching practice: Implications for professional learning. Auckland: Hodder Moa Beckett. 
Timperley, H., \& Parr, J. (2005). Theory competition and the process of change. Journal of Educational Change, 6, 227-251.

Timperley, H., Wilson, A., Barrar, H., \& Fung, I. (2007). Teacher professional learning and development: Best evidence synthesis iteration. Wellington, NZ: Ministry of Education.

Townsend, T., \& Bates, R. (Eds.). (2007). Handbook of teacher education. Dordrecht, The Netherlands: Springer.

van Manen, M. (1977). Linking ways of knowing with ways of being practical. Curriculum Inquiry, 6(3), 205-228.

Verdonschot, S. (2006). Methods to enhance reflective behaviour in innovation processes. Journal of European Industrial Training, 30(9), 670-686.

Villegas-Reimers, E. (2003). Teacher professional development: An international review of the literature. Retrieved from www.unesco.org/iiep

Walliman, N. (2001). Your research project: A step-by-step guide for the first time researcher. London: Sage.

Waters, T., Marzano, R. J., \& McNulty, B. (2003). Balanced leadership: What 30 years of research tell us about the effect of leadership on student achievement. Retrieved July, 2007, from http://www.sai-iowa.org/BalancedLeadership.pdf

Wenger, E. (1998a). Communities of practice: Learning as a social system. The Systems Thinker, 9(5), 1-5.

Wenger, E. (1998b). Communities of practice: Learning, meaning, and identity. Cambridge: Cambridge University Press.

Wenger, E. (1999). Communities of practice: Learning, meaning, and identity. Cambridge: Cambridge University Press.

Whitty, G. (2007). Education(al) research and education policy making. In L. Saunders (Ed.), Educational research and policy-making: Exploring the border country between research and policy. Milton Park, UK: Routledge.

Williamson, B. (1998). Lifeworlds and learning: Essays in the theory, philosophy and practice of lifelong learning. Leicester: NIACE.

Wilson, S., \& Berne, J. (1999). Teacher learning and the acquisition of professional knowledge: An examination of research on contemporary professional development. In A. Iran-Nejad \& P. D. Pearson (Eds.), Review of research in education (Vol. 24, pp. 173-210). Washington, DC: AERA.

Wyatt-Smith, C., Bridges, S., \& Hedemann, M. (2008). Designing professional learning for effecting change: Partnerships for local and system networks. The Australian Educational Researcher, 35(3).

Yin, R. K. (2003). Case study research design and methods (3rd ed.). London: Sage.

Zeichner, K. (2005). Becoming a teacher educator: A personal perspective. Teaching and Teacher Education, 21, 117-124.

Zeichner, K., \& Liston, D. (1996). Reflective teaching: An introduction. Mahwah, NJ: Lawrence Erlbaum. 
Appendices 


\section{Appendix A: Invitation to Participate In Doctoral Research}

Kia ora Koutou,

My name is Margaret Lamont, and I would like to invite you to volunteer to participate in my PhD study. My research topic is 'Research- and evidence-based inquiry into practice for inservice teacher educators'.

I have been a teacher educator (inservice and preservice) for more than twenty years. My research interests are in the area of professional learning and development for student teachers, teachers and teacher educators. I was an INSTEP national facilitator from October 2005 until July 2008. If you were an INSTEP participant in the implementation phase of INSTEP, and you are currently engaging in inquiry into your practice, I would like to invite you to express interest in participating in my $\mathrm{PhD}$ study about professional learning for inservice teacher educators. The research will take place from August 2008 to July 2010. The purpose of the study is to provide a theoretical framework of the process of research- and evidence-based inquiry into practice for inservice teacher educators. Such a framework will help us to understand more clearly how to promote and support this aspect of learning to positively impact on practice.

\section{Who is sought?}

I am seeking approximately twelve inservice teacher educators, all of whom have been previously involved in the INSTEP project, and are currently engaged in research- and evidence-based inquiry into practice. Each volunteer will be asked to complete a selection questionnaire with some personal data. This data will be used to select participants representing a variety of roles, responsibilities, areas of expertise, levels of experience, and base organisations (school, university, private). Subsequently, I wish to work with each participant to gather evidence of the process of their research- and evidence-based inquiry into their practice.

\section{What data or information will be collected and what use will be made of it?}

I wish to conduct no more than three recorded interviews with participants from August 2008 - April 2009 about their work, in order to gather some evidence relating to their inquiry into practice. Each interview should last approximately 45 minutes. I wish to gather information relating to research- and evidence-based inquiry into practice over the previous year. 
The interviews will employ open-questioning techniques, where the precise nature of the questions have not been determined in advance, but will explore aspects of inquiry into practice such as: processes, activities, social interactions and contextual factors.

\section{Confidentiality and anonymity}

The final research report will be summary in form and will therefore preserve the anonymity and confidentiality of the participants. It will not be possible to link anything in the report with particular individuals. All of the information that could identify particular organisations, schools and individuals will be removed from the data and every effort will be made to protect participants' anonymity. The ethical procedures outlined for this project have been reviewed and approved by Victoria University College of Education Ethics Committee.

\section{PhD Supervisors}

My PhD supervisors are: Dr Cedric Hall (cedric.hall@vuw.ac.nz); Dr Liz Jones (liz.jones@vuw.ac.nz); Dr Catherine Savage (catherine.savage@vuw.ac.nz ).

\section{Expression of interest}

If you have any questions about the study, please feel free to contact me. If you wish to express interest in participating in this study, please e-mail me at margaret.lamont@vuw.ac.nz. 


\section{Appendix B: Interview schedules}

\section{Interview 1 Schedule}

\section{Initial open-ended questions}

1. Tell me a little bit about how you do your job as an ISTE:

What who/why/where/how - colleagues /clients / contexts / reasons?

2. When did you begin the process of inquiring into your practice? Why?

3. How would you describe your first reactions in the early stages - as you were about to, or had just begun to engage in the process?

Intermediate questions

4. Describe what is involved in your inquity into practice

- Who is involved?

- What practice is the subject of your inquiry?

- What are the processes you engage in?

- What evidence do you reflect upon?

- How do you incorporate research findings?

- How do you judge effectiveness of/improvement in your practice?

5. Tell me a bit about the feelings and emotions you have experienced at different stages

6. Can you tell me about what/who helps/supports your inquiry into practice?

- People

- Environments

- Personal factors

- Organisationa!

- Resources (e.g. technology)

- Time

7. Can you tell me about anything that makes your inquiry into practice more difficult?

- People

- Environments

- Personal factors

- Organisational

- Resources (e.g. technology)

- Time

8. Why are you conducting inquiry into your practice now? Have the reasons changed over time?

- Appraisal process

- Personal/professional

- PD/research or other contract

- Organisational requirements/systems/processes 
9. Tell me about the ways, if any, that your inquiry into practice has influenced or impacted on you personally and professionally, and your ability to do your job?

- Comfort, challenge, threat, autonomy, efficacy, motivation, commitment, values, beliefs, self esteem, agency

10. What changes, if any, would you like to see in place to support your inquiry into practice?

\section{Ending questions}

11. How have you grown as a person through the process of inquiry into practice?

12. Tell me about how your views have changed since ...?

13. After experiencing the process of inquiring into your practice, what advice would you give to someone who is new to this process?

14. What do you think has been most valuable to you in the process of inquiry?

15. Is there anything that you might not have thought about before, that occurred to you during this interview?

16. Is there anything else you think I should know, to understand your process of inquiry better?

17. Is there anything you would like to ask me? 


\section{Interview 2 Schedule}

1. What was your understanding of the purpose of INSTEP at the start? Did that change?

2. Are you still conducting inquiry into practice? How does it differ from the early INSTEP experience?
a. Collaboration?
b. Evidence?
c. Process?

3. How many of the colleagues you worked with in the INSTEP collaborative inquiry, had you worked closely with before? How did these relationships develop?

4. How relevant/appropriate was the use of literature throughout your inquiry? Did that change over time?

5. What, if any, was the impact of 'going public' - sharing/dissemination of information/experience?

6. What was the impact of your leadership role in INSTEP on your learning and professional growth?

7. Can you describe the inquiry grouping arrangements during and postINSTEP? How formalised were they? Was there a process for participants to inquire into their practice initially, and did that process change over time?

- Make-up of groups - whole/sub; formal/informal

- Self selected or assigned?

- Composition of groups - homogenous /diverse?

- What was your role throughout? How did that develop?

- How did your pod/s surface values and beliefs (if at all)?

8. Did all of the participants deprivatise practice? Was that an expectation? Did that change over time?

9. Were there any specific instances of 'unprofessional behaviour' (e.g. lack of respect, insulting, non-attention)?

10. Were there ever any instances where status (power issues) impacted upon your/other's learning/experience?

11. How have you worked within communities of practice over time - (different levels at different times e.g. NF initially to consolidation phase of INSTEP) 
12. Was/is there a structure and regularity to the interactions and processes during INSTEP, and now?

a. What tools and processes were adopted/developed?

b. What were/are the roles/responsibilities of members of the groups?

13. How did your participants and the activities they engaged in (collaborative inquiry) relate to the larger organisation (identity, common values, role definition, language)?

14. How do you see your role and agency as an individual ISTE, as an ISTE within your organisation, within national ISTE provision? i.e. how do you define yourself?

15. How has your learning from INSTEP impacted on you, and the learning of your clients (students/teachers)

16. Has your perception of your role changed? (as an ISTE/educator)?

17. Has the INSTEP experience (collaborative inquiry) had an impact on the service provision of your organisation; on the service regionally/nationally? 


\title{
Appendix C: Informed consent
}

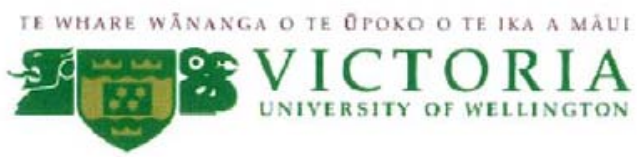

\section{INFORMATION SHEET FOR INSERVICE TEACHER EDUCATOR CASE STUDY PARTICIPANTS}

\author{
Research- and Evidence-Based Inquiry into Practice for Inservice Teacher \\ Educators
}

Thank you for showing an interest in this project. Please read the information below before deciding whether or not to participate. Participation is voluntary. If you decide not to take part there will be no disadvantage to you and I thank you for considering my request. Others may be invited to participate at a later stage as data is analysed and interpreted.

\section{What is the aim of the project?}

This doctoral research is about professional learning for inservice teacher educators. The project will take place from July 2008 to May 2011. The purpose of the study is to provide a theoretical framework of the process of research- and evidence-based inquiry into practice for inservice teacher educators. Such a framework will help us to understand more clearly how to promote and support this aspect of learning to positively impact on practice.

\section{Who is sought?}

I am seeking twelve inservice teacher educators, all of whom have been previously involved in the INSTEP project, and who are or have been engaged in researchand evidence-based inquiry into practice. The participants will be selected to represent a variety of roles, responsibilities, areas of expertise, levels of experience, and base organisations (school, university, private). I wish to work with each participant to gather evidence of the process of their research- and evidence-based inquiry into their practice.

What data or information will be collected and what use will be made of it?

I wish to gather evidence relating to your research- and evidence-based inquiry into your practice. I seek your approval to undertake one or two recorded interviews with you from July 2010 - September 2010. Each interview should last a maximum of 1 hour. I do not think that you will experience any harm or discomfort from participating in this research. However, I will be happy to stop any interviews or discussions at any time if that is what you wish. In addition you will not have to discuss any issues you do not want to. An online survey tool may also be used to gather some demographic data.

The interviews will employ open-questioning techniques where the precise nature of the questions which will be asked have not been determined in advance, but will depend on your reflections and observations of your learning and practice as an inservice teacher education provider. Consequently, although the materials developed for this project have been reviewed in terms of appropriate and ethical practice, reviewers have not been able to review the precise questions to be used. The interviews will focus on the description of the processes and contexts of professional learning for inservice teacher educators. They will not be evaluative in relation to the learning or practice of teachers or inservice teacher educators. 


\section{Can you change your mind and withdraw from the project?}

You may withdraw from the project at any stage prior to the data analysis. Should you wish to withdraw; all data pertaining to the work undertaken with you will be returned.

\section{Confidentiality and anonymity}

Analyses of the findings will be used to inform the development of a theoretical framework for research-and evidence-based inquiry. Only the named researcher will have access to the raw research data. The online survey will be on a secure, passworded website only accessible to the researcher. The final research report will be summary in form and will therefore preserve the anonymity and confidentiality of the participants. It will not be possible to link anything in the report with particular individuals. All of the information that could identify particular organisations, schools and individuals will be removed from the data and every effort will be made to protect participants' anonymity.

At the end of the project, all audio recordings will be destroyed. All electronic information will be kept in a password-protected file and access will be restricted to the researcher. Any other data will be kept in a secure place at the offices of Victoria University. I will keep the transcripts (without identifying information) for five years. They will then be destroyed.

The final published $\mathrm{PhD}$ thesis and a summary of findings will be available to all participants.

\section{What if participants have any questions?}

If you have any questions about the project, either now or in the future, please feel free to contact the researcher:-

Margaret Lamont, Senior Lecturer ICT, Associate Director BTeach, Victoria

University of Wellington, College of Education.

Phone: 04463 9694; Mobile: 0275639694

Postal address: PO Box 17-310, Karori, Wellington

E-mail: margaret.lamont@vuw.ac.nz

PhD Supervisors:

DrCedric Hall cedric.hall@vuw.ac.nz

Dr Liz Jones liz.jones@vuw.ac.nz

Dr Catherine Savage catherine.savage@vuw.ac.nz

The ethical procedures outlined for this project have been reviewed and approved by Victoria University College of Education Ethics Committee. 


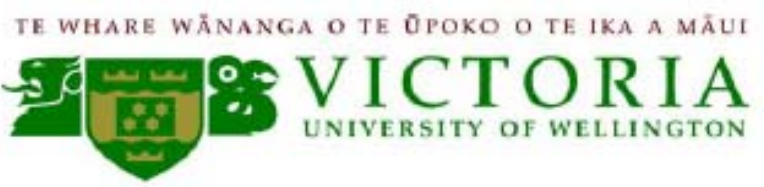

\section{Research- and Evidence-Based Inquiry into Practice for Inservice Teacher Educators CONSENT FORM FOR INSERVICE TEACHER EDUCATORS}

Please read the following and place a tick in each box if you agree with it.

I agree to be a participant in this research.

I have read and understood the purpose of the research, the commitment I will be making and the research conditions.

I understand that interviews may be audio recorded and transcribed. If I have requested this, the transcripts will then be returned to me for verification.

I understand that the research is confidential and every effort will be made to ensure my anonymity.

I understand that the data obtained may be used for conference papers and/or publication.

I understand that the data collected will only be used for the research project as described in the information sheet.

I understand that my participation is entirely voluntary.

I understand that that there is no remuneration or compensation for my participation.

I understand that I can withdraw from the research project at any stage prior to the data analysis and that any data provided would then be destroyed.

I understand that audio recordings will be destroyed or returned to participants at the conclusion of the research project, and that the transcripts will be retained in secure storage for five years, after which they will be destroyed.

With regard to the transcribed interviews, please indicate below whether you wish to receive a copy to read (and make changes, etc) prior to the analysis of this data.

I wish to receive a copy of my interview transcript prior to it being analysed:

Yes

No

Your name:

Your signature:

Date:

The ethical procedures outlined for this project have been reviewed and approved by Victoria University College of Education Ethics Committee. 


\section{Appendix D: Participant profiles}

In order to present a personal snapshot of each individual, and their way of "being in the world" (Dall'Alba \& Barnacle, 2007, p. 681), I identified aspects of knowing, acting and being and presented these as the integral parts of the holistic self (Dall'Alba, 2005; Dall'Alba \& Barnacle, 2007).

Profiles were completed for all participants after the second interviews took place. This chapter presents summaries of the 10 profiles in order to give an impression of each participant's unique background, context and perspective.

In the profiles, the following terms are used:

- knowing aspects of knowledge and theories of practice;

- acting the ways in which theories of practice, values and beliefs are enacted;

- being personal philosophies, values, beliefs and vision. 
Alison

INSTEP role:

ISTE; participated in Phase 3 of INSTEP.

Background: $\quad$ Previously was a principal in a primary school.

Was a university based inservice teacher educator during INSTEP; is no longer an inservice teacher educator, but contributes to undergraduate and postgraduate programmes.

Is currently completing a Ph.D.

Rules, tools, routines:

During INSTEP, was working with a group of 24 lead teachers (from year1 to year 8 in 10 primary schools over 4 years) within a Ministry of Education funded research project looking at teachers' curriculumbased professional development. Was never aware of any of the other INSTEP participants outwith her own pod until involvement in final presentation.

Holistic self

Knowing:

Has always considered she was a reflective practitioner to varying degrees. Appreciated the opportunity to investigate practice. Considered she was a learner along with teachers.

Prior to INSTEP experience; awareness of the need to be contextually responsive.

Aware of the potential to make inaccurate assumptions about learners. Values use of real data and allowing teachers to drive their learning.

Motivated by success in her study and practice.

Acting:

Works in what she considers to be a contextually responsive way; co-constructing with students in her programmes.

Within professional development cluster, collected data on teacher and student capability over 4 years.

Completed research and publications in collaboration with a critical friend.

Always gets feedback from learners in an ongoing way.

Being:

Believes: Own practice with teachers should match practice that is being espoused to teachers; teachers should be able to make their own decisions about their learning; co-construction is the most effective strategy; that both "research led teaching and teaching led research" are crucial; there is always the potential to improve practice and research capacity.

Contributes, through collaborative research, to the practice of teachers in a way that teachers will be able to value and relate to.

Recognises the authenticity and value of hard evidence as opposed to third party recommendations and testimonies.

Metaphor of teaching and learning has evolved from "happy kids learn" to "learning kids are happy".

Is always driven to meet all needs of teachers at all stages by incorporating relevant, authentic, and purposeful context and content.

Is inclusive, active, responsive and able to illustrate from own experience. Needs to know learners before teaching them.

Is a "social" learner - likes to talk to people about things. Is approachable, informed, interesting and interested, generous, helpful; is motivated by teachers' and student's success; can be determined, stubborn, "stroppy" and resilient.

Learns better when she knows the bigger picture; has an awareness of other perspectives and has ownership of own learning and direction.

Has confidence to be able to deliver what teachers/students need.

Working with people: Within INSTEP worked under RF leadership with a group of 10-12 
ISTEs in the same subject area.

Loyalty and respect for the RF meant deadlines were met.

Frustration working in larger INSTEP group; large meetings unproductive so broke up into smaller self-selected groups of four or five like-minded people. Members of the group came from two diametrically opposed philosophical positions; difficult to converge. INSTEP gave permission for the group not aligning with the philosophies of colleagues in positions of power, to practice according to their own beliefs and values.

Worked with a critical friend to observe teaching and give mutual support with difficult interventions. Critical friendship was mutually honest and respectful, with an underlying friendship, incorporating challenge and difficult questions. Critical friend relationships still continued through 2008 and 2009. Research continued with critical friends.

Although all ISTEs in the pod worked within one large workspace, in close proximity, critical friends generally formed and met in schools or off-site.

Inquiry process: $\quad$ Focus of inquiry arose from a sense of dissonance with personal values and beliefs and what was expected of the role as an ISTE within a particular professional development project.

Individual focus of inquiry was contextual responsiveness.

Ensured all participants involved in the inquiry had a shared understanding of the concept of "contextually responsive".

Identified one critical friend within the INSTEP group to work closely with, and one other colleague involved in the cluster professional development project.

Critical friend gathered focus group data on teachers' perceptions (interviewed and took notes) of whether or not practice was considered contextually responsive within the previous years' professional development.

Carried out a member-checking with teachers to confirm analysis of interview.

Used a range of literature to support inquiry. 
Anne

INSTEP role:

ISTE (RTLB); participated in Phase 3 of INSTEP.

Background: $\quad$ Previously, was an itinerant Resource Teacher of Special Needs working one-on-one with students.

Been an RTLB since 1999.

Completed a Masters degree in 2004.

Rules, tools, routines:

Works in a cluster of 9 schools; based in one school within a team of 3 RTLB (each employed by different schools). Each of the team is responsible to their principal and a management committee consisting of all principals in the cluster. Each member of the team works predominantly individually with a particular case load, although sometimes work with one or two other team members. The RTLB team meets every week where they discuss issues and support each other (peer supervision). Clinical supervision (discussion around a case) takes place within the team by a person external to the team.

RTLB are allocated to clients according to strengths and areas of expertise. Clients are students, teachers, and classes. Works with individuals or across the system; but predominantly with teachers.

Is an expectation that RTLB always inquire into their practice, but no system or process to support this. Training was provided for the RTLB role.

Holistic self

Knowing:

Believes: it is important to nurture good relationships with teachers There is a tendency to be "too nice" and not engage in challenging conversations. Tendency to "slip back into old ways".

Perception of role is to promote inclusive practices within schools.

Those RTLB who participated in INSTEP were influenced by the experience, but the influence has not spread to the wider RTLB community in the region or beyond.

Acting:

Uses video with teachers in stimulated recall situation which enables a focus on the practice of the teacher, and helps de-personalise the issue.

Entry meeting with client establishes timeframe, objectives, roles, and data gathering tools. At the second meeting, data is reviewed, and the situation re-evaluated.

Course of action is determined through collaborative processes (usually with teacher and teacher aide). Holistic approach includes student, teacher, classroom, peers, home and caregivers. Liaison takes place with other agencies (speech, language, group special education, mental health organisations, field workers, public health nurse, and police) as required.

Currently conducting inquiry into practice using supervision system to inquire into way in which team meets Education Review Office expectations. Evidence under consideration includes cluster policies and practices and case examples.

Presented INSTEP paper at RTLB conference.

Being: Is intrinsically motivated; loves learning; excited and motivated about doing a better job and doing things differently.

RTLB training in 2000-2001 sat well with personal philosophy of practice. 
Working with people: RTLB role - within team of 3; all roles and contexts are familiar- lots of discussion and peer supervision.

Within INSTEP group - most people open about their problems of practice; some aspects were common to the group (e.g. "doing all the talking; interrupting"). Perceived that this may be due to expectations by teachers of the RTLB to come in as the expert and provide a solution.

ISTE pod felt safe - everyone could relate to one another and the problems of practice; they were supportive; there was affirmation and sense of relief to hear others having similar struggles with the job, as it is not an easy job.

Was agreed that the reflections were shared in confidence within the group, so everyone could feel free to be honest and open.

A supportive colleague (a critical friend) within the pod kept her motivated; was encouraging; challenging; and shared readings.

Working with a diverse group of colleagues whose challenges are similar was affirming and comforting, and provided a diversity of ideas.

Inquiry process: Was ambiguous and challenging at first. Deciding on a focus for inquiry was very important.

Inquiry focus was interactions with teachers (learning conversations); which involved recording and transcribing conversations. Transcripts were discussed at INSTEP meetings. Goal was to give the teacher a voice, and space to talk.

Used a range of literature to develop frameworks to analyse audio and transcripts.

Used literature to examine values and beliefs within the INSTEP group. Also used this process with teachers at first meeting and in some professional development sessions.

INSTEP gave permission to look closely at practice.

Inquiry requires supportive people so you can be honest with yourself and examine your values and beliefs.

Surfacing of values, beliefs and assumptions was a significant aspect of discussion at ISTE meetings, as were common challenges in learning conversations, ideas and support, and language used. 
Aroha

INSTEP role:

Background:

Rules, tools, routines:

Holistic self

Working with people:
NF in all except the final Phase 4 of INSTEP.

Previously, was a deputy principal in a primary school.

Been an inservice teacher educator since 1992; holds a management position within her university based organisation.

Completed a Masters degree in 2007, and working towards Ph.D.

Organisational expectation that each facilitator will inquire into their practice using artefacts as evidence (usually audio or video).

Co-authored three discussion papers which were instrumental in developing an organisational professional learning and appraisal programme designed to balance inquiry into practice with accountability.

Previous appraisal system was problematic with inconsistencies. All organisational facilitators, and the New Zealand Education Institute were consulted before the new programme was implemented, which incorporates pay progression linked to professional learning portfolios.

Sharing portfolios with team leaders and managers is built in at different stages of the process, with a timeline and support for the process.

To support the programme, a rubric of standards of effective facilitator practice is being developed. The development of portfolios is monitored closely by the managers who receive reports from team leaders.

$\mathrm{Ki}$ te Aotūroa and the Teacher Professional Development Best Evidence Synthesis are key resources within the organisation. There is an assumption within the organisation that these two documents are well read and used to inform effective practice.

INSTEP project aligned with management's desire to support facilitators as learners, so the INSTEP experience informed the development of the programme.

The development of the programme aligns with the organisation's strategic plan which aims for "an inquiry based organisation"; there is a shared vision of purpose with support from senior management.

There is still ongoing change which, in part, is governed by the political climate, financial constraints and the contestable nature of the environment. The nature of the programme will be influenced by these changes and resulting constraints.

Aroha's interview focussed on the organisational context, and her role as NF, as opposed to her own practice and learning, therefore there was minimal data in relation to her holistic self.

Within INSTEP, RFS who were confident about, and committed to inquiry motivated and encouraged their ISTE pods to do the same, and vice versa.

Although in a leadership position, she saw the situation very much as a learning partnership.

Although there is always the potential for uneven relationships of power and unprofessionalism within group meetings; there are strategies in place to deal with them. Team leaders and managers are implementing strategies gleaned from their focussed professional development programmes about leadership and collaboration.

Strategies employed in the team leader and management team meetings are being taken forward into the curriculum teams by the team leaders.

Works in a number of levels of communities of practice including the management team, team leaders, and curriculum teams. Each has a different purpose, and it is crucial to clarify the purpose of each community and each meeting.

Staff who are new to the organisation are more open to the new 
Inquiry process: Inquired into her own practice although that was not necessarily a requirement of the project as a NF.

ISTEs used video evidence of practice, with an understanding and expectation that evidence would be shared and discussed within the group.

Some participants (RFs and ISTEs) were happy with collaborative inquiry, and some struggled with the concept of deprivatising practice and confronting the incongruence of espoused theory with theoriesin-use.

The group of RFs collaboratively developed the process that was adopted in INSTEP, including guidelines and protocols for meetings and interactions.

Key literature was used for different aspects of the project.

Readings were required to be read prior to each meeting. They were then discussed and informed the ongoing process of inquiry.

Literature informed the development of frameworks for reviewing evidence.

Although it would appear that that evidence-based inquiry is embedded within the organisation, Aroha remains cautious and agrees that although it is accepted and expected, there is no guarantee that it's always done well by individuals. 
Elaine

INSTEP role:

Background:

Rules, tools, routines:

Holistic self

Knowing:

Acting:
NF in all 4 phases of INSTEP.

Previously, was senior manager in large secondary school.

Been an inservice teacher educator since 2002. Was a facilitator within a private provider organisation during INSTEP.

Currently working towards a Masters degree.

Works with principals and clusters of schools providing professional development and developing plans for improvement.

Expectation within organisation that facilitators will improve practice in a rigorous way. Organisational professional learning and appraisal process (developed since INSTEP) includes specific criteria to measure progress. System and tools were developed through shared understandings and collaboration. The process is iterative, incorporating hard evidence, peer feedback and regular monitoring of self determined professional learning goals. Flexibility allows individuals to select professional learning "buddies". Feedback from facilitators has been positive; the system works well; is based on the INSTEP collaborative model.

In a leadership role, oversees individuals' progress by meeting with them at regular intervals to discuss and reflect on progress.

Formalising time for inquiry is difficult due to conflicting demands.

Works from a very strong theoretical base.

Now much more aware of other research literature and theory, and being aware of different perspectives.

Thinking shifting to more acute awareness of own practice and how that might be improved/enhanced.

Values a framework for analysing practice.

Small organisation quite insular; need to look elsewhere for different perspectives.

Teachers and facilitators each operate from their own (sometimes conflicting) theories of practice and assumptions.

Espoused theory not always her theory in use; tendency to 'deliver' a pre-planned workshop without giving participants the opportunity to input or check understanding.

Increased depth of theoretical knowledge over time through working with others.

In previous role - observed others' practice and gave feedback. In role as a facilitator, prior to INSTEP, did some personal informal videoing of practice but did not follow up in any rigorous way.

Currently uses role play, video and theory in more formalised way to improve practice. Takes ownership of the inquiry process rather than it being driven by the leader and expert.

Models inquiry with teachers.

Has collaboratively developed an organisational framework for analysing practice.

Engages in wider reading of literature.

Continues to develop leadership skills; now in leadership role for professional learning within the organisation; INSTEP role was a vehicle for that development, which led to increased confidence in leading learning.

Approach to inquiry now much rigorous and more proactive than reactive. 
Being:

Working with people:

(1)

Inquiry process:
Comfortable being a learner; not an expert, although transition from perception of self as a practitioner to more of an academic engaging in literature.

Embraces challenge of taking on new roles in new content areas.

Believes that all facilitators require core facilitation skills alongside specific content knowledge.

Believes there is a need to surface values, beliefs and assumptions in the clients she works with.

Perceives that her values and the way she works within her organisation align with the values and processes of her organisation.

Happy to expose practice in small informal and self-selected groups of $2 / 3$ where it: is easier to relate to, and identify with others' problems of practice; is not directed or monitored in any way; has engendered increased trust and value of others' opinions.

Values diversity of facilitators and the national, intra-organisational relationships forged through INSTEP; is enriched by finding out about others' work.

Some fear of exposing practice and being judged by peers.

Relationships among ISTEs working in Phase 4 were "fraught" due to competing organisational commitments and the competitive contractual environment.

INSTEP experience with other ISTE organisations has given insight into the ways in which they work, and their underpinning theories; could identify commonalities and overlaps, and respect the differences, facilitating close working relationships in a national context.

Focus of personal inquiry is feedback to teachers. Uses video, observation, stories of practice, transcripts, role play, and analyses practice against a framework.

Literature is important within the process.

Inquiry process within organisation has evolved from an ad-hoc basis to being much more explicit and rigorous.

INSTEP participants had a full understanding of the process because they took time to explore and get clarity around the purpose and process.

The group of RFs in the exploration phase worked well together; used a schema that was developed to facilitate reflection on specific aspects of practice (pre-cursor to the organisational tools they now use to examine their practice). 
Eva

INSTEP role:

Background:

Rules, tools, routines:

Holistic self

Knowing:

Acting:
RF; participated in Phases 2 and 3 of INSTEP

Previously was a classroom teacher and mediation coordinator in secondary school.

Been an inservice teacher educator since 2003; is no longer an inservice teacher educator, but contributes to undergraduate and postgraduate programmes.

Was awarded a Masters degree in 2008, and currently working towards Ph.D.

Worked in schools at all levels providing curriculum support; mainly in classroom with the teacher. National INSTEP seminars were of value: allowed opportunities to see the bigger picture. Valued formally organised inquiry with explicit processes and allocation of time.

Prepared for INSTEP by consulting with the NF and reading the material provided. As an RF, developed tools for reflection and understanding of critical friendship in operation, so can work in that way with colleagues now.

Has a clearer understanding of inquiry processes due to reading around reflection and learning communities.

Has more clarity around objectives and rigour in ways of working. Is a reflective practitioner. Appreciates different ways of reflecting on her contribution and sense of self.

Now much more aware of values and beliefs with increased value of her own professional contribution.

Philosophy of research-led teaching sits well with her philosophy of practice.

Is self motivated; takes responsibility towards students and teachers very seriously; embraces opportunity to improve practice. Has an understanding of opportunities and risks involved in inquiry.

Now more at ease in role as a teacher educator; has a greater awareness of her influence upon others; aware of the need to instil in teachers and student teachers the importance of collaborative inquiry, critical friendship and the surfacing of values and beliefs.

Plans a lot more now; conscious of need for a critical friend.

More focussed "as a researcher".

Inquiry and tools were informed by literature. Now engages with literature as part of the process of teaching and research.

Became more proactive in seeking feedback from teachers and colleagues. More evidence gathered at the beginning of an intervention now. Makes more effort to improve practice on an ongoing basis.

Much more selective about whom she aligns herself to work with; very clear about the alliances she wants, and those she does not; clear about values and beliefs, and the way she wants to work; aligns with like-minded people.

Work with teachers and student teachers is now clearer and more direct. Is now very confident in mentoring.

Attributes growth and confidence in leadership to INSTEP experience. 
Being:

Working with people:

Inquiry process:
Has courage to keep taking risks to take learning forward.

Has a "deep-seated sense of equity" which had to be managed when others were not investing and exposing their practice.

Hard work ethic and sense of moral responsibility ensured personal commitment to INSTEP.

Believes learning is more meaningful when it involves risk-taking. Enjoys exploring "new territory".

Reflection on practice can bring about transformation and ultimately provide a better education for students in the classroom.

INSTEP allowed the development of trust with some colleagues which enabled "unguarded conversations", as well as benefits of the richness of different perspectives.

Learning community engendered "support and energy"; roles were clearly defined; there was an understanding of protocols; the objectives were clear. Protocols helped lessen the risk of exposing practice.

Felt exposed when others did not take risks and expose practice; no reciprocity of challenge led to lack of trust.

Critical friendships were trusting and respectful with like-minded colleagues.

Processes were valued that facilitated sharing food, laughter, appreciation, and celebrations of success; which promoted affirmation, encouragement, and guidance.

Adopted different roles within the: critical friendship; learning community; and leadership of pod of ISTEs. Experienced some uneven relationships of power at organisational level, and within ISTE pod. Issues of moral responsibility and equity should be made explicit; addressed; and managed within a group.

Has developed confidence to contribute in a number of different forums; knows who to engage with to advance thinking.

Inquiry focus was on being contextually responsive; worked with a critical friend. Clarity of the process of inquiry was crucial.

Mirrored her process of surfacing her values and beliefs with teachers in order to examine their espoused theory and compare it with what was actually happening in practice; used readings, video recording, and questionnaires. This process with teachers requires established relationships "built on trust, respect and care".

Had difficulty in identifying a puzzle of practice but persevered and found that the tools she developed helped her to identify and conduct inquiry into her practice and also worked in the same way for teachers.

Values having been through the process to raise awareness of what to critique in her practice, and how to go about it. 
Evelyn

INSTEP role:

RF; participated in Phases 2 and 3 of INSTEP.

Background:

Rules, tools, routines:

Previously was an assistant principal in a primary school; had been in Special Education, and taught overseas.

Been an inservice teacher educator in a university setting since 1999. Changes within the university mean she now works within a small curriculum-based team of facilitators.

Was awarded a Masters degree in 2002.

Analysis frameworks were particularly valuable, such as the one used for focusing on a particular aspect for feedback/review, and the framework for identifying values and beliefs.

Having a particular process of inquiry was of value for her work with teachers.

Time allocation, leadership, and the flexibility to be creative, were valued.

Holistic self

Knowing:

Has always been a reflective practitioner, although it was done in a "piecemeal" rather than systematic way, using student voice and observation of student behaviour as evidence.

Acting:

In some schools she is currently able to work with a critical friend because they work in pairs, but that's not normally the case because it's too labour intensive.

One of the key aspects of value was having to provide evidence of her practice.

Is "much better now at keeping quiet and letting teachers do the talking"; data collection has improved; and she now uses e-mail more to pose questions and give time for teachers to respond.

Being provided with relevant readings by the NF during INSTEP was a great support.

Uses relevant literature with teachers, but it is difficult to source literature in advance to suit the diverse needs of each client school/teacher in advance.

Has developed her ability to critically reflect on practice on her own, having gone through the process with a critical friend in INSTEP. She considers that she still critically reflects on evidence of her work with teachers and students.

Setting up critical friendships in schools would require lots of support. Puts more effort into setting up an intervention than she did previously: getting schools to do a self review prior to her work with them including gathering student data/student voice.

Being: Passionately loves what she does, although there are times when it can be difficult.

Her perception of her role in schools has changed since INSTEP. She reflects on how she has changed: she works with schools in a much more inclusive way than she did before. 
Working with people: Developed an extremely valuable and effective critical friendship with a colleague during INSTEP. Although they were in different areas of expertise, with different backgrounds, they had similar philosophies of practice. She valued being able to "talk in shorthand". Impromptu conversations took place in the corridor and over the phone.

The experience of leading the INSTEP pod was demanding due to the dynamics and personalities within the group. There were clashes of personality and values.

Although the larger group did not work well for reflecting on practice, Evelyn managed to get groups of two or three ISTEs to work as critical friends. Some did that naturally whereas some benefitted from Evelyn acting as an arbitrator.

Describes her small team that she works with now as being committed to the team.

Inquiry process: Used video and audio transcripts as evidence of practice.

Focus of practice was that she tended to talk too much. She had not been aware of that tendency prior to listening to the evidence.

Worked with her RF and ISTE pod (and with her teachers) using a questionnaire to surface beliefs and values. Values the collaboration, tools, procedures and frameworks to support reflection on practice and surfacing of values, beliefs and assumptions.

The act of reading the recommended literature in Phase 2 as a pod of RFs informed the inquiry process and provided a bank of literature that could be provided for the ISTEs in Phase 3. 
Hannah

INSTEP role:

Background:

Rules, tools, routines:

Holistic self

Knowing:

Acting:

Being:
NF; participated in Phases 1-3 of INSTEP.

Is an inservice teacher educator within a university setting. Works with Heads of Department and individual teachers from whole school to one-on-one settings.

Currently has a role as a leader of professional learning.

Prior to INSTEP, there was no process to gauge effectiveness of practice, so there was no structure, time or mechanism to reflect on evidence of practice.

The organisation is moving towards the collection and use of evidence to inform practice and appraisal, linking learning to performance management.

All facilitators in the organisation are involved in professional learning groups which meet regularly to discuss and reflect on practice. Groups have progressed from being peer tutorial groups on separate campuses to formalised groups with assigned leaders. Groups are assigned, and structured deliberately to be diverse (mixed gender, mixed region, mixed disciplines, experienced and newly inducted). Meetings take place as one whole group in one venue over two days, and smaller groups meet separately. Within each learning group there is an expectation that practice will be discussed. Learning group leaders design the learning experiences - which always relate to implications for, and problems of, practice. There is no requirement to produce hard evidence of practice. Some ISTEs who work together have observed each other informally, but for those who work in isolation this does not happen naturally.

Although there is an expectation of improvement and change in practice within Ministry of Education funded contracts, the reporting formats do not incorporate professional learning for inservice teacher educators.

The organisational policy on the process of inquiry is not coherent or clearly communicated to facilitators, resulting in ad-hoc adoption of the inquiry process.

Had a sense that practice was effective but knew that progress with hard evidence would be challenging.

Aware of the importance of building relationships with clients and the need to analyse what works and what does not.

Realised that ISTE practice is not only about professional knowledge and understanding when working with clients - but also about interactions with people at all levels.

Has always studied and used academic literature; Has always been reflective, but INSTEP was first of using hard evidence of practice.

Focus of practice was around tone and language.

Had a clear purpose and vision for her organisation within the context of the INSTEP project: to formalise the process and achieve coherency.

Uses her own operational framework based on principles of andragogy.

Believes: the progression of learning and practice is more likely to happen with some structure and support; there is a need to evaluate practice against the New Zealand Teachers Council registered teacher dimensions; inservice teacher educator capacity and professional growth cannot be self sustained - requires structure and resourcing; inservice teacher educators' agency is impacted upon majorly by social and cultural contexts, and the way in which individuals and communities interplay within the schools; professional learning and growth is hampered by the lack of 
formalised systems and tools for reflection on practice.

Perception of role as an inservice teacher educator has evolved over time to focus more on the how of facilitation rather than the what.

Visioned the structuring of a programme to transition people into the inservice teacher education. Had an awareness of that need due to lack of clarity around the role in her early experience.

Deprivatising practice is viewed as a learning experience; has the desire to grow professionally, but needs clarity around goals and direction; there needs to be a vision.

Working with people: Important to have trust and respect for those who are observing your practice, and that the critical friend values you, knows about the context within which you work, and is willing to work with you. Although apprehensive there was a trust that the feedback would be framed positively within a learning context. Leading learning with peers is challenging.

Is supported by a leader who is a learner; clear in her role; models, encourages, makes connections and reconnections, seeks feedback on her facilitation, uses tools to evaluate her practice, leads by example.

There are instances of uneven relationships of power impacting on individuals' freedom to deprivatise practice. Learning inhibited by antagonists who do not share the same vision of inquiry.

The focus and structure of INSTEP worked well to promote learning.

Inquiry process: $\quad$ Focus of inquiry was on leadership skills with peers and interactions with teachers; involved peer observation, teacher interviews and feedback, focussed on use of challenging language and her acknowledgement of cultural context of clients.

Inquiry is less formal and rigorous now due to lack of leadership within learning groups, and lack of time and formalised tools. Professional learning has lost focus due to changes in the university environment.

Is using the School Leadership and Student Outcomes Best Evidence Synthesis to develop performance indicators for leadership practice, and seeking feedback from peers in relation to this.

Considers research literature crucial for inquiry. 
Laura

INSTEP role:

RF (RTLB); Participated in Phases 2 and 3 of INSTEP.

Background:

Previously was an itinerant Resource Teacher Special Needs. Has been an inservice teacher educator in some capacity since 1994. Has been an RTLB since 1998.

Was awarded a Masters degree in 2005, and is now working towards her Ph.D.

Rules, tools, routines:

Works with teachers and students; involves meetings with teacher, observations, discussion, problem solving, use of video, sharing of resources and making links with relevant literature.

Role is complex, with tensions in representing the cluster base, the principal of the school, and the wider RTLB community.

Time is an issue; often insufficient time for preparation and setting up the intervention.

Although reflection is an essential part of the job, the format for reporting does not appreciate the need for reflection on practice; the role of RTLB does not require you to be a reflective practitioner. The role requires support in the form of an INSTEP-type approach to professional learning and inquiry. Reflection is done in own time not supported by the system.

Holistic self

Knowing:

The movement from behavioural to a much more holistic approach in special education prompted her to examine values and beliefs.

Opinions and decisions must consider all perspectives as well as remaining loyal to the principal.

Has become a much better informed person; reads a lot more and applies research to practice; more aware of own knowledge. Has been an enriching experience - aligning theory with practice.

Increased credibility and efficacy; has to feel that time teachers are spending with her is worthwhile.

Many more professional contacts since INSTEP.

Acting:

Decisions are difficult due to competing loyalties.

Inquiry now embedded into practice.

Uses video with teachers to enable their reflection on practice.

Now able to source more literature - knows where to look. Appreciates attending conferences and hearing authors of papers she has read.

Now much more confidence to work in the way she espouses RTLB should practice. Used to feel guilty if not producing resources as was often expected. Now is more inclusive of the teacher in problem solving.

Acknowledges RTLB practice is inconsistent - not all using the collaborative consultation model.

Appreciates a principal with similar values and beliefs.

Time is a challenge; collaborative consultation takes more time.

Being: Believes that reflection is necessary in order to really examine practice against what you value and believe is the way to work. Is interested in teaching learning without a disability focus. Considers credibility to be important.

Is currently experiencing frustration, concern and disillusionment with the proposed new direction for RTLB. Believes that the proposal to work in groups of 20 under one manager will be quite different to the current situation where she works in a small group of 3 or 5 , reporting to a management committee, which includes the principals of the schools she works with. Believes that RTLB are moving to a one size fits all rather than the current way she is working which is collaborative consultation with teachers to decide on the best programme of intervention for particular students. 
Working with people: Protocols were not made explicit within the group but were understood.

Acknowledges the value of working with like-minded people.

Initially, found it difficult to be understood in Phase 2 with a very diverse group of RFs; there were some uneven relationships of power. The situation was managed very effectively by the NF's leadership skills.

Leading peers was challenging; learned not to make assumptions. Critical reflection requires a critical friend; much more difficult in isolation.

INSTEP pod continued to meet beyond INSTEP because of the solitary nature of the work, and the relationships that were developed. They have a shared vision around learning conversations.

Works in close proximity to one of the ISTEs from Phase 3 of INSTEP, and they have a close critical friendship.

Important to work with supportive and like-minded people when you deprivatise practice and find the unexpected.

Inquiry process: $\quad$ Focus of inquiry was learning conversations; explored learning conversations with 5 teachers (language used, approach); discovered she often talked too much; was too sympathetic; used literature to develop a framework of criteria for analysis. Gave alternative ideas for openings.

It took a long time to understand the process.

Initially evidence took form of student data and audio recordings; then moved to video.

Inquiry needs to be legitimised; with policies, structure and funding. Within INSTEP pod meetings, there was a requirement to bring evidence of practice to the group and tools were used for reflection. In ongoing meetings, no formal structure now for reflecting on problems of practice - they are just shared with the group.

Video now used with teachers to help them reflect on their practice. Clear agendas and notes of meetings kept the group on track. 
Olivia

INSTEP role:

Background:

Rules, tools, routines:

Holistic self

Knowing:

Acting:
ISTE (RTLB); participated in Phase 3 of INSTEP.

Previously was a senior teacher in primary school. Been an RTLB since 2000.

Was awarded a Masters degree in 2006.

Works from a base school with 2 RTLB colleagues who were not involved in INSTEP.

Works in 11 schools, from new entrants to year 10 in a semi-rural environment, so it involves travel. Collaborates, in an ongoing way, with others such as occupational therapists, speech therapists. Sometimes works with parents, but predominantly teachers.

Role is to "support the teacher to make changes for students in the classroom to improve their outcomes".

Awareness that success of an intervention is more likely if knowledge is shared within a community rather than an individual teacher; and that role is to "get teachers to think more deeply". The ability to do that is dependent on the relationship with the teacher.

Has always reflected on practice as an individual pursuit; now aware that other perspectives are necessary in order to be challenged about decisions and practice. Wants to be challenged by peers to take learning and practice forward.

Awareness of the tendency to follow a routine and not be so attentive to what the teacher was saying; therefore not be so effective in bringing a new perspective for teachers.

Saw no reason to change practice until transcripts were examined closely. Practice tended to perpetuate the "warm fuzzy" relationships with teachers and not develop the ones who were difficult to reach.

Better understanding of the reasons for making particular decisions and practicing in a particular way with some teachers.

Sense of agency not increased due to teachers' lack of reported changed practice; needs to look more closely at teachers' practice and not rely on their self-reporting as they may have changed but not be aware of it.

Now able to view own practice in a detached way. Ability to look at evaluations more professionally and objectively.

Now much more aware of others and their needs; more aware of own biases.

Has always implemented some form of reflection over the last decade.

Currently reverted to prior habits of practice.

Now spends more quality time on gathering data and reflecting on interventions.

Has changed practice to incorporate the teacher's perspective and ideas rather than "own it" and bring a load of solutions and resources to the table, as was inclined to do previously.

Follow up with teachers established a lack of impact of practice in spite of inquiry and change of practice.

Actively seeking the critical friendship she found lacking since her experience with a colleague over a decade ago. Has initiated meetings with a supervisor within the RTLB service, to critically reflect on her practice.

Is conscious of taking things much more slowly with difficult situations, and gathering evidence for reflection. Still having difficulty with questioning.

Now uses literature more in practice; has a better understanding of its importance; literature stimulates discussion.

Still recalls and applies the framework for learning conversations 
used in INSTEP.

Being:

Interprets individual role as one of trying to set up "collegial community" within the schools around a case. Interpretation of role as a facilitator has grown from being the person who solves the problem to identifying the problem and helping the teacher devise solutions. Believes in the importance of reflection in professional learning - critical examination of practice.

Engages in inquiry because of the continual and ongoing need for improvement and growth. Wants to make a difference to children. Believes that being able to spend time with teachers and communities within the school is vital to the role of RTLB and effective practice.

Concerned about the move towards RTLB practice becoming more consistent and prescriptive.

Working with people: Ongoing INSTEP group meetings did not meet perceived need due to lack of critical friend perspectives on her practice. Aspects of practice have not been reflected upon in depth with critical friends. Colleagues in workplace do not take on the role of a challenging critical friend due to the unfamiliarity of the collaborative evidencebased inquiry model.

Has not found that she has participated in effective communities of practice during or since INSTEP. Due to the pressure of time, often the most valuable interactions with teachers seem to take place informally and infrequently in the staff room.

Inquiry process: Uses video as evidence of teacher practice. Used literature to help surface teacher values and beliefs. Used "hard data in and out of the classroom" to identify and clarify the issue before offering useful articles and information.

Focused on questioning as an aspect of practice. Used transcripts of conversations with teacher as evidence of own practice, but did not collaboratively reflect on evidence in depth within INSTEP group or since. Reflection was more of an individual pursuit using literature to reflect on practice.

Is working with supervisor on a difficult case and intends to transcribe a conversation for critical reflection. May use role play as a strategy for reflection. 
Theresa

INSTEP role:

NF; participated in all 4 phases of INSTEP.

Background:

Previously was a primary teacher.

Been an inservice teacher educator since 1988. Is no longer an inservice teacher educator; returned to classroom teaching.

Was awarded a Masters degree in 1995.

Rules, tools, routines:

Worked in schools for periods of over 2 years or more; worked predominantly with teachers, lead teachers and principals.

Was an expectation that each individual within the organisation will inquire into their practice in order to improve, although there was a great deal of choice and flexibility within that.

ISTEs decided they would rather be in a small group (3 or 4 selfselected) when they show their videos of practice, but they do have the choice, and some choose to share in the large group. Generally had a big group meeting and then would break off into smaller groups for reflection and inquiry.

Holistic self

Knowing:

Previously learning was driven by others rather than self determined. The theory was difficult to grasp initially, and it was a slow process "putting that together".

Acknowledges importance of listening to others' ways of working, and being aware of other theories.

Tensions when presenting large workshops (70 people) and ensuring that all are engaging when co-constructing is not an option.

Trying to read more widely. Knowledge around theory deepens from being in a leadership role.

Realisation that there may be unsubstantiated fear around trying some new things when, in actual fact they go smoothly.

Felt daunted going into a new job with unfamiliar content knowledge

Acting:

Was aware of the tendency to launch into a workshop "expecting everybody to know what's in my head".

Engaged in inquiry during previous teaching role - observed by, and observed peers' practice; trainers gave feedback on practice.

Used role play, video and theoretical framework to improve practice; Worked with other facilitators in a leadership role.

Through research and development, collaboratively developed (within the organisation) a framework for analysing practice.

Was affirmed and satisfied by example of working with teacher and simply by probing an issue further supported the teacher in surfacing her assumptions about her own practice.

Now working in a school with a leadership role in literacy. Works with teachers to support them to improve their literacy programmes. Finds it refreshing to be closer to student learning. Is working on how to effectively use the inquiry cycle with teachers.

Being: $\quad$ Perceives self as a leader and a learner: "We're learners but we're leaders ... we're always learning".

Works with teachers using same principles as working with students. Likes the challenge of new learning.

Believes the bigger picture is important; values all colleagues' perspectives.

Working with people: Acknowledges that by working in small groups $(2 / 3$ self-selected), it is easier to relate to, and identify with others' problems of practice. Sharing videos of practice helps to break barriers. Acknowledgement of fear of exposing practice and being judged by peers.

Working nationally with other ISTE INSTEP groups challenged assumptions: "we take each other further all the time", and enabled a 
more in-depth look at practice with teachers.

During Phase 4 there were instances of disrespect and unprofessionalism by other ISTEs within the group who were not willing to invest in inquiry.

Inquiry process: $\quad$ Focus of practice was feedback to teachers on a one-on-one level, as well as being inclusive in a group workshop. Worked in a small group to share videos of practice. Use of video, observation, stories of practice, transcripts, role play.

Was always aware that the aim was to inquire into her own practice, but became aware over time that there was a strong focus on the impact of practice at all levels, and the need to look at hard evidence of that.

Is focussing on relationship building with co-teachers as a prelim to engaging in an inquiry cycle.

Is no longer conducting rigorous collaborative inquiry into her own practice. 


\section{Appendix E: Open coding with categories and dimensionalised properties of EBIP}

\begin{tabular}{|c|c|c|c|}
\hline \multicolumn{4}{|c|}{ Broad category: Individual, knowledge, acting, being } \\
\hline Subcategory & Properties/dimensions & \multicolumn{2}{|c|}{ Dimensionalised examples } \\
\hline Dispositions & $\begin{array}{l}\text { Committed, risk-taking, responsibility, } \\
\text { openness }\end{array}$ & $\begin{array}{l}\text { Self assured } \\
\text { Courageous } \\
\text { Confident 'stroppy moo' }\end{array}$ & $\begin{array}{l}\text { Tentative, unsure 'In a quagmire' } \\
\text { Fearful } \\
\text { No confidence }\end{array}$ \\
\hline Professional identity & $\begin{array}{l}\text { Efficacy, Confidence, Agency, } \\
\text { philosophy }\end{array}$ & $\begin{array}{l}\text { Satisfied with practice } \\
\text { Sense of efficacy } \\
\text { Strong philosophical approach }\end{array}$ & $\begin{array}{l}\text { Sense of dissonance /dissatisfaction } \\
\text { Lack of efficacy } \\
\text { Philosophy not clearly communicated }\end{array}$ \\
\hline \multirow[t]{7}{*}{ Emotions and feelings } & Clarity of role/purpose & 'I was very clear' & 'We didn't know what we were doing' \\
\hline & Affirmation & $\begin{array}{l}\text { Affirmed by others facing similar } \\
\text { challenges (It's not an easy job) }\end{array}$ & $\begin{array}{l}\text { Self affirmed by 'finding ways that reflected who I was and } \\
\text { what I bring' }\end{array}$ \\
\hline & Confidence & $\begin{array}{l}\text { Lack of confidence to keep going at } \\
\text { times }\end{array}$ & $\begin{array}{l}\text { 'Being more courageous about what it is I think we need } \\
\text { to do and why we do it' }\end{array}$ \\
\hline & Approach and response to inquiry & Excited and nervous anticipation & daunting \\
\hline & Safety & $\begin{array}{l}\text { 'I felt quite threatened' 'a constant } \\
\text { feeling of being insecure' }\end{array}$ & 'quite happy to expose [practice]' \\
\hline & Dissonance / personal challenge & $\begin{array}{l}\text { 'We all have the same kind of failure' } \\
\text { 'It's quite a lesson really, to listen to } \\
\text { yourself' }\end{array}$ & $\begin{array}{l}\text { 'I crashed and burned' 'If I perceive that they're not } \\
\text { contributing } \ldots \text { I find that a real moral and professional } \\
\text { dilemma' }\end{array}$ \\
\hline & Satisfaction & $\begin{array}{l}\text { Discouragement when trying to reflect in } \\
\text { isolation }\end{array}$ & $\begin{array}{l}\text { Encouraged to tackle a difficult situation and come out } \\
\text { with a good outcome }\end{array}$ \\
\hline \multirow[t]{3}{*}{ Learning and professional growth } & Change of practice & One or two isolated mentions & Embedded change of practice (as a habit) \\
\hline & Learning & $\begin{array}{l}\text { 'became far more proactive in seeking } \\
\text { feedback from friends' }\end{array}$ & 'hard to teach an old dog new tricks' \\
\hline & Professional growth & 'almost feeling disillusioned' & 'I am a professional' \\
\hline
\end{tabular}




\begin{tabular}{|c|c|c|c|}
\hline \multicolumn{4}{|c|}{ Broad category: Working with people } \\
\hline Subcategory & Properties & Dimensionalised examples & \\
\hline Leadership & Participation & $\begin{array}{l}\text { A knowledgeable expert who modeled } \\
\text { and set expectations }\end{array}$ & Lack of involvement and commitment 'no-one even asked' \\
\hline \multirow[t]{2}{*}{ Collaborative arrangements } & Communities/Large group & Clusters/teams who work together & Stakeholders and other organisations \\
\hline & Pairs/small group & $\begin{array}{l}\text { Determined by work contexts and } \\
\text { opportunity }\end{array}$ & Determined by common 'problems of practice' \\
\hline \multirow[t]{5}{*}{ Critical friends } & Size & one or two people & Whole INSTEP pod (15?) \\
\hline & Support & By affirming and challenging & Lack of investment and reciprocity of risk-taking \\
\hline & Challenging & Challenging and being challenged & $\begin{array}{l}\text { Not challenging / challenging with no reciprocity of being } \\
\text { challenged }\end{array}$ \\
\hline & Like-minded & 'someone like me' & No 'common ground' \\
\hline & Relationships, activities, environment & $\begin{array}{l}\text { 'have a quick giggle'; 'sharing kai'; } \\
\text { laughter }\end{array}$ & Not being honest; moral dilemma \\
\hline Diversity of perspectives & & Other perspectives add value & Feeling let down by lack of commitment \\
\hline Protocols (ways of working) & & Formalised agreed ways of working & No reference to protocols / group couldn't work together \\
\hline Trust, respect and safety & Collaborative environments & 'felt threatened' & Deep sense of trust \\
\hline
\end{tabular}




\begin{tabular}{|c|c|c|c|}
\hline \multicolumn{4}{|c|}{ Broad category: Rules, tools and routines } \\
\hline Subcategory & Properties/dimensions & Dimensionalised examples & \\
\hline Management & Vision/Strategic plan?? & Communicated and understood & Not clear / non existent \\
\hline Resourcing & Time & unallocated time & Time-consuming reporting \\
\hline \multirow[t]{3}{*}{ Requirements } & Reporting and documentation & $\begin{array}{l}\text { Formal appraisal and } \\
\text { accountability (e.g. MoE } \\
\text { outputs) }\end{array}$ & Informal feedback and personal journals \\
\hline & $\begin{array}{l}\text { Expectations and requirements } \\
\text { Who? When? How articulated? }\end{array}$ & $\begin{array}{l}\text { Senior management } \\
\text { Explicit statements } \\
\text { Government initiated changes }\end{array}$ & $\begin{array}{l}\text { Self imposed } \\
\text { Implicit assumptions } \\
\text { Organisational /individual changes }\end{array}$ \\
\hline & Professional development & Regular attendance mandatory & Ad-hoc, self-selected \\
\hline \multirow[t]{3}{*}{$\begin{array}{l}\text { Structure, processes and } \\
\text { mechanisms }\end{array}$} & $\begin{array}{l}\text { Professional Communities Who? } \\
\text { Why? When? }\end{array}$ & $\begin{array}{l}\text { Critical friends } \\
\text { Formal arrangements }\end{array}$ & $\begin{array}{l}\text { Inter-organisational stakeholders, peers } \\
\text { Ad-hoc, informal }\end{array}$ \\
\hline & Individual & Action plan and evaluation tools & No structure \\
\hline & Organisational & Collective tools and mechanisms & 'No tools and teeth' \\
\hline
\end{tabular}




\begin{tabular}{|c|c|c|c|}
\hline \multicolumn{4}{|l|}{ Broad category: Inquiry process } \\
\hline Subcategory & Properties/dimensions & Dimensionalised examples & \\
\hline \multirow[t]{5}{*}{ Inquiry Cycle } & Research and theory informed & $\begin{array}{l}\text { Underpinned inquiry and practice (at } \\
\text { organisational level) }\end{array}$ & Some (individual) reference to literature \\
\hline & Clarity / ambiguity & Being clear about the process & 'Didn't know what I was doing' \\
\hline & Feedback & Within a group situation & With one or two critical friends \\
\hline & Process of inquiry & $\begin{array}{l}\text { Proactive identification of an aspect of } \\
\text { personal practice }\end{array}$ & $\begin{array}{l}\text { Reactive response to a generally identified (common) } \\
\text { area of practice }\end{array}$ \\
\hline & Evidence & $\begin{array}{l}\text { Hard evidence available / triangulated } \\
\text { (video, teacher voice) }\end{array}$ & Reported evidence / one source - not sighted \\
\hline \multirow[t]{4}{*}{ Analysis tools and frameworks } & Development - How? & $\begin{array}{l}\text { Developed within the organisation over } \\
\text { a long period }\end{array}$ & Developed within and for the INSTEP project \\
\hline & $\begin{array}{l}\text { Strategies and tools - How did they } \\
\text { analyse? }\end{array}$ & $\begin{array}{l}\text { Video/audio; role play; conversation } \\
\text { analysis frameworks }\end{array}$ & No use of frameworks; anecdotal \\
\hline & $\begin{array}{l}\text { Frameworks - Who owned and used } \\
\text { them? }\end{array}$ & Owned and used by whole organisation & Individually owned and used \\
\hline & Value / benefits & Integral to process & Not useful / barrier to growth \\
\hline Values and beliefs in inquiry & Critical evaluation & 'Cosy chat' stage & Surfacing values and beliefs \\
\hline Investment & Responsibility, driving learning & No investment & Mutual engagement \\
\hline Perspectives within inquiry & & Richness of different perspectives & Too diverse to come together \\
\hline
\end{tabular}




\section{Appendix F: Quantitative analysis}

\begin{tabular}{|c|c|c|c|c|c|}
\hline 1_Working with people & & & Sources & References & Total References \\
\hline Management and leadership & & & 13 & 65 & 65 \\
\hline \multicolumn{6}{|l|}{ Collaborative arrangements } \\
\hline & Communities_Large groups & & 16 & 68 & \\
\hline & Factors & & 7 & 20 & \\
\hline & Pairs or small group & & 11 & 22 & \\
\hline & & & & & 110 \\
\hline \multicolumn{6}{|l|}{ Critical friends } \\
\hline & Challenging & & 11 & 18 & \\
\hline & Like-minded & & 9 & 26 & \\
\hline & \multicolumn{2}{|l|}{ Relationships, activities and environment } & 15 & 63 & \\
\hline & Size & & 3 & 19 & \\
\hline & Support & & 6 & 14 & 140 \\
\hline \multicolumn{2}{|c|}{ Different perspectives and diversity } & & 11 & 27 & 27 \\
\hline Protocols & & & 7 & 13 & 13 \\
\hline \multirow[t]{2}{*}{ Trust respect and safety } & & & 13 & 31 & 31 \\
\hline & & & & & 386 \\
\hline \multicolumn{6}{|l|}{$\begin{array}{l}\text { 2_Rules, tools, routines } \\
\text { Requirements }\end{array}$} \\
\hline \multicolumn{6}{|l|}{ Requirements } \\
\hline & Expectations and requirements & & 13 & 30 & \\
\hline & & Change & 4 & 8 & \\
\hline & Professional Development & & 5 & 11 & \\
\hline & Reporting & & 9 & 16 & \\
\hline & & Documentation & 3 & 6 & \\
\hline & & Ministry contracts & 3 & 8 & \\
\hline & & & & & 79 \\
\hline \multirow[t]{3}{*}{ Resources } & & & 13 & 31 & \\
\hline & Time & & 9 & 27 & \\
\hline & & & & & 58 \\
\hline \multicolumn{6}{|c|}{ Structures, processes and mechanisms } \\
\hline & Communities & & 15 & 48 & \\
\hline & \multicolumn{2}{|l|}{ Individual processes and mechanisms } & 6 & 32 & \\
\hline & \multicolumn{2}{|l|}{ Organisational structures and processes } & 15 & 65 & \\
\hline & Vision and ownership & & 15 & 31 & 176 \\
\hline & & & & & 313 \\
\hline \multicolumn{6}{|c|}{ 3_Individual - knowledge, action, being } \\
\hline Dispositions & & & 8 & 33 & 33 \\
\hline \multicolumn{6}{|l|}{ Emotions and feelings } \\
\hline & Affirmation & & 5 & 14 & \\
\hline & \multicolumn{2}{|l|}{ Approach and response to inquiry } & 11 & 36 & \\
\hline & Clarity of purpose or role & & 7 & 9 & \\
\hline & Confidence & & 8 & 17 & \\
\hline & \multicolumn{2}{|l|}{ Dissonance and personal challenge } & 12 & 52 & \\
\hline
\end{tabular}




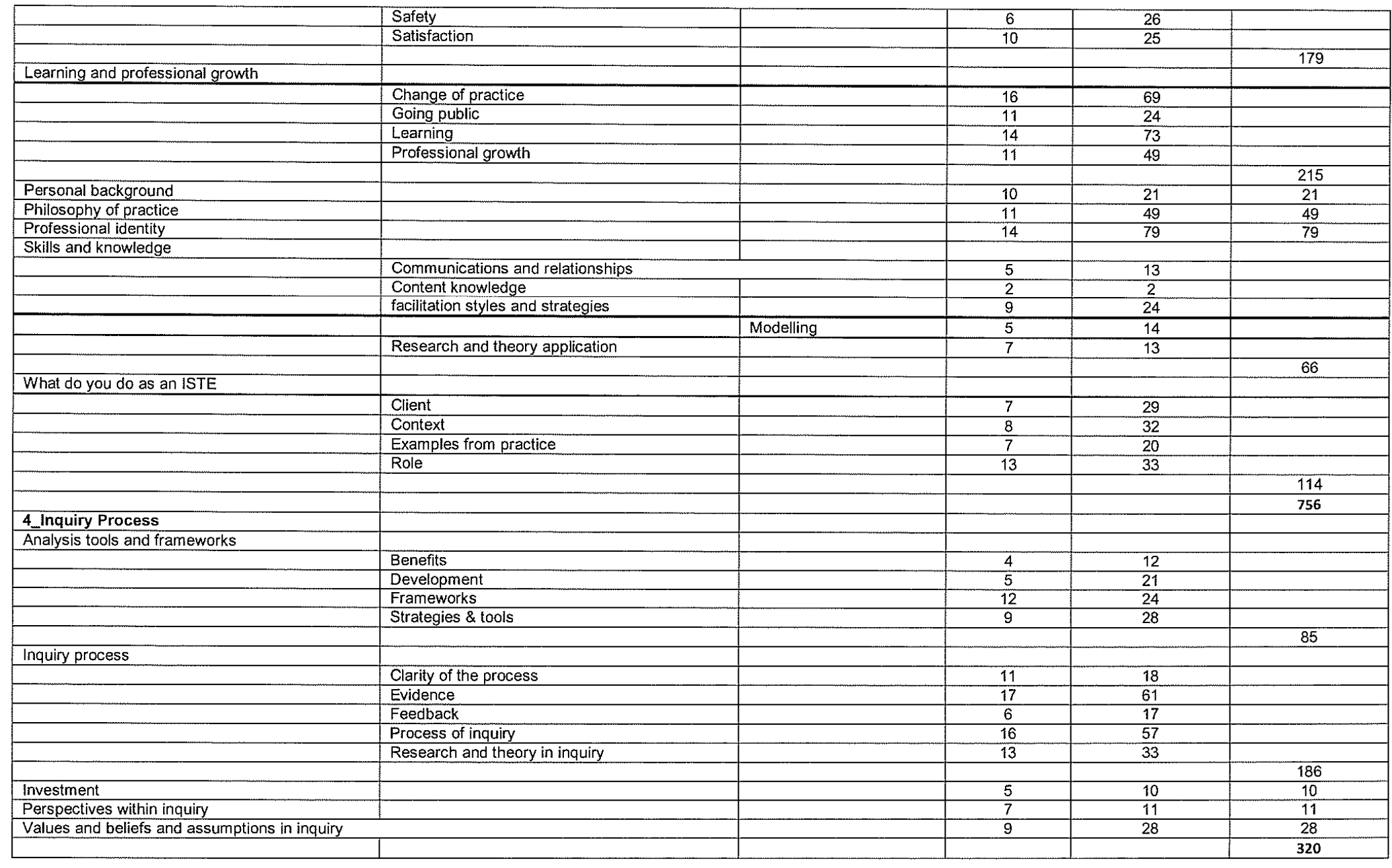




\section{Appendix G: Progress report excerpt}

\section{Examining practice}

Various methods of deconstructing practice were discussed, and because of time constraints and the fact that each facilitator was working within different contexts with a different focus, it was agreed to explore the use of digital video and audio to capture facilitator / teacher interactions. The digital media would present us with samples of practice to reflect on and share with the others in the group. One of the first facilitators to 'deprivatise' their practice in this way shared a series of video clips of facilitator / teacher interaction. Although the initial idea was to focus on questioning techniques, the group all agreed that the video evidence demonstrated excellent facilitation skills. Each individual in the group was allocated a different question centred around aspects of practice and asked to view the video with that question in mind. There was much discussion around what took place:

Transcripts from group feedback session 18 May 06

F1 I'll tell you what most impressed me was your silence because you were absolutely non judgemental, just letting her talk and then when she had finished coming in with a question. Or a prompt. And I mean that is just so nice, you weren't saying, God it was bad you were just prompting her to come out with it and it was just lovely so your questions were very nice.

My question that you have down for me was to decide whether the teacher's ideas took centre stage, presumably that means within that scenario and I mean that they really did. I mean I think the way you laid your questions down to get here to talk about the things was just the right way to do it and she told you everything. You gave her very little information rather than pointing her in the right direction and giving her the next prop. So it did place her centre stage, yes.

think too, you said at the end, what will you take away from today? And she said that there is hope for this class. So she has, she saw the class as a different entity after that, she saw that there could be a class that would respond.

And isn't that wonderful? So she took it beyond herself that she was caring about the kids. 
So in a way you were doing non judgemental feedback. You were getting her to...You said with me to ask her what are these issues that (inaudible) drawing, the safe and the unsafe environment so that was... And then you went what was I doing, how did I do that, what did I do and then you went on to the more specific. What was it about my voice? What was it about my presence? What was it about my body language? What does that mean? Like not being intimidating and then you reiterated the main points again. Body language, voice, expectations and then you said what about pace? So you sort of went from the general to the more specific and I just thought that was great because I think that's why... (inaudible)

F2 The conversation we had after this one was about her saying I know what I've got to do now and I know what l've got to do in the next module and I'll go home in the holidays and I'm going to rewrite a couple of things and I'm going, I really modelled to her how to use the contract. I put the contract on the board the next class when we were team teaching and I just referred to it and I said I understand that this was the contract that you worked out with (name) and I said OK and so we started working and I said, no stop class, now look l'm not feeling respected, why am I not feeling respected and I pointed to the contract (inaudible) we made a contract, I expect you to hold that contract and she'd never done anything like that before so she wasn't using it as a tool so we got a really lovely conversation about how she was going to use the contract as a tool for teaching. So it was that, she was really thinking about what we had done together and how she could incorporate that so the next conversation will be I'll go back and I'll see what happened when she trialled those things because I don't think she needs me there to trial them I think it's more important that I come back later and see how they've worked.

F1 You're like the super nanny!

F2 So in terms of critical friends which you are at this moment, what would you say would be worthwhile for me pursuing in terms of becoming a stronger facilitator?

F3 Well I don't see how you could have actually improved on that. I mean I think that's a really, that's an example for other advisors to go from in a 
way. I mean in a way they are the vulnerable people, the failing teachers and there she is looking very happy about the situation and even actually trusting someone to come in when you are failing is pretty amazing. So $I$ think the use of questioning was really really good.

F1 So what are you asking when you say stronger? What are you asking?

F2 The whole thing about this is to make us stronger as facilitators.

F1 It's quite difficult actually to do as you ask in a sense because that's quite a small piece of the conversation. Because what I'd want to know about and I'm sure you must have done is to have found out from her how she felt she could have improved. I mean the conversation was entirely about what did she think of how you were and analysing that and that of course is really important and fully valuable, but the other side of it is OK now what are you going to do with me, and what did you do then, where do you think your weaknesses are and what are you going to do about them? You know, that side of things, OK let's go and try that and then the conversation after that, OK how did that go, do we need to change any of that, were you right in your assumptions of (inaudible) deal with those issues, so that side of the conversation is something I think you probably had anyway but we didn't see there.

F4 That was my question to you, was how did you establish what her goals were because there is no reference to her goals in there and that came out in one of the readings I gave you about coaching and mentoring. What are the teacher's goals and to keep them foremost and then to put that up and say this is what we're looking at. You said that took place earlier on and there was a negotiation and that's what (inaudible) in order to address her goals. So is...

F4 So where from here? What do you want to take away from today?

F2 What I meant to do before I started was to say to you I think my strengths are and I would have said my strengths are listening, I think my strengths are being quite gentle in terms of my voice and speaking quietly and encouraging them, I'm an encourager. 


\section{Appendix H: Teacher feedback analysis}

Following Professional Development led by on two dispositions toward facilitation - design adherence and contextual responsiveness the In-School Facilitators were asked to critique my facilitation style and note what they believed was following a design adherence model and what was following a contextually responsive model.

\section{Under design adherence was}

- The timetable for the day - following it with flexibility

- Can be quite assertive in leading people to where/what she wants

Comment received from in-school facilitator following feedback:

\section{$\mathrm{Hi}$}

Steering people towards a quicker, or even predetermined, outcome is not necessarily a negative thing. We all operate under time constraints and if we don't do this some people will go off on all sorts of tangents and achieve little. Had a good time today, it was a varied, interesting sessionwonderful facilitation.

\section{Under contextually responsive we had}

- Clearly explains what is expected and why what we (in-school facilitators) are doing is important

- Organised

- Using humour and stories to entertain and inform

- Using relevant contexts to the participants knowledge and experiences

- Meeting individual and collective needs/ responsive to individual needs

- Allowed the group (in-school facilitators) to decide the time given for different activities and the order in which the activities occurred

- Provided frameworks and ideas but we didn't have to follow them - we could use them or we could use them as guidelines

- Adapting the plan for the day and being wiling to change the time scale depending on the needs/requests of the participants

- Open to changing my ( mind and reviewing my own opinions - models being a reflective teacher

- Keen to learn and explore - open to suggestions - not the sole holder of knowledge

- Doesn't present themselves as the expert of everything - does not have a fixed position and is willing to hear others

- Uses own experiences to illustrate and reinforce points being made - great analogies

- Doesn't 'read' power-point slides out loud to us

- Brought in 'experts' to show different approaches.

- Varied the presentation style and participant participation. 


\section{Appendix I: Visual conversation analysis}

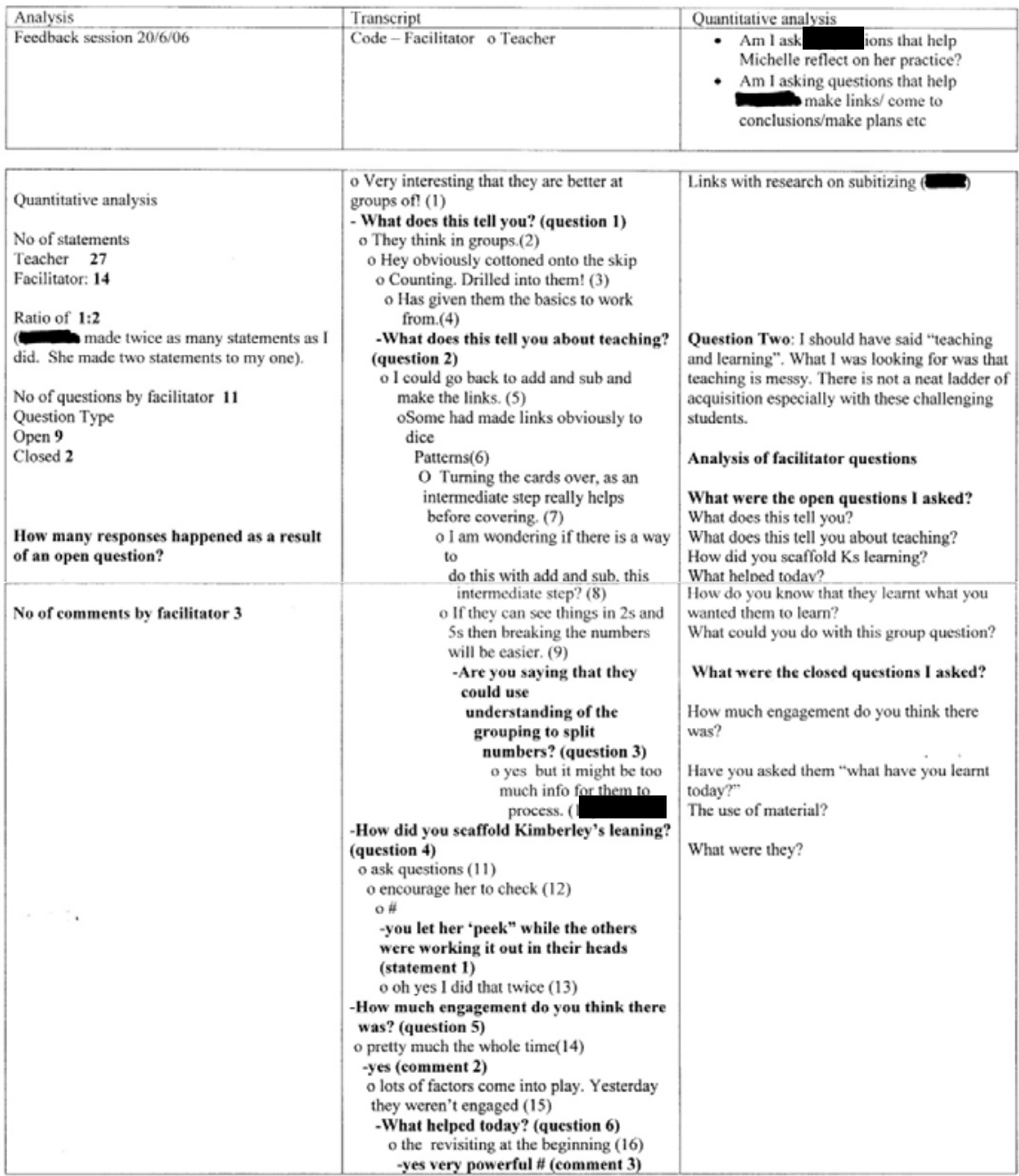




\section{Appendix J: Subjective/objective conversation analysis}

\section{Transcript Analysis by Teacher}

PD Goal: To analyse data so we may raise student achievement in Teacher two's classroom.

Objective Analysis: remove all emotion / personal interest so to distance your viewpoint, for example the student's reflective writing lacked objective self analysis because of a reported history of a learning disorder from the reading recovery teacher.

Subjective Analysis: This is your own personal viewpoint: what you feel happened. For example: the student's reflective writing lacked objective self-analysis because the student is hyperactive.

\begin{tabular}{|c|c|c|c|}
\hline Transcript & $\begin{array}{l}\text { Objective Analysis } \\
\text { Identify the } \\
\text { objective } \\
\text { comments }\end{array}$ & $\begin{array}{l}\text { Subjective } \\
\text { Analysis } \\
\text { Identify the } \\
\text { subjective } \\
\text { comments }\end{array}$ & $\begin{array}{l}\text { Critical Reflection on } \\
\text { Subjective and } \\
\text { Objective Data }\end{array}$ \\
\hline $\begin{array}{l}\text { Facilitator: } \\
\text { Teacher looking at } \\
\text { those journals and } \\
\text { looking at the } \\
\text { evidence of student } \\
\text { achievement, what } \\
\text { would you say the } \\
\text { themes were } \\
\text { across those } \\
\text { journals we just } \\
\text { looked at in relation } \\
\text { to gaps in your } \\
\text { teaching? } \\
\text { That that they don't } \\
\text { seem to fully } \\
\text { understand umm } \\
\text { what is meant by } \\
\text { recording process. } \\
\text { That they are not } \\
\text { putting in, even } \\
\text { when they get a } \\
\text { resubmit when they } \\
\text { had } \\
5 \text { days, that they } \\
\text { are producing } \\
\text { incredibly limited } \\
\text { amounts of work in } \\
\text { general, one page } \\
\text { extra. ... }\end{array}$ & & $\begin{array}{l}\text { Deeper level thinking } \\
\text { is required in order } \\
\text { to create deeper } \\
\text { level answers. In } \\
\text { turn this means } \\
\text { deeper level } \\
\text { questioning. }\end{array}$ & $\begin{array}{l}\text { I think that I need to } \\
\text { scaffold the process } \\
\text { through questions and } \\
\text { also give more in class } \\
\text { time to the journaling } \\
\text { process. That way it is } \\
\text { structured and also } \\
\text { creates an opportunity } \\
\text { for it to become a } \\
\text { regular thing that } \\
\text { happens both in and out } \\
\text { of class. The out of } \\
\text { class bit I cannot control } \\
\text { but I do not give marks } \\
\text { out 'til journals are } \\
\text { handed in, in order to } \\
\text { see their processes. }\end{array}$ \\
\hline
\end{tabular}




\section{ISTE Analysis of Interview Transcript}

We have examined the year nine journals of students who did not achieve and resubmitted their work. This is the conversation that follows.

\begin{tabular}{|c|c|c|}
\hline Analysis of Framework & $\begin{array}{l}\text { Transcript } \\
\end{array}$ & Reflection \\
\hline $\begin{array}{l}\text { Annan, Lai \& Robinson } \\
\text { Teacher Talk } \\
\text { Analytical talk: } \\
\text { We are using the journals as } \\
\text { evidence to discuss the } \\
\text { themes regarding student } \\
\text { underachievement with a } \\
\text { view to see if Teacher's } \\
\text { teaching is contributing to } \\
\text { student underachievement. }\end{array}$ & $\begin{array}{l}\text { Facilitator: Teacher looking } \\
\text { at those journals and looking } \\
\text { at the evidence of student } \\
\text { achievement, what would you } \\
\text { say the themes were across } \\
\text { those journals we just looked } \\
\text { at in relation to gaps in your } \\
\text { teaching? } \\
\text { Teacher: The Themes? Just } \\
\text { basically the commonalities? } \\
\text { Facilitator: Yes. } \\
\text { Teacher: Ummm, that that } \\
\text { they don't seem to fully } \\
\text { understand umm what is } \\
\text { meant by recording process. } \\
\text { (Pause) Yeah. But yeah, that } \\
\text { they are not putting in, even } \\
\text { when they get a resubmit } \\
\text { when they had } 5 \text { days, that } \\
\text { they are producing incredibly } \\
\text { limited amounts of work in } \\
\text { general, one page extra. } \\
\text { Ummm that they're not going } \\
\text { deep enough in their journals. } \\
\text { That they, are incredibly } \\
\text { surface and superficial and } \\
\text { jt's almost as though the } \\
\text { journals are unimportant and } \\
\text { there's not real um (and it's } \\
\text { just on these ones) there is } \\
\text { no sense of actual proper } \\
\text { reflection. Um they're not } \\
\text { really reflecting on what they } \\
\text { are doing and I don't know } \\
\text { and maybe that is a skill that } \\
\text { needs, I think for some } \\
\text { Transcript } \\
\text { kids it is a skill that needs to } \\
\text { be taught. I think } \\
\text { some are lazy, um I mean } \\
\text { how can you tell if someone } \\
\text { is lazy or not? But from } \\
\text { seeing what they do in } \\
\text { drama, and when I verbally } \\
\text { talk to them I am assuming } \\
\text { they're lazy because when I } \\
\text { see their journals they are not } \\
\text { what they say to me. } \\
\text { Facilitator: Okay } \\
\text { Teacher: And I dunno, so }\end{array}$ & 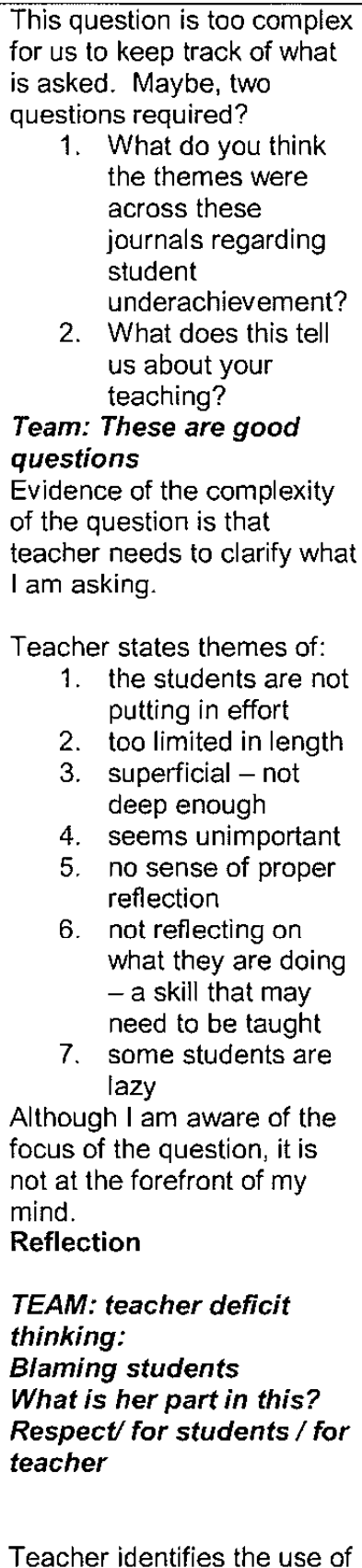 \\
\hline
\end{tabular}




\section{Appendix K: Feedback analysis framework}

Reflective framework for facilitator feedback (adapted from www.plotpd.com 19/6/06)

Controlling

+ direct/tell

+ make judgements

+ give feedback

+ determine requirements

+ specify alternatives ......

+ teachers choice from these......

No/little choice in teacher decision making

Date Facilitator empowering

+ mutual sharing/ideas/agreement

, pose wonderings

+ give/receive feedback

+ collegial reflections

+ negotiate requirements
+ listen

+ ask questions

+ explore possibilites

+ offer/seek feedback

+ teacher reflections

+ teacher self plan

Teacher 


\section{Appendix L: Appraisal criteria}

\begin{tabular}{|c|c|c|c|c|}
\hline \multicolumn{5}{|c|}{ Appraisal documentation (2011) } \\
\hline \multicolumn{5}{|c|}{ Job Satisfaction Rating } \\
\hline \multicolumn{5}{|c|}{$\begin{array}{l}\text { Part A: Facilitation Capabilities } \\
\text { Instructions for completing Part A } \\
\text { This section comprises comparison of } 2011 \text { and } 2010 \text { self rating (out of 10) then a column for evidence of or explanation for your rating. Discussion with peer is essential and their } \\
\text { comments should be recorded where appropriate. }\end{array}$} \\
\hline & & 11 & 10 & Self/peer assessment comments \\
\hline \multirow[t]{7}{*}{$\begin{array}{l}\text { Assessment } \\
\text { Literacy } \\
\text { Capability }\end{array}$} & $\begin{array}{l}\text { AfL - theory } \\
\text { (understand the capabilities, including CitC, AfL matrix) }\end{array}$ & & & \\
\hline & $\begin{array}{l}\text { AfL practice } \\
\text { (able to demonstrate the capabilities e.g., able to model for teachers, } \\
\text { engage with teachers/leaders in an AfL way) }\end{array}$ & & & \\
\hline & $\begin{array}{l}\text { Evidence based Inquiry } \\
\text { (Use of inquiry cycle at all stages of PD intervention and a clear process } \\
\text { for this. Make the process explicit and model it with an expectation that } \\
\text { school will use the evidence based inquiry) }\end{array}$ & & & \\
\hline & $\begin{array}{l}\text { Assessment Systems } \\
\text { (able to support schools to evaluate their current processes for gathering, } \\
\text { analysing and using evidence at all levels, including NS systems, NCEA, } \\
\text { reporting to parents/BOTs. }\end{array}$ & & & \\
\hline & $\begin{array}{l}\text { Assessment tools } \\
\text { (Knowledge and use of most appropriate tool for purpose. Ability to } \\
\text { critique advantages and limitations of each tool) }\end{array}$ & & & \\
\hline & $\begin{array}{l}\text { Data Analysis } \\
\text { (Able to gather, analyse and use data effectively) }\end{array}$ & & & \\
\hline & $\begin{array}{l}\text { Evaluative Capability } \\
\text { (able to draw defensible conclusions from evidence and make } \\
\text { recommendations) }\end{array}$ & & & \\
\hline
\end{tabular}




\begin{tabular}{|c|c|c|}
\hline \multirow{2}{*}{$\begin{array}{l}\text { Leadership } \\
\text { knowledge and } \\
\text { capability }\end{array}$} & Knowledge of dimensions of leadership BES (Robinson) & \\
\hline & $\begin{array}{l}\text { Ability to help leaders use the inquiry cycle to improve achievement } \\
\text { and sustain effective practice }\end{array}$ & \\
\hline \multirow{2}{*}{$\begin{array}{l}\text { Interpersonal } \\
\text { Effectiveness }\end{array}$} & Open to Learning/Model 2 theory & \\
\hline & Model 2 scenarios completed & \\
\hline \multirow[t]{3}{*}{$\begin{array}{l}\text { Intervention } \\
\text { Management }\end{array}$} & Knowledge and use of consultation process & $\begin{array}{l}\text { Reference Intervention Management Consultation Skills Peter } \\
\text { Block.pdf }\end{array}$ \\
\hline & Efficiency of time use in intervention & \\
\hline & Use of action methods & \\
\hline $\begin{array}{l}\text { Curriculum } \\
\text { Knowledge }\end{array}$ & $\begin{array}{l}\text { Knowledge of Curriculum and curriculum resources } \\
\text { (note specific focus for year if applicable) }\end{array}$ & \\
\hline Current research & $\begin{array}{l}\text { Knowledge of current research } \\
\text { (particularly to your area of work) }\end{array}$ & \\
\hline $\begin{array}{l}\text { Written } \\
\text { Communication } \\
\text { Skills }\end{array}$ & $\begin{array}{l}\text { (ability to write documents such as data reports, evaluations, proposals } \\
\text { articles etc) }\end{array}$ & \\
\hline $\begin{array}{l}\text { Presentation } \\
\text { Skills }\end{array}$ & $\begin{array}{l}\text { (ability to present to a high standard at seminars, workshops, staff } \\
\text { meetings - see separate criteria) }\end{array}$ & $\begin{array}{l}\text { Reference } \text { Criteria for presenting to groups.docx } \\
\text { Self assessment template - presenting to groups.docx }\end{array}$ \\
\hline \multirow[t]{2}{*}{$\begin{array}{l}\text { Knowledge of } \\
\text { learners }\end{array}$} & How to build and maintain Learning focused relationships & \\
\hline & $\begin{array}{l}\text { Understand and be able to demonstrate responsiveness to the } \\
\text { culture of learners } \\
\text { (including knowledge of Ka hikitia and Pasifika Education Plan) }\end{array}$ & \\
\hline
\end{tabular}




\section{Criteria for Facilitating with Groups}

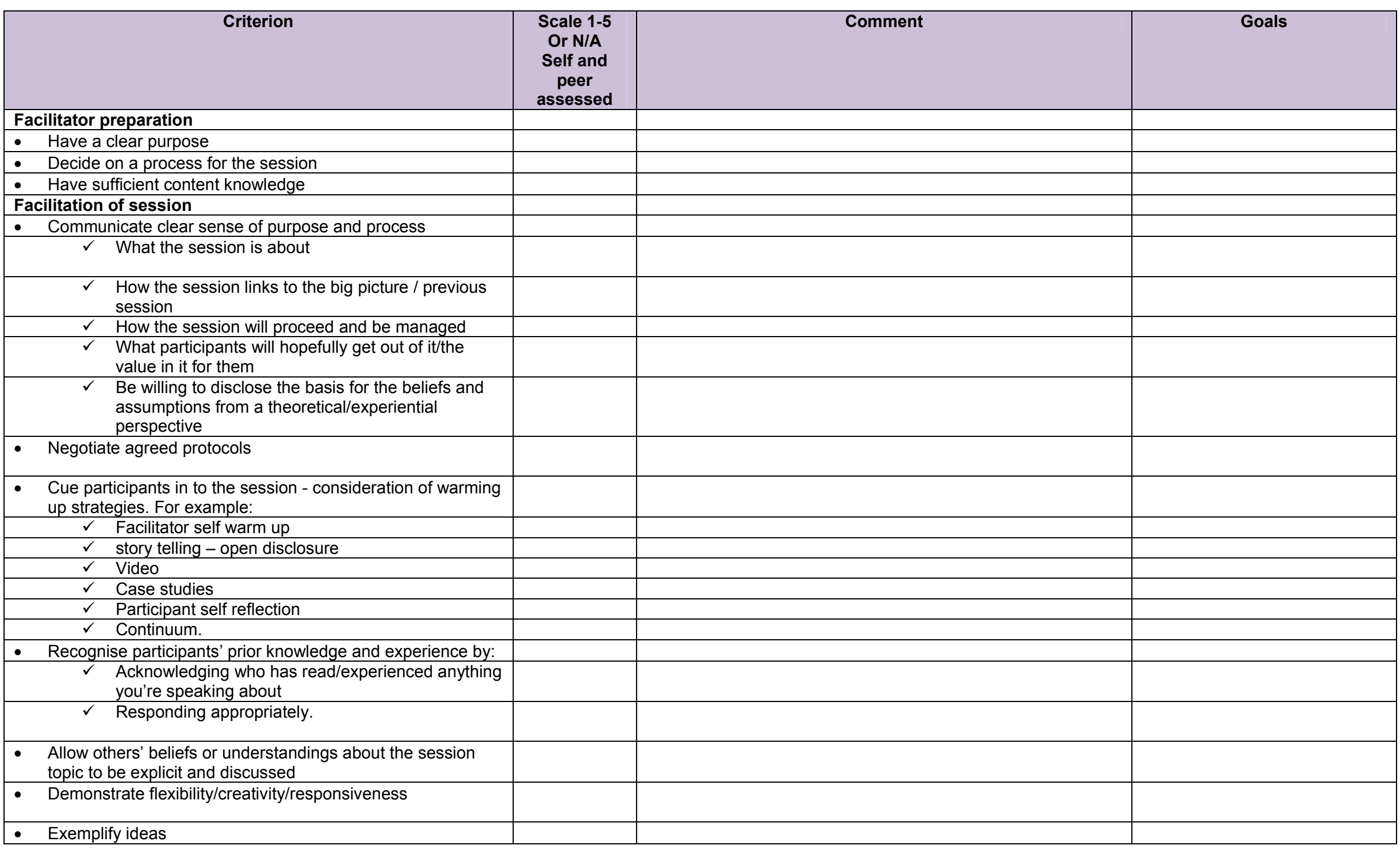




\begin{tabular}{|c|c|c|c|}
\hline Criterion & $\begin{array}{c}\text { Scale 1-5 } \\
\text { Or N/A } \\
\text { Self and } \\
\text { peer } \\
\text { assessed }\end{array}$ & Comment & Goals \\
\hline - Be explicit about modelling & & & \\
\hline $\begin{array}{l}\text { - Check-in about understanding and usefulness of session } \\
\text { (checking engagement) }\end{array}$ & & & \\
\hline - Connecting all activities/actions/resources to the purpose & & & \\
\hline - Create practical ideas and/or resources to take away & & & \\
\hline $\begin{array}{l}\text { - Specific participatory activities - mix of instruction and } \\
\text { meaningful collaborative work }\end{array}$ & & & \\
\hline Manage time & & & \\
\hline $\begin{array}{l}\text { - Lead genuine reflection: next steps co constructed for next } \\
\text { seminar }\end{array}$ & & & \\
\hline
\end{tabular}


Appendix M: Summarised list of participants and document sources

\begin{tabular}{|c|c|c|l|}
\hline Pseudonym & $\begin{array}{c}\text { INSTEP } \\
\text { role }\end{array}$ & $\begin{array}{c}\text { Type of } \\
\text { provider }\end{array}$ & \multicolumn{1}{|c|}{ Role in organisation } \\
\hline Alison & ISTE & $\begin{array}{c}\text { University } \\
\text { setting }\end{array}$ & $\begin{array}{l}\text { Inservice teacher educator } \rightarrow \\
\text { pre-service lecturer }\end{array}$ \\
\hline Anne & ISTE & $\begin{array}{c}\text { RTLB } \\
\text { service }\end{array}$ & $\begin{array}{l}\text { RTLB inservice teacher } \\
\text { educator }\end{array}$ \\
\hline Aroha & NF & $\begin{array}{c}\text { University } \\
\text { setting }\end{array}$ & $\begin{array}{l}\text { Manager within SSS with key } \\
\text { role in developing and } \\
\text { implementing PD programme }\end{array}$ \\
\hline Elaine & NF & $\begin{array}{c}\text { Private } \\
\text { provider }\end{array}$ & $\begin{array}{l}\text { Inservice teacher educator } \rightarrow \\
\text { role in leading learning }\end{array}$ \\
\hline Evelyn & RF & $\begin{array}{c}\text { University } \\
\text { setting }\end{array}$ & $\begin{array}{l}\text { Inservice teacher educator } \rightarrow \\
\text { pre-service lecturer and } \\
\text { researcher }\end{array}$ \\
\hline Hannah & NF & $\begin{array}{c}\text { University } \\
\text { setting }\end{array}$ & $\begin{array}{l}\text { Inservice teacher educator } \\
\text { within SSS }\end{array}$ \\
\hline Laura & RF & $\begin{array}{l}\text { RTLB } \\
\text { service } \\
\text { role in leading learning }\end{array}$ & $\begin{array}{l}\text { RTLB inservice teacher } \\
\text { educator }\end{array}$ \\
\hline Olivia & ISTE & $\begin{array}{c}\text { RTLB } \\
\text { service }\end{array}$ & $\begin{array}{l}\text { RTLB inservice teacher } \\
\text { educator }\end{array}$ \\
\hline Theresa & NF & $\begin{array}{c}\text { Private } \\
\text { provider }\end{array}$ & $\begin{array}{l}\text { Inservice teacher educator } \rightarrow \\
\text { teacher }\end{array}$ \\
\hline
\end{tabular}

\begin{tabular}{|c|c|c|}
\hline $\begin{array}{l}\text { Document } \\
\text { Source }\end{array}$ & Title & Synopsis \\
\hline Source A & $\begin{array}{l}\text { Higgins, J., Parsons, R., \& Bonne, L. } \\
\text { ( } 2011 \text { in press). Processes of inquiry. } \\
\text { Rotterdam: Sense. }\end{array}$ & $\begin{array}{l}\text { An edited book of accounts from the } \\
\text { participants and those involved in the } \\
\text { INSTEP project }\end{array}$ \\
\hline Source B & $\begin{array}{l}\text { Ministry of Education. (2008). Ki te } \\
\text { Aotūroa: Improving inservice teacher } \\
\text { educator learning and practice. } \\
\text { Wellington Learning Media. }\end{array}$ & $\begin{array}{l}\text { A book and DVD of resources as the } \\
\text { outcome of the INSTEP project }\end{array}$ \\
\hline Source C & $\begin{array}{l}\text { Mcllraith, G., Hope, C., Leslie, S., \& Pym, } \\
\text { C. (2009). INSTEP - Learning about } \\
\text { practice: A dynamic inquiry. Paper } \\
\text { presented at the New Zealand } \\
\text { Association for Research in Education. }\end{array}$ & $\begin{array}{l}\text { A paper presented at NZARE by INSTEP } \\
\text { participants }\end{array}$ \\
\hline Source D & $\begin{array}{l}\text { Sankar, M.. (2009). Evaluation of } \\
\text { inservice teacher education practice } \\
\text { project (INSTEP) (Report to the Ministry } \\
\text { of Education). Wellington, NZ: Ministry } \\
\text { of Education. }\end{array}$ & An evaluation of the INSTEP project \\
\hline Source E & $\begin{array}{l}\text { Baskerville, D., \& Goldblatt, H. (2009). } \\
\text { Learning to be a critical friend: from } \\
\text { professional difference through challenge } \\
\text { to unguarded conversations. Cambridge } \\
\text { Journal of Education, 39(2), 205-221. }\end{array}$ & $\begin{array}{l}\text { A journal article by } 2 \text { INSTEP participants } \\
\text { about their experience as critical friends }\end{array}$ \\
\hline Source F & $\begin{array}{l}\text { Lamont, M. (2009). Enhancing } \\
\text { professional learning for the } \\
\text { improvement of practice of inservice } \\
\text { teacher educators: Professional learning } \\
\text { for inservice teacher educators. The } \\
\text { International Journal of Learning, 16(16), } \\
431-444 \text {. }\end{array}$ & $\begin{array}{l}\text { A journal article by myself (as INSTEP } \\
\text { national facilitator) about findings from } \\
\text { Phase } 1 \text { of INSTEP }\end{array}$ \\
\hline
\end{tabular}

